\title{
CUMPRIMENTO DA LEGISLAÇÃO BRASILEIRA PARA O CONTROLE DE SUBSTÂNCIAS PSICOATIVAS EM UM HOSPITAL UNIVERSITÁRIO DE GRANDE PORTE.
}

\section{PAULO ROBERTO MIELE}

Tese de Doutorado apresentada ao Departamento de Prática em Saúde Pública, da Faculdade de Saúde Pública da Universidade de São Paulo para obtenção do grau de Doutor

Área de concentração: Administração Hospitalar

ORIENTADORA: Profa. Dra. VITÓRIA KEDY CORNETTA

São Paulo 2003 BibliotecalCIR 


\section{Dedico este trabalho}

a minha família: Marilza, Alexandre, Fernanda, Juliana e Rafael que muito me ajudaram para que este trabalho fosse possivel.

aos meus pais: José Miele de Andrade e Magda Fonseca Miele. pelo exemplo, quando em vida ... sempre em minha memória. 


\section{AGRADECIMENTOS}

À Prof ${ }^{\mathrm{a}}$. Dr ${ }^{\mathrm{a}}$. Vitória Kedy Cometta, orientadora, por ter acreditado no trabalho.

Ao Prof. Dr. Antônio Flávio Mídio, em especial, pela orientação informal, confiança, incentivo e acima de tudo amizade.

Ao Prof. Dr. Antônio Carlos Zanini, pela oportunidade e lealdade.

Ao Marcelo Wadt, pela ajuda na elaboração do banco de dados.

As estudantes de farmácia, Liliam Toledo Rodrigues, Marcela Oliveira Santoro, Karina Prince Rodrigues Sal, Liliane Neto Amorim e Igor Linhares de Castro pela colaboração nos trabalhos de compilação dos dados e pesquisa bibliográfica. Ao Fernando Basaglia pela ajuda no programa Microsoft Excel.

Ao Prof. Dr. Moacyr Azeisten, pela ajuda na revisão bibliográfica.

Aos meus companheiros de direção da Faculdade de Ciências Farmacêuticas e Bioquímicas "Oswaldo Cruz" Adelaide J. Vaz, Alice A. da Matta Chasin e Eduardo B. Govato pela compreensão e colaboração durante o desenvolvimento deste trabalho.

Ao Gléverson, meu assistente, pela paciência e ajuda.

A Prof. Irene dos Santos Jacob Mori, pelo incentivo. 


\section{RESUMO}

Miele PR. Cumprimento da legislação brasileira para o controle de substâncias psicoativas em um hospital universitário de grande porte.

São Paulo 2003 [Tese de Doutorado - Faculdade de Saúde Pública da USP]

Realizou-se um estudo observacional, descritivo e retrospectivo a fim de se detectar alguns pontos na viabilidade do cumprimento da legislação brasileira em vigor, Portaria 344/98. Para tanto, foi criado um banco de dados contendo informações a respeito da prescrição ambulatorial em 4.405 receitas emitidas em cinco dias seguidos, durante o mês de novembro de 2002, nos diferentes setores do Hospital das Clínicas da Faculdade de Medicina da Universidade de São Paulo e dispensadas na Divisão de Farmácia do mesmo hospital. Os dados coletados de cada receita, foram usados para verificar a conformidade dos procedimentos relativos a referida portaria. Os resultados obtidos foram: as prescriçōes dos medicamentos não foram realizadas, na sua totalidade, de acordo com a denominação comum brasileira (DCB), o que vai contra os dispositivos da portaria; a prescrição de morfina foi muito baixa $(0,25 \%)$, seguindo a tendência internacional; as prescriçōes de anorexigenos foram muito poucas $(0,2 \%$ do total); com relação aos retinóicos, estes não foram prescritos; limitações das quantidades de medicamentos para tratamento de doenças crônicas e preenchimento incompleto das receitas foi também observado; a farmácia do Hospital das Clínicas cumpre os dispositivos legais da Portaria 344/98 diante de baixas não conformidades constatadas neste estudo $e$ a dispensação de medicamentos na farmácia hospitalar do HC parece diferir de uma farmácia comercial.

Descritores: Legislação de medicamentos psicoativos, dispensação de medicamentos psicoativos, controle de substâncias psicoativas, prescrição de psicotrópicos e/ou entorpecentes e análise da legislação de psicotrópicos e/ou entorpecentes. 


\section{SUMMARY}

Miele PR. Feasibility of complying with Brazilian legislation on the control of psychoactive substances in a major university hospital.

São Paulo 2003 [Tese de Doutorado - Faculdade de Saúde Pública da USP]

Brazilian legislation on prescriptions and dispensing of psychoactive dugs is enforced by "Portaria 344/98" enacted by "Secretaria de Vigilância Sanitária"Ministry of Health as a result of the jointing of two former laws which were valid until 1998. Current legislation is quite complex and in many points does not contemplate some recommendations of international conventions. Professionals taking part in psychoactive-drug dispensing when not familiar with the legislation can bring difficulties to accomplish its determinations. The aim of this observational, descriptive, retrospective five-day survey was to detect points of vulnerability of the current legislation, as far as the documents for dispensing controlled drugs are concerned in a major university hospital in the city of São Paulo, Brazil. Database constructed with information about prescriptions and clinical dispensing of controlled drugs was used to verify the conformity of procedures related to "Portaria 344". The obtained results were as follows: Brazilian designation for drugs applied to public hospitals was not fully used; only $0.25 \%$ of prescriptions involved opiates like morphine followed the intemational tendency; anoretic and retinoid drugs were practically not prescribed; limitations in quantity of drugs prescribed for chronic diseases as well as incomplete prescriptions make out were also detected; the hospital pharmacy of College of Medicine of University of São Paulo has satisfied the legal requisites of "Portaria $344 / 98^{\prime \prime}$ once low compliance during the execution of this study has been noticed; all psychoactive dispensing in hospital pharmacies seems to be quite different from dispensing in commercial drugs .

Key Words: legislation on psychoactive drugs, dispensing of psychoactive drugs, control of psychoactive substances, psychotropic/narcotic prescription, and legislation on drugs. 


\section{ÍNDICE}

1 INTRODUÇÃO

1.1 Acesso a medicamentos 2

1.2 Programas do Ministério da Saúde 5

1.3 Mudanças na Vigilância Sanitária 11

1.40 excesso de normatização 14

1.5 Uso racional de medicamentos $\quad 16$

$\begin{array}{ll}1.6 \text { Uso racional de medicamentos psicoativos } & 18\end{array}$

2 CONTROLE DE SUBSTÂNCIAS PSICOATIVAS 21

2.1 Narcóticos e psicotrópicos $\quad 22$

2.2 Ações regulatórias 25

2.3 Controle internacional 26

2.4 Controle repressivo $\quad 27$

2.5 Uso de medicamentos psicoativos 28

2.5.1 Indisponibilidade de medicamentos 28

2.5.2 Prescrição insuficiente 29

$\begin{array}{ll}\text { 2.5.3 Prescrição excessiva } & 31\end{array}$

$\begin{array}{ll}\text { 2.5.4 Prescrição fraudulenta } & 31\end{array}$

2.6 Legislação em Saúde Pública 33

2.6.1 Multiplicidade de leis 35

2.6.2 Ações de vigilância sanitária $\quad 35$

$\begin{array}{ll}2.6 .3 \text { Avanços } & 37\end{array}$

3 OBJETIVO E PLANO DE TRABALHO 38

4 MATERIAL E MÉTODOS $\quad 40$

4.1 Amostra - Casuística $\quad 41$

4.2 Coleta de dados $\quad 41$

4.3 Organização da base de dados 43

4.3.1 Tabela primária 43

4.3.2 Tabela secundária para análise dos dados $\quad 44$ 
5 RESULTADOS

5.1 Tabelas para análise dos dados 46

5.1.1 Tabelas relativas à prescrição 46

5.1.2 Tabelas relativas à dispensação 53

6 DISCUSSÃO 57

7 CONCLUSÕES

77

8 REFERÊNCIAS BIBLIOGRÁFICAS 80 
1 INTRODUÇÃO 


\section{INTRODUÇÃO}

\subsection{Acesso a medicamentos}

A Constituição Federal define, em seu artigo 196, que a "saúde é um direito de todos e dever do Estado, garantido mediante políticas sociais e económicas que visem redução do risco de doença e de outros agravos e ao acesso universal e igualitário às ações de serviços para a sua promoção, proteção e recuperação" (BRASIL CONSTITUIÇÃO, 2000).

Criar políticas e condiçōes para que toda população tenha acesso aos medicamentos de que precisam é tarefa do Estado, por meio do Sistema Único de Saúde (SUS), criado pela lei 8080/90, coordenado pelo Ministério da Saúde, em âmbito federal, e também pelas secretarias estaduais e municipais de saúde em suas respectivas jurisdiçōes (BRASIL, 1990).

O Ministério da Saúde definiu por meio da Portaria GM/MS n³.916 de 30 de Outubro de 1998, a Politica Nacional de Medicamentos, cuja elaboração exigiu ampla discussão, muitas contribuições e aprovação das três instâncias de governo (MS, 1998b). Configura-se como decisão de caráter geral que assinala os caminhos $\mathrm{e}$ as estratégias a serem utilizadas na gerência de medicamentos no âmbito nacional. Os propósitos maiores dessa política é o de garantir necessária segurança, eficácia e qualidade aos medicamentos, a promoção do uso racional e o acesso da população àqueles considerados essenciais.

Em sua justificativa, a Política Nacional de Medicamentos reconhece o fato de que o segmento social que tem renda de zero a quatro salários mínimos, que representa $51 \%$ da população, consome apenas $16 \%$ do comercializado pelo mercado de medicamentos e tem uma despesa média anual de 18,95 dólares, per capita. O grupo de $15 \%$ de brasileiros mais ricos é responsável por cerca de $48 \%$ do faturamento do setor, com gasto per capita de 205 dólares.

O Relatório da CPI -Medicamentos da mesa da Câmara dos Deputados federais $51^{\mathrm{a}}$ Legislatura - $2^{\mathrm{a}}$ Sessāo legislativa de 2000 , destinada a investigar os reajustes de preços e a falsificação de medicamentos, materiais hospitalares e insumos de laboratórios afirma que embora a revista americana The Economist coloque o Brasil como o nono mercado de medicamentos do 
mundo, quando se trata de consumo per capita, fica-se atrás de mais de cinqüenta paises. Enquanto alguns grupos sociais no Brasil têm um consumo anual semelhante aos dos paises avançados, a grande maioria da população tem um consumo parecido com aqueles dos paises mais pobres do mundo (PODER LEGISLATIVO CPI, 2000).

No interior de segmentos de maior consumo per capita, certamente existem grupos cuja despesa média anual é próxima de zero. Estes dependem exclusivamente dos programas governamentais. Outros grupos, apesar de ter algum consumo, com despesa própria, despendem uma grande parte dos seus recursos para comprar medicamentos, deixando de atender outras necessidades, ou então, não conseguem comprar todos os medicamentos que necessitam.

O processo de envelhecimento da população brasileira, e o conseqüente aumento e prevalência de doenças crônico-degenerativas, torna ainda mais dramática a situação daqueles que não podem comprar medicamentos por sua própria conta e cria uma demanda cada vez maior, de maior custo, para o sistema de saúde.

Dados observados no Boletim Estatístico da SPS/MPSA, de janeiro de 2000 , mostram que $74,6 \%$ dos aposentados brasileiros ganham até dois salários mínimos. A faixa etária dos aposentados é a que apresenta a maior prevalência de doenças crônico-degenerativas, que são doenças que necessitam do consumo contínuo de medicamentos visando a compensação de processos fisiológicos de alguma maneira deficientes ou alterados. 0 equilibrio de sua saúde, na maioria dos casos, depende do uso continuado de medicamentos. Como sua renda mensal não é suficiente para a compra de medicamentos, considerando os outros gastos pessoais, os aposentados constituem-se em um dos segmentos populacionais mais dependentes do sistema de saúde, sendo os mais prejudicados pelos aumentos dos preços dos medicamentos (PODER LEGISLATIVO CPI, 2000).

À vista desses fatos, segundo o Relatório da CPI - Medicamentos, fica notória a importância e a imprescindibilidade de uma politica de assistência farmacêutica no interior do SUS, para que esta grande parte da população que nāo tem acesso a medicamentos, ou o tem insuficientemente, possa tê-lo nos momentos em que dele necessite. 
Por outro lado, a parcela da população que tem acesso aos medicamentos, está exposta a um consumo abusivo e inadequado por conta da liberalidade, ilegalidade e da desqualificação do comércio farmacêutico em nosso país (PODER LEGISLATIVO CPI, 2000).

Uma política de assistência farmacêutica deve, portanto necessariamente contemplar as duas situações para que seus resultados sejam benéficos aos indivíduos e ao sistema de saúde.

Como conclusões da CPI - Medicamentos o relatório aponta, como imprescindivel, a existência de uma ampla politica de assistência farmacêutica tendo em vista as condições estruturais da distribuição de renda no Brasil e o grande segmento de brasileiros que dependem, exclusivamente, dos programas governamentais para ter os medicamentos que necessitam.

Esta política de assistência farmacêutica, entendida como parte essencial da Política Nacional de Saúde, constitui um dos elementos fundamentais para a efetiva implementação de ações capazes de promover a melhoria das condições de assistência à saúde da população. Seu propósito precípuo é o de garantir a necessária segurança, eficácia e qualidade dos medicamentos, fiscalizando também, o consumo abusivo e inadequado dos medicamentos, por parte da população com poder aquisitivo suficiente, que é alavancado pela falta de cumprimento da legislação vigente.

Com relação ao SUS, as modalidades de abastecimento em medicamentos são fragmentadas em inúmeros programas, com lógicas distintas e sem articulação entre si, o que enfraquece o poder institucional das compras governamentais. Dentre eles os programas de medicamentos excepcionais, pelo seu alto custo, e os estratégicos, necessitam de uma profunda análise para um melhor equacionamento.

A CPI - Medicamentos apresentou as seguintes recomendações:

- que o Ministério da Saúde determine estudos no sentido de realizar uma revisão das modalidades de suprimentos de medicamentos do SUS com o objetivo de harmonizar sua lógica, adequá-las às políticas de promoção, prevenção e assistência à saúde e organizar a questão do abastecimento de medicamentos bem como da sua prescriçāo e dispensação nos serviços de 
saúde do SUS. Como sugestão apontou para o estudo de um sistema de reembolso;

- que o Ministério da Saúde determine o estudo de uma política de produção de similares e genéricos dos medicamentos de alto custo bem como a produção local de hemoderivados, cujo valor anual das importações supera em cerca de quatro vezes o custo de construção de uma planta produtora no Brasil;

- recomendação aos órgãos públicos para especial atenção ao suprimento pleno de assistência farmacêutica, com vistas ao atendimento dos mais carentes da população, considerando-se que cerca de 50 milhões de brasileiros ainda não tem acesso ao mercado nacional;

- recomendação especial para que o Ministério da Saúde propicie o abastecimento regular, a preços compatíveis, dos medicamentos de uso contínuo, especialmente para a terceira idade, examinando, se necessário, a possibilidade dos laboratórios públicos oficiais produzi-los para o mercado com preços pré-fixados;

- projeto de lei que tem o objetivo de organizar a assistência farmacêutica universal no âmbito do SUS;

- que o Ministério da Saúde determine a execução de uma política de assistência farmacêutica que discipline, também, o consumo abusivo e inadequado dos medicamentos, por parte da população com poder aquisitivo suficiente, que é alavancado pela falta de cumprimento da legislação vigente (PODER LEGISLATIVO CPI, 2000).

\subsection{Programas do Ministério da Saúde}

A base do SUS é a equidade das ações de saúde para toda a população. $\dot{E}$ um sistema complexo e seu desenvolvimento tem sido realizado com dificuldades, envolvendo estabelecimentos públicos e particulares na prestação de serviços, com unidades de atenção básica, até hospitais de grande resolução e milhares de procedimentos. Em 2001 foram 2.400 .565 partos, 12.277.655 internaçōes em hospitais, 305.579.096 doses de produtos imunobiológicos e três bilhões de unidades farmacêuticas diretamente distribuídas pelo Ministério da Saúde. Ainda que os números acima sejam 
expressivos, parte da população é excluida de algum tipo de atenção. No Brasil temos as doenças típicas de paises em desenvolvimento e agravos à saúde característicos de países desenvolvidos. Percebe-se que ao mesmo tempo em que há prevalência de doenças crônicas degenerativas, há um aumento aumenta a morbidade decorrente da violência, especialmente os homicidios e acidentes de trânsito. Emergem e reemergem outras doenças, como a dengue. Além disso, o envelhecimento populacional faz com que os modelo de atenção à saúde sejam revistos e adequados de modo a conferir prioridade aos aspectos preventivos das ações de promoção, proteção e recuperação da saúde (FISCHER-PÜHLER, 2002).

Segundo esse mesmo autor, a análise de indicadores especificos e sociais mostra que atualmente a sociedade tem mais acesso a medicamentos, ainda que não universal, mas maior do que há alguns anos. Em sua visão, explica o aumento desse acesso com quatro importantes decisões que foram relevantes na vida política da nação: a desativação da Central de Medicamentos; o produto farmacêutico como ação concreta de saúde pública; a criação da Agência Nacional de Vigilância Sanitária e a instituição dos medicamentos genéricos.

A desativação da Central de Medicamentos (CEME) em 24/07/199, promoveu uma grande revolução no sistema de aquisição e distribuição de medicamentos realizados pelo Governo Federal. Se por um lado houve uma redução no poder de pressão do Estado sobre o preço dos medicamentos, deixando de comprar volumes maiores, por outro lado atendeu a direção prioritária da política de saúde atual, onde a aquisição dos medicamentos passa a ser cada vez mais uma atribuição dos estados e municípios. A mudança estimulou, também, a revitalização dos laboratórios farmacêuticos vinculados aos governos estaduais, denominados Laboratórios Oficiais. Assim - Ministério da Saúde criou um sistema de oferta de produtos para Atenção Básica de Saúde.

Laboratórios Oficiais são instituições com acentuada conotação social, cujo "lucro" é a contribuição que fazem à efetivação das políticas públicas. Em 1997, o MS através do projeto "Guarda-Chuva", pôs em prática um programa de investimento nos laboratórios oficiais da ordem de $R \$ 38$ milhões e contrapartida dos estados no valor de R\$ 5 milhōes, com o objetivo de aumentar a capacidade produtiva e desenvolver técnicas gerenciais para 
maximizar os recursos disponiveis. Este investimento alterou significativamente a capacidade produtiva desses laboratórios, antes com 1,8 milhöes de unidades para 7,5 milhões de unidades farmacêuticas produzidas. No mês de outubro de 2003 o governo anunciou mais um aporte de investimentos na ordem de $R \$ 135$ milhões, contemplando todos os laboratórios oficiais.

O produto farmacêutico como uma ação concreta de saúde pública, tem sua expressão num sistema de oferta de produtos para a Atenção Básica de Saúde, com o surgimento da denominada Farmácia Básica que distribuiu em 1997 e 1998 um conjunto de medicamentos para cada município com no máximo 21 mil habitantes (4.447 municípios). Os conjuntos eram entregues às Secretarias Municipais de Saúde a cada três meses. O programa atendeu 35 milhōes de pessoas.

Outro programa do MS denominado "Medicamentos Estratégicos" que por meio da sua secretaria executiva distribui diretamente às secretarias estaduais de saúde os medicamentos necessários aos programas de atenção à Aids (anti-retrovirais), tisiologia, hanseníase, sangue e hemoderivados (fator VIII, fator IX, complexo protrombínico e fator VII ativado), diabetes (insulina) e controle de endemias (leishimaniose, esquistossomose, malária etc). 0 custo deste programa em 2002 foi aproximadamente de $R \$ 1,1$ bilhão.

Os medicamentos necessários ao tratamento da Aids, de alto custo e protegidos por patentes, motivou um posicionamento político governamental sem precedentes na história dos paises em desenvolvimento. Impossibilitado de enfrentar a epidemia com a inclusão de todos os doentes desta enfermidade, pelos altos preços impostos pelos fabricantes, o governo brasileiro destacou-se, em foros internacionais, ao defender o princípio, segundo o qual, a saúde pública não pode ser subordinada aos abusos do poder econômico.

Liderados pelo Brasil, vários paises com o suporte de organizações não governamentais levantaram o problema e demonstraram a inadequação do sistema de monopólio de patentes para setores industriais com tanta influência sobre as das nações. A declaração de Doha, no Catar, na $4^{a}$ Conferência Ministerial da Organização Mundial de Comércio (OMC) em 14 de novembro de 2001, firmada pelos ministros acreditados na OMC, diz claramente que o tema 
saúde pública deve sobrepor-se a direitos patrimoniais concedidos pela propriedade industrial (MS 2001).

Nas reuniōes da Organização Mundial da Saúde (OMS), na sessão especial da Assembléia Geral das Naçōes Unidas sobre Aids, e em encontros com nações desenvolvidas e em desenvolvimento, o Brasil defende a tese de que os governos democráticos têm dupla obrigação de assegurar que suas populações tenham amplo acesso a medicamentos e que os pacientes estejam protegidos contra abusos de preços gerados por competição insuficiente e conseqüente falhas de mercado. As autoridades brasileiras repetem, insistentemente, que nos casos de interesse público e de emergências nacionais, o monopólio concedido pelo Estado quanto a patentes farmacêuticas não deve ser usado para enfraquecer os esforços do governo na adoção de providências excepcionais requeridas para assegurar a saúde de sua população.

A firmeza com que o governo brasileiro negociou preços mais baixos de medicamentos contra a Aids, foi vista como um ato de rebeldia contra o principio de proteção de patentes apoiado por organizações não governamentais tais como "Médicos sem Fronteira" e "Oxfan".

A revista The New York Times apoiou o Brasil através de seu editorial de 31 de outubro de 2001, juntamente com uma série de organizações internacionais: Nações Unidas, Organização Mundial da Saúde, Comissão de Direitos Humanas e a própria Organização Mundial de Comércio, incluindo a opinião pública mundial. Ainda é cedo para se saber as conseqüências da declaração da $4^{a}$ Conferência Ministerial da Organização Mundial de Comércio em Doha sobre o destino de milhões de doentes sem meios de pagar pelos medicamentos. A OMC foi instada a buscar soluções para aqueles países que não detenham capacidade industrial para fazer uso de licenças compulsórias, previstas na Lei n 9279/96 (FISCHER-PÜHLER, 2000) (BRASIL, 1996).

A crise dos medicamentos para essa grave doença deve gerar novas discussōes sobre o sistema internacional de patentes. Isto evidencia que não apenas no setor farmacêutico mas em todos os demais, os abusos devem ser impedidos, as licenças compulsórias nem sempre se mostram suficientes e adequadas e que países em diferentes graus de desenvolvimento não devem ser obrigados a nivelar sua legislação com a dos países desenvolvidos. Caso 
não se resolvam essas diferenças, pode-se prever uma grave crise no sistema internacional de propriedade industrial e o projeto sobre propriedade intelectual negociado no âmbito do Acordo Final Sobre Tarifas e Comércio (GATT), denominado TRIPS (Trade-Related Aspects of Intellectual Property Rights), não terá vida longa (CONTIJO, 2003).

Outro programa pelo qual os medicamentos chegam diretamente à população é caracterizado pela palavra "Farmácias".

O programa "Farmácia Popular" é o mais antigo e distribui um conjunto de medicamentos para o Programa de Saúde da Familia (PSF). Este já atingiu um marco histórico de atenção a 50 milhões de cidadãos. Os custos com medicamentos neste programa está estimado em $\mathrm{R} \$ 75$ milhões/ano.

No programa "Farmácia Hipertensão Arterial" o MS distribui às Secretarias Municipais da Saúde produtos farmacêuticos para tratar as pessoas com hipertensão arterial. São entregues: hidroclorotiazida $(25 \mathrm{mg})$, captopril ( $25 \mathrm{mg}$ ) e propanolol $(40 \mathrm{mg}$ ). O pais tem 8 milhōes de hipertensos e 5,4 milhỏes deles recebem de maneira regular os medicamentos gratuitamente. Os custos com medicamentos está estimado para 2003 em R\$ 100 milhões.

No "Farmácia Diabetes Mellitus" o MS identifica que existe cerca de 2,8 milhões de pessoas sujeitas à diabete, das quais 2,4 milhões necessitam de tratamento farmacológico. Deste total $20 \%$ fazem uso de insulinas e $80 \%$ necessitam de hipoglicemiantes orais (metformina e glibenclamida), com previsão de $\mathrm{R} \$ 107$ milhões/ano.

No "Farmácia Mulher" faz-se a distribuição de produtos anticoncepcionais para o programa saúde da mulher. Os medicamentos são enviados a 4.400 municípios atendendo a aproximadamente 33 milhões de mulheres por ano em idade fértil, com um custo anual de cerca de $R \$ 10$ milhões.

No "Farmácia Presídio" o governo pretende beneficiar cerca de 172 mil presos. Este programa teve início em 2002 na expectativa de atender cerca de $20 \%$ da população carcerária com Aids e $10 \%$ com sífilis e hepatite, com gastos na ordem de $\mathrm{R} \$ 320$ mil/ano. 
Ainda tem-se que registrar o "Farmácia Apoio Ministério da Saúde - 47" que é distribuído quando ocorrem catástrofes ou calamidades públicas. Em 2001 foram distribuídos 97 conjuntos com medicamentos a um custo de $R \$ 1$ milhão e o "Farmácia Domicílio" iniciado em 2002 tem como objetivo entregar medicamentos em domicílio após consulta em unidades de saúde de Secretarias Municipais de saúde.

No programa "Fármacos Excecionais" a população recebe gratuitamente medicamentos por ocasião do tratamento hospitalar (incluídos no programa das Autorizações de Internação Hospitalar - AIH) e ambulatorial. Neste programa os medicamentos são de uso prolongado e dispensados em ambulatórios. O programa garante o financiamento e transfere os recursos para o Estado para a compra e distribuição de 41 medicamentos considerados como de dispensação excecional. Em 2001 foram atendidos 110 mil pacientes e dispendidos recursos da ordem de $\mathrm{R} \$ 80$ milhōes.

O Piso de Atenção Básica (PAB) é um mecanismo de financiamento do SUS que altera a sistemática de pagamento por produção e recebe o financiamento diretamente do Fundo Nacional de Saúde (remessa fundo a fundo) um montante per capita, previamente fixado, e a administração local assume a responsabilidade pela atenção básica à saúde da população de seu território. Com esse modelo a prefeitura passa de prestadora de serviços de saúde a administradora do SUS do município com a elaboração de planos de ações em saúde de acordo com a realidade local. Um municipio para receber os recursos do PAB precisa atender aos seguintes critérios: criação de um Fundo Municipal de Saúde; funcionamento do Conselho Municipal de Saúde; apresentação do Plano Municipal de Saúde e o envio de informações ao MS é obrigatória. Neste sistema, o próprio administrador de saúde do município define quais produtos que serão adquiridos, resultando em racionalidade nas aquisições. Em 2001 o MS transferiu R\$ 166,3 milhões aos estados e municipios, que acrescidos da contra partida de cada um deles, geraram recursos de $R \$ 332,7$ milhões.

O Programa de "Saúde Mental" distribui os medicamentos à base de ácido valpróico, clomipramina, metilfenidato, nortriptilina, periciazina, seleginina e tiamina. O custo anual do programa é de cerca de $\mathrm{R} \$ 28$ milhões dos quais 22 são recursos do MS ( $80 \%$ do total). 
O Programa Nacional de Carências Nutricionais tem como finalidade reduzir e controlar a desnutrição infantil e as carências nutritivas especificas, particularmente a anemia ferropriva e a hipovitaminose A, além de estimular a prática do aleitamento. Em 2002 o MS adquiriu e distribuiu aos estados o ergosterol e o sulfato ferroso a um custo estimado de $R \$ 1$ milhão.

\subsection{Mudanças na Vigilância Sanitária.}

No início de 1999, outra grande alteração ocorreu na estrutura administrativa federal relativa à saúde: a transformação da Secretaria de Vigilância Sanitária em Agência Nacional de Vigilância Sanitária (ANVISA), através da medida provisória n. 1791 , aprovada por aclamação em 13 de janeiro de 1999 e promulgada pelo Congresso Nacional como Lei n. ${ }^{\circ} 9782$ em 27 de janeiro de 1999 (BRASIL, 1999a).

A Lei n. ${ }^{\circ}$ 9782/99 dispōe sobre o Sistema Nacional de Vigilância Sanitária, cria a Agência Nacional de Vigilância Sanitária (ANVS), passando a ser chamada de ANVISA, definindo sua estrutura organizacional, competências, modelo de gestão, cargos e funções, patrimônio e receitas e fixando taxas pelos serviços prestados. Esta mesma lei transfere o Instituto Nacional de Controle de Qualidade em Saúde (INCQS) da Fundação Oswaldo Cruz para a ANVISA, e altera o Decreto-Lei $n .^{\circ} 986 / 69$ e a Lei $n .^{\circ} 6360 / 76$ (BRASIL, 1969, 1976a, 1999a).

Para COSTA (1999), ao dispor sobre o Sistema Nacional de Vigilância Sanitária a lei mostra um vazio quanto à sua configuração, princípios e diretrizes, com formulação geral no artigo $1 .^{\circ}$ que referenda disposições da Lei Orgânica de Saúde nos seguintes termos:

"O Sistema Nacional de Vigilância Sanitária compreende um conjunto de ações definidas pelo $\S 1 .^{\circ}$ do art. $6 .^{\circ}$ e pelos arts. 15 a 18 da Lei $n . .^{\circ} 8080$, de 19 de setembro de 1990, executado por instituições da Administração Pública direta e indireta da União, dos Estados, do Distrito Federal e dos Municípios, que exerçam atividades de regulação, normatização, controle e fiscalização na área de vigilância sanitária" (BRASIL, 1990).

Passam a ser de competência da União, no âmbito do Sistema Nacional de Vigilância Sanitária e nos termos da Lei: 
- definição da política de Vigilância Sanitária e do sistema Nacional de Vigilância Sanitária, normatização, controle e fiscalização de produtos, substancias e serviços de interesse para a saúde;

- vigilância sanitária de portos aeroportos e fronteiras, atribuição esta, que poderá ser complementada pelos Estados, Distritos Federal e Municípios;

- coordenação e acompanhamento das açōes estaduais, distritais e municipais de vigilância sanitária;

- prestação de Cooperação técnica e financeira aos Estados, ao Distrito Federal e aos Municipios;

- atuação em circunstâncias especiais de risco à saúde e

- manutenção do sistema de informação em Vigilância Sanitária em cooperação com os Estados, o Distrito Federal e os Municípios.

À ANVISA cabem as seguintes atribuições:

- controle sanitário dos produtos, bens e serviços submetidos à vigilância sanitária, bem como os processos e tecnologias relacionados com os mesmos;

- controle dos portos, aeroportos e fronteiras e

- normatização do setor.

A ANVISA é ligada ao Ministério da Saúde por contrato de gestão, mas tem independência administrativa e autonomia financeira. Desde a sua criação, várias iniciativas foram tomadas no sentido de organizar o confuso setor de medicamentos no Brasil, através de atitudes como: modificação nos critérios para a emissão de registros; restrição ou retirada do mercado de medicamentos sem comprovação terapêutica; elaboração de normas (como "Boas Práticas") para os setores produtivos, distribuidoras e comércio farmacêutico. No entanto, quanto à fiscalização, percebe-se ainda uma grande precariedade. 
Como as ações de vigilância sanitária cabem aos Estados e Municípios, de acordo com a Lei $n .^{\circ} 6360 / 76$, a efetividade nas ações dependerá dos recursos orçamentários das Secretarias de Estado/Município da Saúde para os Centros de Vigilância Sanitária (CVS). Neste sentido está em curso a descentralização das ações de vigilância sanitária do Estado para os Municipios que tenham estrutura e disposição política para realizá-las (BRASIL, 1976a).

$\mathrm{Na}$ área de medicamentos é muito importante a especialização e a capacitaçẳo técnica dos recursos humanos para exercer a inspeção nos laboratórios produtores. Em caso recente de falhas na qualidade de produto farmacêutico causando mortes, o laboratório produtor tinha laudo que comprovava sua capacitação técnica e idoneidade. O laudo foi obtido por meio do certificado de Boas Práticas de Fabricação (BPF), após minuciosa inspeção, determinada pela Resolução 134/2001, posteriormente modificada pela Resolução $n^{\circ} 210 / 2003$ que determina a todos os estabelecimentos fabricantes de medicamentos o cumprimento das diretrizes estabelecidas no regulamento técnico das BPF de medicamentos e, no entanto, não foi capaz de impedir os desvios de qualidade no produto fabricado (MS 2001,2003d). Este produtor recebeu as sançōes previstas na Lei $6437 / 1977$ (BRASIL, 1977).

Apesar de se ter muito a aperfeiçoar, não se pode deixar de citar, dentro do panorama farmacêutico recente, algumas conquistas significativas, como a implantação dos medicamentos genéricos, um novo marco normativo através da Lei n. ${ }^{\circ}$ 9782/99 (BRASIL, 1999a).

A Lei dos Genéricos, formulada com base em Projeto de Lei do deputado federal Eduardo Jorge, foi sancionada pelo presidente da República em 10 de fevereiro de 1999, resultado de um longo processo de negociação para vencer resistências no interior do próprio governo e a oposição obstinada das indústrias farmacêuticas transnacionais, e também respeitar acordos de patentes. Estabeleceu as bases legais para o registro, produçāo e controle de qualidade destes medicamentos, resgatando parte dos preceitos do Decreto n. ${ }^{\circ}$ 793/93, dispondo sobre a utilização de nomes genéricos em produtos farmacéuticos e dando outras providências, entre as quais determinando a obrigatoriedade de adoção da Denominação Comum Brasileira (DCB) e na sua falta, a Denominação Comum Internacional (DCI) nas aquisiçōes de 
medicamentos e nas prescrições médicas e odontológicas no âmbito do Sistema Único de Saúde (BRASIL, 1993).

Neste sentido assinala COSTA (1999), uma preocupação quanto à eficácia dessas normas, pois entre os elementos a serem regulamentados, quando se trata dos critérios para a dispensação dos medicamentos nos serviços públicos ou privados, determina-se respeitar "a decisão expressa de não intercambiabilidade do profissional prescritor", ou seja, obediência à posição do prescritor de não admitir troca de nome de marca por um medicamento similar.

Cerca de dois anos após sua regulamentação, o número de medicamentos genéricos disponíveis aproximava-se de 500 itens. Este número superava as próprias previsões da ANVISA para tal período de tempo, previsões estas feitas quando a lei foi implantada.

\subsection{0 excesso de normatização.}

O discurso normativo, iniciado nos anos noventa, renovado pelo movimento social, reitera a temática da qualidade dos produtos e da proteção do consumidor, iniciando a incorporação da informação como responsabilidade institucional e direito do cidadão. Entretanto, as normas não são suficientes para assegurar a qualidade de produtos e o mercado sempre demonstrou ser incapaz de auto-regulação para assegurar os interesse da coletividade. 0 modelo cartorial da Vigilância Sanitária que, no passado, muito beneficiou o setor produtivo em razão de insuficientes exigências de observância das normas sanitárias, passa por um processo inverso. Produz um excesso de normas técnicas, de eficácia duvidosa sob o ponto de vista sanitário, dificultando o desenvolvimento dos "laboratórios oficiais" e das indústrias farmacêuticas nacionais, ao exigir por meio da RDC $n^{\circ} 133$ de 29 de maio de 2003, que dispõe sobre o registro de medicamento similar e dá outras providências, a biodisponibilidade relativa para todos os produtos farmacêuticos denominados similares. Este teste é realizado através de uma pesquisa clínica em voluntários com custos unitários em média na ordem de $\mathrm{R} \$ 50$ mil por teste (MS, 2003a). 
Se levada a sério hoje, esta medida na prática impede o registro de produtos farmacêuticos dos próprios laboratórios oficiais, que não dispõem de recursos para a realização dos testes, antes de solicitar os registros de novos produtos e de renovar o registro dos existentes. Dificulta, também, as indústrias farmacêuticas nacionais que operam quase que exclusivamente com a transformação dos princípios ativos, não protegidos por patentes em especialidades farmacêuticas, concorrendo com as empresas transnacionais que comercializam tanto os produtos similares quanto os produtos com novas moléculas; trazidas de seu pais de origem, seguramente sem concorrência.

Sem diminuir a importância das normas atualizadas, ao examinar a legislação produzida até o momento, depreende-se que os maiores males podem ser causados tanto pelo "excesso de zelo" no rigor científico, gerando o que chamamos de "furor normativo" (grifo nosso), na esperança em que as normas possam assegurar a qualidade dos produtos farmacêuticos no mercado, quanto da falta de vontade política de transformar a legislação normativa existente, em prática.

O exemplo mais recente de excesso de normatização podemos citar a publicação pela ANVISA da RDC n. ${ }^{\circ} 139$ de 29 de maio de 2003 que dispõe sobre o registro e a isenção de registro de medicamentos homeopáticos industrializados, trazendo para o Ministério da Saúde o ônus da prova de eficácia da ação farmacológica desse grupo de produtos, ao contrário dos produtos farmacêuticos alopáticos onde o fabricante e produtor dos fármacos tem a obrigação de provar cientificamente que seus medicamentos são seguros e eficazes para que obtenha seu registro no país (MS, 2003b).

Em sentido contrário ao envolvimento cada vez maior das novas ciências, o químico e médico alemão Samuel Hahnemann lançou as bases da homeopatia no inicio do século XIX, que significa "cura pela semelhança" (homeo $=$ semelhante; pathos $=$ doença). Hahnemann, que também foi um cientista com trabalhos relevantes, rejeitou a ciência $e$ indústria farmacêutica de seu tempo. Hahnemman propôs o uso de doses infinitamente menores do que as usadas em terapia com medicamentos, a tal ponto que é praticamente impossivel dosar os princípios ativos presentes. Seus medicamentos são preparados empregando-se técnicas especiais de diluiçōes sucessivas, 
intercaladas com agitações vigorosas ou "dinamizações". Até o início do século XXI, não existia nenhum trabalho comprovando a eficácia dos remédios homeopáticos (ZANINI et al., 1985) (NASSIF, 1995).

\subsection{Uso racional de medicamentos.}

Em 1985 a Organização Mundial da Saúde, na reunião de especialistas sobre uso racional de medicamentos, em Nairobi, Quênia, estabeleceu que o uso racional de medicamentos necessita que "pacientes recebam a medicação apropriada para a sua situação clínica, nas doses que satisfaçam as necessidades individuais, por um periodo adequado, e ao menor custo possivel para ele e sua comunidade" (OMS, 1985).

Os critérios para atender a afirmação acima, segundo Management Sciences for Health/OMS (SOBRAVIME 2001), podem ser traduzidos como:

- indicação de produtos que tenham eficácia comprovadas por trabalhos científicos;

- dose, administração e duração necessárias para o tratamento;

- verificação das condições dos pacientes para saber se o mesmo apresenta condiçōes para receber a medicação;

- dispensação com informação apropriada aos pacientes sobre a utilização correta do medicamento e

- acompanhamento farmacoterápico dos pacientes.

O uso racional dos medicamentos requer um equilíbrio no equacionamento da relação médico, paciente e farmacêutico. $O$ médico para promover uma prescrição adequada necessita ter uma formação sólida em farmacologia e terapêutica, orientada ao uso correto do medicamento, com atualizações constantes imunes às influências da indústria farmacêutica.

O farmacêutico tem papel crucial neste processo, pois a dispensação, atividade exclusiva de sua profissão, exige capacitação contínua e prática profissional na direção da farmacoterapia. Nos paises em desenvolvimento, as farmácia representam uma das principais alternativas na assistência primária a 
saúde, pois são procuradas em primeiro lugar na busca de resolução dos problemas de saúde. Assim na prática da atenção farmacêutica é fundamental o engajamento do profissional farmacêutico aos centros de informações de medicamentos para obter conhecimento a respeito daqueles com novos fármacos e efeitos colaterais e adversos não conhecidos de medicamentos já existente no mercado.

$O$ paciente, consciente e bem informado, estabelece $O$ equilibrio necessário para dar sustentação no uso racional dos medicamentos. "A automedicação é a situação na qual os consumidores utilizam os medicamentos sem que exista intermediação de prescrição de um agente oficialmente qualificado" (SOBRAVIME, 2001).

No Brasil, devido à extrema liberdade de ação das farmácias e drogarias, que vendem qualquer medicamento a qualquer pessoa que os procura, o problema da automedicação apresenta uma dimensão muito maior quando comparado com países onde a farmácia é considerada como um estabelecimento de saúde. (PODER LEGISLATIVO CPI, 2000)

Estudos realizados em paises da Europa e nos Estados Unidos estimam que entre $30 \%$ e $90 \%$ das doenças săo inicialmente tratadas por automedicação e somente um terço da população, com algum mal estar ou enfermidade, consulta um médico (SOBRAVIME, 2001).

O aumento da automedicação justifica a necessidade de melhorar as informações que são dirigidas aos pacientes e é fundamental que sejam adequadas ao seu grau de instrução e conhecimento. $O$ farmacêutico é a única via de informação do paciente que se auto medica e por isso sua intervenção é fundamental para melhorar o uso dos medicamentos (CHETLEY,1993).

COSTA (1999), afirma que: o conceito de uso racional suscita muitas indagações e até a respeito de quais medicamentos. A própria eficácia é sabidamente influenciada por vários fatores de ordem econômica, social, psicológica e cultural; abrange a qualidade dos serviços de saúde que inclui a relação médico paciente e outras amenidades (bem estar, adequada recepção ao usuário). Assim, resta aguardar que as políticas que vierem a ser 
implementadas não se convertam em negação do discurso; essa será sempre uma frente de luta, sublinha Kanter, "promover o uso racional de medicamentos é tarefa de um projeto global de educação, que envolve a erradicação do analfabetismo, a informação adequada dos médicos, equipes de saúde e consumidores e ainda, o livre e amplo acesso ao conhecimento .

\subsection{Uso racional de medicamentos psicoativos.}

Os psicofármacos, em geral, são os exemplos mais recentes de descobertas ao acaso, que posteriormente evoluíram para novas fórmulas, possíveis em virtude dos novos avanços em química farmacêutica e farmacologia.

Nos anos 40 a pesquisa do iminodibenzilino forneceu o conhecimento do mecanismo de ação da MAO (enzima monoaminoxidase). Os sais de lítio foram introduzidos para síndrome maniaco-depressiva, em 1949.

Na década de 50 foram descobertos os bloqueadores de captura de neurotransmissores como a imipramina que foi originalmente sintetizada para atuar como antipsicótico. A estrutura da ergotamina foi elucidada em 1951 e sua síntese em 1961, ambas por A. Hoffmann. A iproniazida, em 1957, originalmente um tuberculostático, e a isoniazida, em 1958, inauguraram a classe dos antidepressivos que agem sobre a MAO. (Wadt, 2003).

Os ansiolíticos, outra classe de vendas volumosas, são relativamente recentes. Os pioneiros foram o meprobamato, em 1955, e o clordiazepóxido, em 1957, desenvolvido por Sternbach, seguidos por outros benzodiazepinicos: diazepam, oxazepam, nitrazepam e outros mais recentes. O fenobarbital e a fenitoína, da primeira metade do século $X X$, e mais recentemente 0 ácido valpróico e a carbamazepina permitiram bons resultados no tratamento das convulsões cerebrais desde o início do século passado (Wadt, 2003).

Em todos os países, substâncias e medicamentos que alterem funções do sistema nervoso central (SNC) são passiveis de regulamentação para exposições humanas. No Brasil, tal regulamentação na forma de Lei, elaborada com base em acordos internacionais vem sendo imposta desde o início dos anos 60 . 
A legislação brasileira em vigor, tornada obrigatória para substâncias psicoativas, capazes de provocar alterações de comportamento e dependência física e/ou psíquica é a Portaria, 344/98 do Ministério da Saúde (P-344) que dispõe sobre Substâncias e Medicamentos sob Controle Especial, incluindo também outras substâncias como, por exemplo, os retinóicos de uso sistêmico e os anti-retrovirais para o tratamento da síndrome da imunodeficiência adquirida (AIDS). Esta portaria é o resultado da junção de duas outras que estiveram em vigor até maio de 1998: as portarias 27 e 28/86 (MS, 1986a, 1986b, 1998a)

A legislação atual é complexa, e em muitos aspectos (inclusive na documentação exigida para a dispensação das substâncias que ela engloba) foge a algumas das recomendações de Acordos Internacionais, assinados por vários países com o objetivo de assegurar a disponibilidade e o controle de entorpecentes e narcóticos: a Convenção Única de Entorpecentes de Viena de 1961 e os fármacos psicotrópicos, pela Convenção de Psicotrópicos de Nova lorque de 1971, ambas ainda em vigor (WHO, 1977).

Entre nós, a pouca familiaridade dos profissionais de saúde, envolvidos na dispensação dessas substâncias, com a legislação e mesmo com certos procedimentos exigidos pela P-344, podem trazer dificuldades para 0 cumprimento de suas determinaçōes.

Quanto à prescrição de medicamentos psicoativos, ainda há muito que aprender. Em trabalho recente em que se analisou a prescrição e dispensação de medicamentos psicotrópicos, por meio de análise de receitas/notificações retidas, em diferentes estabelecimentos de dois municípios de São Paulo, os autores concluiram que os resultados confirmam a ocorrência de uso irracional e uma série de práticas inadequadas que envolvem a prescrição desses medicamentos. Portanto, indicam a necessidade de uma ampla revisão no atual sistema de controle dessas substâncias no país (NOTO et al., 2002).

A partir das convenções de 1961 e 1971 que tem por objetivo assegurar a disponibilidade de medicamentos controlados para uso médico ao mesmo tempo evitando seu mau uso e o encaminhamento para o abuso.

A implementação bem sucedida desses programas de controle de medicamentos, entretanto, requer medidas regulatórias afim de que mecanismos de controle não restrinjam sua acessibilidade. 
Estudos anteriores indicam que em muitos paises amplas medidas regulatórias restritivas na distribuição de substâncias narcóticas possam constituir impedimentos legais à disponibilidade resultando em grande sofrimento para pacientes ce câncer.

Como um primeiro passo para encontrar uma solução para este problema, foram desenvolvidos guias com o propósito de dar assistência às autoridades nacionais para conduzir autodiagnóstico dos seus sistemas regulatórios com a finalidade de identificar as deficiências, se houver (YOSHIDA, 2003).

É fácil entender que complicadores no atendimento farmacêutico, devido ao excesso de documentos exigidos e da burocracia, só fazem prejudicar o trabalho, numa situação onde é imprescindivel a agilidade de ações, visando, antes de tudo a assistência ao paciente. Some-se a isso o fato de que tais complicadores não conseguem, infelizmente, deter o desvio e o uso ilicito dos medicamentos submetidos a tal controle. 


\section{CONTROLE DE SUBSTÂNCIAS PSICOATIVAS.}

\subsection{Narcóticos e psicotrópicos.}

Vencer a dor é uma busca da humanidade, desde seus primeiros tempos. O uso do ópio na analgesia já é citado nos escritos de Teopharastus, no terceiro século antes de Cristo. O médico grego Lucano, que hoje conhecemos como o evangelista Lucas, preparava uma bebida feita com o suco de sementes de papoula maceradas no vinho e ministrava aos seus pacientes aos poucos, para aliviar-Ihes a dor. Assim inicia-se a prática da administração de substâncias psicoativas em tratamentos médicos (GOODMAN, GILMAN, 1983).

Depois de séculos de esquecimento (devido à sua toxicidade), atribui-se a Paracelso (1493-1541) a reintrodução do ópio na Europa (GOODMAN, GILMAN, 1983). A morfina (isolada em 1803 por Serturner) é, ainda hoje, o protótipo dos hipnoanalgésicos no alívio da dor de moderada a grave, devida a causas diversas (KOROLKOVAS, 1982).

O ópio ajudou muito a aliviar a dor na medicina antiga, impotente diante de tantos males para os quais não havia tratamento (SYDENHAM escreveu, em 1680: "Dentre os remédios que Deus Todo-Poderoso quis dar ao homem para alívio de seus sofrimentos, nenhum é tão universal, tão eficaz quanto o ópio"). No entanto, os problemas causados pela dependência aos opiáceos também sāo conhecidos há muito tempo.

Salienta-se, com relação aos opiáceos, que o mais importante para seus descobridores foram às propriedades euforizantes e narcóticas que apresentavam, antes de descobertos seus efeitos terapêuticos (FINKEL, 2001).

A relação entre o homem e as drogas (fora do uso médico), tem sido alimentada também pelos rituais religiosos, com o sentido de fortalecer ligações entre seus membros; neste caso, o individuo as utiliza não para si próprio, mas para cumprir um papel designado pelo seu grupo (MASUR, 1985). Assim, as baforadas ou beberagens usadas nas manifestações religiosas de muitos povos indígenas encerram substâncias psicotrópicas - é o caso do cacto peyote, usado pelos apaches no sudoeste dos Estados Unidos, e da planta alucinógena ahyuasca, utilizada no ritual do Santo Daime na Amazônia Brasileira. 
A alteração da realidade por drogas foi artifício também de outros segmentos sociais: nos circulos intelectuais e artisticos europeus do inicio dos anos 1900 , era muito forte a presença de estimulante e outras substâncias para alterar o estado de consciência e para ampliar o poder de criação (PLONKA-SYROKA, 1997). Bem depois, nos anos 60, as drogas voltaram a aparecer com força na bagagem artística de muitos ícones de então: várias músicas dos Beatles foram inspiradas pelo uso de alucinógenos. Bob Dylan, Cat Stevens e os Rolling Stones também utilizaram drogas para aumentar sua criatividade.

Outra forma de aproximação com as drogas (aceita socialmente, inclusive) seria o uso "utilitário", individual ou corporativo. O primeiro pode ser ilustrado pelo consumo de álcool por profissionais de vendas, que entretêm seus clientes durante reuniões de negócios; ou por pessoas que tomam bebida alcoólica para expressar o que não conseguiriam, se estivessem sóbrias. $O$ utilitarismo corporativo pode ser visto nos grandes empreendimentos comerciais que geram empregos e vantagens a partir da produção e venda de bebidas alcoólicas, produtos do tabaco e outras drogas. Os governos também se utilizam destas vendas, garantindo grandes receitas através de impostos e taxas cobradas sobre tais itens (KALANT, ROSCHLAU, 1998).

Controlar a dor, fugir à realidade, cumprir rituais religiosos, usar a droga de forma "utilitária" além de todos estes fatores que atuam como "aproximadores" entre o homem e as drogas, há outros: MALACHIAS (1999) lembra as instabilidades sociais, que levam à insegurança e à falta de perspectiva quanto ao futuro, situação marcada principalmente pela desigualdade de oportunidades.

Outro uso para os narcóticos e outras drogas de abuso é a procura por uma realidade menos penosa. Esta necessidade de "fuga", que sempre fez parte da condição humana, constitui perigo real não só para o usuário como para a coletividade, uma vez que o dependente possui verdadeira compulsão pela droga, cometendo inclusive atos criminosos para obtê-la (ZANINI, OGA, 1994).

A dependência torna-se ainda mais cruel porque não atinge apenas o indivíduo, mas sua familia e a comunidade onde ele vive. As substâncias psicoativas têm estreita relação com a dependência física ou psíquica (ou 
ambas), levando o usuário à procura compulsiva e à tolerância. Assim, é possivel obter lucro através delas, de onde surge o tráfico, atividade tão antiga quanto o próprio uso compulsivo de drogas.

O narcotráfico é uma poderosa atividade comercial de milhōes de dólares, que se estende por todo o planeta. Possui instrumentos sofisticados de atuação e está, freqüentemente, associado ao terrorismo (FRANKLIN, 1993).

Paralelamente ao uso não-médico, ilícito, a utilização terapêutica de fármacos psicoativos tem-se aperfeiçoado, e sua aplicação no campo médico é cada vez mais diversificada.

Olhando para o passado, vemos que a morfina foi empregada de formas até bizarras: CHAST, (1998), descreve o tratamento do poeta alemão Heine que sofria de dor constante devido a uma neurosífilis - com o uso de cristais de morfina colocados sob a pele. Tal forma de administração, desconfortável para o paciente, era considerada eficaz, e foi popular entre 1830 e 1860; MALCOLM (1999), discute os métodos usados para a descontinuação do tratamento com a morfina entre os anos 1900-1930, e relata procedimentos estranhos: foi usada inclusive a atropina, que causava delírios, para encobrir os problemas da retirada do opiáceo.

As formas de utilização médica para a morfina sofisticaram-se, deixando para trás a simples injeção, que tinha de ser aplicada a intervalos de tempo cada vez menores. Atualmente, a administração pode ser feita através de bombas de infusão controladas pelo próprio paciente, para alívio da dor crônica; pela injeção intratecal, para controle da dor pós-operatória (MATSUDA et al., 2001); pelo uso de derivados sintéticos, como o fentanil, em sistemas transdérmicos, fornecendo o analgesia para o paciente por várias horas (MYSTAKIDOU et al., 2001); e para o uso pediátrico (HUNT et al., 2001). Hoje há um sem-número de possibilidades para o emprego clínico dos opiáceos, seja na dor crônica de várias origens (PIMENTA, TEIXEIRA et al., 1999), e na dor oncológica (OZAKI, NARITA, SUZUKI, 2001).

Com a diversificação do uso, os opiáceos e outras drogas e fármacos narcóticos esbarram em questões éticas que envolvem discussões delicadas, como o suicídio assistido e a injeção letal (FOLKER et al., 1996). Mesmo para 
a utilização clínica, a conduta frente a tais substâncias tem sido questionada (TRUOG,ARNOLD,ROCHOFF, 1991).

A história nos tem mostrado que novas drogas e fármacos surgem, como substitutos seguros de outros mais antigos, que produzem dependência. No entanto, estas substâncias/medicamentos também acabam provocando dependência, após certo tempo de utilização clínica. Assim foi com o álcool, ópio e morfina; também com a cocaina, heroina, brometos e cloral; mais recentemente, com os barbitúricos e benzodiazepínicos. Até a metanfetamina MDMA, conhecida hoje como "ecstasy", foi sintetizada para administração em psicoterapia, e acabou se tornando droga de abuso (FERIGOLO et al., 1998). Os barbitúricos, quando lançados, foram anunciados como "absolutamente seguros". Ao longo de dez anos surgiram inúmeros informes de superdoses fatais. Hoje eles têm poucas indicaçōes na terapêutica; mas são "medicamentos de eleição para suicidar-se, para o que são extremamente efetivos" (CHETLEY, 1993).

\subsection{Ações regulatórias.}

Entrando no campo das ações regulatórias/restritivas ao uso de drogas e fármacos, não houve controle efetivo por parte dos governos, até metade do século XVIII. A partir dessa época, após uma guerra entre China e Inglaterra a Guerra do Ópio, causada pela proibição do comércio do ópio pelos chineses (comércio este feito pelos ingleses), tem início uma preocupação real com a dependência às drogas e o seu tráfico. Só após cinqüenta anos, e um enorme esforço nacional, a China conseguiu controlar a dependência (ZANINI, OGA, 1994).

Inicia-se assim a elaboração de regulamentações para 0 uso de substâncias causadoras de dependência. As leis foram se modificando com o correr dos tempos, na medida em que o conhecimento e a avaliação risco /benefício das drogas também foi mudando, por exemplo, a cocaína era largamente usada no começo do século $X X$, como tônico estimulante, vendida livremente em mercearias e quitandas nos Estados Unidos e outros paises. A heroina (diacetilmorfina) foi introduzida na terapêutica em 1898, como produto seguro, sem os efeitos indesejáveis da morfina. No entanto, seu intenso poder 
euforizante e alta capacidade de causar dependência, fizeram com que sua produção e uso fossem proibidos por lei (ZANINI, OGA, 1994).

\subsection{Controle internacional}

Procurando enfrentar a organização e o elevado poder financeiro dos produtores e traficantes de drogas ilícitas, várias nações buscaram cooperação mútua, convencidas de que assim, os resultados seriam melhores que com açōes isoladas.

São elaborados tratados internacionais firmados entre elas, no período de 1912 a 1972, com o objetivo de assegurar que as drogas por eles controladas fossem utilizadas exclusivamente com propósitos médicos ou científicos (ZANINI et al., 1985).

O primeiro tratado para o controle de substâncias psicoativas foi proposto em 1912, a fim de que o ópio e seus derivados ficassem sob controle internacional. Hoje, três tratados internacionais fornecem as bases legais para o controle internacional dessas substâncias. São eles: Single Convention on Narcotic drugs de 1961, Convention on Psychotropic Substances de 1971 e United Nations Convention Against llicit Traffic in Narcotic Drugs and Psychotropic Substances de 1988.

Quando a Organização Mundial da Saúde (OMS) foi criada em 1948, 18 substâncias derivadas do ópio, folha de coca e maconha estavam sob controle internacional. Após 1948 a OMS tem sido responsável pela revisão da lista de substâncias psicoativas, do ponto de vista médico e científico, propondo adição de novas substâncias, removendo outras e mesmo transferindo substâncias de listas, por decisão da United Nation Commission on Narcotic Drugs (UNCND) (YOSHIDA 2003).

Somente a OMS pode submeter modificaçōes neste comitê internacional. Quando os governos signatários propõem modificaçōes, estas devem ser primeiramente estudadas e aprovadas pela OMS por maioria simples $(1 / 2+1)$ quando se tratar de substâncias narcóticas e por maioria absoluta (2/3 dos membros) quando se tratar de substâncias psicotrópicas.

Em 1999, através deste mecanismo de decisão envolvendo a OMS e a UNCND, o número de substâncias narcóticas sob controle internacional passou 
de 18 para 118 e o de substâncias psicotrópicas de 32 para 111. As listas são disponibilizadas pelo International Narcotics Control Board (INCB), órgão responsável pela implementação dos tratados internacionais de controle. A lista de drogas narcóticas é conhecida como "lista amarela" e de substâncias psicotrópicas como "lista verde" (JIFE,2001) (JIFE, 2002).

A OMS revisou mais de 400 substâncias psicoativas desde 1949, através de seu comitê de especialistas. As decisões deste comitê são publicadas no World Health Organization Technical Report Series (TRS). A trigésima segunda reunião foi publicada no TRS $n^{\circ} 903$. A trigésima terceira reunião recomenda a inclusão da substância amineptine e o reestudo do delta9 tetraidrocanabinol (YOSHIDA 2003). Estas recomendações estão disponíveis na rede mundial de computadores (internet) em Guidelines for the WHO review of dependence-producing psychoactive substances for internacional control, adoado pelo comitê executivo em janeiro de 2000 (WHO, 2000).

Quando uma substância tem controle internacional, o INCB e as Organizações das Nações Unidas (ONU) assumem a responsabilidade pela implementação das medidas de controle a serem definidas nos tratados internacionais. Por decisão de sua assembléia a OMS passou a ser responsável pelo sucesso da implementação dos tratados internacionais usando guias tais como: Model Guidelines for the International Provision of Controlled Medicines for Emergency Medical Care (1996) e Guidelines for the Control of Narcotic and Psychotropic Substances (1984).

Para que se torne efetivo o controle internacional, cada pais, dentro dos limites de sua jurisdição, deve realizar seu controle (ZANINI et al.,1985a). No Brasil, tais acordos foram acatados através de decretos presidenciais, que determinavam seu cumprimento e execução.(BRASIL 1938, 1964, 1972, 1977 e 1991).

\subsection{Controle repressivo}

A prevenção e repressão ao abuso de drogas e fármacos psicoativos é objeto, no Brasil, das Leis 6368/76 (em vigor) e 10409/02, que dispõem sobre o tráfico ilícito e uso indevido de tais substâncias. A desobediência a Lei 
6368/76, não constitui apenas infração sanitária apenas, mas também de natureza criminal (BRASIL, 1976b e 2002).

A Lei 6368 mostra que o profissional de saúde, por procedimentos inadequados ou descuidados, pode ser enquadrado como infrator, mesmo sem nunca ter tido contato com drogas ilícitas ou "de rua", mas por procedimentos do dia-a-dia, pois para tanto basta estar "... fabricando, adquirindo, vendendo, expondo à venda...transportando, tendo em depósito...substância entorpecente ou que determine dependência física ou psíquica...em desacordo com determinação legal ou regulamentar ... ". Tal "determinação legal" se traduz, hoje, pela Portaria 344/98 (BRASIL, 1976b).

Com a Lei 6368, as atitudes em relação às substâncias psicoativas perdem seu caráter restrito à área da saúde, e passam a ser instrumentos da justiça. Em relação às substâncias controladas, todos quantos são investidos de autoridade sanitária assumem, por força de lei, a função de instrumentos da mesma lei (ZANINI et al., 1985).

\subsection{Uso de medicamentos psicoativos.}

A prescrição de medicamentos psicoativos a base de substâncias constantes das listas A1 e A2, denominadas entorpecentes, A3, B1 e B2, psicotrópicas, devem, obrigatoriamente, estar acompanhados da Notificação de Receita, que autoriza a dispensação desses medicamentos.

O uso de medicamentos psicoativos sofre, em nosso pais, uma série de falhas de procedimentos que acabam por prejudicar, principalmente, o paciente que delas necessita. Vamos identificar as mais significativas:

\subsubsection{Indisponibilidade de medicamentos.}

O Brasil vive um paradoxo quanto à situação de alguns medicamentos analgésicos e outros psicoativos: ao mesmo tempo em que os analgésicos não-narcóticos (de venda livre, pela nossa legislação) são abusados pela população, os narcoanalgésicos não estão adequadamente disponiveis, seja para o tratamento ambulatorial, seja no próprio ambiente hospitalar. As razōes para estas dificuldades são muitas. Seguem-se duas delas: 
- entraves causados pela própria legislação - esta situação ainda ocorre, mas é hoje muito menor do que no início dos anos 80 , quando era enorme a dificuldade para se conseguir medicamentos anticonvulsivantes, neurolépticos ou analgésicos-narcóticos para pacientes em tratamento ambulatorial (ZANINI et al.,1985). O medo do uso indevido e do tráfico fazia com que as autoridades sanitárias se esquecessem dos pacientes: aqueles que precisassem de tais medicamentos (ou seu familiar) teriam de percorrer um difícil trajeto até encontrar uma farmácia onde encontrá-los, mesmo estando com a receita correta, absolutamente de acordo com a legislação. Hoje, há maior facilidade para obtenção, tendo contribuído para tal mudança a Portaria da Divisão Nacional de Medicamentos da Secretaria Nacional de Vigilância Sanitária DIMED 02/84, que assegura ao paciente a continuidade de seu tratamento. Apesar de ter melhorado, o acesso a tais medicamentos, (principalmente nos locais distantes dos grandes centros), a dificuldade em se prover um tratamento com opiáceos para um paciente ambulatorial continua sendo grande (MS, 1984) (ZANINI et al., 1985).

- desconhecimento dos esquemas de uso de analgésicos-opiáceos pelo próprio médico - a apreciação inadequada ou negligência para com o problema da dor (TEIXEIRA et al.,1998) torna comum a afirmação, nos hospitais, que "só se dá morfina aos pacientes em último caso". Isto significa, não raro, que o paciente está pedindo para que o deixem morrer, tamanho é o seu sofrimento. Tal situação, ainda muito comum no nosso dia-a-dia hospitalar, reflete que o interesse médico vê o problema da dor apenas como parte do distúrbio físico, com pouca atenção dada aos fatores de ordem psicológica e cultural envolvidos, que influenciam diretamente na severidade da doença e na maneira como cada indivíduo enfrenta o processo doloroso (WILLIAMS, WILSON, 1983).

Alguns pesquisadores têm registrado a dificuldade dos médicos quanto a prescrição de substâncias psicoativas. Em um estudo onde 52 médicos foram avaliados quanto à prática e atitudes de prescrever medicamentos psicoativos para crianças, apenas $1 / 4$ (13 médicos) se sentiam confiantes e o restante $3 / 4$ (39 médicos) precisaram consultar um colega psiquiatra infantil antes de prescrever (MONTOLIU, CRAWFORD, 2002). 


\subsubsection{Prescrição insuficiente}

Embora seja sempre esperados algum grau de dependência física e tolerância quando um opiáceo é administrado em doses terapêuticas por períodos prolongados, o médico, se atento adequadamente ao problema, não permitirá que seu paciente (em especial aquele em estado terminal) sofra qualquer tipo de dor incontrolável (DELGADO, 1998).

"Nenhum paciente deve jamais desejar a morte devido à relutância de seu médico em usar quantidades adequadas de opiáceos eficazes" (GOODMAN, GILMAN, 1983).

O comparativo mostrado a seguir, com dados da Organização Mundial da Saúde (OMS), é de 1990, mas ilustra uma realidade ainda presente no nosso país:

Gráfico 1 - Consumo de morfina em doses / dia por milhão de habitantes.

Doses/dia/milhão hab.

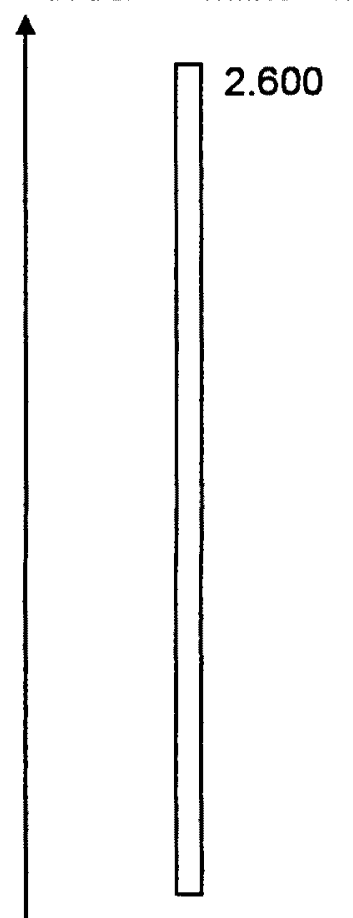

660

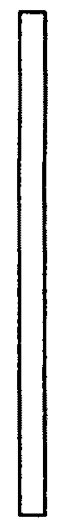

70

Dinamarca

EUA

Uruguai

Argentina

Brasil

(obs: desenho não em escala) 
Certamente, tal situação não nos faz supor que no Brasil os doentes sintam menos dor. O que acontece é que a dor, entre nós, é sub-avaliada. $O$ médico não a tem como um fator preponderante para a cura da doença na sua origem. Sabe-se, no entanto, que o paciente com dor crônica evolui de forma muito menos satisfatória que aquele onde a dor esteja sendo adequadamente monitorada.

Nos últimos anos, esta forma de encarar a dor tem-se modificado, através da formação (principalmente nos hospitais-escola, centros de referência e grandes hospitais) de Centros de Tratamento da Dor, ou "Grupos de Dor", como são comumente conhecidos.

Os Grupos de Dor são formados por equipes multiprofissionais (neurologistas, psiquiatras, enfermeiros, fisioterapeutas), cuja função é, primordialmente, o controle da dor, para que o paciente tenha, no decorrer de seu tratamento, uma melhor qualidade de vida, o que influencia decisivamente para a evolução favorável de seu quadro.

\subsubsection{Prescrição excessiva}

É difícil avaliar se uma prescrição é excessiva, ou insuficiente. Tal conclusão só pode ser feita a partir de estudos epidemiológicos do consumo de medicamentos em uma dada população (ZANINI, PAULO, 1985).

A prescrição excessiva é a principal maneira de se chegar ao abuso, a partir do uso lícito. Os fatores desencadeantes podem ter origem no próprio médico, ou na utilização do médico por dependentes ou traficantes. Com origem no médico existe a indução pela propaganda, os efeitos agradáveis referidos pelos pacientes, a diminuição do tempo de consulta, que é resolvida pela prescrição. Com o foco nos pacientes (ou pessoas que buscam o médico visando tão somente a obtenção da droga), é comum conseguir-se a receita através da "amizade", ou através da simulação de um quadro de doença. São também comuns os casos de pessoas que procuram vários médicos (sem que um saiba da existência ou conduta do outro) para obter seus medicamentos (ZANINI et al., 1985). 


\subsubsection{Prescrição fraudulenta}

A padronização do receituário (Notificações $A$ e $B$ ) teve como um de seus motivos impedir fraudes do ato médico. $A$ introdução destes modelos de receituário implantada pela Portaria DIMED 02/84 e modificada pelas Portarias 27 e 28/86 tendo continuidade com a Portaria 344/98, da Secretaria Nacional de Vigilância Sanitária (MS, 1984,1986a, 1986b e 1998a).

Se a padronização, por um lado, buscava a facilitação para os controles feitos pela autoridade sanitária, ela trouxe, por outro, um exagero no número de itens controlados: por exemplo, os benzodiazepínicos, substâncias psicoativas classificada como grau IV pela Convenção de Psicotrópicos das Nações Unidas de 1971 ainda em vigor, não necessitam, pela mesma Convenção, nem de registro, nem de retenção de receita; bastaria apenas a apresentação da receita médica. $O$ exagero de receitas retidas deve-se justamente à não-obediência pelos estabelecimentos de dispensação quanto à apresentação da receita médica.

Para a obtenção de um medicamento ambulatorial, todos os dados colocados na receita podem ser falsos, mas alguém tem de se apresentar para retirar o produto: dai a necessidade de se identificar o portador, comprovando sua identidade, endereço e telefone (ZANINI, PAULO, 1997).

No ambiente hospitalar, a fraude numa prescrição assume um aspecto diferente: o médico que assim procede pode estar tentando conseguir um medicamento para seu próprio uso, por exemplo, um analgésico narcótico, o que envolve o delicado problema da dependência a drogas por profissionais da saúde.

Tal situação, difícil de ser constatada, pode ser verificada através da documentação interna, verificando registros de receituário, prontuários de pacientes, quando a prescrição que levantou suspeita se referir a um paciente internado. Para as prescrições em nome de pacientes ambulatoriais, deve haver uma verificação cuidadosa e constante das receitas padronizadas, por meio de notificações de receita, com relação às exigências feitas pela autoridade sanitária.

A verificação de receitas e outros documentos, não substitui o trabalho do farmacêutico e uma equipe bem treinada à frente da dispensação. 
Profissionais com bom embasamento no assunto, realizando a dispensação com cuidado e critério, oferecem resultados muito mais positivos que a vistoria nos papéis referentes aos atendimentos realizados.

O que ocorre em nosso pais (como em outros, onde o controle não é eficiente), um controle aparente, com a exigência de uma quantidade enorme de documentos. Na prática, são tantas receitas, e o volume de papel se torna tão imenso, que é humanamente impossivel fazer registro adequado da dispensação. A fraude é mais bem-combatida quando são feitas inspeções minuciosas, contando-se os estoques e fazendo-se comparações com os registros de compra e venda; esta atitude seria mais adequada para se identificar a ocorrência de má prática médica ou farmacêutica (ZANINI, PAULO,1997).

\subsection{Legislação em Saúde Pública}

Nas Portarias 27 e 28/1986, que vigoraram por doze anos, foram inclusos muitos fármacos além dos citados nas Convençōes Internacionais, inclusive substâncias cujos efeitos não trazem alterações significativas do SNC, como, por exemplo, a talidomida, substância imunossupressora e o misoprostol agente anti-úlcera e indutor de aborto (BRASIL, 1986).

Em maio de 1998, a Secretaria de Vigilância Sanitária do Ministério da Saúde aprovou a Portaria 344/98 (P-344), ou Portaria Única, revogando as duas anteriores. Nela, mais substâncias passaram a figurar, como os retinóicos de uso sistemico, os anti-retrovirais para o tratamento da AIDS e os derivados androgênicos usados como anabolizantes (BRASIL, 1998a)

Pela diversidade de listas que possui, esta legislaçăo deixou de enfocar apenas substâncias e medicamentos psicoativos. É uma legislação que dispōe sobre "Substâncias e Medicamentos sujeitos a Controle Especial", conforme o próprio texto define.

Para simplificar o entendimento, apresentamos na Tabela I as características mais importantes da P-344. 
Tabela 1 - Resumo das principais características da P-344

\begin{tabular}{|c|c|c|c|c|c|c|c|c|c|}
\hline Lista & $\begin{array}{c}\text { Classe } \\
\text { terapêutica }\end{array}$ & $\begin{array}{l}\text { Notifi- } \\
\text { cação }\end{array}$ & $\begin{array}{l}\text { Notifr- } \\
\text { cação } \\
\text { (cor) }\end{array}$ & $\begin{array}{c}\text { Impresso } \\
\text { emitido } \\
\text { pelo } \\
\end{array}$ & $\begin{array}{c}\text { Retençāo } \\
\text { receita }\end{array}$ & $\begin{array}{l}\text { Val. } \\
\text { dias }\end{array}$ & Quantidade & Escrituração & OBS \\
\hline $\mathbf{A 1}$ & $\begin{array}{c}\text { Entorpecentes } \\
(88) \\
\end{array}$ & SIM & amarela & Governo & SM & 30 & $\begin{array}{l}5 \text { ampolas } \\
30 \text { dias trat. }\end{array}$ & \multirow{2}{*}{$\begin{array}{c}\begin{array}{c}\text { Livro de } \\
\text { registro }\end{array} \\
\text { especificico } \\
\text { Cada página } \\
1 \text { subs. } 2 \text { anos } \\
\end{array}$} & \\
\hline A2 & $\begin{array}{l}\text { Entorpecentes } \\
\text { conc. esp. (15) }\end{array}$ & SIM & amarela & Governo & SIM & 30 & $\begin{array}{l}5 \text { ampolas } \\
30 \text { dias trat }\end{array}$ & & \\
\hline $\mathbf{A} 3$ & $\begin{array}{c}\text { Psicotrópicos } \\
\text { (13) }\end{array}$ & SIM & amarela & Governo & SIM & 30 & $\begin{array}{l}5 \text { ampolas } \\
30 \text { dias trat }\end{array}$ & \multirow{3}{*}{ 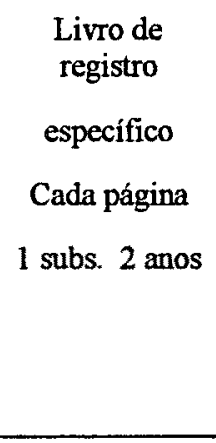 } & \\
\hline B1 & $\begin{array}{c}\text { Psicotrópicos } \\
(67) \\
\end{array}$ & SIM & azul & Médico & SIM & 30 & $\begin{array}{l}5 \text { ampolas } \\
60 \text { dias trat }\end{array}$ & & \\
\hline B2 & $\begin{array}{c}\text { Psicotrópicos } \\
\text { Anorexígenos } \\
\text { (7) }\end{array}$ & SIM & azul & Médico & SIM & 30 & $\begin{array}{l}5 \text { ampolas } \\
60 \text { dias trat }\end{array}$ & & \\
\hline $\mathrm{C1}$ & $\begin{array}{l}\text { Outras subs- } \\
\text { tâncias (151) }\end{array}$ & NÃO & & Médico & SIM & 30 & $\begin{array}{l}5 \text { ampolas } \\
60 \text { dias trat }\end{array}$ & \multirow{4}{*}{$\begin{array}{l}\text { Livro de } \\
\text { registro } \\
\text { específico } \\
\text { Cada página } \\
1 \text { subs. } 2 \text { anos }\end{array}$} & $\begin{array}{l}\text { Máx } 3 \\
\text { subs } \\
\text { receita }\end{array}$ \\
\hline $\mathrm{C} 2$ & $\begin{array}{l}\text { Subst. } \\
\text { retinóicas (5) }\end{array}$ & SIM & branca & Médico & SM & 30 & $\begin{array}{l}5 \text { ampolas } \\
30 \text { dias trat }\end{array}$ & & \\
\hline C5 & $\begin{array}{c}\text { Anabolizantes } \\
\text { (8) }\end{array}$ & NÃO & & Médico & SIM & 30 & $\begin{array}{l}5 \text { ampolas } \\
60 \text { dias trat }\end{array}$ & & \\
\hline $\mathrm{C4}$ & $\begin{array}{l}\text { Anti-retrovirais } \\
\text { (8) }\end{array}$ & SIM & $\mathrm{S} / \mathrm{R}$ & Governo & SnM & $\mathrm{S} / \mathrm{R}$ & $\mathrm{S} / \mathrm{R}$ & & $\begin{array}{c}\text { Máx } 5 \\
\text { subs/ } \\
\text { receita }\end{array}$ \\
\hline $\mathbf{C 3}$ & $\begin{array}{c}\begin{array}{c}\text { Imunossupres } \\
\text { sores }\end{array} \\
\text { (1) } \\
\end{array}$ & SIM & branca & Governo & SIM & 15 & 30 dias & $\begin{array}{l}\text { Livro de } \\
\text { registro } \\
\text { especifico }\end{array}$ & $\begin{array}{c}\begin{array}{c}\text { Manter } \\
\text { livro }\end{array} \\
5 \text { anos }\end{array}$ \\
\hline D1 & $\begin{array}{l}\text { Precursores de } \\
\text { entorp. ou } \\
\text { psicot. } \\
\text { (24) }\end{array}$ & $\mathrm{NÃO}$ & & Médico & NÃO & $\mathrm{S} / \mathrm{R}$ & $\mathbf{S} / \mathbf{R}$ & $\begin{array}{l}\text { Livro de } \\
\text { registro } \\
\text { especifico }\end{array}$ & \\
\hline
\end{tabular}

Balanço: De substâncias (BSPO) FABRICANTE - Trimestral e anual - toda a lista - OBRIGATÓRIO

De Medicamentos (BMPO) FARMÁCIAS E DROGARIAS-Trimestral e anual (A1,A2,A3,B2 E C4 - OBRIGATÓRIO BMPO e BSPO para HOSPITAIS E CLÍNICAS MÉdICAS E VETERINÁRIAS DISPENSADO 


\subsubsection{Multiplicidade de leis.}

As confusōes geradas pelo grande número de leis em nosso pais não se restringem somente à área da saúde, ou de medicamentos. Falando-se especificamente em medicamentos sob controle especial, tal situação também traz dúvidas para os profissionais que os prescrevem, pacientes que deles fazem uso e profissionais que fazem sua dispensação.

Exemplificando, citamos a Lei 9.965, de 27 de abril de 2000, assinada diretamente pelo então Presidente da República, Fernando Henrique Cardoso e não por um órgão legislador em Saúde, como a ANVISA. Essa Lei dá instruçōes para a dispensação e venda de medicamentos anabolizantes, cobrando ainda mais dados, como o CPF do prescritor (BRASIL, 2000).

Estranhe-se que tais determinações, se devem ser exigidas como lei, não figurem nas atualizações feitas nas Listas da própria Portaria 344 (neste caso, à Lista C5, das substâncias anabolizantes). A multiplicidade de leis para um mesmo assunto desorienta o profissional, que acaba por não observá-las e, em conseqūência, não segui-las. Seria necessário que todas as determinações constassem de uma mesma fonte.

\subsubsection{Ações de vigilância sanitária.}

Desde a sua criação, a Agência Nacional de Vigilância Sanitária (ANVISA) tem tomado várias iniciativas no sentido de organizar o confuso setor de medicamentos no Brasil, através de atitudes como: modificação nos critérios para a emissão de registros; restrição ou retirada do mercado de medicamentos sem comprovação terapêutica; elaboração de normas, tais como as de "Boas Práticas" para os setores produtivos, distribuidores e comércio farmacêutico.

No entanto, quanto à fiscalização, ou seja, cobrança de resultados, percebe-se ainda uma grande precariedade, principalmente nas ações de vigilância sanitária em que os Estados tem o dever de realizar (MS, 2001).

Outras açōes da ANVISA deixam a desejar, diante de um mercado farmacêutico marcadamente irracional como o nosso. Como exemplo, cita-se um Parecer Técnico de 07/2000 (SOBRAVIME 2001), onde a Agência se mostra favorável à continuidade da comercialização de anorexígenos à base 
de anfetaminas, e o não-anfetamínico mazindol (produtos não-comercializados em vários paises, devido aos riscos cardiovasculares). Tal parecer faz afirmações ambíguas, como:

"Os medicamentos anorexígenos comercializados no Brasil, à base de anfepramona, femproporex e mazindol, são eficazes no tratamento da obesidade, de acordo com estudos cientificos controlados";

"Sua relação risco/benefício pode ser favorável, desde que prescritos criteriosamente" e

"Para muitos pacientes, podem ser mais eficazes que os agentes antiobesidade mais modernos" (SOBRAVIME, 2001).

Além de exemplos como estes, faltam providências com relação a associaçōes irracionais de medicamentos, medicamentos desnecessariamente caros e sem vantagens quanto à eficácia e segurança, sobre outros análogos existentes no mercado. Temos hoje muitos registros para um mesmo principio ativo. Convivemos com a miscelânea medicamentos-referência, similares e agora, genéricos. Enfim, um número exagerado de apresentaçőes no mercado.

Também quanto ao número de apresentações o Brasil contraria as recomendações da Organização Mundial da Saúde. Segundo a OMS, são necessárias cerca de 200 drogas essenciais para tratar a maioria das doenças. No mercado brasileiro existem cerca de 20.000 apresentaçöes, sendo que o número exato, ninguém sabe. $E$ embora se tenha um número enorme de medicamentos, faltam àqueles essenciais, enquanto tantos outros são usados como drogas de abuso. O Deputado Federal Elias Murad descreveu esta situação em 1987, mas infelizmente, ela se aplica até hoje. É um dos grandes desafios que a ANVISA precisa enfrentar. "Pensamos ser justamente esta a maior missão da AGENCIA, ainda não-efetivada: a concretização de uma política de medicamentos, não como legislação apenas, mas como um conjunto de principios que orientam a tomada de decisóes e ações a longo prazo. A esta conduta devem se reportar todos os componentes do setor farmaceutico, colocando os interesses da saúde pública acima de outros interesses" (SOBRAVIME, 2001). 


\subsubsection{Avanços}

Apesar do enorme caminho ainda a ser percorrido, algumas conquistas foram significativas. A Lei dos Genéricos estabeleceu as bases legais para o registro, produção e controle de qualidade destes medicamentos. Cerca de dois anos após sua regulamentação, o número de medicamentos genéricos disponiveis aproximava-se de 500 itens. Este número superava as próprias previsões da ANVISA para tal período de tempo, previsões estas feitas quando a lei foi implantada (BRASIL, 1999b).

Há que se registrar também os esforços do Ministério da Saúde, nos últimos três anos, para propiciar a flexibilizaçåo das leis internacionais que protegem as patentes de medicamentos e o acesso aos insumos de saúde, usando como canal a Organização Mundial do Comércio (OMC).

Através da OMC ○ Brasil, com o apoio de mais de cinqüenta países, enfrentou a resistência de alguns paises desenvolvidos (como os Estados Unidos e Japão) para conseguir a quebra de patentes de medicamentos considerados prioritários à saúde pública, como os anti-retrovirais para o tratamento da AIDS.

Inserindo-nos neste panorama de mudanças e busca de um melhor atendimento em saúde, pretendemos que este trabalho colabore para 0 conhecimento e aperfeiçoamento com relação aos procedimentos habituais de dispensação e controle das substâncias e medicamentos sob controle especial, em especial os medicamentos psicoativos. 


\section{OBJETIVO E PLANO DE TRABALHO}




\section{OBJETIVO E PLANO DE TRABALHO}

A legislação Brasileira em vigor que dispõe sobre substâncias e medicamentos sob controle especial, dentre estes os psicoativos, é a Portaria $344 / 98$ do Ministério da Saúde. Apesar de atual, é complexa, fugindo das recomendações de acordos internacionais. A pouca familiaridade dos profissionais de saúde responsáveis pela prescrição, e dispensação, dessas substâncias e medicamentos com os procedimentos exigidos dificulta o seu cumprimento.

Assim o presente estudo, observacional, descritivo e retrospectivo terá por objetivo estudar a viabilidade do cumprimento desta legislação no controle desses medicamentos em um hospital universitário de grande porte

Para tanto foi elaborado o seguinte plano de trabalho:

- Criação de um banco de dados contendo informações a respeito da prescrição e dispensação ambulatorial de medicamentos psicoativos.

Com os seguintes objetivos específicos:

- Levantamento e caracterização dos medicamentos constantes na Portaria 344/98;

- Análise e avaliação de dados significativos com vistas o cumprimento do disposto na Portaria $344 / 98$ que disciplina a utilização segura desses medicamentos;

- Seleção de alguns dados adicionais que permitam sinalizar problemas inerentes a prescrição, dispensação e utilização pelo paciente (regulamentação do uso de substâncias psicoativas). 


\section{MATERIAL E MÉTODOS}

\subsection{Amostra - Casuistica}

Receitas prescritas para pacientes dos ambulatórios do Hospital das Clínicas da Universidade de São Paulo, conhecidos como PAMB, dispensadas sob a responsabilidade da Divisão de Farmácia do mesmo hospital e coletadas durante uma semana (do dia 25 ao dia 29) do mês de novembro de 2002 , constituem a amostra com 4405 receitas. Não pertence a esta amostra os pacientes atendidos nos seguintes Institutos: Coração, Psiquiatria, criança, Ortopedia e Emílio Ribas.

Para fins de casuistica serão utilizadas, para confeç̧ão do banco de dados, todas as receitas recebidas para dispensação. No estudo, a fim de atender os critérios de inclusão e exclusão, serão consideradas somente aquelas receitas que contenham medicamentos psicoativos sujeitos a controle especial conforme determinado pela Portaria $344 / 98$ seus anexos e retificaçōes (MS 1998a).

O estudo será do tipo observacional, descritivo e retrospectivo.

Em virtude da pesquisa referir-se somente à análise de documentos relativos a receitas de pacientes, identificados apenas por suas iniciais do nome completo, não houve necessidade da solicitação do termo de consentimento do paciente.

O projeto foi aprovado pelo Comitê de Ética da Faculdade de Saúde Pública através do oficio COEP $n^{\circ} 164 / 03$.

\subsection{Coleta dos Dados}

Equipamentos de informática com acesso à internet, e emprego de aparelhos de várias especificações. Programas em configurações mínimas para reprodução do trabalho:

- Microcomputador (CPU):

- processador PII-400 MHz; 
- 128 Mb de memória primária (RAM);

- 4,3 Gb de memória secundária (hard disk);

- "drive" para disco flexivel de $31 \frac{12}{2}$;

- "drive" leitor de CD-ROM;

- "modem" padrão de 56 Kbs (acesso discado à internet) e

- placa de rede 100/10 (acesso ADSL à internet).

- Programas de computador:

- gerenciador MS Windows 98;

- MS Office 97 em versão profissional (MS Word, MS Excel, MS Access

e, MS Power Point) e

- MS Internet Explorer 5.0 ou superior.

- Periféricos e suprimentos:

- monitor SVGA de 14";

- impressora jato de tinta ou laser e

- suprimentos (papel, arquivos, disquetes, CDs, etc.).

- Acesso à Internet:

- linha telefônica comum (acesso discado) e

- linha telefônica para transmissão de dados em banda larga (acesso ASDL).

- Dados coletados de cada receita:

- número de registro do paciente no hospital;

- data da receita;

- unidade geradora da receita (serviço);

- iniciais do nome completo do paciente e

- medicamentos prescritos e dispensados: 
- forma farmacêutica;

- concentração do princípio ativo;

- quantidade receitada no tratamento;

- quantidade dispensada para o tratamento, incluindo informações de faltas e não padronização e

- posologia e esquema terapêutico.

- classificações terapêuticas adotadas: ALFA (ZANINI et al., 1997) e ATC Index (WHO, 2000);

- identificação dos medicamentos psicoativos que necessitam de notificação;

- identificação terapêutica adotada Guiamed (Guia de Medicamentos) e Dicionário de Genéricos (ZANINI et al., 1997) e

- Observações relativas à prescrição e dispensação de cada medicamento.

\subsection{Organização da Base de Dados.}

Banco de dados contendo tabela relativa ao receituário sob análise (Anexo1), tabela auxiliar de classes terapêuticas ALFA (ZANINI et al, 1997) e ATC Index (WHO, 2000), quantidade usual de utilização de medicamento por dia (DDD), preconizada pelo e ATC Index (WHO, 2000).

\subsubsection{Tabela primária.}

Textos e dados originais do receituário transcritos em formato de tabela de banco de dados usando-se o programa MS Access.

Dados considerados:

- Nome do paciente - registro somente das iniciais; 
- Registro do paciente - referente a identidade do paciente junto ao hospital;

- Data da prescrição - dia, mês e ano;

- Medicamento - nome genérico ou marca comercial, conforme o especificado pelo médico;

- Quantidade dispensada - número de comprimidos (ou equivalente em forma sólida), ampolas, frascos (quando em forma líquida) ou bisnagas (para forma de creme ou pomada);

- Posologia - indicação de uso do medicamento prescrito e

- Unidade geradora - setor do hospital responsável pela emissão da prescrição.

Esta fase do processo consistiu, basicamente, em transferir as prescrições, todas manuscritas, para formato eletrônico.

4.3.2 Tabela secundárias para análise dos dados.

Dados harmonizados com os campos do programa introduzidos ou aperfeiçoados:

- Relativos ao paciente;

- Relativos ao medicamento;

- Relativos à formulação prescrita e

- Relativos à dispensação e posologia. 


\section{RESULTADOS}

5.1 Tabelas para análise dos dados obtidos.

Os dados coletados a partir das receitas com as prescrições foram organizados num banco a partir do qual foram geradas as tabelas que serão apresentadas a seguir.

Durante o período de 25 a 29 de novembro de 2002 foram emitidas 4.405 receitas e/ou notificações de receitas para 4.103 pacientes dos ambulatórios do Hospital das Clínicas (HC) onde foram prescritos 12.521 medicamentos controlados ou não.

5.1.1 Tabelas relativas à prescrição

O quadro geral do receituário para pacientes ambulatoriais do HC no periodo de 25 a 29 de novembro de 2002 está disposto na Tabela 2.

Tabela 2 - Receitas de medicamentos controlados e não controlados pela Portaria 344/98, para pacientes do Hospital das Clínicas

\begin{tabular}{|c|c|c|c|c|c|}
\hline \multirow{2}{*}{$\begin{array}{c}\text { Medicamentos } \\
\text { fornecidos } \\
\end{array}$} & \multicolumn{2}{|c|}{ Pacientes } & \multicolumn{2}{|c|}{ Prescriçōes } & \multirow[t]{4}{*}{ Média } \\
\hline & quantidade & $\%$ & quantidade & $\%$ & \\
\hline Controlados & $1.268(a)$ & 30,9 & 1.793 & 14,3 & \\
\hline Não controlados & 2.835 & 69,1 & 10.728 & 85,7 & \\
\hline Total (4.405 receitas) & 4.103 & & 12.521 & & 3,05 (b) \\
\hline
\end{tabular}

(a) = pacientes que tiveram pelo menos uma prescrição de medicamentos controlados pela Portaria $344 / 98$.

(b) = média de medicamentos por paciente.

Pela Lei $9782 / 99$, em todas as receitas emitidas no âmbito do Sistema Único de Saúde (SUS), as prescrições pelo profissional responsável adotarão obrigatoriamente a Denominação Comum Brasileira (DCB), ou na sua falta, a Denominação Comum Internacional (DCI) (BRASIL, 1999). 
A Tabela 3 apresenta as denominações dos medicamentos e quantidades prescritas e fornecidas. A Figura 1 apresenta a porcentagem de medicamentos controlados.

Tabela 3 - Denominação de medicamentos constantes nas receitas emitidas e atendidas no período estudado

\begin{tabular}{l|r|r|r|r}
\multirow{2}{*}{ Denominação } & \multicolumn{3}{|c|}{ Medicamentos não controlados } & \multicolumn{2}{c}{ Medicamentos controlados } \\
\cline { 2 - 5 } & Prescrito & Fornecido & \multicolumn{1}{c}{ Prescrito } & \multicolumn{1}{c}{ Fornecido } \\
\hline genérica & 7.423 & 6.963 & 1.046 & 1.054 \\
\hline Comercial $®$ & 2.924 & 2.841 & 744 & 741 \\
\hline $\mathrm{HC}(1)$ & 483 & 467 & 3 & 3 \\
\hline não identificado & 298 & (a) 291 & & 1.798
\end{tabular}

(B) - Medicamento de referência ou similar (marca registrada)

(1) - Produtos preparados na Farmácia HC/USP/SP.

(a) - Medicamentos não identificados na hora da digitação, porém, identificados no momento da dispensação, pois foram entregues.

Medicamentos controlados

HC

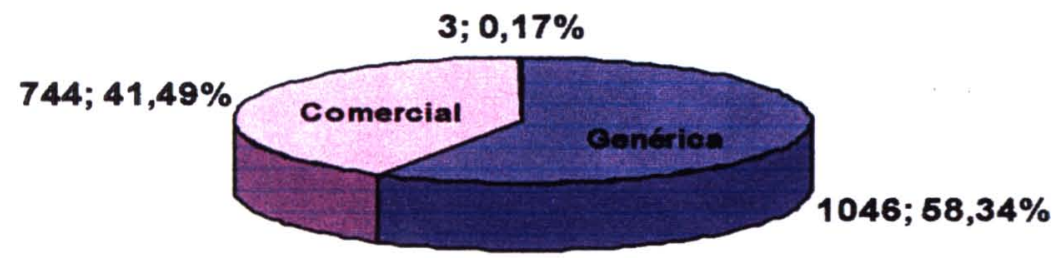

Figura 1 - Medicamentos controlados prescritos

HC = produzido na Farmácia Hospitalar do Hospital das Clínicas/SP

Os dados coletados das receitas e/ou notificaçöes de receitas e os campos do programa aperfeiçoados permitiram a construção de uma Tabela 4 na qual 
estão relacionadas às indústrias farmacêuticas produtoras dos medicamentos receitados.

Tabela 4 - Relação das indústrias farmacêuticas produtoras dos medicamentos controlados e freqüência de prescrição durante o periodo estudado

\begin{tabular}{l|c|c|c} 
Indústria & & & \\
farmacêutica & $\mathrm{N} / \mathrm{T}$ & $\mathrm{F}$ & $\%$ \\
\hline Cristália & $\mathrm{N}$ & 236 & 31,7 \\
\hline Aventis & $\mathrm{T}$ & 101 & 13,7 \\
\hline Roche & $\mathrm{T}$ & 88 & 11,8 \\
\hline Abbott & $\mathrm{T}$ & 62 & 8,3 \\
\hline Pfizer-Pharmacia & $\mathrm{T}$ & 49 & 6,6 \\
\hline União Quimica & $\mathrm{N}$ & 44 & 5,9 \\
\hline Sigma Pharma & $\mathrm{T}$ & 40 & 5,4 \\
\hline Novartis & $\mathrm{T}$ & 29 & 3,9 \\
\hline Janssen-Cilag & $\mathrm{T}$ & 22 & 3,0 \\
\hline Prodome & $\mathrm{T}$ & 20 & 2,7 \\
\hline Zodiac & $\mathrm{T}$ & 13 & 1,7 \\
\hline Biosintética & $\mathrm{N}$ & 10 & 1,3 \\
\hline Biolab-Sanus & $\mathrm{N}$ & 5 & 0,7 \\
\hline Eli Lilly & $\mathrm{T}$ & 3 & 0,4 \\
\hline Farmasa & $\mathrm{N}$ & 3 & 0,4 \\
\hline Knoll & $\mathrm{T}$ & 3 & 0,4 \\
\hline Asta Médica & $\mathrm{T}$ & 2 & 0,3 \\
\hline Boehringer & $\mathrm{T}$ & 2 & 0,3 \\
\hline Cazi & $\mathrm{N}$ & 2 & 0,3 \\
\hline Eurofarma & $\mathrm{N}$ & 2 & 0,3 \\
\hline Wyeth & $\mathrm{T}$ & 2 & 0,3 \\
\hline Zest & $\mathrm{T}$ & 2 & 0,3 \\
\hline Aché & $\mathrm{N}$ & 1 & 0,1 \\
\hline Farmalab & $\mathrm{T}$ & 1 & 0,1 \\
\hline GlaxoSmithKline & $\mathrm{T}$ & 1 & 0,1 \\
\hline Schering Plough & $\mathrm{T}$ & 1 & 0,1 \\
\hline Total & & 744 & \\
\hline
\end{tabular}

$N=$ Indústria nacional.

$T=$ Indústria transnacional.

Das 11.128 prescrições, 2.924 foram com nome comercial sendo dessas, 744 medicamentos controlados pela Portaria 344/98. 
A Tabela 5 apresenta 59 produtos farmacêuticos para 47 princípios ativos, a freqüência com que foram prescritos e listas a que pertencem.

Tabela 5 - Medicamentos controlados prescritos por nome comercial, princípio ativo, lista a que pertencem na P-344 e indústria produtora

\begin{tabular}{|c|c|c|c|c|c|}
\hline medicamentos $(R)$ & SIR & princípio ativo & $\mathbf{F}$ & lista & indústria \\
\hline AMYTRIL & $\mathbf{s}$ & Amitriptilina & 161 & C1 & Cristalia \\
\hline LONGACTIL & $\mathbf{s}$ & Clorpromazina & 64 & $C_{1}$ & Cristália \\
\hline DEPAKENE & $\mathbf{R}$ & ácido valprólco (ou derivado) & 62 & C1 & Abbott \\
\hline RIVOTRIL & $\mathbf{R}$ & Cionazepam & 59 & B1 & Roche \\
\hline FRISIUM & $\mathbf{R}^{*}$ & Clobazam & 48 & B1 & Aventis \\
\hline TRAMAL & $\mathbf{R}$ & Tramadol & 46 & Azad & Pfizer Pharmacta \\
\hline DORLESS-TRAMADOL & s & Tramadol & 44 & A2ad & \begin{tabular}{|l} 
Uniăo Química \\
\end{tabular} \\
\hline DAFORIN & $\mathbf{s}$ & \begin{tabular}{|l|} 
Fluoxetina \\
\end{tabular} & 38 & $C_{1}$ & Sigma Pharma \\
\hline PROLOPA & $\mathbf{R}^{*}$ & levodopa e benserazida - assoc. & 23 & C1 & \begin{tabular}{|l} 
Roche \\
\end{tabular} \\
\hline TRYPTANOL & $\mathbf{R}$ & Amitriptlina & 20 & $c_{1}$ & \begin{tabular}{|l} 
Prodome \\
\end{tabular} \\
\hline AMPUCTL & $\mathbf{R}^{*}$ & Clorpromazina & 14 & C1 & Aventis \\
\hline ANAFRANIL & $\mathbf{R}^{*}$ & Clomipramina & 14 & $\mathbf{C I}$ & Novartis \\
\hline TOPAMAX & $\mathbf{R}^{*}$ & Topiramato & 13 & C1 & \begin{tabular}{|l|} 
Janssen-Cilag \\
\end{tabular} \\
\hline OXYCONTIN & $\mathbf{R}^{*}$ & Oxicodiona & 13 & A1 & Zodiac \\
\hline URBANIL & $\mathbf{s}$ & Clobaram & 11 & B1 & Aventls \\
\hline PROGRESSE & $\mathbf{s}$ & Gabapentina & 10 & C1 & Blosintética \\
\hline ARAVA & $\mathbf{R}^{*}$ & \begin{tabular}{|l} 
Leflunomida \\
\end{tabular} & 7 & $C 1$ & Aventis \\
\hline NEULEPTIL & $\mathbf{R}^{*}$ & \begin{tabular}{|l|} 
Periclazina \\
\end{tabular} & 7 & $c_{1}$ & \begin{tabular}{|l|l|} 
Aventis \\
\end{tabular} \\
\hline GARDENAL & $\mathbf{R}^{*}$ & Fenobarbltal & 7 & Blad & \begin{tabular}{|l|} 
Aventis \\
\end{tabular} \\
\hline CINETOL & $s$ & Biperideno & 7 & $\mathrm{Cl}_{1}$ & Cristália \\
\hline TRILEPTAL & $\mathbf{R}^{*}$ & Oxcarbazepina & 7 & $C_{1}$ & \begin{tabular}{|l} 
Novartis \\
\end{tabular} \\
\hline TEORETOL & $\mathbf{R}$ & Carbamazepina & 6 & C1 & \begin{tabular}{|l} 
Novartis \\
\end{tabular} \\
\hline HIDANTAL & $\mathbf{R}^{*}$ & fenttoína (hidantoina) & 4 & $C_{1}$ & \begin{tabular}{|l|} 
Aventis \\
\end{tabular} \\
\hline EPILENIL & $s$ & ácido valprólco (ou derivado) & 4 & $C_{1}$ & Biolab-Sanus \\
\hline TYLEX & $\mathbf{R}^{*}$ & codelna: paracetamol & 4 & A2ad & Janssen-Cilag \\
\hline PROLOPA HBS & $\mathbf{R}^{*}$ & levodopa e benserazida - assoc. & 4 & $c 1$ & Roche \\
\hline NEOZZNE & $\mathbf{R}^{*}$ & levomepromazina (metotrime prazina) & 3 & C1 & \begin{tabular}{|l|} 
Aventis \\
\end{tabular} \\
\hline HALOOL & $\mathbf{R}$ & \begin{tabular}{|l} 
Haloperidol \\
\end{tabular} & 3 & C1 & \begin{tabular}{|l} 
Janssen-cillag \\
\end{tabular} \\
\hline SIFROL & $s$ & Pramipexol & 2 & Ci & Boehringer \\
\hline TRIPSOL & s & Amlutriptilina & 2 & Ci & Caxt \\
\hline FENOCRIS & 5 & Fenobartital & 2 & Blad & Cristalia \\
\hline PROZAC & $\mathbf{R}$ & \begin{tabular}{|l|} 
Fluoxetina \\
\end{tabular} & 2 & $C_{1}$ & Ell Luly \\
\hline LORALERG-D & $\mathbf{s}$ & loratadina; pseudoefedrina & 2 & Di & Farmasa \\
\hline AKINETON & $\mathbf{R}$ & \begin{tabular}{|l|} 
Bipenideno \\
\end{tabular} & 2 & C1 & Knoll \\
\hline TOFRANIL & $R^{*}$ & Imipramina & 2 & $c_{1}$ & \begin{tabular}{|l} 
Novartis \\
\end{tabular} \\
\hline NEURONTIN & $\mathbf{R}$ & Gabapentina & 2 & C1 & Pfizer \\
\hline ACTIFEDRIM & $R^{*}$ & triprolldina; pseudoefedrina & 2 & D1 & Zest \\
\hline NOTUSS & $\mathbf{R}^{*}$ & $\begin{array}{l}\text { difantdramina; dropropizina; } \\
\text { pseudoefedrtna; paracetamol }\end{array}$ & 1 & D1 & Ache \\
\hline DUALIDS & $\mathbf{R}^{*}$ & \begin{tabular}{|l} 
anfepramona (dietilpropiona) \\
\end{tabular} & 1 & B2 & Asta Médica \\
\hline IXEL & $\mathbf{R}^{*}$ & \begin{tabular}{|l|l|} 
Milnaciprana \\
\end{tabular} & 1 & C1 & Roche \\
\hline CINETIC-CISAPRIDA & $\mathbf{s}$ & Cisaprida & 1 & C1 & Biolab-Sanus \\
\hline RISPERIDON & $\mathbf{s}$ & Risperidona & 1 & C1 & Crtstślla \\
\hline DIMORF & $\mathbf{s}$ & Morfina & 1 & A1 & Cristália \\
\hline DOLOXENE-A & $\mathbf{R}^{*}$ & ácido acedilsalleflico; propoxifeno & 1 & A2ad & Ell Uily \\
\hline PONDERA & $\mathbf{s}$ & Paroxetina & 1 & Ci & Eurotarma \\
\hline CARBOLITIUM & $\mathbf{R}^{*}$ & iftolo (e dertvado) & 1 & CI & Eurofarma \\
\hline JUMEXIL & $\mathbf{R}$ & Selegilina & 1 & C1 & Farmalab \\
\hline PSICOSEDAN & $\mathbf{R}^{\boldsymbol{*}}$ & Clordiazepóxido & 1 & B1 & Farmasa \\
\hline AROPAX & $\mathbf{R}^{*}$ & Paroxutina & 1 & ct & Glaxosmithikine \\
\hline RISPERDAL & $\mathbf{R}^{*}$ & \begin{tabular}{|l|} 
Risperidona \\
\end{tabular} & 1 & c1 & Janssen-Cllag \\
\hline ORAP & $\mathbf{R}^{*}$ & Pimozida & 1 & ci & Janssen-cilag \\
\hline MIAR & $\mathbf{s}$ & \begin{tabular}{|l|} 
Selogillina \\
\end{tabular} & 1 & ct & Knoll \\
\hline FRONTAL & $\mathbf{R}$ & Alprazolam & 1 & B1 & Pfizertharmacia \\
\hline ROHYPNOL & $\mathbf{R}^{*}$ & Flunitrazepam & 1 & B1 & Roche \\
\hline CLARITIN D & $\mathbf{R}$ & loratadina; pseudoefedrina & 1 & D1 & Schering Plough \\
\hline SONEBON & $\mathbf{s}$ & \begin{tabular}{|l|} 
Nitrazepam \\
\end{tabular} & 1 & B1 & \begin{tabular}{|l} 
Slgma Pharma \\
\end{tabular} \\
\hline HIPOFAOIN S & $\mathbf{s}$ & anfepramona (dietilpropiona) & 1 & B2 & \begin{tabular}{|l} 
Sigma Pharma \\
\end{tabular} \\
\hline LORAX & $\mathbf{R}$ & Lorazepam & 1 & B1 & meth \\
\hline \multirow[t]{2}{*}{ EFEXOR } & $R^{*}$ & Veniafaxina & 1 & Ct & moth \\
\hline & & & 744 & & \\
\hline
\end{tabular}

$F=$ freqüência

$S=$ similar

$R=$ referência

$\mathbf{R}^{*}=$ eventual referência 
A fim de identificar as listas de substâncias controladas bem como os tipos de receituários exigidos pela P-344 foi construída a Tabela 6 que apresenta também freqüência com que os medicamentos foram receitados e tipo de receituário.

Tabela 6 - Identificação das listas das substâncias controladas pela P-344, freqüência de prescrição e tipo de receituário

\begin{tabular}{|c|c|c|c|c|}
\hline \multirow{2}{*}{ Lista } & \multicolumn{2}{|c|}{ Freqüência } & \multirow{2}{*}{ Tipo Receituário } & \multirow{2}{*}{ Observações } \\
\hline & Qtde & $\%$ & & \\
\hline A1 & 32 & $1,8 \%$ & notificação A amarela & $\begin{array}{l}\text { Entorpecentes ( narco- } \\
\text { analgésicos) }\end{array}$ \\
\hline A2 & - & - & Idem & $\begin{array}{l}\text { Entorpecentes ( em } \\
\text { concentrações especiais) }\end{array}$ \\
\hline $\mathrm{A3}$ & - & - & Idem & Psicotrópicos (anfetamínicos) \\
\hline B1 & 221 & $12,3 \%$ & notificação B azul & Psicotrópicos \\
\hline $\mathrm{B} 2$ & 4 & $0,2 \%$ & Idem & Psicotrópicos (anorexígenas) \\
\hline$\overline{c 1}$ & 1.204 & $67,2 \%$ & controle especial 2 vias & Outras substâncias \\
\hline$\overline{\mathrm{C} 2}$ & - & - & notificação branca & Retinóicos \\
\hline $\mathrm{C3}$ & 3 & $0,2 \%$ & Idem & Imunossupressores \\
\hline $\mathrm{C} 4$ & - & - & controle especial 2 vias & Antirretrovirais \\
\hline C5 & 1 & $0,1 \%$ & Idem & Anabolizantes \\
\hline D1 & 6 & $0,3 \%$ & receita comum & $\begin{array}{l}\text { Precursores de entorpecentes } \\
\text { e psicotrópicos. }\end{array}$ \\
\hline A1-ad & - & - & controle especial 2 vias & (1) \\
\hline A2 - ad & 242 & $13,5 \%$ & Idem & (1) \\
\hline$B 1-a d$ & 80 & $4,5 \%$ & Idem & (1) \\
\hline B2-ad & - & - & Idem & (1) \\
\hline Total & 1.793 & & & \\
\hline
\end{tabular}

(1) - Concentração do fármaco correspondente, abaixo da concentração terapêutica usual. Monofármacos ou em associaçōes.

Para identificar os fármacos ou associações de fármacos prescritos pelas diferentes fontes geradoras das receitas dos ambulatórios do $\mathrm{HC}$ e dispensadas pela farmácia hospitalar, foi construída a Tabela 7 sem, contudo, incorporar os dados referentes à lista $D$. 
Tabela 7 - Listas das substâncias controladas pela P-344 por fonte geradora de receita

\begin{tabular}{|c|c|c|c|c|c|c|c|c|c|c|c|c|c|c|c|c|c|c|c|c|c|c|c|}
\hline$\frac{L}{344}$ & $\begin{array}{c}\text { Princípio } \\
\text { ativo ou } \\
\text { associação }\end{array}$ & 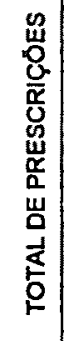 & 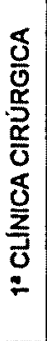 & 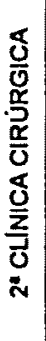 & 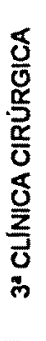 & 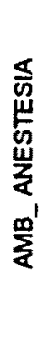 & 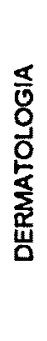 & 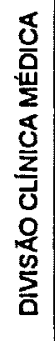 & 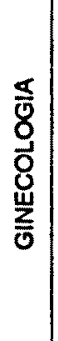 & $\begin{array}{l}\frac{5}{8} \\
\frac{8}{3} \\
\stackrel{\underline{x}}{5}\end{array}$ & 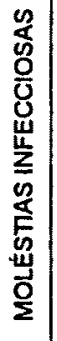 & 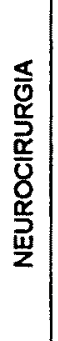 & 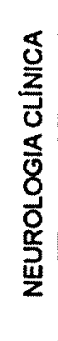 & 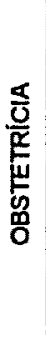 & $\begin{array}{l}\frac{\alpha}{8} \\
8 \\
\frac{1}{2} \\
\frac{8}{8} \\
0\end{array}$ & $\begin{array}{l}\frac{5}{0} \\
\frac{8}{8} \\
\frac{1}{2} \\
\frac{3}{5} \\
\frac{5}{0}\end{array}$ & 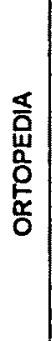 & 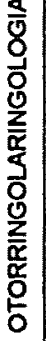 & 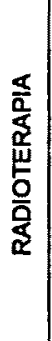 & 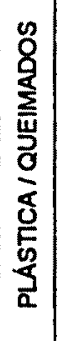 & $\begin{array}{l}\frac{\nwarrow}{\bar{\alpha}} \\
\frac{\S}{\bar{g}} \\
\frac{\mathrm{g}}{\grave{\alpha}}\end{array}$ & 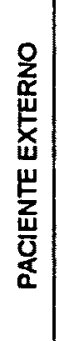 & 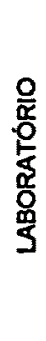 \\
\hline $\mathrm{C}_{1}$ & amitriptilina & 344 & 8 & 6 & 3 & 11 & 9 & 106 & 6 & 6 & 3 & 24 & 104 & & & 2 & 2 & 1 & & & 3 & 50 & \\
\hline C1 & carbarnazepina & 193 & 2 & 1 & & 4 & 4 & 19 & 3 & & 2 & 11 & 122 & & & 1 & & & 1 & & & 23 & \\
\hline A2a & codeina; parac. & 134 & 3 & 4 & 3 & 1 & 4 & 45 & 3 & 1 & 1 & 1 & 6 & & & 1 & 25 & 1 & & & & 35 & \\
\hline CI & fluoxelina & 110 & & 2 & 2 & & 3 & 60 & 8 & 1 & 1 & & 8 & & & & & 1 & 1 & & & 23 & \\
\hline$A 2 a$ & tramadol & 104 & 19 & 1 & 7 & 1 & 2 & 9 & 2 & & & 1 & 6 & & & 1 & 18 & & & 1 & 2 & 33 & 1 \\
\hline C1 & sertralina & 96 & 1 & & & & 2 & 65 & & 1 & 1 & & 15 & & & 2 & & & & 1 & & 8 & \\
\hline C1 & clorpromazina & 90 & 4 & & 2 & 2 & 1 & 3 & 2 & 2 & 1 & 3 & 55 & & & & & 2 & & & 1 & 12 & \\
\hline B1 & clobazam & 83 & & & & & & & 1 & & & & 66 & & 1 & & & & & & & 15 & \\
\hline B1a & fenobarbital & 80 & 1 & 3 & & & & 8 & & & & 6 & 49 & & & & & 1 & & & & 12 & \\
\hline C1 & Acido valprobico & 67 & 1 & & 1 & & & 1 & & & & & 51 & & & & & & & & & 13 & \\
\hline B1 & clonazepam & 64 & & & 1 & & & 7 & & 1 & 1 & & 43 & & & 1 & & & & & & 10 & \\
\hline C1 & fonitoina & 03 & 1 & 1 & 3 & & 1 & 6 & & & & 11 & 31 & & & & & & & & & 9 & \\
\hline$C_{1}$ & imipramina & 51 & 5 & & & & & 14 & 5 & 4 & & & 17 & & & 1 & & & & & & 5 & \\
\hline BI & diazepam & 46 & 1 & & & 1 & & 10 & 2 & & & 1 & 20 & 1 & & & & & & & & 10 & \\
\hline C1 & gabapentina & 39 & & & 1 & 9 & 1 & 5 & & 1 & & & 18 & & & & & 1 & & & & 3 & \\
\hline C1 & levodopa e bens & 28 & 1 & & & & & 10 & & & 2 & 1 & 10 & & & & & & & & & 4 & \\
\hline B1 & nitrazepam & 24 & & & & & & & & & & 1 & 21 & & & & & & & & & 2 & \\
\hline A1 & morfina & 19 & 1 & 1 & & $\mathbf{3}$ & & 4 & 1 & 1 & & 1 & 2 & & & & & & & 1 & & 4 & \\
\hline$C_{1}$ & clomipramina & 15 & & & & & 2 & 2 & 1 & & 1 & & 7 & & & & & & & & & 2 & \\
\hline C1 & topiramato & 14 & & & & & & & & & & & 12 & & & 2 & & & & & & & \\
\hline A1 & oxicodona & 13 & & & & 10 & & 3 & & & & & & & & & & & & & & & \\
\hline C1 & amantadina & 11 & & & & & & 4 & & & & 1 & 6 & & & & & & & & & & \\
\hline C1 & biperideno & 9 & & & & & & 1 & & & 1 & 1 & 4 & & & & & & & & & 2 & \\
\hline C1 & leflunomida & 9 & & & & & 2 & 5 & & & & & & & & & & & & & & 2 & \\
\hline C1 & haloperidol & 8 & 1 & & & & & 1 & & & & & 6 & & & & & & & & & & \\
\hline C1 & selegilina & 8 & & & & & & 3 & & 1 & & & 3 & & & & & & & & & 1 & \\
\hline C1 & oxcarbazepina & 7 & & & & & & & 1 & & & & 5 & & & & & & & & & 1 & \\
\hline C1 & periciazina & 7 & & & & & & 2 & & 1 & & 1 & 2 & & & & & & & & & 1 & \\
\hline C1 & pramipexol & 6 & & & & & & & & & & & 6 & & & & & & & & & & \\
\hline C1 & primidona & 5 & & & & & & 2 & & & & & 3 & & & & & & & & & & \\
\hline C1 & cisaprida & 4 & & 1 & & & & 2 & & & & & & & & & & & & & & 1 & \\
\hline C1 & levomepromazina & 4 & & & & & & & & & & & 4 & & & & & & & & & & \\
\hline C1 & lítio (e derivado) & 4 & & & & & & & & 1 & & & 2 & & & & & & & & & 1 & \\
\hline$C 1$ & paroxotina & 4 & 1 & & & & & 1 & & & & & & & & & & & & & & 2 & \\
\hline A2a & codeina;beladona & 3 & & & & & & 1 & & & & & & & & & & & & & & 2 & \\
\hline C3 & talidomida & 3 & & & & & 1 & 1 & & & & & 1 & & & & & & & & & & \\
\hline B2 & anfepramona & 2 & & & & & & 1 & & & & & & & & 1 & & & & & & & \\
\hline B2 & femproporex & 2 & & & & & & 2 & & & & & & & & & & & & & & & \\
\hline C1 & nortriptilina & 2 & & & & & & 1 & & & & & 1 & & & & & & & & & & \\
\hline C1 & risperidona & 2 & & & & & & 1 & & & & 1 & & & & & & & & & & & \\
\hline B1 & bromrazepam & 1 & & & & & & 1 & & & & & & & & & & & & & & & \\
\hline C1 & buspirona & 1 & & & & & & & & & & & & & & & & & & & & 1 & \\
\hline B1 & clordiazepóxido & 1 & & & & & & & 1 & & & & & & & & & & & & & & \\
\hline B1 & flunitrazepam & 1 & & & & & & & & & & & 1 & & & & & & & & & & \\
\hline B1 & lorazepam & 1 & 1 & & & & & & & & & & & & & & & & & & & & \\
\hline C1 & milnaciprana & 1 & & & & & & & 1 & & & & & & & & & & & & & & \\
\hline C1 & pimazida & 1 & & & & & & & 1 & & & & & & & & & & & & & & \\
\hline A2a & propoxifeno; aas & 1 & & & & & & & & & & & 1 & & & & & & & & & & \\
\hline C5 & testosterona & 1 & & & & & & & 1 & & & & & & & & & & & & & & \\
\hline C1 & venlafaxina & 1 & & & & & & & & & & & 1 & & & & & & & & & & \\
\hline
\end{tabular}


A correlação das diferentes classes terapêuticas dos fármacos (principios ativos) ou associações de fármacos, prescritos por unidades geradoras das receitas, estão descritas na Tabela 8.

Tabela 8 - Classes terapêuticas dos fármacos ou associações de fármacos por unidade geradora de receitas

\begin{tabular}{|c|c|c|c|c|c|c|c|c|c|c|c|c|c|c|c|c|c|c|c|c|}
\hline $\begin{array}{c}\text { Classe } \\
\text { Terapêutica }\end{array}$ & 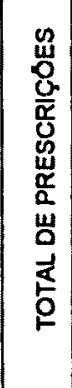 & 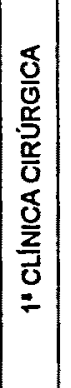 & 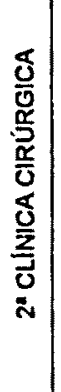 & 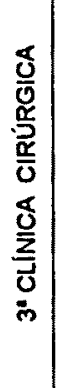 & 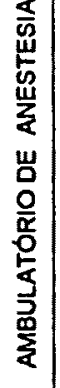 & 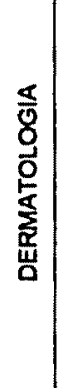 & 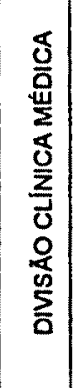 & 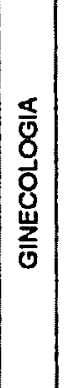 & $\begin{array}{l}\frac{5}{8} \\
8 \\
0 \\
0 \\
\frac{8}{5}\end{array}$ & 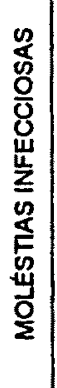 & 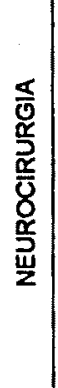 & 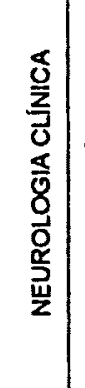 & 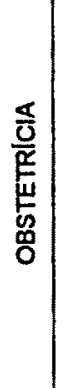 & 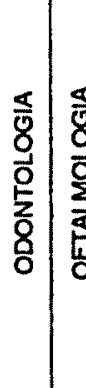 & 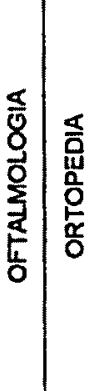 & 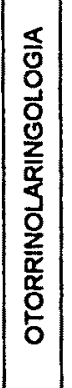 & 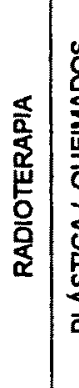 & 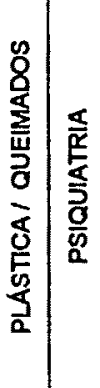 & 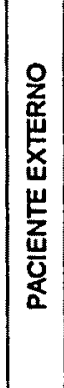 & 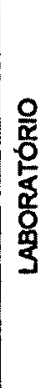 \\
\hline Antidepressivo & 628 & 15 & 8 & 5 & 11 & 16 & 249 & 21 & 13 & 6 & 24 & 155 & & & \begin{tabular}{l|l}
5 & 2 \\
\end{tabular} & 2 & $1 \mid$ & \begin{tabular}{l|l}
1 & 3 \\
\end{tabular} & 91 & 1 \\
\hline Anticonvulsiv. & 532 & 5 & 5 & 6 & 13 & 6 & 48 & 4 & 2 & 3 & 28 & 334 & & & 4 & 2 & 1 & & 71 & \\
\hline Analg.opióide & 271 & 23 & 6 & 10 & 15 & 6 & 61 & 6 & 2 & 1 & 3 & 15 & & & $2 \sqrt{23}$ & 1 & 1. & \begin{tabular}{l|l}
1 & 2 \\
\end{tabular} & 72 & 1 \\
\hline Antipsicóticos & 145 & 6 & & 2 & 2 & 1 & 13 & 4 & 3 & 1 & 5 & 84 & & & & 2 & & 1 & 21 & \\
\hline Ansiolíticos & 125 & 1 & & & 1 & & 5 & 3 & & & 2 & 91 & 1 & 1 & & & & & 20 & \\
\hline Antiparkins. & 62 & 1 & & & & & 18 & & 1 & 3 & 3 & 29 & & & & & & & 7 & \\
\hline Imunossupres. & 15 & & & & & 3 & 7 & & & & & 1 & & & & & & & 4 & \\
\hline Anorexigenos & 4 & & & & & & 3 & & & & & & & & 1 & & & & & \\
\hline Antieméticos & 4 & & 1 & & & & 2 & & & & & & & & & & & & 1 & \\
\hline Anabolizantes & 1 & & & & & & & 11 & & & & & & & & & & & & \\
\hline
\end{tabular}

As porcentagens das diferentes classes terapêuticas em função do número de prescrições e a freqüência em função das unidades geradoras de receitas estão descritas na Tabela 9. 
Tabela 9 - Porcentagem das diferentes classes terapêuticas em função do número de prescrições e a freqüência em função das unidades geradoras

\begin{tabular}{|c|c|c|c|c|c|c|c|c|c|c|c|c|c|c|c|c|c|c|c|c|c|c|}
\hline $\begin{array}{c}\text { Classe } \\
\text { Terapêutica }\end{array}$ & 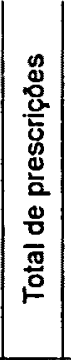 & 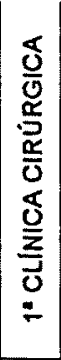 & 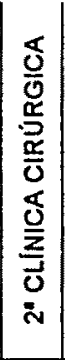 & 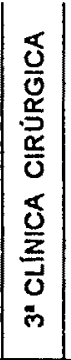 & 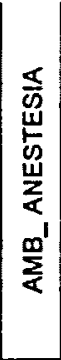 & 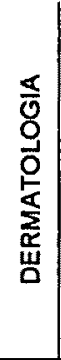 & 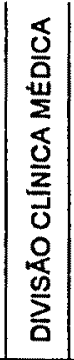 & \begin{tabular}{|l}
$\frac{5}{8}$ \\
8 \\
0 \\
0 \\
4 \\
$\frac{4}{0}$ \\
0
\end{tabular} & $\begin{array}{l}\text { s } \\
0 \\
0 \\
0 \\
\text { 똑 }\end{array}$ & 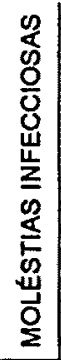 & 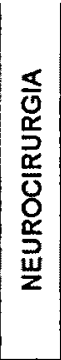 & 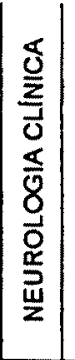 & 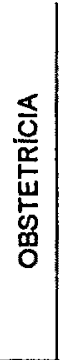 & $\begin{array}{l}\frac{x}{0} \\
0 \\
0 \\
0 \\
0 \\
0 \\
0\end{array}$ & $\mid \begin{array}{l}\frac{x}{8} \\
8 \\
0 \\
0 \\
\frac{3}{1} \\
0 \\
0 \\
0\end{array}$ & 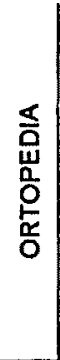 & 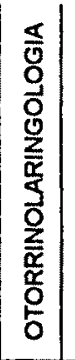 & 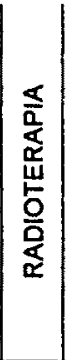 & 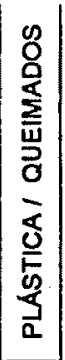 & 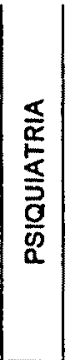 & 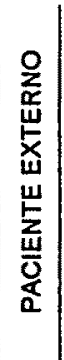 & 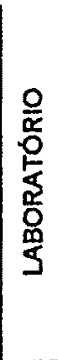 \\
\hline $\begin{array}{l}\text { Total } \\
\text { Prescriçōes } \\
\text { da ud. } \\
\text { geradora }\end{array}$ & $\stackrel{\infty}{\stackrel{\infty}{=}}$ & $\bar{\infty}$ & is & $\mathscr{N}$ & F & ले & $\frac{8}{4}$ & $g$ & $\overline{4}$ & \pm & : & 足 & - & - & $\simeq$ & 4 & r & $m$ & $N$ & 0 & $\widehat{\mathfrak{N}}$ & - \\
\hline Antidepress. & $\frac{2}{8}$ & 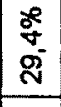 & $\begin{array}{l}\circ \\
\\
\\
\end{array}$ & $\left|\begin{array}{l}a \\
\frac{a}{2}\end{array}\right|$ & $\begin{array}{l}\stackrel{\circ}{\mathrm{N}} \\
\stackrel{\mathrm{N}}{\mathrm{o}}\end{array}$ & $\begin{array}{l}0 \\
0 \\
0 \\
0\end{array}$ & \begin{tabular}{|l|}
8 \\
0 \\
8 \\
8 \\
\end{tabular} & 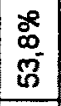 & \begin{tabular}{|c|}
5 \\
6 \\
\end{tabular} & 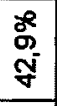 & \begin{tabular}{|l|}
${ }^{2}$ \\
8 \\
6 \\
\end{tabular} & $\frac{\mathrm{N}}{\stackrel{2}{\circ}}$ & & & \begin{tabular}{|l|}
2 \\
5 \\
\end{tabular} & 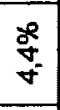 & 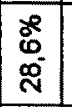 & \begin{tabular}{|l|}
\multirow{2}{*}{} \\
\\
\\
$m$ \\
\end{tabular} & \begin{tabular}{|l}
8 \\
8 \\
8 \\
8
\end{tabular} & \begin{tabular}{|l|}
8 \\
0 \\
8 \\
8 \\
\end{tabular} & \begin{tabular}{|l|}
$\frac{2}{2}$ \\
$\frac{m}{m}$
\end{tabular} & \\
\hline Anticonvulsiv & 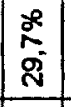 & \begin{tabular}{|l|l}
0 \\
0 \\
0 \\
\end{tabular} & \begin{tabular}{|c|}
8 \\
0 \\
ñ \\
\end{tabular} & $\mid$\begin{tabular}{l|}
$\frac{2}{60}$ \\
$\frac{6}{2}$
\end{tabular} & $\begin{array}{l}8 \\
\vdots \\
5 \\
\end{array}$ & $\begin{array}{l}\infty^{\infty} \\
\infty \\
\infty \\
0 \\
\end{array}$ & $\begin{array}{l}\stackrel{2}{\stackrel{2}{2}} \\
=\end{array}$ & \begin{tabular}{|c|}
0 \\
0 \\
0 \\
0
\end{tabular} & 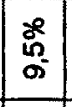 & $\begin{array}{l}\stackrel{8}{+} \\
\frac{N}{N}\end{array}$ & $\frac{8}{g}$ & $\frac{8}{5}$ & & & \begin{tabular}{|l|}
8 \\
$j$ \\
$\tilde{e}$ \\
\end{tabular} & & 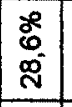 & \begin{tabular}{|l|}
$j^{\circ}$ \\
$m$ \\
$m$ \\
\end{tabular} & & & 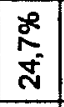 & \\
\hline $\begin{array}{l}\text { Analg. } \\
\text { Opióide }\end{array}$ & $\frac{x}{\underline{x}}$ & $\frac{g}{8}$ & $\begin{array}{c}8 \\
\\
\end{array}$ & \begin{tabular}{|c|}
2 \\
$i n$ \\
$g$ \\
\end{tabular} & $\begin{array}{c}\stackrel{2}{1} \\
u^{\circ} \\
0\end{array}$ & $\begin{array}{c}2 \\
\infty \\
\infty \\
\infty \\
-\end{array}$ & 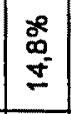 & 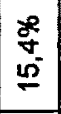 & $\begin{array}{l}8 \\
0 \\
0 \\
0 \\
\end{array}$ & $\frac{2}{5}$ & 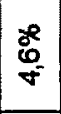 & $\frac{\sigma^{2}}{4}$ & & & \begin{tabular}{|c|}
0 \\
0 \\
0 \\
\end{tabular} & $\begin{array}{l}8 \\
0 \\
8 \\
0\end{array}$ & 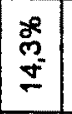 & \begin{tabular}{|l|} 
\\
\\
$m$ \\
$m$ \\
\end{tabular} & \begin{tabular}{|l}
80 \\
80 \\
8 \\
8
\end{tabular} & 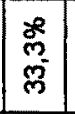 & 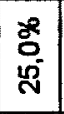 & $\begin{array}{l}8 \\
0 \\
8 \\
8\end{array}$ \\
\hline Antipsicótico & $\frac{8}{\infty}$ & 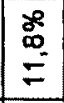 & & \begin{tabular}{c|}
0 \\
$p$ \\
$\infty^{-}$ \\
\end{tabular} & $\begin{array}{c}\stackrel{0}{0} \\
\vdots \\
+\end{array}$ & $\frac{x}{m}$ & $\stackrel{\substack{N \\
m}}{ }$ & 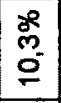 & 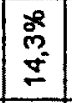 & $\frac{x^{p}}{\pi}$ & $\frac{x^{\circ}}{i}$ & 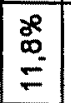 & & & & & 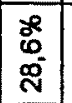 & & & $\begin{array}{l}2 \\
0 \\
6 \\
6\end{array}$ & 总 & \\
\hline Ansiolíticos & 奋 & \begin{tabular}{c}
\multirow{2}{*}{} \\
N \\
\end{tabular} & & & 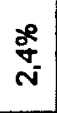 & & $\stackrel{\underset{f}{N}}{=}$ & $\frac{\pi}{2}$ & & & $\frac{2}{m}$ & 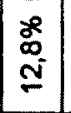 & $\begin{array}{l}8 \\
8 \\
8 \\
0\end{array}$ & \begin{tabular}{l|}
8 \\
0 \\
8 \\
0
\end{tabular} & & & & & & & $\begin{array}{l}2 \\
0 \\
0 \\
0 \\
6\end{array}$ & \\
\hline Antiparkins. & $\begin{array}{l}x^{2} \\
\text { in } \\
m \\
m\end{array}$ & in & & & & & $\frac{8}{\sigma}$ & & \begin{tabular}{l}
0 \\
0 \\
0 \\
\hdashline
\end{tabular} & $\begin{array}{l}g^{e} \\
\stackrel{N}{N}\end{array}$ & 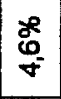 & $\frac{2}{8}$ & & & & & & & & & $\frac{4}{j}$ & \\
\hline Imunossup. & \begin{tabular}{|l|}
0 \\
0 \\
0 \\
0
\end{tabular} & & & & & \begin{tabular}{|l|}
0 \\
0 \\
0 \\
\end{tabular} & $\underline{2}$ & & & & & $\frac{8}{0}$ & & & & & & & & & \begin{tabular}{|l|} 
\\
\\
0 \\
0
\end{tabular} & \\
\hline Anorexigeno & 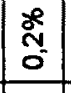 & & & & & & $\begin{array}{c}\frac{8}{0} \\
0 \\
0\end{array}$ & & & & & & & & \begin{tabular}{|l|}
$\infty$ \\
0 \\
$\infty$ \\
$\infty$
\end{tabular} & & & & & & & \\
\hline Antieméticos & 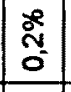 & & \begin{tabular}{|l|}
0 \\
0 \\
$n$ \\
\end{tabular} & & & & $\begin{array}{l}8 \\
4 \\
0 \\
0\end{array}$ & & & & & & & & & & & & & & & \\
\hline Anabolizante & $\left|\frac{x}{0}\right|$ & & & & & & & $\mid \begin{array}{c}0 \\
0 \\
0 \\
c\end{array}$ & & & & & & & & & & & & & & \\
\hline
\end{tabular}

\subsubsection{Tabelas relativas a dispensação.}

Durante a captação dos dados relativos a dispensação dos medicamentos foram observados em 4.405 receitas e/ou notificação de receitas, 258 com pelo menos um dado incompleto.

Na Tabela 9 estão registrados dados incompletos relativos às receitas elou notificações de receitas e sua freqüência. 
Tabela 10 - Dados incompletos observados em 258 receitas elou notificações

\begin{tabular}{l|c|c|c}
\hline \multirow{2}{*}{ DADO } & \multicolumn{2}{|c|}{$\begin{array}{c}\text { Freqüência de } \\
\text { ocorrência }\end{array}$} & $\begin{array}{c}\text { \% do total de } \\
\text { receitas } \\
(4.405)\end{array}$ \\
\cline { 2 - 3 } & Quantidade & $\%$ & \\
\hline Nome do paciente & 27 & $10,5 \%$ & $0,61 \%$ \\
\hline Registro do paciente no HC & 101 & $39,1 \%$ & $2,29 \%$ \\
\hline Unidade geradora de receitas do HC & 208 & $80,6 \%$ & $4,72 \%$ \\
\hline Nome, registro e unidade geradora & 26 & $10,1 \%$ & $0,59 \%$
\end{tabular}

A fim de verificar a quantidade de medicamentos controlados por receita e ou notificação, limitada a 3 pela Portaria 344/98, foram tabulados dados diários a partir do número total de receitas emitidas no período estudado (4.405). Os dados estão apresentados na Tabela 11. A Tabela 12 construida a partir dos dados da tabela anterior, fornece o resumo do número de receitas e ou notificações contendo pelo menos 1 medicamento controlado.

Tabela 11 - Número de medicamentos por receita e ou notificação em cada um dos dias do período estudado

Dia 25 - 1001 receitas emitidas

\begin{tabular}{c|c|c|c|c|c|c|c|c|c|c|c|c|c|c|c}
\hline$N^{\circ}$ med/receita & 1 & 2 & 3 & 4 & 5 & 6 & 7 & 8 & 9 & 10 & 11 & 12 & 13 & 14 & Totais \\
\hline Total de receita & 304 & 264 & 168 & 110 & 60 & 51 & 10 & 13 & 9 & 4 & 6 & 0 & 1 & 1 & \\
\hline Total $P-344$ & 46 & 63 & 52 & 32 & 14 & 12 & 6 & 4 & 1 & 2 & 2 & 0 & 0 & 1 & \\
\hline$P-344$ com 1 & 46 & 37 & 36 & 20 & 9 & 7 & 5 & 4 & 1 & 2 & 2 & 0 & 0 & 1 & 170 \\
\hline$P-344$ com 2 & 0 & 26 & 10 & 11 & 2 & 3 & 1 & 0 & 0 & 0 & 0 & 0 & 0 & 0 & 53 \\
\hline$P-344$ com 3 & 0 & 0 & 6 & 1 & 3 & 2 & 0 & 0 & 0 & 0 & 0 & 0 & 0 & 0 & 12 \\
\hline$P-344$ com 4 & 0 & 0 & 0 & 0 & 0 & 0 & 0 & 0 & 0 & 0 & 0 & 0 & 0 & 0 & 0 \\
\hline
\end{tabular}

Dia 26 - 900 receitas emitidas

\begin{tabular}{l|r|r|r|r|r|r|r|r|r|r|r|r|r|r|c}
\hline$N^{\circ}$ med/receita & 1 & 2 & 3 & 4 & 5 & 6 & 7 & 8 & 9 & 10 & 11 & 12 & 13 & 14 & Totais \\
\hline Total de receita & 267 & 254 & 161 & 75 & 48 & 37 & 25 & 18 & 9 & 4 & 1 & 1 & 0 & 0 & \\
\hline Total P - 344 & 43 & 48 & 25 & 16 & 16 & 12 & 6 & 4 & 5 & 2 & 1 & 1 & 0 & 1 & \\
\hline $\mathrm{P}-344$ com 1 & 43 & 32 & 19 & 10 & 14 & 11 & 6 & 2 & 4 & 1 & 1 & 1 & 0 & 1 & 145 \\
\hline $\mathrm{P}-344$ com 2 & 0 & 16 & 2 & 6 & 2 & 1 & 0 & 1 & 1 & 1 & 0 & 0 & 0 & 0 & 30 \\
\hline $\mathrm{P}-344$ com 3 & 0 & 0 & 4 & 0 & 0 & 0 & 0 & 1 & 0 & 0 & 0 & 0 & 0 & 0 & 175 \\
\hline $\mathrm{P}-344$ com 4 & 0 & 0 & 0 & 0 & 0 & 0 & 0 & 0 & 0 & 0 & 0 & 0 & 0 & 0 & 0 \\
\hline
\end{tabular}


Tabela 11 (cont)

Dia 27- 652 receitas emitidas

\begin{tabular}{l|r|r|r|r|r|r|r|r|r|r|r|r|r|r|c}
\hline $\mathrm{N}^{\circ}$ med/receita & 1 & 2 & 3 & 4 & 5 & 6 & 7 & 8 & 9 & 10 & 11 & 12 & 13 & 14 & Totais \\
\hline Total de receita & 162 & 164 & 122 & 93 & 59 & 14 & 10 & 8 & 7 & 4 & 4 & 4 & 1 & 0 & \\
\hline Total P- 344 & 25 & 31 & 23 & 24 & 14 & 6 & 2 & 3 & 3 & 1 & 2 & 1 & 0 & 0 & \\
\hline $\mathrm{P}-344$ com 1 & 25 & 21 & 14 & 13 & 12 & 4 & 2 & 3 & 3 & 1 & 2 & 1 & 0 & 0 & 101 \\
\hline $\mathrm{P}-344$ com 2 & 0 & 10 & 7 & 10 & 2 & 1 & 0 & 0 & 0 & 0 & 0 & 0 & 0 & 0 & 30 \\
\hline $\mathrm{P}-344$ com 3 & 0 & 0 & 2 & 1 & 0 & 0 & 0 & 0 & 0 & 0 & 0 & 0 & 0 & 0 & 3 \\
\hline $\mathrm{P}-344$ com 4 & 0 & 0 & 0 & 0 & 0 & 1 & 0 & 0 & 0 & 0 & 0 & 0 & 0 & 0 & 1 \\
\hline
\end{tabular}

Dia 28 - 788 receitas emitidas

\begin{tabular}{l|r|r|r|r|r|r|r|r|r|r|r|r|r|r|c}
\hline $\mathrm{N}^{\circ}$ med/receita & 1 & 2 & 3 & 4 & 5 & 6 & 7 & 8 & 9 & 10 & 11 & 12 & 13 & 14 & Totais \\
\hline Total de receita & 231 & 185 & 133 & 81 & 58 & 38 & 21 & 20 & 14 & 4 & 1 & 2 & 0 & 0 & \\
\hline Total P - 344 & 48 & 35 & 29 & 18 & 15 & 9 & 11 & 6 & 7 & 1 & 0 & 1 & 0 & 0 & \\
\hline $\mathrm{P}-344 \mathrm{com} 1$ & 48 & 17 & 16 & 11 & 8 & 8 & 9 & 6 & 6 & 1 & 0 & 1 & 0 & 0 & 131 \\
\hline $\mathrm{P}-344 \mathrm{com} 2$ & 0 & 18 & 12 & 6 & 4 & 0 & 0 & 0 & 0 & 0 & 0 & 0 & 0 & 0 & 40 \\
\hline $\mathrm{P}-344 \mathrm{com} 3$ & 0 & 0 & 1 & 0 & 3 & 1 & 2 & 0 & 1 & 0 & 0 & 0 & 0 & 0 & 8 \\
\hline $\mathrm{P}-344 \mathrm{com} 4$ & 0 & 0 & 0 & 1 & 0 & 0 & 0 & 0 & 0 & 0 & 0 & 0 & 0 & 0 & 1 \\
\hline
\end{tabular}

Dia $29-1.064$ receitas emitidas

\begin{tabular}{l|r|r|r|r|r|r|r|r|r|r|r|r|r|r|c}
\hline$N^{\circ}$ med/receita & 1 & 2 & 3 & 4 & 5 & 6 & 7 & 8 & 9 & 10 & 11 & 12 & 13 & 14 & Totais \\
\hline Total de receita & 329 & 273 & 183 & 107 & 71 & 34 & 28 & 15 & 7 & 10 & 6 & 1 & 0 & 0 & \\
\hline Total P - 344 & 68 & 47 & 46 & 24 & 15 & 10 & 9 & 5 & 1 & 3 & 4 & 0 & 0 & 0 & \\
\hline $\mathrm{P}-344$ com 1 & 68 & 29 & 30 & 11 & 13 & 9 & 8 & 3 & 1 & 3 & 3 & 0 & 0 & 0 & 178 \\
\hline $\mathrm{P}-344$ com 2 & 0 & 18 & 11 & 10 & 2 & 1 & 1 & 2 & 0 & 0 & 0 & 0 & 0 & 0 & 45 \\
\hline $\mathrm{P}-344$ com 3 & 0 & 0 & 5 & 3 & 0 & 0 & 0 & 0 & 0 & 0 & 1 & 0 & 0 & 0 & 9 \\
\hline $\mathrm{P}-344$ com 4 & 0 & 0 & 0 & 0 & 0 & 0 & 0 & 0 & 0 & 0 & 0 & 0 & 0 & 0 & 0 \\
\hline
\end{tabular}

Tabela 12 - Número total de medicamentos por receita e ou notificação no periodo estudado

Receitas emitidas no período $=4.405$

\begin{tabular}{l|r|r|r|r|r|r|r|r|r|r|r|r|r|r|r}
\hline $\mathrm{N}^{\circ}$ med/receita & 1 & 2 & 3 & 4 & 5 & 6 & 7 & 8 & 9 & 10 & 11 & 12 & 13 & 14 & Totais \\
\hline Total de receita & 1293 & 1140 & 767 & 466 & 296 & 174 & 94 & 74 & 46 & 26 & 18 & 8 & 2 & 1 & \\
\hline Total P - 344 & 230 & 224 & 175 & 114 & 74 & 49 & 34 & 22 & 17 & 9 & 9 & 3 & 0 & 2 & 962 \\
\hline $\mathrm{P}-344 \operatorname{com} 1$ & 230 & 136 & 115 & 65 & 56 & 39 & 30 & 18 & 15 & 8 & 8 & 3 & 0 & 2 & 725 \\
\hline $\mathrm{P}-344 \operatorname{com} 2$ & 0 & 88 & 42 & 43 & 12 & 6 & 2 & 3 & 1 & 1 & 0 & 0 & 0 & 0 & 198 \\
\hline $\mathrm{P}-344 \operatorname{com} 3$ & 0 & 0 & 18 & 5 & 6 & 3 & 2 & 1 & 1 & 0 & 1 & 0 & 0 & 0 & 37 \\
\hline $\mathrm{P}-344 \mathrm{com} 4$ & 0 & 0 & 0 & 1 & 0 & 1 & 0 & 0 & 0 & 0 & 0 & 0 & 0 & 0 & 2 \\
\hline
\end{tabular}


Para se prescrever os medicamentos controlados, necessário se faz respeitar o limite máximo de 30 ou 60 dias, dependendo da lista a que se enquadra. A Tabela 13 relaciona o número de prescrições totais com 0 número de prescriçōes excedentes.

Tabela 13 - Número de prescrições totais e que excederam o limite de tratamento permitido para as diferentes listas

\begin{tabular}{l|l|c|c|c|c} 
& & & \multicolumn{2}{|c|}{ Prescrições } & \multirow{2}{*}{ Lista } \\
& Tipo de receituário & LT & Total & Exc. & $\%$ \\
\hline $\mathrm{A} 1$ & notificação amarela & 30 & 32 & 5 & 15,6 \\
\hline $\mathrm{A} 2$ & Idem & 30 & - & - & - \\
\hline $\mathrm{A} 3$ & Idem & 30 & - & - & - \\
\hline $\mathrm{B} 1$ & notificação azul & 60 & 221 & 3 & 1,35 \\
\hline $\mathrm{B} 2$ & Idem & 60 & 4 & - & - \\
\hline $\mathrm{C} 1$ & controle especial 2 vias & 60 & 1204 & 51 & 4,23 \\
\hline $\mathrm{C} 2$ & notificação branca & 30 & - & - & - \\
\hline $\mathrm{C} 3$ & Idem & 30 & 3 & - & - \\
\hline $\mathrm{C} 4$ & controle especial 2 vias & - & - & - & - \\
\hline $\mathrm{C} 5$ & Idem & 60 & 1 & - & - \\
\hline $\mathrm{A} 1$ ad. & Idem & - & - & - & - \\
\hline $\mathrm{A} 2$ ad. & Idem & 60 & 242 & 1 & 0,4 \\
\hline $\mathrm{B} 1$ ad. & Idem & 60 & 80 & - & - \\
\hline $\mathrm{B} 2$ ad. & Idem & - & - & - & -
\end{tabular}

$L T=$ Limite de tratamento em dias.

Exc. $=$ Número de prescriçōes que excederam o limite de tratamento. 


\section{DISCUSSÃO}

As receitas, suas cópias carbonadas e suas notificações foram atendidas pela Farmácia de Ambulatórios proveniente das diversas unidades do Hospital das Clínicas da Faculdade de Medicina da Universidade de São Paulo. Depois de aviadas, os documentos necessários para controle de dispensação foram recolhidos para arquivo na Divisão de Farmácia, pelo tempo estabelecido por lei.

As baixas para as quantidades de medicamentos dispensados foram feitas da Farmácia Central para a Farmácia de Ambulatórios, e não para cada receita/notificação após o seu atendimento.

Em novembro de 2002, os tipos de documentos exigidos para controle de medicamentos estão resumidos na Tabela 1.

O grande número de documentos exigidos pela $P$ - 344 em função da quantidade de medicamentos controlados resultante da retenção das receitas, poderá tornar mais ineficiente o sistema de controle.

Embora medicamentos do mercado brasileiro sejam licenciados através de uma classificação terapêutica, os apresentados neste trabalho foram revisados por meio de citações e indicações referenciadas em publicações científicas. Portanto, as classificaçōes terapêuticas adotadas nesta revisão atenderam aos critérios da classificação Base ALFA (ZANINI et al., 1997) e ATC Index (WHO, 2000).

A base ALFA é fundamentada na utilização da denominação genérica, portanto, do principio ativo, sua classificação terapêutica, e outras características de utilização de modo a destacar o valor clínico e farmacológico dos medicamentos (ZANINI et al., 1997).

Para a identificação de medicamento do mercado brasileiro, foi adotado o banco de dados desenvolvido por Zanini e colaboradores para suporte das ediçōes do Guiamed (Guia de Medicamentos) e Dicionário de Genéricos (ZANINI et al., 1997, 2001).

Todos os medicamentos prescritos por nome comercial tiveram formulação e classificação terapêutica a fim de conduzi-los a uma denominação genérica. 
A titularidade (propriedade das marcas) dos medicamentos prescritos, tanto os não controlados como os controlados pela Portaria 344/98 (Tabela 4) por nome próprio foi verificada por meio da revista especializada do comércio varejista de medicamentos ABCFARMA, ou nas páginas da "internet" ("homepage") das indústrias farmacêuticas (MS, 1998a).

Neste trabalho considerou-se como receita, o conjunto de prescriçōes de medicamentos a um mesmo paciente, no momento da consulta. Quando duas ou mais receitas estavam juntas no momento da captação (digitação), foi considerada única.

Como a forma de preenchimento de uma prescrição médica manuscrita é de foro íntimo do médico, o resultado final (a receita que o paciente recebe) é absolutamente diverso. Para harmonizar as informações, condição indispensável para obtenção das análises pretendidas, vários campos foram introduzidos ou aperfeiçoados, conforme descrição a seguir:

No denominado atributo do paciente, foram considerados códigos numéricos distintos para cada combinação de siglas do nome com um número de registro tornando, portanto, anônimos todos os pacientes dessa pesquisa.

Em atributo dos medicamentos prescritos foram considerados: nome do medicamento de marca conforme grafia do fabricante, ou do nome genérico conforme Denominação Comum Brasileira - DCB (Portaria n¹179/96; PEREIRA 2003); nome do laboratório titular da marca comercial prescrita, quando for o caso e índice de prescrição preenchido com as palavras "marca" quando a prescrição foi por nome comercial, "genérico" quando usada a denominação genérica, e "HC" quando se tratou de produção interna do hospital (MS, 1996).

Como atributos da formulação prescrita, consideramos a denominação da porção ativa do fármaco correspondente, quer tenha sido a prescrição feita por nome genérico ou marca; a via de administração conforme característica da forma farmacêutica prescrita e modo de uso; a especificação da lista de medicamentos controlados a qual pertence a prescrição, quando foi o caso; a descrição do tipo de receituário ou notificação exigida, em campo preenchido somente para medicamentos controlados; a denominação da classe terapêutica correspondente; o código alfanumérico do princípio ativo ou associação preconizada pelo ATC Index; o nome em inglês preconizado pelo 
ATC Index. e finalmente, a dose diária definida (DDD), quantidade usual de utilização do medicamento por dia, preconizada pelo ATC Index.

Atributos da dispensação e posologia foram também considerados. A caracterização do modo de uso da prescrição como: concentração em miligramas do medicamento por unidade individual quando sólida ou injetável, em miligramas por $\mathrm{ml}$ quando liquido e miligramas por grama quando creme ou pomada; número de unidades sólidas ou ampolas, de frascos quando líquido ou colirio e de bisnagas para creme ou pomada; número de vezes ao dia correspondente a indicação de uso; descrição da forma unitarizada (comprimido, $\mathrm{ml} \mathrm{etc.).}$

Finalmente atributos de controle foram utilizados: campos preenchidos para melhor propiciar análises especificas de medicamentos controlados; limite legal de estoque para medicamentos controlados, conforme tipo de lista prevista na Portaria 344/98, e de seus adendos; previsão de tempo do tratamento, ou seja, o cálculo executado conforme dados de posologia e quantidade de medicamento fornecida; diferença entre previsão de tempo de tratamento e limite legal previsto na P-344; fonte geradora agrupada por suas unidades básicas e indicador de erro para identificar as prescriçōes que estavam incompletas (MS 1998a).

Essa estrutura constituiu-se na base de dados organizada de modo a permitir diversas possibilidades de relação. Dispositivos existentes no programa propiciaram consultas pertinentes aos objetivos deste trabalho.

A análise dos dados da Tabela 2 mostram que das 4.405 receitas emitidas para 4.103 pacientes, oriundas de 18 setores do Hospital das Clinicas (clínicas, divisões e ambulatórios que serão referidas posteriormente) e pacientes externos do Sistema Único de Saúde (SUS) 1.268 (30,9\%) apresentavam pelo menos 01 medicamento sujeito ao controle da P-344. Os pacientes receberam em média três medicamentos por receita.

Dos 4.103 pacientes, $2.835(69,1 \%)$ não receberam medicamentos controlados pela P-344.

Das 12.521 prescrições de medicamentos, 10.728 (85,7\%) corresponderam aos medicamentos não controlados; 1.793 (14.3\%) eram medicamentos controlados, não só os psicoativos, mas todos os demais constantes das listas da P-344. 
Das 4.405 receitas, 962 apresentam pelo menos 01 medicamento controlado pela P-344, ver Tabela 12 , ou seja, $21,8 \%$ de todas as receitas dispensadas na Divisão de Farmácia do Hospital das Clínicas (HC). Estas necessitam de controle (escrituração, balanço e comunicação aos Órgãos de Vigilância Sanitária), estabelecida pela P-344.

A Figura 1 mostra a porcentagem dos medicamentos prescritos e suas denominações. Nem todos os medicamentos prescritos nas receitas foram fornecidos aos pacientes sendo, entretanto, muito baixa a percentagem de medicamentos não atendidos.

Segundo CALIL (2001), os modelos e exigências para prescrição das receitas, instituídos pela P-344 mantiveram-se na burocracia ineficiente. Exigese endereço e telefone do paciente (como se a fiscalização fizesse visitas domiciliares); identificação da gráfica onde foi impresso o talonário numerado (numeração emitida para cada médico pela Vigilância Sanitária local); receitas em duas vias, resultando em desperdício de papel. Resumindo: a P-344 apresenta 27 artigos, 33 parágrafos normatizando 460 substâncias em 16 listas de medicamentos e 10 anexos com modelos de requisição de receituário, modelos de esclarecimento ao paciente e termo de responsabilidade e consentimento. Foi complementada pela Portaria 06 de 29/01/1999, com mais 26 artigos e 10 parágrafos. Pergunta-se: fiscalizarão todas as drogarias, farão auditoria nas gráficas que imprimem os receituários, na escrituração e no balanço de medicamentos na indústria farmacêutica, e seguirão a numeração $\theta$ o percurso das receitas de todos os médicos das drogarias até a casa dos pacientes? (CALIL, 2001).

Considerando-se que a P-344 controla cerca de 460 substâncias e que a Organização Mundial da Saúde (WHO) preconiza o controle de cerca de 230 denominadas "entorpecentes e psicotrópicos" disponiveis no International Narcotics Control Board - INCB (órgão responsável pela implementação dos tratados internacionais de controle), o Brasil controla o dobro de produtos farmacêuticos quando comparados com a média mundial, e que nos hospitais públicos o sistema de dispensação ocorre somente diante de uma receita médica, a porcentagem de substâncias controladas, acima indicadas, poderia estar reduzida à metade, se esta tivesse um sistema de dispensação diferenciado para hospitais, desonerando o serviço público (WHO, 2000). 
Apesar da existência da Lei 9787/99 e Resolução 135/03 que exigem a denominação genérica nas prescrições em hospitais públicos, observa-se que na Tabela 3 esta disposição não foi cumprida (BRASIL, 1999) (MS, 2003c).

Além de nomes comerciais dos medicamentos de referência ou similares, a denominação própria do Hospital das Clínicas preconizada em seu Guia farmacoterapêutico 2002, foi utilizada em apenas três prescrições da $\mathrm{P}$ 344. Some-se a isso o fato de não ter sido identificado 298 medicamentos no momento da captação dos dados devido a ilegibilidade da prescrição, apesar de expressamente vedado ao médico no Art. 39, Capitulo III de seu código de ética: "receitar ou atestar de forma secreta ou ilegível, assim como assinar em branco folhas de receituário, atestados ou quaisquer outros documentos médicos" (MS 1998a).

Ainda com relação a Tabela 3 , observa-se diferenças entre as quantidades de medicamentos prescritos e os fornecidos. Para os medicamentos controlados com denominações genéricas foi fornecido um número maior do que o prescrito devido o fornecimento ter sido realizado com frascos lacrados. Para os de denominação comercial, forma prescritos $744 \mathrm{e}$ entregues $741 \mathrm{em}$ virtude da falta dos mesmos.

O medicamento industrializado, produto tecnológico decorrente de avanços científicos, socialmente aparece como algo cujo sentido é resolver um estado mal, conduzindo-o para um estado "bom". Isto independe de ser usado para uma real necessidade de saúde ou apenas para obter satisfação (LEFĖVRE, 1991). De acordo com BARROS (1995), à parte o valor simbólico em saúde que the é atribuido, o medicamento é uma mercadoria inserida na lógica de produção e consumo como qualquer outra. Já LISBOA et al., (2001) atribuem aos medicamentos uma natureza credencial, pois o seu consumo depende de escolha exercida quase sempre pelo médico.

A indústria farmacêutica se utiliza da natureza credencial dos medicamentos como vantagem competitiva, valorizando suas marcas, através de estratégias de marketing, junto à classe médica, especialmente àqueles formadores de opinião, que normalmente podem ser encontrados em Hospitais Universitários como o HC/SP (BATTISTI, 2003). 
Explorando a assimetria de informação relativa aos medicamentos, a indústria farmacêutica vem direcionando a promoção preferencialmente à classe médica. A promoção direta ao público tem registrado crescimento, utilizando-se de comunicação supostamente institucional. Nos Estados Unidos, a legislação permite a divulgação leiga de medicamentos sob prescrição médica. Esta se encontra em franca expansão (FINDLAY, 2001) (NIHCM, 2003).

A preocupação com o consumo e estratégias mercadológicas fez com que os produtores de medicamentos propusessem, com base em diversos estudos até então realizados, uma análise crítica do papel da propaganda, com ênfase no papel do propagandista de laboratório e na sua eficácia como instrumento preferencial de que lançam mão os produtores para influenciar os hábitos de prescrição dos médicos, dirigindo-os prioritariamente à satisfação dos interesses dos produtores, em detrimento dos consumidores (BARROS, 1983).

Sanitaristas e especialistas de diversas regiões afirmam que a promoção não ética de medicamentos é um problema grave, na maior parte do mundo, principalmente em países em vias de desenvolvimento, gerando mau uso dos medicamentos, produzindo prescriçōes desnecessárias, automedicação e o abuso. (BERMUDEZ, 1999).

JONATHAN (2003), responsável pela politica e medicamentos essenciais da OMS tem recebido muitos relatos de pessoas do mundo inteiro a respeito de propaganda de medicamentos e disponibilizado ao interessados no e-mail: e-drug@healthnet.org.

A Agência Nacional de Vigilância Sanitária (ANVISA), atenta a este crescimento, publicou em 2000 matéria normatizando a propaganda de medicamentos com a Resolução 102/2000 (MS, 2000).

Apesar desse avanço, no Brasil não temos ainda, um sistema de análise de propagandas de medicamentos como na agência americana Food and Drug Adminstration (FDA) ou a equivalente agência francesa.

MASTROIANNI (2003), estudando a influência da legislação sobre as propagandas de medicamentos psicoativos no Brasil, aponta várias irregularidades presentes nos anúncios nacionais e observa que a implantação 
deste regulamento foi insuficiente para evitar as irregularidades em anúncios de medicamentos.

A SOBRAVIME (2001) discutindo a respeito da prescrição, lembra que poucas são as Faculdades de Medicina, sobretudo em países em desenvolvimento, oferecem cursos de farmacologia clínica e de terapêutica no ensino de graduação, orientados ao uso correto de medicamentos. Esta deficiência também é registrada entre os dispensadores (farmacêuticos) pela falta de capacitação contínua na prática profissional.

A deficiência na formação dos profissionais de saúde, especialmente dos médicos, acima descrita, aliada a influência indevida da promoção farmacêutica exercida pela indústria, motivou o Conselho Federal de Medicina publicar resolução $\mathrm{CFM} n^{\circ} 1595$. Em seu Art. $1^{\circ}$ proibe a vinculação da prescrição médica ao recebimento de vantagens materiais oferecidas por agentes econômicos, interessados na produção ou comercialização de produtos farmacêuticos ou equipamentos de uso na área médica (CFM, 2000).

Nos serviços privados de saúde a prescrição fica a critério do profissional, podendo ser realizado por nome comercial. Este fato não deveria ser observado no serviço público.

A Lei 9787/99 e Resolução 135/2003, já citadas anteriormente, determinam que as prescrições, no âmbito do Sistema Único de Saúde (SUS) sejam obrigatoriamente realizadas adotando a $\mathrm{DCB}$ e na sua ausência a DCI (BRASIL, 1999b), (MS, 2003c). Assinale-se uma preocupação quanto às limitações da eficácia destas normas. Entre os elementos a serem regulamentados, quando se trata dos critérios para a dispensação de medicamentos nos serviços públicos ou privados, determina-se respeitar "a decisão expressa de não intercambiablidade do profissional prescritor" ou seja, obediência à posição do prescritor de não admitir troca do nome de marca por um medicamento similar (COSTA, 1999).

A fim de minimizar o efeito da propaganda de medicamentos sobre os médicos, sobretudo em hospitais públicos, estes criaram Câmaras de Fármacos e Medicamentos, para padronizar o uso, induzindo a prescrição por nomes genéricos. No Hospital das Clínicas está disponivel o no Guia Farmacoterapêutico (HC, 2000). 
Dos 744 medicamentos prescritos com nome comercial (Tabela 4), correspondente a $41,5 \%$ do total de 1793 , representados por 59 produtos, (19 similares e 40 referências, Tabela 5 ), $40,6 \%$ foram provenientes de oito indústrias nacionais. Entretanto, apenas duas indústrias representam $37,5 \%$ do total e seis representam $58 \%$ dos medicamentos receitados. Para as 14 industrias transnacionais $(59,4 \%)$, apenas três já perfazem um total de $33.8 \%$ das prescriçōes.

A partir desses resultados pode-se observar a eficiência da propaganda médica das indústrias farmacêuticas junto aos médicos que atuam nos ambulatórios do Hospital das Clínicas da USP, pois apesar da compra dos medicamentos ter sido realizada, obrigatoriamente, com nome da DCB (Lei 9787/99), os médicos continuam receitando pelo nome comercial (BRASIL, 1999b).

Dos 47 principios ativos que foram receitados nesse periodo, sete correspondem às listas controladas internacionalmente; os demais (40) correspondem às listas $\mathrm{C} 1$, A2ad. e B2ad. não controlados internacionalmente, mas controlados pela P-344 (Tabela 5).

Para prescriçāo de substâncias psicoativas e outras constantes das listas A1, A2, A3, B1, B2, C2 e C3, da Portaria 344/98 é necessário solicitar bloco de notificação correspondente, com folhas numeradas na Secretaria de Estado da Saúde - Centro de Vigilância Sanitária. Entretanto para as demais listas (C1, C4, C5, D1, A2ad. e B2ad) é exigida a receita em cópia carbonada onde a primeira via segue com o paciente e a segunda é retida para registro interno e posterior verificação pelos órgãos competentes (Tabela 6).

A análise da Tabela 6 mostra que nem todas as listas da Portaria 344/98 estiveram contempladas nas prescrições examinadas.

A lista A1 (entorpecentes/narcoanalgésicos) esteve representada por 32 prescriçōes $(1,8 \%)$. Considerando-se a morfina um fármaco de grande efetividade e baixo custo na analgesia dos casos de câncer, sua baixa freqüência (19 prescrições Tabela 7) parece seguir a tendência observada em outros paises.

O estabelecimento de regras muito restritivas pode constituir impedimentos legais à disponibilidade de medicamentos, contendo drogas 
narcóticas, aos pacientes que necessitam, causando grande sofrimento. Para dar suporte aos paises signatários, na tentativa de minimizar este problema, a OMS tem desenvolvido guias que auxiliam no autodiagnóstico dos seus sistemas regulatórios para identificar as deficiências (YOSHIDA 2003).

No Brasil, CARLINI et al., (2003) também registra este fato, estudando a influência da notificação da receita $A$ (cor amarela) sobre a prática de prescrição por médicos brasileiros.

LENKE (2001) discute procedimentos de dispensação de emergência, retenção de registros de substancias controladas, a transferência de opióides entre farmácias e programas de tratamento com substancias narcóticas no estado americano de Wisconsin.

JAVIER (2001) demonstrou que o consumo de opióides no controle da dor crônica, em estudo realizado com 314 médicos na região metropolitana de Manila, Filipinas, é muito baixa (15kg/ano) e contradiz com o consumo ( 87 $\mathrm{kg} / \mathrm{ano}$ ) informado pelo governo de seu pais à International Narcotics Control Board (INCB).

Estudos comparativos de critérios estabelecidos pela OMS e INCB para uso de opióides, realizado em cinco países da América Latina (Argentina, Colômbia, Costa Rica, Peru e México) e o estado norte americano do Texas demonstraram que com exceção do estado do Texas (94\%), os paises latino americanos atendem parcialmente os critérios para a prescrição de opióides, a Argentina (41\%), Colômbia (53\%), Costa Rica (53\%), México $(24 \%)$ e Peru (41\%). Este resultado indica a necessidade de revisão das leis e regulamentos, identificando as barreiras existentes necessárias para o acesso seguro ao tratamento com opióides (LILIANA, 2001).

A criminalização do uso recreacional de opióides vem dificultando sua aplicação terapêutica. RAJAGOPOL (2001) descreve o efeito dessa medida draconiana sobre a falta de prescrição de opioides em Kerela, India.

Um projeto que visa reinterpretar a legislação, em função da melhor utilização fármacos opióides e barbitúricos, foi apresentado em congresso nos Estados Unidos. Este trabalho analisa os argumentos apresentados, a necessidade de reinterpretação e conseqüências para o alívio da dor (WERTH, 2001). 
O medo da criminalização pelo uso terapêutico de opióides, está amplamente difundido entre os profissionais de saúde. Relatos de enfermeiras que se recusam aplicar injeções de morfina em pacientes com dores severas foram relatados por DIMOND (2003).

Com base nesses fatos, a Organização Mundial da Saúde (OMS) tem promovido, em vários paises, painéis para estimular o uso seguro dessa substância nos casos de câncer.

O programa japonês de alívio da dor de câncer foi iniciado com um teste de campo em 1982, gerenciado através das guias promovidas pela OMS. Este estudo demonstrou que $87 \%$ dos pacientes com câncer poderiam ter sua dor aliviada. Mesmo assim os profissionais japoneses continuaram ignorando este fato. Em 1987 uma equipe de pesquisadores, apoiados pelo Ministério da Saúde e Bem estar japonês, reavaliaram a filosofia dos cuidados paliativos nos casos de câncer. Foram reavaliadas as medidas de controle de narcóticos com a finalidade de melhorar a acessibilidade aos analgésicos opióides. $O$ consumo de morfina aumento no mínimo 15 vezes durante o período de 86 a 89 . Atualmente a morfina é administrada principalmente na forma oral. A fim de promover aumentos adicionais ao uso de analgésicos opióides, em 1990 aproximadamente $70 \%$ das escolas de enfermagem e medicina no Japão, inseriram em seu currículo, cuidados de alivio da dor nos casos de câncer. Mesmo assim o consumo da morfina no Japão é menor que 1/6 do consumo dos Estados Unidos.

Estimular o médico prescrever de maneira segura os opióides, necessita de um intenso programa educacional, devido a existência de legislação restritiva que influencia negativamente suas prescrições (GILSON, 2001).

$\mathrm{Na}$ Itália, a preocupação com o uso terapêutico seguro de opióides em pacientes com dores causadas pelo câncer, fizeram com que as autoridades modificassem os procedimentos, simplificando os requerimentos necessários para a prescrição desses fármacos (BLENGINI, 2003).

No Brasil, foi editada a Lei $n^{\circ} 10.409$, de 11 de janeiro de 2002, que dispõe sobre prevenção, tratamento, fiscalização, controle e repressão à produção, ao uso e ao tráfico ilícito de produtos, substâncias ou drogas ilícitas que causem dependência física ou psíquica relacionadas pelo Ministério da 
Saúde, e dá outras providências. O aspecto polêmico desta lei continua sendo a criminalização do usuário, não o elevando à condição de doente-dependente, dificultando sua recuperação social. (BRASIL, 2002).

Fármacos constantes das listas A2 e A3 nas quais estão inscritos entorpecentes e psicotrópicos, segundo a nomenclatura da P-344, exigem notificação a exemplo da lista A1 e não foram, surpreendentemente, observadas no periodo estudado, uma vez que estão inscritas nestas listas substâncias de bastante interesse farmacológico, conforme relacionado no Anexo I da P-344 (MS, 1998a).

Das substâncias que necessitam de notificação nas precrições, as pertencentes à lista B1 (psicotrópicos) foram as mais freqüentemente prescritas (12,3\%). Por outro lado, da lista B2 foram observados apenas 2 medicamentos prescritos 4 vezes,correspondente a $0,2 \%$. São fármacos estimulantes do sistema nervoso central (SNC) que apresentam o efeito anorexigeno, diferentemente do que acontece nas farmácias públicas que manipulam, onde se observa grande número de fórmulas emagrecedoras a base desses dois fármacos.

A Portaria 344/98 não consegue coibir o uso irracional das drogas psicoativas. Ao analisar a prescrição e dispensação de medicamentos psicotrópicos por meio da análise de receitas em diferentes estabelecimentos de dois municípios de São Paulo, em parceria com a Vigilância Sanitária desses municipios, foram coletadas e analisadas as prescrições retidas em drogarias, farmácias de manipulação, postos de saúde e hospitais no ano de 1999. Os dados contidos nas receitas/notificações foram digitados e tabulados. Das 108.215 prescrições processadas, 76.954 eram de benzodiazepínicos, 26.930 de anorexígenos, 3.540 de opiáceos e 788 de outros. Os benzodiazepínicos mais frequentes foram: diazepam (31.644), bromazepam (16.911) e clonazepam (7.929) e, entre os anorexígenos, dietilpropiona (14.800) e femproporex (10.942). As mulheres, em geral, receberam mais prescrições em comparação com os homens, especialmente para os anorexígenos, com uma relação dez vezes maior nas prescrições de dietilpropiona e femproporex. As poucas farmácias de manipulação $(n=6)$ chegaram a movimentar mais prescrições do que as drogarias $(n=49)$. Também foi detectada uma série de erros e incoerências nas prescriçōes analisadas. Os autores concluem que os resultados confirmam a ocorrência de uso irracional 
de uma série de práticas inadequadas que envolvem a prescrição desses medicamentos no Brasil e, portanto, indicam a necessidade de uma ampla revisão no atual sistema de controle dessas substâncias no país (NOTO, 2002).

A utilização dos benzodiazepínicos é revista por KAPCZINSKI (2001) em estudo de revisão epidemiológica no Brasil. Foram discutidos neste trabalho a legislação existente, a falta de informação e os fatores econômicos que contribuem para o abuso dos benzodiazepínicos, um problema para o país.

Os fármacos constantes da lista $\mathrm{C} 1$ são dispensados sob prescrição médica na maioria dos países do mundo, não exigindo controle especial nos moldes da P-344 (MS, 1998a). Nossos dados mostram que a maior freqüência de prescrição $(67,2 \%)$ foram de especialidades farmacêuticas com fármacos da lista C1, de várias classes farmacológicas (Tabela 6 e 7). Desvios de utilização, abuso e mau uso, pela falta de rigidez na exigência da receita por ocasião da dispensação, fizeram com que estas especialidades farmacêuticas e seus fármacos necessitassem de controle, supostamente mais rigoroso, exigindo assim que a receita fosse emitida com cópia (cópia carbonada em duas vias). Este fato foi amplamente debatido por ocasião da CPI dos medicamentos (PODER LEGISLATIVO, 2000).

Com relação às demais listas $\mathrm{C}$, a $\mathrm{C} 2$ que descrimina os retinóicos não foi observada neste estudo como era de se esperar. Seu controle de utilização, num hospital público deve estar muito mais ligado a um programa de saúde pública do que junto a um controle de substâncias psicoativas.

Já no caso da lista C3 $(0,2 \%)$ em que estão evidenciados os imunossupressores, apesar de não se observar desvios de utilização aparente como no caso dos fármacos da lista $\mathrm{C} 1$ estão a meu ver, controlados erroneamente pela P-344 (MS, 1998a).

Não estiveram presentes fármacos pertencentes à lista C4 (antiretrovirais), o que era esperado, pois devem estar ligados a programas especiais de saúde pública.

Os fármacos pertencentes à lista C5 estão representados pelos anabolizantes com frequeência de $0,1 \%$ em nosso estudo. Conforme anteriormente citado neste trabalho, a Lei 9965/2000 determina instruções 
especiais para dispensação e venda de anabolizantes o que reforça mais uma vez a tese de que a dispensação comum não é levada a sério em nosso país (PODER LEGISLATIVO CPI, 2000).

Princípios ativos pertencentes à lista D1 (Tabela 7), estão representados em $0,3 \%$ do receituário, pelo fato de serem precursores de fármacos "entorpecentes" e ou "psicotrópicos". São dispensados com receita comum. Entretanto, deve ter seu registro de dispensação e comercialização informada às autoridades competentes. Dados relativos a esta lista não estão contemplados na nas Tabelas 7 e 8 apesar de serem controlados pela P-344, pela exigência de receita comum.

Para as listas A1, A2, B1 e B2 existe seu correspondente adendo. O tipo de receituário segue o preconizado para as listas $C$, com exceção de $C 4$, ou seja, receita carbonada em duas vias.

Adendos, de uma maneira geral, referem-se a limitações de concentraçōes de principios ativos na formulação (concentrações menores quando comparadas a utilização do produto como monofármaco na respectiva lista ou quando em associações).

Isômeros de fármacos, quando referenciados nos adendos, devem ter o seu controle pela respectiva lista.

Foram consideradas como fonte geradora das receitas no periodo estudado, os ambulatórios, as clínicas médicas e cirúrgicas, bem como o laboratório de análises clínicas do HC/SP.

Como o estudo foi realizado em um hospital universitário, onde os pacientes foram atendidos em clínicas especializadas, acredita-se ter sido eliminado o aspecto de imprecisão de diagnóstico, que pode ocorrer quando o paciente é atendido por médicos generalistas. Assim os medicamentos prescritos refletem a conduta médica na prescrição. MONTOLIU et al., (2002) observaram em um estudo já descrito anteriormente que $3 / 4$ dos médicos generalistas não se sentiam confiantes em prescrever medicamentos psicotrópicos.

O maior número de receitas foram geradas na divisão de clínica médica seguido pela neurologia clínica (Tabela 7). De fato as classes terapêuticas que mais apresentaram prescrições foram as dos antidepressivos e dos 
anticonvulsivantes (lista $\mathrm{C} 1$ ), prescritas, respectivamente, pelas divisões de clínica médica e neurologia clínica (Tabela 8), o que contraria observações obtidas em outros paises.

Dentre os antidepressivos (628 prescrições) a amitriptilina (344 prescriçōes) predomina igualmente nas duas clínicas citadas. Das 532 prescriçōes de anticonvulsivantes, 344 foram prescritas pela neurologia clínica. Estes dados, tornam-se importantes por tratar-se de fármacos de uso contínuo e pertencentes à lista $\mathrm{C} 1$. Como na P-344 a quantidade de medicamentos que podem ser prescritas pertencentes a essa lista estão limitadas para um período de 60 dias de tratamento e 30 dias para os das listas C2 e C3. Portanto algumas considerações merecem ser feitas: para dar continuidade ao tratamento o paciente deverá retornar ao ambulatório e somente após uma nova consulta terá acesso a mais medicamentos, para igual prazo, e assim sucessivamente enquanto durar sua doença. Isto não só sobrecarrega o serviço médico, como acarreta prejuizo ao paciente atendido (custo de transporte, perda de dias de trabalho e tempo de espera, não computados neste estudo), contribuindo para excluir novos eventuais pacientes que deixarão de ser atendidos nas unidades públicas hospitalares. Além do mais, serviços médicos públicos estão cada vez mais assoberbados de trabalho, prejudicando sua eficiência tão exigida em nossos dias (MS, 1998a).

O fato acima pode ser corroborado com observações em trabalhos já publicados (CALIL, 2001) que se referem a "medicamentos constantes da lista $B$ que restringe o volume para 60 dias de tratamento. Por exemplo, para paciente em uso de $4.0 \mathrm{mg}$ de clonazepam ao dia, pode-se prescrever 6 caixas de clonazepam, comprimidos de $2,0 \mathrm{mg}$, que o paciente comprará de uma vez. Ainda se pode prescrever no receituário com cópia carbonada, a um paciente em uso de $300 \mathrm{mg}$ diários de clomipramina, doze caixas de clomipramina em comprimidos de $75 \mathrm{mg}$ diários. Anticonvulsivantes podem ser prescritos por seis meses; assim um paciente em uso de $300 \mathrm{mg}$ de hidantoína poderá receber 27 caixas em sua prescrição e deverá comprá-las de uma só vez, ou resta ao médico dar receitas de uma caixa toda semana. Em serviços públicos, cada prescrição pode gerar uma consulta onerando, desnecessariamente, o sistema de saúde".

Uma das possíveis soluções para o problema, no que se refere ao controle de substância psicoativas seria a P-344 não instituir um prazo de 
validade para a receita (30 dias) e a quantidade de medicamentos para o tratamento (30 ou 60 dias) permitindo que a mesma prescrição fosse utilizada por períodos maiores sob a supervisão do farmacêutico. Este incumbir-se-ia de reencaminhar o paciente ao médico quando qualquer intercorrência no tratamento for detectada (MS, 1998a).

Ainda como classes terapêuticas importantes, analgésicos opióides representados principalmente pelo tramadol, foram prescritos em todas as divisōes geradoras de receitas com exceção da obstetrícia e odontologia. Das 271 prescrições (Tabela 8 ) apenas 19 foram de morfina. Este fato reforça o baixo uso da morfina já discutido anteriormente. Assim porcentagem das diferentes classes terapêuticas em função do número total de prescriçōes bem como a porcentagem das prescrições de cada classe terapêutica em função das unidades geradoras está descrita na Tabela 9.

A discussão dos dados relativos à dispensação das receitas e ou notificação com as respectivas prescrições dos medicamentos dizem respeito diretamente às determinações do disposto na P-344 em que tanto as notificações como receituários devem estar devidamente preenchidos. Vários são os dados necessários sendo os mais importantes a identificação do paciente, seu registro no hospital e nome da unidade geradora.

Das 4.405 receitas apenas $258(5,85 \%)$ estavam com dados incompletos (Tabela 10). Desses dados, predomina a omissão do nome da unidade geradora do receituário com $80,6 \%$. Já a falta do registro do paciente no hospital foi constatado ser de $39,1 \%$. Inacreditavelmente, $10,5 \%$ do receituário incompleto não continham o nome do paciente.

No preenchimento do receituário, omissões podem acontecer inadvertidamente. Entretanto, a ausência do nome do paciente, obrigatoriamente, inutilizaria a receita e ou notificação. Tal fato parece não ter acontecido para as 26 receitas em que a identificação dos três campos não foi cumprida.

Com relação ao número de prescrições a $\mathrm{P}-344$ não permite mais do que três medicamentos por receita e 01 medicamento por notificação (MS, 1998a). 
Assim, a partir do número total de receitas no periodo, separadas por dia, foi construida uma tabela (Tabela 11 ) definida em 5 quadros com dados das receitas emitidas em cada dia. O Quadro 1 mostra a distribuição observada.

Quadro 1 - Distribuição das 4.405 receitas e ou notificações por dia de observação

\begin{tabular}{|l|c|c|}
\hline Dia & $n^{0}$ de receitas emitidas & $\%$ do total \\
\hline $25-2^{\mathrm{a}}$ feira & 1.001 & 22,79 \\
\hline $26-3^{\mathrm{a}}$ feira & 900 & 20,43 \\
\hline $27-4^{\mathrm{a}}$ feira & 652 & 14,80 \\
\hline $28-5^{\mathrm{a}}$ feira & 788 & 17,88 \\
\hline $29-6^{\mathrm{a}}$ feira & 1.604 & 24,15 \\
\hline
\end{tabular}

O quadro acima mostra que no periodo estudado (cinco dias) de $2^{\mathbf{a}}$ a $6^{\mathrm{a}}$ feira, houve variação diária do número de receitas e ou notificações emitidas, sendo o dia de menor emissão a $4^{a}$ feira.

A partir da Tabela 11 pode-se observar que o número de medicamentos prescritos por receita (controlados pela P-344 e não controlados) chegou a um número exageradamente alto de até 14 medicamentos, observados em cinco receitas nos dias 25 e 26 (MS, 1998a).

Com relaçāo ao número de medicamentos controlados prescritos por receita, observa-se que no dia 25 foram emitidas 168 receitas e/ou notificações com 01 medicamento, 53 receitas com dois medicamentos e 12 com três medicamentos. No dia 26 foram emitidas 145 receitas e/ou notificações com 01 medicamento, 30 com dois, 3 com três e 01 receita com quatro medicamentos. No dia 27 foram emitidas 101 receitas e/ou notificações com 01 medicamento, 30 com dois, 3 com três e 01 receita com quatro medicamentos. No dia 28 foram emitidas 131 receitas e/ou notificações com 01 medicamento, 40 com dois, $8 \mathrm{com}$ três e 01 receita com quatro medicamentos. No dia 29 foram emitidas 178 receitas e/ou notificações, 45 com dois e 9 receitas com três medicamentos. Assim constatamos que nos dias 27 e 28 foi ultrapassado o 
limite de três medicamentos controlados por receita e ou notificação, conforme preconiza a P-344.

Independentemente do número total de medicamentos por receita a grande maioria delas continha apenas 01 medicamento controlado (725); 198 com dois medicamentos e $87 \mathrm{com}$ três medicamentos. Apenas duas receitas apresentaram quatro medicamentos controlados (Tabela 12).

A P-344 define para as diferentes listas, limite de tratamento em dias e prazo de validade da receita (30 dias). Assim para as listas $A 1, A 2, A 3$ e $C 3$ os medicamentos não podem ser prescritos para mais de 30 dias de tratamento. Para as demais listas o limite estipulado é de 60 dias.

A partir da Tabela 13 pode-se observar que das 32 prescrições e ou notificações de medicamentos da lista A1, cinco (15,6\%) excederam o limite de 30 dias. Para a lista $B 1$ das 221 prescrições e ou notificaçōes, três $(1,35 \%)$ ultrapassaram o limite de 60 dias. Já na lista $C 1$, das 1.204 prescriçōes somente $01(0,4 \%)$ ultrapassou o limite. Nas demais listas não se observaram qualquer irregularidade.

Consideramos que a determinação da quantidade de medicamento para o limite de tempo estabelecido pela P-344 foi quase que totalmente obedecido pela Farmácia do HC.

É importante registrar que a grande maioria das prescriçōes de produtos da P-344 (1.661 prescrições) ficou abaixo do limite de 30 e 60 dias, respectivamente às listas $B$ e $C$. Excluindo-se os analgésicos opióides, ficam os medicamentos de uso contínuo (Quadro 2).

Quadro 2 - Quantidade e dias que as prescrições ficaram abaixo do limite permitido pela P-344

\begin{tabular}{|r|c|c|c|}
\hline Prescriçōes P-344 & Quantidade & $\%$ & $\begin{array}{c}\text { Média de } \\
\text { dias }\end{array}$ \\
\hline abaixo do limite permitido & 1.661 & $93 \%$ & 29 \\
\hline abaixo do limite (exceto analgésicos opióides) & 1.410 & $79 \%$ & 27 \\
\hline total & 1.793 & $100 \%$ & \\
\hline
\end{tabular}


Resta saber se isto é devido, unicamente, à obediência a P-344 ou se ao cumprir este dispositivo, a farmácia atende à demanda de medicamentos. É importante que se averigúe se os tempos de tratamento de pacientes crônicos forem dilatados, haverá ganhos em atendimento ambulatorial (MS, 1998a).

Assim uma dispensação cumulativa pode ser observada para medicamentos de alta utilização como, por exemplo, os benzodiazepínicos (lista B1 com notificação).

O Quadro 3, construído a partir do interesse despertado nas notificações expedidas no mesmo dia, apresenta casos de dispensação cumulativa de benzodiazepínicos pela mesma ou diferentes fontes geradoras de receitas.

Em virtude do tipo de medicamento prescrito (B1), era de se esperar que uma mesma fonte geradora predominasse. De 22 diferentes pacientes incluidos no Quadro 3, doze foram atendidos na divisão de neurologia clínica.

Assim por exemplo, o paciente 0158 , no mesmo dia 26 conseguiu duas notificaçōes/receitas com um total de 420 comprimidos de nitrazepam. 0 paciente 1288 recebeu em dias diferentes, mas na mesma semana, 160 comprimidos de clonazepam e 160 comprimidos de clobazan.

A explicação para tal fato foge do alcance deste trabalho, tendo em vista que não foram observados os mecanismos internos de controle dos ambulatórios do HC/SP.

A ANVISA tem realizado esforços para tentar efetivamente colocar em prática os dispositivos desta Portaria, através da criação de um Sistema Nacional de Gerenciamento de Produtos Controlados - SNGPC que em 28 de Outubro de 2003 encerrou um Projeto piloto para sua implantação no Distrito Federal, entretanto, evidencia uma falha da P-344 que focaliza em toda a sua abrangência o controle das quantidades das substâncias e não $\circ$ paciente, perdendo-se assim a oportunidade de prestar uma ampla atenção farmacêtica, fundamental para o cumprimento do esquema farmacoterápico definido pelo médico (ANVISA,2003). 
Quadro 3 - Casos de dispensação cumulativa de benzodiazepínicos pelas mesmas ou diferentes fontes geradoras de receitas

\begin{tabular}{|c|c|c|c|c|c|}
\hline Paciente & Dia & Prescrição & Quant. & Fármaco & Fonte geradora \\
\hline Pac0018 & 29 & diazepam & $20 \mathrm{cp}$ & Diazepam & NEUROLOGIA CLINICA \\
\hline Pac0018 & 29 & diazepam & $30 \mathrm{cp}$ & Diazepam & NEUROLOGIA CLINICA \\
\hline Pac0042 & 28 & RIVOTRIL & $40 \mathrm{cp}$ & Clonazepam & DIVISÁO CLÍNICA MÉDICA \\
\hline Pac0042 & 28 & RIVOTRIL & $30 \mathrm{cp}$ & Clonazepam & PACIENTE EXTERNO \\
\hline Pac0158 & 26 & nitrazepam & $210 \mathrm{cp}$ & Nitrazepam & NEUROLOGIA CLINICA \\
\hline Pac0158 & 26 & nitrazepam & $210 \mathrm{cp}$ & Nitrazepam & NEUROLOGIA CLI'NICA \\
\hline Pac0229 & 28 & diazepam & $30 \mathrm{cp}$ & Diazepam & NEUROLOGIA CLÍNICA \\
\hline Pac0229 & 28 & RIVOTRIL & $40 \mathrm{cp}$ & Clonazepam & NEUROLOGIA CLINICA \\
\hline Pac0282 & 27 & RIVOTRIL & $60 \mathrm{cp}$ & Clonazepam & NEUROLOGIA CLINICA \\
\hline Pac0282 & 27 & RIVOTRIL & $60 \mathrm{cp}$ & Clonazepam & NEUROLOGIA CLINICA \\
\hline Pac0406 & 27 & \begin{tabular}{|l|} 
nitrazepam \\
\end{tabular} & $90 \mathrm{cp}$ & Nitrazepam & PACIENTE EXTERNO \\
\hline Pac0406 & 27 & nitrazepam & $90 \mathrm{cp}$ & Nitrazepam & NEUROLOGIA CLINNICA \\
\hline Pac0413 & 27 & clobazam & $60 \mathrm{cp}$ & Clobazam & NEUROLOGIA CLÍNICA \\
\hline Pac0413 & 29 & FRISIUM & $60 \mathrm{cp}$ & Clobazam & NEUROLOGIA CLINICA \\
\hline$\overline{P a c 0494}$ & 28 & FRISIUM & $100 \mathrm{cp}$ & Clobazam & NEUROLOGIA CLINICA \\
\hline Pac0494 & 28 & FRISIUM & $100 \mathrm{cp}$ & Clobazam & PACIENTE EXTERNO \\
\hline Pac0567 & 29 & diazepam & $20 \mathrm{cp}$ & Diazepam & PACIENTE EXTERNO \\
\hline Pac0567 & 29 & diazepam & $30 \mathrm{cp}$ & Diazepam & PACIENTE EXTERNO \\
\hline Pac0657 & 29 & FRISIUM & $60 \mathrm{cp}$ & Clobazam & NEUROLOGIA CLINICA \\
\hline Pac0657 & 29 & URBANIL & $60 \mathrm{cp}$ & Clobazam & NEUROLOGIA CLÍNICA \\
\hline Pac0858 & 27 & URBANIL & $60 \mathrm{cp}$ & Clobazam & NEUROLOGIA CLINICA \\
\hline Pac0858 & 27 & FRISIUM & $120 \mathrm{cp}$ & Clobazam & NEUROLOGIA CLÍNICA \\
\hline Pac1008 & 27 & RIVOTRIL & $30 \mathrm{cp}$ & Clonazepam & $3^{a}$ CLINICA CIRÚRGICA EMERG. \\
\hline Pac1008 & 27 & RIVOTRIL & $40 \mathrm{cp}$ & Clonazepam & PACIENTE EXTERNO \\
\hline Pac1009 & 29 & nitrazepam & $270 \mathrm{cp}$ & Nitrazepam & NEUROLOGIA CLINICA \\
\hline Pac1009 & 29 & nitrazepam & $90 \mathrm{cp}$ & Nitrazepam & NEUROLOGIA CLÍNICA \\
\hline Pac1288 & 28 & RIVOTRIL & $160 \mathrm{cp}$ & Clonazepam & NEUROLOGIA CLINICA \\
\hline Pac1288 & 25 & FRISIUM & $160 \mathrm{cp}$ & Clobazam & NEUROLOGIA CLINIICA \\
\hline Pac1361 & 29 & diazepam & $20 \mathrm{cp}$ & Diazepam & DIVISÃO CLÍNICA MÉDICA \\
\hline Pac1361 & 29 & diazepam & $20 \mathrm{cp}$ & Diazepam & DIVISĀO CLÍNICA MÉDICA \\
\hline Pac1722 & 27 & FRISIUM & $40 \mathrm{cp}$ & Clobazam & PACIENTE EXTERNO \\
\hline Pac1722 & 27 & clobazam & $30 \mathrm{cp}$ & Clobazam & NEUROLOGIA CLINICA \\
\hline Pac1773 & 25 & RIVOTRIL & $40 \mathrm{cp}$ & Clonazepam & PACIENTE EXTERNO \\
\hline Pac1773 & 25 & clonazepam & $20 \mathrm{cp}$ & Clonazepam & PACIENTE EXTERNO \\
\hline Pac1955 & 29 & RIVOTRIL & $90 \mathrm{cp}$ & Clonazepam & NEUROLOGIA CLINICA \\
\hline Pac1955 & 29 & RIVOTRIL & $40 \mathrm{cp}$ & Clonazepam & NEUROLOGIA CLINIICA \\
\hline Pac2636 & 26 & clobazam & $90 \mathrm{cp}$ & Clobazam & NEUROLOGIA CLÍNICA \\
\hline Pac2636 & 26 & FRISIUM & $100 \mathrm{cp}$ & Clobazam & PACIENTE EXTERNO \\
\hline Pac2728 & 29 & clobazam & $100 \mathrm{cp}$ & Clobazam & NEUROLOGIA CLINICA \\
\hline Pac2728 & 29 & clobazam & $90 \mathrm{cp}$ & Clobazam & NEUROLOGIA CLINICA \\
\hline Pac3764 & 26 & URBANIL & $30 \mathrm{cp}$ & Clobazam & NEUROLOGIA CLINICA \\
\hline Pac3764 & 26 & URBANIL & $60 \mathrm{cp}$ & Clobazam & NEUROLOGIA CLINICA \\
\hline Pac3827 & 25 & nitrazepam & $90 \mathrm{cp}$ & Nitrazepam & NEUROLOGIA CLINICA \\
\hline Pac3827 & 25 & nitrazepam & $90 \mathrm{cp}$ & Nitrazepam & NEUROLOGIA CLINIICA \\
\hline
\end{tabular}




\section{CONCLUSÕES}

No presente trabalho foi estudada a viabilidade do cumprimento da legislação brasileira de controle de substância psicoativas através da Portaria $344 / 98$.

O estudo foi realizado a partir das receitas prescritas, durante um período de cinco dias, nos diferentes setores do Hospital das Clínicas da Faculdade de Medicina da Universidade de São Paulo e dispensadas na Divisão de Farmácia do mesmo hospital.

Os dados selecionados de cada receita, foram usados para a criação de um banco de dados a partir do qual foi verificada a conformidade dos procedimentos com relação à P-344.

Considerando os resultados do trabalho observacional e retrospectivo obtidos podemos concluir que:

1. a propaganda de medicamentos junto à classe médica do Hospital das Clínicas, parece ter sido muito efetiva e contribuído significativamente para impedir que utilizem, em suas prescrições, as Denominações Comuns Brasileiras (DCB) e na sua ausência as Denominações Comuns Internacionais (DCl), determinadas pela legislação, o que foi cumprido parcialmente;

2. a prescrição da morfina, como analgésico, é muito baixa, quase insignificante (apenas $32 \mathrm{em} 12.521$ prescrições, 0,25\%). Segue tendência internacional. Sugere-se estimular o seu uso correto em hospitais públicos utilizando-se os dispositivos ("guidelines"), preconizadas pela Organização Mundial da Saúde (OMS);

3. a incidência de prescrições de fármacos anorexígenos no hospital em estudo, é muito baixa se comparada com dados da literatura que mostram ser grande o número normalmente aviadas em farmácias que manipulam;

4. os medicamentos constantes da lista C2 (retinóicos) e C4 (antirretrovirais) não foram observados neste estudo, o que era de se esperar, pois estão ligados a programas especiais de saúde pública. Sugere-se portanto sua exclusão da P-344;

5. a limitação das quantidades de medicamentos para tratamento das doenças crônicas, estipuladas pela P-344 (30 ou 60 dias), causa problemas 
econômicos, pois obriga o paciente a retornar em consulta médica (para a mesma doença), a fim de ter acesso a mais medicamentos;

6. o preenchimento incompleto na receita dos dados de identificação, registro dos pacientes e da unidade geradora de receitas no hospital (5,85\% do total), não pode ser admitido em um Hospital Universitário, independentemente do item incompleto;

7. a Farmácia Hospitalar do Hospital das Clínicas de Universidade de São Paulo, cumpre os dispositivos legais da P-344, diante da baixa não conformidade constatadas no decorrer deste trabalho;

8. a dispensação de medicamentos que ocorre em uma farmácia hospitalar difere da dispensação de medicamentos em farmácias e drogarias. Sugere-se, portanto, uma legislação adequada para cada um dos setores;

9. a educação continuada em farmacologia clínica e terapêutica, para prescritores e dispensadores, se faz necessária para o uso correto e racional dos medicamentos;

10. pode-se também concluir deste trabalho que a Portaria $344 / 98$ controla mais substâncias psicoativas que o preconizado internacionalmente. Incluem outras substâncias cujo controle pode ser exercido pela própria dispensação realizada pelo profissional farmacêutico e não pela ausência dele, que obriga a criação desnecessária de mecanismos que tentam, em vão, impedir o desvio de uso, o mau uso e abuso de produtos farmacêuticos. 


\section{REFERÊNCIAS}

[ANVISA] Agência Nacional de Vigilância Sanitária. Apresentação da Instituição [on line] Disponivel em <url:http:// www.anvisa.gov.br/inst/apresentação.htm > [ 2003 out 30]

[ANVISA] Agência Nacional de Vigilância Sanitária. Notícias da Anvisa: diário e mensal. Grupo do SNGPC encerra Projeto Piloto no Distrito Federal. [on line] Disponivel em: <url:http://

www.anvisa.gov.br/divulga/notícias/2003/281003.htm > [2003 out 28]

Barros JAC. Estratégias mercadológicas da Indústria farmacêutica e o consumo de medicamentos. Rev Saúde Pública, 1983; 17:377-86.

Barros JAC. Propaganda de medicamentos: atentado à saúde? São Paulo: Hucitec; 1995.

Battisti PD. Gestão estratégica aplicada a dois laboratórios farmacêuticos transnacionais. São Paulo; 2003.[Dissertação de Mestrado - Escola de Administração de Empresas de São Paulo - Fundação Getúlio Vargas].

Bermudez, J.A.Z.; Bonfim, J.R.A. Medicamentos e a reforma do setor saúde. São Paulo: Hucitec, 1999.

Blengini $C$, Joranson DE, Ryan KM. Italy reforms national policy for cancer pain relief and opioids. Eur J Cancer Care (Engl) 2003; 12: 28-34.

Brasil. Constituição da República Federativa do Brasil .Titulo VIII Da Ordem Social, Capítulo II Da Seguridade Social, Seção II Da Saúde, Art. 196. 
Organizado por Claudio Brandão de Oliveira, atualizada pela EC 28 de 2000, 6 ed. Rio de Janeiro: DP\&A, 2000.

Brasil. Decreto-Lei n. ${ }^{\circ} 891$ de 25 de novembro de 1938. Aprova a Lei de Fiscalização de Entorpecentes. Diário Oficial da República Federativa do Brasil, Rio de Janeiro, 25 nov 1938.

Brasil. Decreto n. ${ }^{0} 54.216$ de 27 de agosto de 1964. Promulga a Convenção Única de Entorpecentes. Diário Oficial da República Federativa do Brasil.

Brasil. Decreto-Lei $n$. $^{\circ} 986$ de 21 de outubro de 1969. Institui normas básicas sobre alimentos. Diário Oficial da República Federativa do Brasil, Brasilia (DF), 21 out 1969.

Brasil. Decreto n. ${ }^{\circ} 88$ de 05 de dezembro de 1972. Aprova o texto do Protocolo de Emendas à Convenção Única de Entorpecentes, de 1961, firmado pelo Brasil e por outros paises, em Genebra, a 25 de março de 1972, como resultado da Conferência de Plenipotenciários, convocada pelo Conselho Econômico e Social da Organização das Nações Unidas. Diário Oficial da República Federativa do Brasil. Brasília (DF), 05 dez 1972.

Brasil. Decreto n. ${ }^{\circ} 79.388$ de 14 de março de 1977. Promulga a Convenção sobre Substâncias Psicotrópicas. Diário Oficial da República Federativa do Brasil. Brasília, 14 mar 1977.

Brasil. Decreto n. ${ }^{\circ} 162$ de 14 de julho de 1991. Aprova o texto da Convenção contra o Tráfico llícito de Entorpecentes e de Substâncias Psicotrópicas, aprovada em Viena, em 20 de dezembro de 1988. Diário Oficial da República Federativa do Brasil. Brasília (DF), 14 jul 1991. 
Brasil. Decreto n. ${ }^{\circ} 793$ de 05 de abril de 1993. Altera os Decretos n’s 74.170 , de 10 de junho de 1974 e 79.094, de 5 de janeiro de 1977, que regulamentam, respectivamente, as Leis $n^{\circ}$ s 5.991, de 17 de janeiro de 1973, e 6.360, de 23 de setembro de 1976, e dá outras providências. Diário Oficial da República Federativa do Brasil. Brasilia (DF), 06 abril 1993.

Brasil. Lei $n .{ }^{\circ} 6360$ de 23 de setembro de 1976a. Dispõe sobre a vigilância sanitária a que ficam sujeitos os medicamentos, as drogas, os insumos farmacêuticos e correlatos, cosméticos, saneantes e outros produtos, e dá outras providências. Diário Oficial da República Federativa do Brasil. Brasilia, 24 de setembro de 1976.

Brasil. Lei n. ${ }^{\circ} 6368$ de 21 de outubro de 1976b. Dispõe sobre medidas de prevenção e repressão ao tráfico ilícito e uso indevido de substâncias entorpecentes ou que determinem dependência física ou psíquica, e dá outras providências. Diário Oficial da República Federativa do Brasil. Brasília (DF), 22 out 1976, RET 29 out 1976.

Brasil. Lei n. ${ }^{\circ} 6437$ de 22 de Agosto de 1977. Dispõe sobre infrações à legislação sanitária federal, estabelece as sanções respectivas, e dá outras providências. Diário Oficial da República Federativa do Brasil. Brasilia (DF), 24 ago 1977.

Brasil. Lei n. ${ }^{\circ} 8080$ de 19 de setembro de 1990. Dispõe sobre as condições para a promoção, proteção e recuperação da saúde, a organização e o funcionamento dos serviços correspondentes, e dá outras providências. Diário Oficial da República Federativa do Brasil. Brasilia (DF), 20 set 1990. 
Brasil. Lei n. ${ }^{\circ} 9279$ de 14 de maio de 1996. Regula os direitos e obrigações relativas à propriedade industrial. Diário Oficial da República Federativa do Brasil. Brasília (DF), 14 maio 1996.

Brasil. Lei n. 9782 de 26 de janeiro de 1999a. Define o Sistema Nacional de Vigilância Sanitária, cria a Agência Nacional de Vigilância Sanitária, e dá outras providências. Diário Oficial da República Federativa do Brasil. Brasilia (DF), 11 fev 1999, Seção 1, p 1. Alterada pela Medida Provisória ${ }^{\circ}$ 2190-34, 23 ago 2001.

Brasil. Lei n. ${ }^{\circ} 9787$ de 10 de fevereiro de 1999b. Altera a Lei $n^{\circ} 6.360$, de 23 de setembro de 1976, que dispõe sobre a vigilância sanitária, estabelece o medicamento genérico, dispõe sobre a utilização de nomes genéricos em produtos farmacêuticos e dá outras providências. Diário Oficial da República Federativa do Brasil. Brasilia (DF), 10 fev 1999.

Brasil. Lei n. ${ }^{\circ} 9965$ de 27 de abril de 2000 . Restringe a venda de esteróides ou peptídeos anabolizantes e dá outras providências. Diário Oficial da República Federativa do Brasil. Brasília (DF), 27 abril 2000.

Brasil. Lei n. ${ }^{0} 10.409$, de 11 de janeiro de 2002. Dispõe sobre a prevenção, o tratamento, a fiscalização, o controle e a repressão à produção, ao uso e ao tráfico ilícitos de produtos, substâncias ou drogas ilícitas que causem dependência física ou psíquica, assim elencados pelo Ministério da Saúde, e dá outras providências. Diário Oficial da República Federativa do Brasil. Brasilia (DF), 14 jan 2002.

Calil LC. Aceitação e credibilidade na eficácia das atuais normas de prescrição para psicofarmacos. Rev Psiquiatr Clin 2001; 28:228-32. 
Carlini ER, Nappo SA, Nogueira V, Naylor FGM. Methylphenidate: infuence of notification of prescriptions drug A (yellow collor)about of prescription by Brazilians physicians. Rev Psiquiatr Clin. 2003; 30: 11-20.

Chast F. [Morphine by external route, prescribed to Heinrich Heine by David Gruby]. Rev Hist Pharm 1998; 46(320):391-6.

Chetley A. Problem drugs. Amsterdan: Health Action International; 1993 p. 388-90.

[CFF] Conselho Federal de Farmácia. Brasil consegue apoio de paises para discutir patentes na OMC. Rev Pharm Bras. 2001 v 27, jul / ago p.45.

[CFM] Conselho Federal de Medicina. Código de ética médica: resolução CFM nº 1.246/88. Diário Oficial da União, Brasilia (DF), 26 jan 1988 e Disponível em: <url:http://www.portalmedico.org.br/codigo_etica_.asp?portal=> [12 nov 2003].

[CFM] Conselho Federal de Medicina. Resolução CFM $n^{\circ}$ 1.595/2000. Diário Oficial da União, Brasilia (DF), 22 maio 2000 e Disponivel em: <url:http://uww.portalmedico.org.br/resolucoes/cfm2000/1595.htm> [12 nov 2003].

Contijo CIF. Propriedade industrial no século XXI direitos desiguais: principais aspectos da propriedade industrial em negociação nos vários foros internacionais comentários e sugestões. Brasília (DF): Inesc/ Rebrip/Oxfam; 2003.

Costa AE. Vigiláncia sanitária proteção e defesa da saúde. São Paulo: Hucitec/Sobravime; 1999. 
DEF 2001/2002: dicionário de especialidades farmacêuticas. 30.ed. Rio de Janeiro: Publicaçōes Científicas; 2001.

DEF 2002/2003: dicionário de especialidades farmacêuticas. 30.ed. Rio de Janeiro: Publicações Científicas; 2002.

Delgado GL. A dor de origem oncológica. 2. ed. Sorocaba: CCMB - PUCSP; 1998.

Dimond $\mathrm{B}$. Law relating to the classification and regulation of controlled drugs. $\mathrm{Br}$ J Nurs 2003; 12: 502-4.

Ferigolo M, Medeiros FB, Barros HMT. "Éxtase": revisão farmacológica. Rev Saúde Pública 1998; 32: 488-96.

Findlay SD. Direct-to-consumer promotion of prescription drugs: economic implications for patient payers and providers Pharmacoecomics 2001;19: 109-19.

Finkel DM. Opioid tolerance development: myth or reality? Rev Argent Anestesiol 2001;59: 54-6.

Fischer-Pülher P. O acesso ao fármaco In: Negri B, Viana AL D’Ávila. O Sistema Único de Saúde em dez anos de desafios. São Paulo: Sobravime/Celag; 2002 p.315-51.

Folker AP, Holtug $N$, Jensen AB, Kappel K, Nielsen JK, Norup M. Experiences and attitudes towards end-of-life decisions amongst Danish physicians. Bioethics 1996;10:233-49.

Franklin BL. Droga: problema mundial. Quito (Ecuador): Ministerio de Información y Turismo; 1993. 
Gilson AM, Joranson DE. Controlled substances and pain management: changes in knowledge and attitudes of state medical regulators. J Pain Symptom Manage 2001; 21: 227-37.

Goodman L, Gilman A, Gilman AG. The pharmacological basis of therapeutics. 9. ed. New York: Macmillan; 1983. p.435-37.

[HC] Hospital das Clínicas da Faculdade de Medicina da Universidade de São Paulo. Guia farmacoterapêutico 2002-2003. São Paulo; 2002.

Hunt A, Goldman A, Devine T, Phillips M. Transdermal fentanyl for pain relief in a paediatric palliative child population. Palliat Med 2001; 15:405-12.

Javier FO, Magpantay LA, Espinosa EL, Harder SM, Unite MA. Opioid use in chronic pain management in the Philippines. Eur J P 2001;5 Suppl A:83-5.

Jonathan DQ, Hans VH, German V, Ambit R. Perspectives twenty-five years of essential medicine [on line] Available from <url:http://www.who.int/medicines/organization/par/cd 25th anniversary/who bull.pdf> or <url:http://www.google.com/u/who?g=jonathan $+\&$ su=Go\&sitesearch=who.int\& sitesearch=who.int\&domains=who.int $>[2003$ nov 13].

[JIFE] Junta Internacional de Fiscalización de Estupefacientes. Lista de substancias sicotrópicas sometidas a fiscalización internacional (Lista Verde) [on line] [Anexo al informe estadístico anual, 22. ed, dic 2001]. Disponivel em: <url:http://www.incb.org/s/list/menu.htm> [2003 oct].

[JIFE] Junta Internacional de Fiscalización de Estupefacientes. Lista de estupefacientes sometidas a fiscalización internacional (Lista Amarilla) 
[on line] [Anexo a los formularios estadísticos, 44. ed, dic 2002]. Disponivel em: <url:http://www.incb.org/s/list/menu.htm> [2003 oct].

Kalant H, Roschlau WHE. Principles of medical pharmacology. 6. ed. New York: Oxford University Press; 1998.

Kapczinski F, Amaral OB, Madruga M, Quevedo J, Busnello JV , de Lima MS.Use and misuse of benzodiazepines in Brasil: a review. Subst Use Misuse 2001; 36: $1053-69$.

Korolkovas A, Burckhalter JH. Química farmacêutica. Rio de Janeiro: Guanabara Dois; 1982.

Korolkovas A, Cunha BCA, França FFAC. Dicionário terapêutico Guanabara. 6. ed. Rio de Janeiro: Guanabara Koogan; 1999/2000.

Lefèvre, F. O medicamento como mercadoria simbólica. São Paulo: Cortez, 1991.

Lenke J. Clarifying dispensing laws. J Pharm Soc Wisc 2001; 4: 12-4.

Liliana De Lima MH, Sakowski JA, Stratton HC, Bruera E. Legislation analysis according to WHO and INCB criteria on opioid availability: a comparative study of 5 countries and the state of Texas. Health Policy 2001; 56: 99-110.

Lisboa MB, Fiuza EPS, Andrade MV, Ferraz L. Política govemamental e regulação do mercado de medicamentos. Brasília (DF): Secretaria de Acompanhamento Econômico; 2001. [Relatório Técnico].

Lugones R. Marketing y promoción de medicamentos: ¿ qué limites pueden ser implementados? In: Bermudez JAZ; Bonfim JRA. Medicamentos e a reforma do setor saúde. São Paulo: Hucitec; 1999. p.211-21. 
Malachias R. Juventude Interativa: cidadania contra o racismo. Rev Bras Cresc Desenvolv Hum 1999; 9(2):11-22.

Malcolm MT. Morphine withdrawal, treatments 1900-30. Hist Psychiatry 1999; 10:13-26.

Mastroianni PC. A influência da legislação sobre as propagandas de medicamentos psicoativos no Brasil. São Paulo; 2003. [Dissertação de mestrado - Escola Paulista de Medicina - Universidade Federal de São Paulo].

Masur J. O que é toxicomania. São Paulo: Brasiliense; 1985. p.53-65.

Matsuda M, Ueki R, Murakawa K, Sasaki K, Boo K, Tashiro C. [Low dose intrathecal morphine and postoperative pain relief in elderly patients]. Masui $2001 ; 50: 1096-1100$.

[MJ] Ministério da Justiça. Divisão de Repressão a Entorpecentes. Manual de polícia de repressão a entorpecentes. Brasilia (DF); 1983. A-I-041; A-VIII021; A-VIII-073.

[MS] Ministério da Saúde. Brasil é vitorioso na briga de patentes. Inf Saúde, $2001 ; 5(138)$.

[MS] Ministério da Saúde, Divisão Nacional de Medicamentos da Secretaria Nacional de Vigilância Sanitária (DIMED), Portaria DIMED 02/84, de 30/03/1984. DOU de 04/04/84.

[MS] Ministério da Saúde. Portaria n 27, de 24/10/1986. DOU, Seção 1,pp. $16361-4,1986 a$. 
[MS] Ministério da Saúde. Portaria n 28, de 13/11/1986. DOU, Seção 1,pp. $17205-12,1986 b$.

[MS] Ministério da Saúde. Portaria n 1.179, de 17/06/1996. Denominações Comuns Brasileiras. Diário Oficial da União, Brasilia DF, Seção 1, n.116, p. 10.7071996.

[MS] Ministério da Saúde. Portaria 344, de 12 de maio de 1998a. Aprova o regulamento técnico sobre substâncias e medicamentos sujeitos a controle especial. Agência Nacional de Vigilância Sanitária (ANVISA). [on line] Disponivel em:__url:http://www.anvisa.gov.br/legis/portarias/344 98.htm > [2003 nov 12].

[MS] Ministério da Saúde. Portaria GM n 3916, 30 de outubro de 1998 b. Aprova a Política Nacional de Medicamentos. Diário Oficial da República Federativa do Brasil, Brasília (DF), 10 nov,1998. S1, n 215-E, p.18.

[MS] Ministério da Saúde. RDC $n^{\circ} 102$ de 30 de novembro de $2000 . \quad$ Dispõe sobre propagandas, mensagens publicitárias e promocionais e outras práticas cujo objeto seja a divulgação, promoção ou comercialização de medicamentos de produção nacional ou importados, quaisquer que sejam as formas e meios de sua veiculação, incluindo as transmitidas no decorrer da programação normal das emissoras de rádio e televisão. Agência Nacional de Vigilância Sanitária (ANVISA), republicada no Diário Oficial da União em 01 de junho de 2001. [on line] Disponível em: <url:http://www.anvisa.gov.br/legis/resol/2000/102 00rdc.htm> [2003 nov 12].

[MS] Ministério da Saúde. RDC $n^{\circ}$ 134, de 13 de julho de 2001. Determinar a todos os estabelecimentos fabricantes de medicamentos, o cumprimentos 
das diretrizes estabelecidas no Regulamento Técnico das Boas Práticas para a Fabricação de Medicamentos, conforme ao Anexo I da presente Resolução. Agência_Nacional de Vigilância Sanitária (ANVISA). [on line] Disponivel em: <url:http://uww.anvisa.gov.br/legis/resol/134 01rdc.htm> [2003 nov 12].

[MS] Ministério da Saúde. RDC n 133, de 29 de maio de 2003 a. Dispõe sobre o registro de medicamento similar e dá outras providencias. Republicada em 19 de setembro de 2003. Agência_Nacional de Vigilância Sanitária (ANVISA). [on line] Disponivel em:_<url:http://www.anvisa.gov.br/legis/resol/2003/rdd/133 03 rdc.htm> [2003 nov 12].

[MS] Ministério da Saúde. RDC n 139 de 29 de maio de 2003 b. Dispõe sobre o registro e a isenção de registro de medicamentos homeopáticos industrializados. Agência_Nacional de Vigilância Sanitária (ANVISA). [on line] Disponivel em: <url:http://anvisa.gov.br/legis/resol/2003/rdc/139 03rdc.htm> [2003 nov 12].

[MS] Ministério da Saúde. RDC n 135 de 29 de maio de 2003c. Atualiza o Anexo I, Listas de Substância Entorpecentes, Psicotrópicas, Precursoras e Outras sob Controle Especial, da Portaria SVS/MS n³44, de 12 de maio de 1988, republicada no Diário Oficial da União de $1^{\circ}$ de fevereiro de 1999 . Agência Nacional de Vigilância Sanitária (ANVISA). [on line] Disponivel em: <url:http://anvisa.gov.br/legis/resol/2003/rdc/135 03rdc.htm> [2003 nov 12].

[MS] Ministério da Saúde. RDC $n^{\circ}$ 210, de 04 de agosto de 2003d. Determinar a todos os estabelecimentos fabricantes de medicamentos, o cumprimento das diretrizes estabelecidas no Regulamento Técnico das Boas Práticas para a fabricação de medicamentos, conforme Anexo I da presente resolução. 
Agência_Nacional de Vigilância Sanitária (ANVISA). [on line] Disponível em:

<url:http://anvisa.gov.br/legis/resol/2003/index rdc210 ago.htm> [2003 nov 12].

[MS] Ministério da Saúde. RDC $n^{\circ} 254$ de 17 de setembro de 2003e. Dispõe sobre o regulamento técnico para medicamentos genéricos. Agência_Nacional de Vigilância Sanitária (ANVISA). [on line] Disponivel em: <url:http://anvisa.gov.br/legis/resol/2003/index rdc254 set.htm> [2003 nov 12].

Montoliu L, Crawford T. Prescribing practices of general practitioners for children with mental health problems. Child-Adolescent-Mental-Health 2002; 7: 128130

Mystakidou K, Befon S, Kouskouni E, Gerolymatos K, Georgaki S, Tsi E, Vlahos L. From codeine to transdermal fentanyl for cancer pain control: safety and efficacy clinical trial. Anticancer Res $2001 ; 21(3 C): 2225-30$.

Nassif MRG. Compêndio de homeopatia. São Paulo: Robe; 1995.

National Institute for Health Care Management. Prescription drugs and mass media advertising, [on line] Available from:

<url:http://www.nihcm.org/advertising > [2003 nov 07].

Negri B, Viana AL D'Ávila organizadores. O Sistema Único de Saúde em dez anos de desafios. São Paulo: Sobravime/Celag; 2002.

Noto AR, Carlini EA, Mastroiani PC, Alvesa VC, Galduróza JCF, Kuroiwa W et al. . Analisys of prescription and dispensation of psychotropic medications in two cities of São Paulo, Brasil. Rev Bras Psiquiatria 2002; 24: 68-73. 
[OMS] Organización Mundial de la Salud. Uso racional de los medicamentos. Ginebra; 1986. [Informe de la Conferencia de Expertos; 1985 nov 25-29; Nairobi].

Ozaki S, Narita M, Suzuki T. [Basic research for psychological dependence on morphine under chronic pain]. Nippon Rinsho 2001; 59:1704-12.

Pereira OA. Substâncias farmacêuticas comerciais. Rio de Janeiro: ABIQUIF; 2002.

Pimenta CAM, Teixeira MJ, Correa CF, Muller FS, Goes FCG, Marcon RM. Alívio da dor crônica não neoplásica com opiáceos. Rev Latinoam Enferm 1999; 7 : 65-73.

Plonka-Syroka B. Drugs in artistic works of Stanislaw Ignacy Witkiewicz (18851939) on the background of polish modernism at the turn of XIX and XX century. Arch Hist Filoz Med 1997; 60: 361-74.

Poder Legislativo, Câmara dos Deputados. Relatório da CPI-Medicamentos. Comissão parlamentar de inquérito destinada a investigar os reajustes de preços e a falcificação dos medicamentos, materiais hospitalares e insumos de laboratórios. Centro de documentação e Informação, Coordenação de publicações. Brasília (DF), 2000.

Rajagopol MR, Joranson DE, Gilson AM. Medical use, misuse and diversion of opioids in Índia. Lancet 2001; 358(9276) 139-43.

[SOBRAVIME]. Sociedade Brasileira de Vigilância de Medicamentos. O que é uso racional de medicamentos. São Paulo; 2001. 
Silva MTA. Drogas conceitos sem preconceitos. São Paulo: Hucitec; 1986. p.74-5.

Takeda F. The development of use of oral morphine within the last 10 years in Japan. Eur J Pain 2001; v 5 Suppl A: 79-82.

Teixeira MJ, Pimenta CAM, Neves ATA, Perrota AC. A dor e seu controle. São Paulo: FURP; 1998. p.4-5.

Truog RD, Arnold JH, Rockoff MA. Sedation before ventilator withdrawal: medical and ethical considerations. Clin Ethics $1991 ; 2: 127-9$.

Wadt M. Análise econômica de novos fármacos licenciados no Brasil entre 1998 e 2001. São Paulo, 2003. 233 p. Dissertação de Mestrado Faculdade de Ciências Farmacêuticas da Universidade de São Paulo. Departamento de Farmácia.

Werth JL Jr. Reinterpreting the controled substances act: predictions for the effect on pain relief. Behav Sci Law 2002; 20: 287-305.

Williams NE, Wilson H. Pain and its management In: International encyclopedia of pharmacology and therapeutics. Liverpool; 1983. Supplement n. 12.

World Health Organization. Convention on psychotropic substances. Includind final act and resolutions, as agreed by the 1971 United Nations Conference for adoption of a protocol on psychotropic substances, and the schedules annexed to the Convention. United Nations; New York: 1977.

World Health Organization. Centre for Drug Statistics Methodology. Guidelines for ATC classification and DDD assignment. 3.ed. Oslo; 2000. 
Wrobleski A, Tuma R, Charbonneau PE, Gobetti C, Nahas G, Cruz A et al. Drogas : ameaça ao futuro. São Paulo: Federação do Comércio do Estado de São Paulo; 1987.

Yoshida T. Assessment of psychoactive substances for international control [on line] Available from:

<url:http://www.who.int/medicines/organization/qsm/activities/psychotropic/pnd _asses_psychosubstance_drugs.html> [2003 nov 12].

Zanini AC, Basile AC, Wadt M. Dicionário de genéricos Zanini-Oga. 4.ed. Itanhaém: Ipex, 2001.

Zanini AC, Ciola-Sanchez L. Paulo LC. Assistência farmacêutica In:Oga S, Tedesco V, editores. Zanini Oga farmacologia aplicada. [on line]. Disponivel em: <url:http://mww.farmacologia.com.br/publicacao> [2003 set 12].

Zanini AC, Paulo LGA. Compliance: sobre o encontro paciente-médico. São Paulo: IPEX; 1997. p.115-46.

Zanini AC, Paulo LGA, Athayde ML. O controle no Brasil da dispensação de medicamentos psicoativos. Brasilia (DF): Secretaria Nacional de Vigilância Sanitária. Divisão Nacional de Vigilância Sanitária de Medicamentos; 1985.

Zanini AC, Paulo LGA. Necessidade de medicamentos no Brasil: teoria e prática de 1980 a 1985. Rev Assoc Med Brás 1985; 31: 245-7.

Zanini AC, Oga S. Farmacologia aplicada. 5a ed. São Paulo: Atheneu, 1994. p.399-400.

Zanini AC, Oga S, Follador W, Basile A. Guia de medicamentos 97/98. São Roque: IPEX; 1997. 


\section{ANEXO 1 - Listas de substâncias constantes na P - 344}

LISTA - A1

LISTA DAS SUBSTÂNCIAS ENTORPECENTES

(Sujeitas a Notificação de Receita "A")

1. ACETILMETADOL

2. ALFACETILMETADOL

3. ALFAMEPRODINA

4. ALFAMETADOL

5. ALFAPRODINA

6. ALFENTANILA

7. ALILPRODINA

8. ANILERIDINA

9. BEZITRAMIDA

10. BENZETIDINA

11. BENZILMORFINA

12. BENZOILMORFINA

13. BETACETILMETADOL

14. BETAMEPRODINA

15. BETAMETADOL

16. BETAPRODINA

17. BUPRENORFINA

18. BUTORFANOL

19. CLONITAZENO

20. CODOXIMA

21. CONCENTRADO DE PALHA DE

DORMIDEIRA

22. DEXTROMORAMIDA

23. DIAMPROMIDA

24. DIETILTIAMBUTENO

25. DIFENOXILATO

26. DIFENOXINA

27. DIIDROMORFINA

28. DIMEFEPTANOL (METADOL)

29. DIMENOXADOL

30. DIMETILTIAMBUTENO

31. DIOXAFETILA

32. DIPIPANONA

33. DROTEBANOL

34. ETILMETILTIAMBUTENO

35. ETONITAZENO

36. ETOXERIDINA

37. FENADOXONA

38. FENAMPROMIDA

39. FENAZOCINA

40. FENOMORFANO

41. FENOPERIDINA

42. FENTANILA

43. FURETIDINA

44. HIDROCODONA

45. HIDROMORFINOL

46. HIDROMORFONA

47. HIDROXIPETIDINA

48. INTERMEDIÁRIO DA METADONA (4-CIANO-

2-DIMETILAMINA-4,4-DIFENILBUTANO)
49.INTERMEDIÁRIO DA MORAMIDA (ÁCIDO 2METIL-3-MORFOLINA-1,1-DIFENILPROPANO CARBOXILICO)

50. INTERMEDIARIO "A" DA PETIDINA (4

CIANO-1-METIL-4-FENILPIPERIDINA)

51.INTERMEDIÁRIO “B" DA PETIDINA (ÉSTER

ETÍLICO DO ÁCIDO 4-FENILPIPERIDINA-4-

CARBOXILICO)

52. INTERMEDIÁRIO "C" DA PETIDINA (ẢCIDO1-METIL-4-FENILPIPERIDINA-4-CARBOXÍLICO)

53. ISOMETADONA

54. LEVOFENACILMORFANO

55. LEVOMETORFANO

56. LEVOMORAMIDA

57. LEVORFANOL

58. METADONA

59. METAZOCINA

60. METILDESORFINA

61. METILDIIDROMORFINA

62. METOPONA

63. MIROFINA

64. MORFERIDINA

65. MORFINA

66. MORINAMIDA

67. NICOMORFINA

68. NORACILMETADOL

69. NORLEVORFANOL

70. NORMETADONA

71. NORMORFINA

72. NORPIPANONA

73. N-OXICODEINA

74. N-OXIMORFINA

75. ÓPIO

76. OXICODONA

77. OXIMORFONA

78. PETIDINA (MEPERIDINA)

79. PIMINODINA

80. PIRITRAMIDA

81. PROEPTAZINA

82. PROPERIDINA

83. RACEMETORFANO

84. RACEMORAMIDA

85. RACEMORFANO

86. REMIFENTANILA

87. SUFENTANILA

88. TEBACONA (ACETILDIIDROCODEINONA)

89. TEBAINA

90. TILIDINA

91. TRIMEPERIDINA

\section{ADENDO:}

1. ficam também sob controle:

1.1 os sais, éteres, ésteres $\theta$ isômeros (exceto os isômeros dextrometorfano, $(+) 3-m e t o x i-N$-metilmorfinan, e o Dextrorfano, (+) 3-hidroxi-N-metilmorfinan), das substáncias enumeradas acima, sempre que seja possivel a sua existéncia;

1.2 os sais de éteres, ésteres e isômeros (exceto os isômeros dextrometorfano, (+)3-metoxi-Nmetilmorfinan, e - Dextrorfano, (+) 3-hidroxi-N-metilmortinan), das substáncias enumeradas acima, sempre que seja possivel a sua existência. 
2 preparações à base de DIFENOXILATO, contendo por unidade posológica, não mais que 2,5 miligramas de DIFENOXILATO calculado como base, e uma quantidade de Sulfato de Atropina equivalente a, pelo menos, $1,0 \%$ da quantidade de DIFENOXILATO, ficam sujeitas a prescrição da Receita de Controle Especial, em 2 (duas) vias e os dizeres de rotulagem e bula devem apresentar a seguinte frase: "VENDA SOB PRESCRIÇÃO MÉDICA - SÓ PODE SER VENDIDO COM RETENÇÃO DA RECEITA*.

3 preparaçōes à base de ÓPIO, contendo até 5 miligramas de morfina anidra por mililitros ou seja, até 50 miligramas de ÓPIO, ficam sujeitas a prescrição da RECEITA DE CONTROLE ESPECIAL, em 2 (duas) vias e os dizeres de rotulagem e bula devem apresentar a seguinte frase: "VENDA SOB PRESCRIÇÃO MÉDICA SÓ PODE SER VENDIDO COM RETENÇÃO DA RECEITA".

4 fica proibida a comercialização $\theta$ manipulação de todos os medicamentos que contenham ÓPIO e seus derivados sintéticos e CLORIDRATO DE DIFENOXILATO e suas associaçöes, nas formas farmacêuticas líquidas ou em xarope para uso pediátrico (Portaria SVS/MS n. 106 de 14 de setembro de 1994 - DOU 19/9/94).

5 preparações medicamentosas na forma farmacêutica de comprimidos de liberação controlada à base de OXICODONA, contendo não mais que 40 miligramas dessa substância, por unidade posológica, ficam sujeitas a prescrição da RECEITA DE CONTROLE ESPECIAL, em 2 (duas) vias e os dizeres de rotulagem e bula devem apresentar a seguinte frase: "VENDA SOB PRESCRIÇÃO MÉDICA - SÓ PODE SER VENDIDO COM RETENÇÄO DA RECEITA*.

LISTA - A2

LISTA DAS SUBSTÂNCIAS ENTORPECENTES DE USO PERMITIDO SOMENTE EM CONCENTRAÇŌES ESPECIAIS

(Sujeitas a Notificação de Receita "A")
1. ACETILDIIDROCODEINA
2. CODEINA
3. DEXTROPROPOXIFENO
4. DIIDROCODEÍNA
5. ETILMORFINA (DIONINA)
6. FOLCODINA
7. NALBUFINA

\author{
8. NALORFINA \\ 9. NICOCODINA \\ 10. NICODICODINA \\ 11. NORCODEÍNA \\ 12. PROPIRAM \\ 13. TRAMADOL
}

\section{ADENDO:}

1 ficam também sob controle:

1.1 os sais, éteres, ésteres e isômeros das substâncias enumeradas acima, sempre que seja possível a sua existência;

1.2 os sais de éteres, ésteres e isômeros das substâncias enumeradas acima, sempre que seja possivel a sua existência.

2 preparaçöes à baso de ACETILDIIDROCODEINAA, CODEÍNA, DIIDROCODEINA, ETILMORFINA, FOLCODINA, NICODICODINA, NORCODEÍNA, misturadas a um ou mais componentes, em que a quantidade de entorpecentes não exceda 100 miligramas por unidade posológica, e em que a concentração não ultrapasse a 2,5\% nas preparações de formas indivisiveis ficam sujeitas prescrição da Receita de Controle Especial, em 2 (duas) vias e os dizeres de rotulagem e bula devem apresentar a seguinte frase: "VENDA SOB PRESCRIÇÃO MÉDICA -SÓ PODE SER VENDIDO COM RETENÇÃO DA RECEITA ". 3 preparaçס̋ à base de TRAMADOL, misturadas a um ou mais componentes, em que a quantidade não exceda 100 miligramas de TRAMADOL por unidade posológica ficam sujeitas a prescrição da Receita de Controle Especial, em 2 (duas) vias e os dizeres de rotulagem e bula devem apresentar a seguinte frase: "VENDA SOB PRESCRIÇĀO MÉDICA - SÓ PODE SER VENDIDO COM RETENÇÄO DA RECEITA: 4 preparações à base de DEXTROPROPOXIFENO, misturadas a um ou mais componentes, em que a quantidade de entorpecente não exceda 100 miligramas por unidade posológica e em que a concentração não uttrapasse 2,5\% nas preparações indivisiveis, ficam sujeitas a prescrição da Receita de Controle Especial, em 2 (duas) vias e os dizeres de rotulagem e bula devem apresentar a seguinte frase: "VENDA SOB PRESCRIÇÄO MÉDICA - SÓ PODE SER VENDIDO COM RETENÇÄO DA RECEITA *. 5 preparaçöes à base de NALBUFINA, misturadas a um ou mais componentes, em que a quantidade não exceda 10 miligramas de CLORIDRATO DE NALBUFINA por unidade posológica ficam sujeitas a prescrição da Receita de Controle Especial, em 2 (duas) vias $\theta$ os dizeres de rotulagem e bula devem apresentar a seguinte frase: "VENDA SOB PRESCRIÇÃO MÉDICA - SÓ PODE SER VENDIDO COM RETENÇÃO DA RECEITA :

6 preparaçóes à base de PROPIRAM, misturadas a um ou mais componentes, contendo não mais que 100 miligramas de PROPIRAM por unidade posológica e associados, no mínimo, a igual quantidade de metilcelulose, ficam sujeitas a prescrição da Receita de Controle Especial, em 2 (duas) vias $\theta$ os dizeres de rotulagem e bula deverão apresentar a seguinte frase: "VENDA SOB PRESCRIÇÃO MÉDICA - SÓ PODE SER VENDIDO COM RETENÇÄO DA RECEITA : 
LISTA - A3

LISTA DAS SUBSTÂNCIAS PSICOTRÓPICAS

(Sujeita a Notificação de Receita "A")
1. ANFETAMINA
2. CATINA
3. 2CB - ( 4- BROMO-2,5-
DIMETOXIFENILETILAMINA)
4. CLOBENZOREX
5. CLORFENTERMINA
6. DEXANFETAMINA
7. DRONABINOL
ADENDO:

1 ficam também sob controle:

8. FENCICLIDINA

9. FENETILINA

10. FENMETRAZINA

11. LEVANFETAMINA

12. LEVOMETANFETAMINA

13. METANFETAMINA

14. METILFENIDATO

15. TANFETAMINA

1.1 os sais, éteres, ésteres e isômeros das substancias enumeradas acima, sempre que seja possivel a sua existência;

1.2 os sais de éteres, ésteres e isômeros das substâncias enumeradas acima, sempre que seja possivel a sua existéncià.

LISTA - B1

LISTA DAS SUBSTÂNCIAS PSICOTRÓPICAS

(Sujeitas a Notificação de Receita "B")

1. ALOBARBITAL

2. ALPRAZOLAM

3. AMINEPTINA

4. AMOBARBITAL

5. APROBARBITAL

6. BARBEXACLONA

7. BARBITAL

8. BROMAZEPAM

9. BROTIZOLAM

10. BUTALBITAL

11. BUTABARBITAL

12. CAMAZEPAM

13. CETAZOLAM

14. CICLOBARBITAL

15. CLOBAZAM

16. CLONAZEPAM

17. CLORAZEPAM

18. CLORAZEPATO

19. CLORDIAZEPÓXIDO

20. CLORETO DE ETILA

21. CLOTIAZEPAM

22. CLOXAZOLAM

23. DELORAZEPAM

24. DEXMEDETOMIDINA

25. DIAZEPAM

26. ESTAZOLAM

27. ETCLORVINOL

28. ETILANFETAMINA (N-ETILANFETAMINA)

29. ETINAMATO

30. FENOBARBITAL

31. FLUDIAZEPAM

32. FLUNITRAZEPAM

33. FLURAZEPAM

34. GHB - (ÁCIDO GAMA - HIDROXIBUTIRICO)

35. GLUTETIMIDA

36. HALAZEPAM

37. HALOXAZOLAM

38. LEFETAMINA

39. LOFLAZEPATO DE ETILA

40. LOPRAZOLAM

41. LORAZEPAM

42. LORMETAZEPAM

43. MEDAZEPAM

44. MEPROBAMATO

45. MESOCARBO

46. METILFENOBARBITAL (PROMINAL)

47. METIPRILONA

48. MIDAZOLAM

49. NIMETAZEPAM

50. NITRAZEPAM

51. NORCANFANO (FENCANFAMINA)

52. NORDAZEPAM

53. OXAZEPAM

54. OXAZOLAM

55. PEMOLINA

56. PENTAZOCINA

57. PENTOBARBITAL

58. PINAZEPAM

59. PIPRADROL

60. PIROVARELONA

61. PRAZEPAM

62. PROLINTANO

63. PROPILEXEDRINA

64. SECBUTABARBITAL

65. SECOBARBITAL

66. TEMAZEPAM

67. TETRAZEPAM

68. TIAMILAL

69. TIOPENTAL

70. TRIAZOLAM

71. TRIEXIFENIDIL

72. VINILBITAL

73. ZALEPLONA

74. ZOLPIDEM

75. ZOPICLONA

\section{ADENDO:}

1 ficam também sob controle:

1.1. os sais, éteres, ésteres $\theta$ isómeros das substáncias enumeradas acima, sempre que seja possível a sua existência;

1.2. os sais de éteres, ésteres e isômeros das substâncias enumeradas acima, sempre que seja possível a sua existência. 
2 os medicamentos que contenham FENOBARBITAL, METILFENOBARBITAL (PROMINAL), BARBITAL $\theta$ BARBEXACLONA, ficam sujeitos a prescrição da Receita de Controle Especial, em 2 (duas) vias $\theta$ os dizeres de rotulagem e bula devem apresentar a seguinte frase: "VENDA SOB PRESCRIÇÄO MÉDICA - SÓ PODE SER VENDIDO COM RETENÇÄO DA RECEITA*.

3 Em conformidade com a Resolução RDC n ${ }^{\circ} 104$, de 6 de dezembro de 2000 (republicada em 15/12/2000): 3.1. fica proibido o uso do CLORETO DE ETILA para fins médicos, bem como a sua utilização sob a forma de aerosol, aromatizador de ambiente ou de qualquer outra forma que possibilite o seu uso indevido.

3.2. o controle $\theta$ a fiscalização da substância CLORETO DE ETILA, ficam submetidos ao Órgão competente do Ministério da Justiça, de acordo com a Lei no 10.357, de 27 de dezembro de 2001, Lei n. 9.017 , de 30 de março de 1995, Decreto n. ${ }^{\circ}$ 1.646, de 26 de setembro de 1995 e Decreto n. ${ }^{\circ}$.036, de 14 de outubro de 1996.

4 preparaçōes a base de ZOLPIDEM, misturadas a um ou mais componentes, em que a quantidade não exceda 10 miligramas de ZOLPIDEM por unidado posológica ficam sujeitas a prescrição da Receita de Controle Especial, em 2 (duas) vias e os dizeres de rotulagem e bula devem apresentar a seguinte frase: "VENDA SOB PRESCRIÇÃO MÉDICA - SÓ PODE SER VENDIDO COM RETENÇÃO DA RECEITA*.

\section{LISTA - B2}

LISTA DAS SUBSTÂNCIAS PSICOTRÓPICAS ANOREXIGENAS

(Sujeitas a Notificação de Receita "B")
1. AMINOREX
2. ANFEPRAMONA (DIETILPROPIONA)
3. FEMPROPOREX
4. FENDIMETRAZINA

\author{
5. FENTERMINA \\ 6. MAZINDOL \\ 7. MEFENOREX
}

\section{ADENDO:}

1 ficam também sob controle:

1.1. os sais, éteres, ésteres $\theta$ isômeros das substâncias enumeradas acima, sempre que seja possível a sua existência:

1.2. os sais de éteres, ésteres $\theta$ isômeros das substâncias enumeradas acima, sempre que seja possível a sua existência.

LISTA - C1

LISTA DAS OUTRAS SUBSTȦNCIAS SUJEITAS A CONTROLE ESPECIAL

(Sujeitas a Receita de Controle Especial em duas vias)

1. ACEPROMAZINA

2. ÁCIDO VALPRÓICO

3. AMANTADINA

4. AMISSULPRIDA

5. AMITRIPTILINA

6. AMOXAPINA

7. APOMORFINA

8. ARIPIPRAZOL

9. AZACICLONOL

10. BECLAMIDA

11. BENACTIZINA

12. BENFLUOREX

13. BENZOCTAMINA

14. BENZOQUINAMIDA

15. BIPERIDENO

16. BUPROPIONA

17. BUSPIRONA

18. BUTAPERAZINA

19. BUTRIPTILINA

20. CAPTODIAMO

21. CARBAMAZEPINA

22. CAROXAZONA

23. CETAMINA

24. CICLARBAMATO

25. CICLEXEDRINA

26. CICLOPENTOLATO

27. CISAPRIDA

28. CITALOPRAM

29. CLOMACRANO

30. CLOMETIAZOL

31. CLOMIPRAMINA

32. CLOREXADOL
33. CLORPROMAZINA

34. CLORPROTIXENO

35. CLOTIAPINA

36. CLOZAPINA

37. DESFLURANO

38. DESIPRAMINA

39. DEXETIMIDA

40. DIBENZEPINA

41. DIMETRACRINA

42. DISOPIRAMIDA

43. DISSULFIRAM

44. DIVALPROATO DE SÓDIO

45. DIXIRAZINA

46. DONEPEZILA

47. DOXEPINA

48. DROPERIDOL

49. ECTILURÉ|A

50. EMILCAMATO

51. ENFLURANO

52. ESCITALOPRAM

53. ENTACAPONA

54. ETOMIDATO

55. ETOSSUXIMIDA

56. FACETOPERANO

57. FEMPROBAMATO

58. FENAGLICODOL

59. FENELZINA

60. FENIPRAZINA

61. FENITOINA

62. FLUFENAZINA

63. FLUMAZENIL

64. FLUOXETINA 
65. FLUPENTIXOL

66. FLUVOXAMINA

67. GABAPENTINA

68. GALANTAMINA

69. HALOPERIDOL

70. HALOTANO

71. HIDRATO DE CLORAL

72. HIDROCLORBEZETILAMINA

73. HIDROXIDIONA

74. HOMOFENAZINA

75. IMICLOPRAZINA

76. IMIPRAMINA

77. IMIPRAMINÓXIDO

78. IPROCLOZIDA

79. ISOCARBOXAZIDA

80. ISOFLURANO

81. ISOPROPIL-CROTONIL-URÉIA

82. LAMOTRIGINA

83. LEFLUNOMIDA

84. LEVODOPA

85. LEVOMEPROMAZINA

86. LISURIDA

87. LITIO

88. LOPERAMIDA

89. LOXAPINA

90. MAPROTILINA

91. MECLOFENOXATO

92. MEFENOXALONA

93. MEFEXAMIDA

94. MEPAZINA

95. MESORIDAZINA

96. METILPENTINOL

97. METISERGIDA

98. METIXENO

99. METOPROMAZINA

100. METOXIFLURANO

101. MIANSERINA

102. MILNACIPRANO

103. MINAPRINA

104. MIRTAZAPINA

105. MISOPROSTOL

106. MOCLOBEMIDA

107. MOPERONA

108. NALOXONA

109. NALTREXONA

110. NEFAZODONA

111. NIALAMIDA

112. NOMIFENSINA

113. NORTRIPTILINA

114. NOXIPTILINA

115. OLANZAPINA

116. OPIPRAMOL

117. OXCARBAZEPINA

118. OXIBUPROCAÍNA (BENOXINATO)

119. OXIFENAMATO

120. OXIPERTINA
121. PAROXETINA

122. PENFLURIDOL

123. PERFENAZINA

124. PERGOLIDA

125. PERICIAZINA (PROPERICIAZINA)

126. PIMOZIDA

127. PIOGLITAZONA

128. PIPAMPERONA

129. PIPOTIAZINA

130. PRAMIPEXOL

131. PRIMIDONA

132. PROCLORPERAZINA

133. PROMAZINA

134. PROPANIDINA

135. PROPIOMAZINA

136. PROPOFOL

137. PROTIPENDIL

138. PROTRIPTILINA

139. PROXIMETACAINA

140. QUETIAPINA

141. REBOXETINA

142. RIBAVIRINA

143. RISPERIDONA

144. RIVASTIGMINA

145. ROPINIROL

146. SELEGILINA

147. SERTRALINA

148. SEVOFLURANO

149. SIBUTRAMINA

150. SULPIRIDA

151. SULTOPRIDA

152. TACRINA

153. TOLCAPONA

154. TETRACAINA

155. TIANEPTINA

156. TIAPRIDA

157. TIOPROPERAZINA

158. TIORIDAZINA

159. TIOTIXENO

160. TOPIRAMATO

161. TRANILCIPROMINA

162. TRAZODONA

163. TRICLOFÓS

164. TRICLOROETILENO

165. TRIFLUOPERAZINA

166. TRIFLUPERIDOL

167. TRIMIPRAMINA

168. TROGLITAZONA

169. VALPROATO SÓDICO

170. VENLAFAXINA

171. VERALIPRIDA

172. VIGABATRINA

173. ZANAMIVIR

174. ZIPRAZIDONA

175. ZOTEPINA

176. ZUCLOPENTIXOL

ADENDO:

1 ficam também sob controle, todos os sais e isómeros das substâncias enumeradas acima, sempre que seja possivel a sua existência.

2 os medicamentos à base da substância LOPERAMIDA ficam sujeitos a VENDA SOB PRESCRIÇÃO MÉDICA SEM RETENÇĀO DE RECEITA.

3 fica proibido a comercialização e manipulação de todos os medicamentos que contenham LOPERAMIDA ou em associaçōes, nas formas farmacêuticas líquidas ou em xarope para uso pediátrico (Portaria SVS/MS $n .{ }^{\circ} 106$ de 14 de setembro de $1994-D O U$ 19/9/94). 
4 só será permitida a compra e uso do medicamento contendo a substância MISOPROSTOL em estabelecimentos hospitalares devidamente cadastrados junto a Autoridade Sanitária para este fim; 5 os medicamentos à base da substância TETRACAÍNA ficam sujeitos a: (a) VENDA SEM PRESCRIÇÃO MÉDICA - quando tratar-se de preparações farmacêuticas de uso tópico odontológico, não associadas a qualquer outro princípio ativo; (b) VENDA COM PRESCRIÇÃO MÉDICA SEM A RETENÇÃO DE RECEITA quando tratar-se de preparações farmacêuticas de uso tópico ortorinolaringológico, especificamente para Colutórios e Soluções utilizadas no tratamento de Otite Extema e (c) VENDA SOB PRESCRIÇÃO MEDICA COM RETENÇÃO DE RECEITA - quando tratar-se de preparaçőes farmacêuticas de uso tópico oftalmológico.

6 excetuam-se das disposições legais deste Regulamento Técnico as substâncias TRICLOROETILENO, DISSULFIRAM $\theta$ LiTIO (metálico e seus sais), quando, comprovadamente, forem utilizadas para outros fins que não os de efeito à área de saúde, e portanto não estão sujeitos ao controle e físcalização previstos nas Portarias SVS $M$ MS n. ${ }^{\circ} 344 / 98$ e 6/99.

7 as empresas detentoras de registro de medicamentos a base da substância TROGLITAZONA e PIOGLITAZONA ficam obrigadas a proceder o monitoramento clínico e bioquímico dos pacientes que utilizam os referidos medicamentos.

LISTA - C2

LISTA DE SUBSTÂNCIAS RETINÓICAS

(Sujeitas a Notificação de Receita Especial)

1. ACITRETINA

2. ADAPALENO

3. ISOTRETINOINA

4. TRETINOINA

ADENDO:

1 ficam também sob controle, todos os sais e isômeros das substâncias enumeradas acima, sempre que seja possível a sua existência.

2 os medicamentos de uso tópico contendo as substâncias desta lista ficam sujeitos a VENDA SOB

PRESCRIÇÄO MÉDICA SEM RETENÇÄO DE RECEITA.

LISTA - C3

LISTA DE SUBSTÃNCIAS IMUNOSSUPRESSORAS

(Sujeita a Notificação de Receita Especial)

1. FTALIMIDOGLUTARIMIDA (TALIDOMIDA)

ADENDO:

1 ficam tembém sob controle, todos os sais $\theta$ isômeros das substáncias enumeradas acima, sempre que seja possivel a sua existéncia.

LISTA - C4

LISTA DAS SUBSTÂNCIAS ANTI-RETROVIRAIS

(Sujeitas a Receituário do Programa da DST/AIDS ou Sujeitas a Receita de Controle Especial em duas vias)

1. ABACAVIR

2. AMPRENAVIR

3. ATAZANAVIR

4. DELAVIRDINA

5. DIDANOSINA (dd)

6. EFAVIRENZ

7. ESTAVUDINA (d4T)

8. INDINAVIR

9. LAMIVUDINA (3TC)

10. LOPINAVIR

11. NELFINAVIR

12. NEVIRAPINA

13. RITONAVIR

14. SAQUINAVIR

15. TENOFOVIR

16. ZALCITABINA (ddc)

17. ZIDOVUDINA (AZT)

\section{ADENDO:}

1 ficam também sob controle, todos os sais e isômeros das substáncias enumeradas acima, sempre que seja possível a sua existência.

2 os medicamentos à base de substâncias anti-retrovirais acima elencadas, devem ser prescritos em receituário próprio estabelecido pelo Programa de DST/AIDS do Ministério da Saúde, para dispensação nas farmácias hospitalares/ambulatoriais do Sistema Público de Saúdo.

3 os medicamentos à base de substáncias anti-retrovirais acima elencadas, quando dispensados em farmácias e droganias, ficam sujeitos a venda sob Receita de Controle Especial em 2 (duas) vias. 
LISTA - C5

LISTA DAS SUBSTÂNCIAS ANABOLIZANTES

(Sujeitas a Receita de Controle Especial em duas vias)

1. ANDROSTANOLONA

2. BOLASTERONA

3. BOLDENONA

4. CLOROXOMESTERONA

5. CLOSTEBOL

6. DEIDROCLORMETILTESTOSTERONA

7. DROSTANOLONA

8. ESTANOLONA

9. ESTANOZOLOL

10. ETILESTRENOL

11. FLUOXIMESTERONA OU

FLUOXIMETILTESTOSTERONA

12. FORMEBOLONA

13. MESTEROLONA

14. METANDIENONA

15. METANDRANONA

16. METANDRIOL

17. METENOLONA

18. METILTESTOSTERONA

19. MIBOLERONA

20. NANDROLONA

21. NORETANDROLONA

22. OXANDROLONA

23. OXIMESTERONA

24. OXIMETOLONA

25. PRASTERONA

(DEIDROPIANDROSTERONA - DHEA)

26. SOMATROPINA (HORMÔNIO DO

CRESCIMENTO HUMANO)

27. TESTOSTERONA

28. TREMBOLONA

\section{ADENDO:}

1 ficam também sob controle:

1.1 os sais, éteres, ésteres e isômeros das substâncias enumeradas acima, sempre que seja possível a sua existência;

1.2 os sais de éteres, ésteres e isómeros das substâncias enumeradas acima, sempre que seja possível a sua existência.

2 os medicamentos de uso tópico contendo as substâncias desta lista, ficam sujeitos a VENDA SOB

PRESCRIÇĀO MÉDICA SEM RETENÇĀO DE RECEITA.

LISTA - D1

LISTA DE SUBSTÂNCIAS PRECURSORAS DE ENTORPECENTES EJOU PSICOTRÓPICOS

(Sujeitas a Receita Médica sem Retenção)

1. 1-FENIL-2-PROPANONA

2. 3,4 - METILENDIOXIFENIL-2-PROPANONA

3. ACIDO ANTRANILICO

4. ÁCIDO FENILACETICO

5. ÁCIDO LISÉRGICO

6. ÁCIDO N-ACETILANTRANILICO

7. DIIDROERGOTAMINA

8. DIIDROERGOMETRINA

9. EFEDRINA

10. ERGOMETRINA

11. ERGOTAMINA

12. ETAFEDRINA

13. ISOSAFROL

14. ÓLEO DE SASSAFRÁS

15. OLEO DA PIMENTA LONGA

16. PIPERIDINA

17. PIPERONAL

18. PSEUDOEFEDRINA

19. SAFROL

\section{ADENDO:}

1 ficam também sob controle, todos os sais das substâncias enumeradas acima, sempre que seja possivel a sua existência.

2 excetua-se do controle estabelecido nas Portarias SVS/MS n. ${ }^{\circ} 344 / 98$ e 6/99, as formulações não medicamentosas, que contém as substâncias desta lista quando se destinarem a outros seguimentos industriais.

3 bleo de pimenta longa é obtido da extração das folhas e dos talos finos da Piper hispidinervum C.DC., planta nativa da Regiâo Norte do Brasil.

LISTA-D2

LISTA DE INSUMOS QUIMIICOS UTILIZADOS PARA FABRICAÇĀO E SINTESE DE ENTORPECENTES EIOU PSICOTRÓPICOS

(Sujeitos a Controle do Ministério da Justiça)
1. ACETONA
2. ÁCIDO CLORÍDRICO
3. ÁCIDO SULFÚRICO
4. ANIDRIDO ACÉTICO
5. CLORETO DE ETILA
6. CLORETO DE METILENO

7. CLOROFÓRMIO

8. ÉTER ETÍLICO

9. METIL ETIL CETONA

10. PERMANGANATO DE POTÁSSIO

11. SULFATO DE SÓDIO

12. TOLUENO 
ADENDO:

1 produtos e insumos químicos, sujeitos a controle da Polícia Federal, de acordo com a Lei $n^{\circ} 10.357$ de 27/12/2001, Lei n. ${ }^{\circ} 9.017$ de 30/03/1995, Decreto n. ${ }^{\circ} .646$ de 26/09/1995, Decreto n. ${ }^{\circ} 2.036$ de 14/10/1996, Resolução n. ${ }^{\circ} 01 / 95$ de 07/11/1995 e Instrução Normativa $n .^{\circ} 06$ de 25/09/1997;

2 o insumo químico ou substância CLOROFÓRMIO está proibido para uso em medicamentos. 3 o CLORETO DE ETILA, por meio da Resoluçäo $n .^{\circ} 1$, de 5 de fevereiro de 2001, foi incluido na relação de substâncias constatntes do ertigo $1^{\circ}$ da Resolução n. ${ }^{\circ}$ 1-MJ, de 7 de novembro de 1995.

4 quando os insumos desta lista, forem utilizados para fins de fabricação de produtos sujeitos a vigilância sanitária, as empresas devem atender a legis/ação sanitánia específica.

LISTA - E

LISTA DE PLANTAS QUE PODEM ORIGINAR SUBSTÂNCIAS ENTORPECENTES EIOU PSICOTRÓPICAS

1. Cannabis sativa L..

2. Claviceps paspali Stevens \& Hall.

5. Lophophora williamsii Coult.

3. Datura suaveolens Willd.

4. Erythroxylum coca Lam.

6. Papaver Somniferum $L$.

7. Prestonia amazonica J. F. Macbr.

ADENDO:

1 ficam também sob controle, todos os sais e isômeros das substâncias obtidas a partir das plantas elencadas acima.

2 a planta Lophophora williamsii Coult. é comumente conhecida como cacto peyote.

LISTA - $F$

LISTA DAS SUBSTÂNCIAS DE USO PROSCRITO NO BRASIL

LISTA F1 - SUBSTÂNCIAS ENTORPECENTES

1. 3-METILFENTANILA ou N-(3-METIL-1-

(FENETIL-4-PIPERIDIL)PROPIONANILIDA

2. 3-METILTIOFENTANILA ou $N$-[3-METIL-1-[2-

(2-TIENIL)ETIL]-4-PIPERIDILJPROPIONANILIDA

3. ACETIL-ALFA-METILFENTANILA ou N-[1-

(ALFA-METILFENETIL)-4-

PIPERIDILIACETANILIDA

4. ACETORFINA OU 3-O-ACETILTETRAHIDRO-

7-ALFA-11-HIDROXI-1-METILBUTIL)-

6,14-ENDOETENO-ORIPAVINA

5. ALFA-METILFENTANILA OU N-1-(ALFA-

METILFENETIL)-4-PIPERIDIL]PROPIONANILIDA

6. ALFA-METILTIOFENTANILA ou $N$-[1-11-METIL-

2-(2-TIENII)ETIL]-4-

PIPERIDILIPROPIONANILIDA

7. BETA-HIDROXI-3-METILFENTANILA ou N-11-

(BETA-HIDROXIFENETIL)-3-METIL-4-

PIPERIDIL]PROPIONANILIDA

8. BETA-HIDROXIFENTANILA ou $N-1$ - (BETA-

HIDROXIFENETIL)-4-

PIPERIDIL]PROPIONANILIDA
9. CETOBEMIDONA OU 4-META-HIDROXIFENIL1-METIL-4-PROPIONILPIPERIDINA 10. COCAIINA OU ÉSTER METÍLICO DA BENZOILECGONINA

11. DESOMORFINA OU DIIDRODEOXIMORFINA 12. DIIDROETORFINA OU 7,8-DIIDRO-7-ALFA-[1(R)-HIDROXI-1-METILBUTILY-6,14ENDOETANOTERTAHIDROORIPAVINA 13. ECGONINA ou (-)-3-HIDROXITROPANO-2CARBOXILATO

14. ETORFINA OU TETRAHIDRO-7-ALFA-(1HIDROXI-1-METILBUTIL)-6,14ENDOETENO-ORIPAVINA

15. HEROINA OU DIACETILMORFINA 16. MPPP ou 1-METIL-4-FENIL-4-PROPIONATO DE PIPERIDINA (ÉSTER)

17. PARA-FLUOROFENTANILA OU 4'-FLUORON-(1-FENETIL-4-PIPERIDIL])PROPIONANILIDA 18. PEPAP ou 1-FENETIL-4-FENIL-4-ACETATO DE PIPERIDINA (ÉSTER)

19. TIOFENTANILA ou N-[1-[2-(TIENIL)ETIL]-4PIPERIDIL]PROPIONANILIDA

\section{ADENDO:}

1 ficam também sob controle:

1.1.todos os sais $\theta$ isômeros das substâncias enumeradas acima, sempre que seja possível a sua existência. 1.2.todos os ésteres $\theta$ derivados da substância ECGONINA que sejam transformáveis em ECGONINA E COCAINA.

LISTA F2 - SUBSTÃNCIAS PSICOTRÓPICAS 1. (+) - LISÉRGIDA Ou LSD; LSD-25; 9,10DIDEHIDRO-N,N-DIETIL-6-METILERGOLINA8BETA-CARBOXAMIDA

2. 4-METILAMINOREX ou (I)-CIS-2-AMINO-4METIL-5-FENIL-2-OXAZOLINA

3. 4-MTA OU 4-METILTIOANFETAMINA

4. BENZOFETAMINA ou N-BENZIL-N,ALFADIMETILFENETILAMINA
5. BROLANFETAMINA OU DOB; ( \pm -4-BROMO2,5-DIMETOXI-ALFA-METILFENETILAMINA 6. CATINONA ou (-)-(S)-2AMINOPROPIOFENONA

7. DET ou 3-[2-(DIETILAMINO)ETIL]INDOL

8. DMA ou ( \pm )-2,5-DIMETOXI-ALFAMETILFENETILAMINA 
9. DMHP ou 3-(1,2-DIMETILHEPTIL)-7,8,9,10TETRAHIDRO-6,6,9-TRIMETIL-6HDIBENZO B,DIPIRANO-1-OL

10. DMT OU 3-2-(DIMETILAMINO)ETIL] INDOL; $N, N$-DIMETILTRIPTAMINA

11. DOET ou ( \pm )-4-ETIL-2,5-DIMETOXI-ALFAFENETILAMINA

12. ETICICLIDINA OU PCE ; N-ETIL-1FENILCICLOHEXILAMINA

13. ETRIPTAMINA OU 3-(2-AMINOBUTIL)INDOL 14. MDE oU N-ETIL MDA; ( \pm )-N-ETIL-ALFAMETIL-3,4-(METILENEDIOXI)FENETILAMINA 15. MDMA ou ( \pm )-N,ALFA-DIMETIL-3,4(METILENODIOXI)FENETILAMINA; 3,4 METILENODIOXIMETANFETAMINA

16. MECLOQUALONA OU 3-(O-CLOROFENIL)-2METIL-4(3H)-QUINAZOLINONA

17. MESCALINA OU 3,4,5-

TRIMETOXIFENETILAMINA

18. METAQUALONA OU 2-METIL-3-O-TOLIL4(3H)-QUINAZOLINONA

19. METCATINONA OU 2-(METILAMINO)-1FENILPROPAN-L-ONA

20. MMDA OU 2-METOXI-ALFA-METIL-4,5(METILENODIOXI)FENETILAMINA
21. PARAHEXILA ou 3-HEXIL-7,8,9,10TETRAHIDRO-6,6,9-TRIMETIL-6HDIBENZO B,DIPIRANO-1-OL

22. PMA OU P-METOXI-ALFA-

METILFENETILAMINA

23. PSILOCIBINA OU FOSFATO

DIIDROGENADO DE 3-[2-

(DIMETILAMINOETIL)]INDOL-4-ILO

24. PSILOCINA OU PSILOTSINA ; 3-[2-

(DIMETILAMINO)ETIL]INDOL-4-OL

25. ROLICICLIDINA OU PHP; PCPY ; 1-1FENILCICLOHEXILIPIRROLIDINA

26. STP OU DOM ; 2,5-DIMETOXI-ALFA,4-

DIMETILFENETILAMINA

27. TENAMFETAMINA OU MDA; ALFA-METIL3,4-(METILENODIOXI)FENETILAMINA 28. TENOCICLIDINA OU TCP ; 1-[1-(2TIENIL)CICLOHEXIL]PIPERIDINA

29. TETRAHIDROCANNABINOL OU THC

30. TMA ou ( \pm )-3,4,5-TRIMETOXI-ALFAMETILFENETILAMINA

31. ZIPEPROL OU ALFA-(ALFA-METOXIBENZIL)4-(BETA-METOXIFENETIL)-1-

PIPERAZINAETANOL

\section{ADENDO:}

1 ficam também sob controle:

1.1.todos os sais $\theta$ isômeros des substências enumerades acima, sempre que seja possivel a sua existência. 1.2. os seguintes isómeros e suas varientes estereoquímicas da substáncia TETRAHIDROCANNABINOL 7,8,9,10-tetrahidro-6,6,9-trimetil-3-pentil-6H-dibenzo[b,d]pirano-1-ol (9R, 10aR)-8,9,10,10a-tetrahidro-6,6,9 trimetil-3-pentil-6H-dibenzolb, d]pirano-1-ol (6aR,9R, 10aR)-6a,9,10,10a-tetrahidro-6, 6,9-trimetil-3-pentil-6Hdibenzo[b, d]pirano-1-ol (6aR, 10aR)-6a, 7,10, 10a-tetrahidro-6,6,9-trimeti-3-pentil-6H-dibenzo[b, d]pirano-1-ol 6a,7,8,9-etrahidro-6,6,9-trimetil-3-pentil-6H-dibenzo[b,d]pirano-1-ol (6aR, 10aR)-6a, 7, 8, 9,10,10a-hexahidro6,6-dimetil-9-metileno-3-pentil-6H-dibenzolb,d]pirano-1-ol

\section{LISTA F3 - SUBSTÂNCIAS PRECURSORAS}

1. FENILPROPANOLAMINA

ADENDO:

1 ficam também sob controle todos os sais e isômeros das substâncias enumeradas acima, sempre que seja possivel a sua existência.

\section{LISTA F4 - OUTRAS SUBSTÂNCIAS}

1. ESTRICNINA

2. ETRETINATO

3. DEXFENFLURAMINA
4. FENFLURAMINA
5. LINDANO
6. TERFENADINA

\section{ADENDO:}

1 ficam também sob controle todos os sais e isômeros das substâncias enumeradas acima, sempre que seja possivel a sua existência.

2 fica autorizado o uso de LINDANO como preservativo de madeira, sob o controle do Instituto Brasileiro do Meio Ambiente e dos Recursos Neturais Renováveis - IBAMA. 


\section{ANEXO 2 - Prescrições de medicamentos controlados pela P.344}

$D T=$ Dias de tratamento fornecido $\quad L L=$ Limite legal

\begin{tabular}{|c|c|c|c|c|c|c|c|c|c|}
\hline $\begin{array}{l}\text { código } \\
\text { paciente }\end{array}$ & Prescrição & Indústria & Principio Ativo & Alinea & Fornecimento & Posologia & DT & LL & DT $-L L$ \\
\hline Pac2240 & TRYPTANOL & Prodome & amitriptilina & C1 & $20 \mathrm{cp}(25 \mathrm{mg})$ & $0,5 \mathrm{cp} / \mathrm{dia}$ & 40 & 60 & -20 \\
\hline Pac2752 & TEGRETOL & Novartis & carbamazepina & C1 & $60 \mathrm{cp}(200 \mathrm{mg})$ & $2 \mathrm{cp} / \mathrm{dia}$ & 30 & 60 & -30 \\
\hline Pac2752 & amitriptilina & & amitriptilina & C1 & $40 \mathrm{cp}(25 \mathrm{mg})$ & $1 \mathrm{cp} / \mathrm{dia}$ & 40 & 60 & -20 \\
\hline Pac0073 & $\begin{array}{l}\text { codeina; } \\
\text { paracetamol }\end{array}$ & & \begin{tabular}{|l|} 
codeína; \\
paracetamol
\end{tabular} & \begin{tabular}{|c|}
$\begin{array}{c}\mathrm{A} 2- \\
\text { adendo }\end{array}$ \\
\end{tabular} & $90 \mathrm{cp}(30 \mathrm{mg})$ & $3 \mathrm{cp} / \mathrm{dia}$ & 30 & 60 & -30 \\
\hline Pac1355 & carbamazepina & & carbamazepina & C1 & $90 \mathrm{cp}(200 \mathrm{mg})$ & $3 \mathrm{cp} / \mathrm{dia}$ & 30 & 60 & -30 \\
\hline Pac2221 & TRYPTANOL & Prodome & amitriptilina & C1 & $40 \mathrm{cp}$ (25 mg) & $1 \mathrm{cp} / \mathrm{dia}$ & 40 & 60 & -20 \\
\hline Pac2221 & AMPLICTIL & Aventis & clorpromazina & C1 & \begin{tabular}{|l|}
$40 \mathrm{ml}(0,4$ \\
$\mathrm{mg} / \mathrm{ml})$
\end{tabular} & $1 \mathrm{~m} / \mathrm{dia}$ & 40 & 60 & -20 \\
\hline Pac2111 & gabapentina & & gabapentina & C1 & $90 \mathrm{cp}(300 \mathrm{mg})$ & $3 \mathrm{cp} / \mathrm{dia}$ & 30 & 60 & -30 \\
\hline Pac4048 & PROLOPA & Roche & $\begin{array}{l}\text { levodopa } \mathrm{e} \\
\text { benserazida }\end{array}$ & C1 & $120 \mathrm{cp}(250 \mathrm{mg})$ & $4 \mathrm{cp} / \mathrm{dia}$ & 30 & 60 & -30 \\
\hline Pac4048 & amantadina & & amantadina & C1 & $90 \mathrm{cp}(100 \mathrm{mg})$ & $3 \mathrm{cp} / \mathrm{dia}$ & 30 & 60 & -30 \\
\hline Pac1100 & fenobarbital & & fenobarbital & \begin{tabular}{|c|}
$\mathrm{B1}-$ \\
adendo
\end{tabular} & $20 \mathrm{cp}(100 \mathrm{mg})$ & $2 \mathrm{cp} / \mathrm{dia}$ & 10 & 60 & -50 \\
\hline Pac1100 & TRYPTANOL & Prodome & amitriptilina & c1 & $40 \mathrm{cp}(25 \mathrm{mg})$ & $3 \mathrm{cp} / \mathrm{dia}$ & 13 & 60 & -47 \\
\hline Pac1100 & fenitoina & & \begin{tabular}{|l|} 
fenitoina \\
(hidantoina)
\end{tabular} & c1 & $40 \mathrm{cp}(100 \mathrm{mg})$ & $3 \mathrm{cp} / \mathrm{dia}$ & 13 & 60 & -47 \\
\hline Pac1987 & fluoxetina & & fluoxetina & C1 & $40 \mathrm{cp}(20 \mathrm{mg})$ & $1 \mathrm{cp} / \mathrm{dia}$ & 40 & 60 & -20 \\
\hline Pac3600 & amitriptilina & & amitriptilina & C1 & $20 \mathrm{cp}(25 \mathrm{mg})$ & $0,5 \mathrm{cp} / \mathrm{dia}$ & 40 & 60 & -20 \\
\hline Pac2306 & $\begin{array}{l}\text { codeina; } \\
\text { paracetamol }\end{array}$ & & \begin{tabular}{|l|} 
codeina; \\
paracetamol
\end{tabular} & \begin{tabular}{c|} 
A2 - \\
adendo
\end{tabular} & $120 \mathrm{cp}(30 \mathrm{mg})$ & $4 \mathrm{cp} / \mathrm{dia}$ & 30 & 60 & -30 \\
\hline Pac2306 & LORAX & Wyeth & lorazepam & B1 & $30 \mathrm{cp}(100 \mathrm{mg})$ & $1 \mathrm{cp} / \mathrm{dia}$ & 30 & 60 & -30 \\
\hline Pac3321 & $\begin{array}{l}\text { codeína; } \\
\text { paracetamol }\end{array}$ & & \begin{tabular}{|l|} 
codeina; \\
paracetamol
\end{tabular} & \begin{tabular}{|c|}
$A 2-$ \\
adendo
\end{tabular} & $120 \mathrm{cp}$ (30 mg) & $4 \mathrm{cp} / \mathrm{dia}$ & 30 & 60 & -30 \\
\hline Pac2191 & fenobarbital & & fenobarbital & \begin{tabular}{|c|}
$\begin{array}{c}\text { B1 - } \\
\text { adendo }\end{array}$ \\
\end{tabular} & $20 \mathrm{cp}(100 \mathrm{mg})$ & $1 \mathrm{cp} / \mathrm{dia}$ & 20 & 60 & -40 \\
\hline Pac2191 & HIDANTAL & Aventis & \begin{tabular}{|l|} 
fenitoina \\
(hidantoina)
\end{tabular} & C1 & $30 \mathrm{cp}(100 \mathrm{mg})$ & $3 \mathrm{cp} / \mathrm{dia}$ & 10 & 60 & -50 \\
\hline Pac0569 & $\begin{array}{l}\text { codeína; } \\
\text { paracetamol }\end{array}$ & & \begin{tabular}{|l|} 
codeina: \\
paracetamol
\end{tabular} & \begin{tabular}{|c|}
$\begin{array}{c}\text { A2 - } \\
\text { adendo }\end{array}$ \\
\end{tabular} & $60 \mathrm{cp}$ (30 mg) & $4 \mathrm{cp} / \mathrm{dia}$ & 15 & 60 & -45 \\
\hline Pac3307 & $\begin{array}{l}\text { codeina; } \\
\text { paracetamol }\end{array}$ & & \begin{tabular}{|l|} 
codeina; \\
paracetamol
\end{tabular} & \begin{tabular}{c|} 
A2 - \\
adendo
\end{tabular} & $80 \mathrm{cp}$ (30 mg) & $4 \mathrm{cp} / \mathrm{dia}$ & 20 & 60 & -40 \\
\hline Pac1452 & fenobarbital & & fenobarbital & \begin{tabular}{c|c|}
$\begin{array}{c}B 1 \text { : } \\
\text { adendo }\end{array}$ \\
\end{tabular} & $90 \mathrm{cp}(100 \mathrm{mg})$ & $3 \mathrm{cp} / \mathrm{dia}$ & 30 & 60 & -30 \\
\hline Pac0453 & $\begin{array}{l}\text { codeína; } \\
\text { paracetamol }\end{array}$ & & $\begin{array}{l}\text { codeina; } \\
\text { paracetamol }\end{array}$ & \begin{tabular}{c|}
$\mathrm{A} 2-$ \\
adendo
\end{tabular} & $30 \mathrm{cp}(30 \mathrm{mg})$ & $3 \mathrm{cp} / \mathrm{dia}$ & 10 & 60 & -50 \\
\hline Pac1401 & carbamazepina & & carbamazepina & C1 & $120 \mathrm{cp}(200 \mathrm{mg})$ & $3 \mathrm{cp} / \mathrm{dia}$ & 40 & 60 & -20 \\
\hline Pac2990 & IXEL & Asta Módica & milnaciprana & C1 & $90 \mathrm{cp}(50 \mathrm{mg})$ & $3 \mathrm{cp} / \mathrm{dia}$ & 30 & 60 & -30 \\
\hline Pac2764 & TMEX & Janssen-Cilag & \begin{tabular}{|l|} 
codeina; \\
paracetamol
\end{tabular} & \begin{tabular}{|c|}
$\mathrm{A} 2$ - \\
adendo
\end{tabular} & $90 \mathrm{cp}(7,5 \mathrm{mg})$ & $3 \mathrm{cp} / \mathrm{dia}$ & 30 & 60 & -30 \\
\hline Pac2059 & amitriptilina & & amitriptilina & $\mathrm{C}_{1}$ & $20 \mathrm{cp}(25 \mathrm{mg})$ & $1 \mathrm{cp} / \mathrm{dia}$ & 20 & 60 & -40 \\
\hline Pac1097 & amitriptilina & & amitriptilina & C1 & $40 \mathrm{cp}(25 \mathrm{mg})$ & $1 \mathrm{cp} / \mathrm{dia}$ & 40 & 60 & -20 \\
\hline Pac0734 & sertralina & & sertralina & $\mathrm{C} 1$ & $30 \mathrm{cp}(50 \mathrm{mg})$ & $1 \mathrm{cp} / \mathrm{dia}$ & 30 & 60 & -30 \\
\hline Pac1942 & PROLOPA & Roche & \begin{tabular}{|l|} 
levodopa e \\
benserazida
\end{tabular} & C1 & $90 \mathrm{cp}(250 \mathrm{mg})$ & $3 \mathrm{cp} / \mathrm{dia}$ & 30 & 60 & -30 \\
\hline Pac0361 & $\begin{array}{l}\text { codeina; } \\
\text { paracetamol }\end{array}$ & & $\begin{array}{l}\text { codeina; } \\
\text { paracetamol }\end{array}$ & \begin{tabular}{|c|}
$\begin{array}{c}\text { A2 - } \\
\text { adendo }\end{array}$ \\
\end{tabular} & $90 \mathrm{cp}(30 \mathrm{mg})$ & $3 \mathrm{cp} / \mathrm{dia}$ & 30 & 60 & -30 \\
\hline Pac1528 & sertralina & & sertralina & $C 1$ & $30 \mathrm{cp}(50 \mathrm{mg})$ & $1 \mathrm{cp} / \mathrm{dia}$ & 30 & 60 & -30 \\
\hline Pac1025 & TRAMAL & $\begin{array}{l}\text { Pfizer- } \\
\text { Pharmacia }\end{array}$ & tramadol & \begin{tabular}{c|c|}
$\begin{array}{c}A 2- \\
\text { adendo }\end{array}$ \\
\end{tabular} & $60 \mathrm{cp}(50 \mathrm{mg})$ & $6 \mathrm{cp} / \mathrm{dia}$ & 10 & 60 & -50 \\
\hline Pac0145 & TRYPTANOL & Prodome & amitriptilina & C1 & $40 \mathrm{cp}(25 \mathrm{mg})$ & $1 \mathrm{cp} / \mathrm{dia}$ & 40 & 60 & -20 \\
\hline Pac0095 & carbamazepina & & carbamazepina & C1 & $60 \mathrm{cp}(200 \mathrm{mg})$ & 2 cp/dia & 30 & 60 & 30 \\
\hline Pac0095 & amitriptilina & & amitriptilina & C1 & $40 \mathrm{cp}(25 \mathrm{mg})$ & $1 \mathrm{cp} / \mathrm{dia}$ & 40 & 60 & -20 \\
\hline Pac0095 & $\begin{array}{l}\text { codeina; } \\
\text { paracetamol }\end{array}$ & & \begin{tabular}{|l|} 
codelna; \\
paracetamol
\end{tabular} & $\begin{array}{c}\text { A2 - } \\
\text { adendo }\end{array}$ & $120 \mathrm{cp}(30 \mathrm{mg})$ & $4 \mathrm{cp} / \mathrm{dia}$ & 30 & 60 & -30 \\
\hline
\end{tabular}


$\mathrm{DT}=$ Dias de tratamento fornecido $\quad \mathrm{LL}=$ Limite legal

\begin{tabular}{|c|c|c|c|c|c|c|c|c|c|}
\hline $\begin{array}{l}\text { código } \\
\text { paciente }\end{array}$ & Prescriçāo & Indústria & Principio Ativo & Alinea & Fornecimento & Posologia & DT & LL & DT $-L L$ \\
\hline Pac1550 & amitriptilina & & amitriptilina & C1 & $40 \mathrm{cp}(25 \mathrm{mg})$ & $1 \mathrm{cp} / \mathrm{dia}$ & 40 & 60 & -20 \\
\hline Pac1719 & amitriptilina & & amitriptilina & C1 & $120 \mathrm{cp}(100 \mathrm{mg})$ & $4 \mathrm{cp} / \mathrm{dia}$ & 30 & 60 & -30 \\
\hline Pac3508 & sertralina & & sertralina & C1 & $30 \mathrm{cp}$ (50 mg) & $1 \mathrm{cp} / \mathrm{dia}$ & 30 & 60 & -30 \\
\hline Pac2810 & TRYPTANOL & Prodome & amitriptilina & $\mathrm{C}_{1}$ & $40 \mathrm{cp}$ (25 mg) & $1 \mathrm{cp} / \mathrm{dia}$ & 40 & 60 & -20 \\
\hline Pac0403 & gabapentina & & gabapentina & C1 & $60 \mathrm{cp}(300 \mathrm{mg})$ & $2 \mathrm{cp} / \mathrm{dia}$ & 30 & 60 & -30 \\
\hline $\mathrm{Pac0403}$ & $\begin{array}{l}\text { codeina; } \\
\text { paracetamol }\end{array}$ & & $\begin{array}{l}\text { codeina: } \\
\text { paracetamol }\end{array}$ & $\begin{array}{c}\mathrm{A2}- \\
\text { adendo }\end{array}$ & $120 \mathrm{cp}(30 \mathrm{mg})$ & 4 cpldia & 30 & 60 & -30 \\
\hline Pac0403 & AMPLICTIL & Aventis & clorpromazina & C1 & $\begin{array}{l}20 \mathrm{ml}(0,4 \\
\mathrm{mg} / \mathrm{ml})\end{array}$ & $0,15 \mathrm{~m}$ /dia & 133 & 60 & 73 \\
\hline Pac3690 & fluoxetina & & fluoxetina & $C_{1}$ & $40 \mathrm{cp}(20 \mathrm{mg})$ & $1 \mathrm{cp} / \mathrm{dia}$ & 40 & 60 & -20 \\
\hline Pac3554 & DEPAKENE & Abbott & $\begin{array}{l}\text { ácido valpróico } \\
\text { (ou derivado) }\end{array}$ & $\mathrm{Ct}$ & $50 \mathrm{cp}(250 \mathrm{mg})$ & $1 \mathrm{cp} / \mathrm{dia}$ & 50 & 60 & -10 \\
\hline Pac3554 & DEPAKENE & Abbott & $\begin{array}{l}\text { ácido valpróico } \\
\text { (ou derivado) }\end{array}$ & C1 & $50 \mathrm{cp}(500 \mathrm{mg})$ & $1 \mathrm{cp} / \mathrm{dia}$ & 50 & 60 & -10 \\
\hline Pac0448 & carbamazepina & & carbamazepina & c1 & $50 \mathrm{cp}(200 \mathrm{mg})$ & $1 \mathrm{cp} / \mathrm{dia}$ & 50 & 60 & -10 \\
\hline Pac1716 & TRAMAL & $\begin{array}{l}\text { Pfizer- } \\
\text { Pharmacia }\end{array}$ & tramadol & \begin{tabular}{c|} 
A2 - \\
adendo
\end{tabular} & $30 \mathrm{cp}(50 \mathrm{mg})$ & $3 \mathrm{cp} / \mathrm{dia}$ & 10 & 60 & -50 \\
\hline Pac3144 & morfina & & morfina & A1 & $180 \mathrm{cp}(10 \mathrm{mg})$ & $6 \mathrm{cp} / \mathrm{dia}$ & 30 & 30 & 0 \\
\hline Pac3144 & amilriptilina & & amitriptilina & C1 & $60 \mathrm{cp}(25 \mathrm{mg})$ & $2 \mathrm{cp} / \mathrm{dia}$ & 30 & 60 & -30 \\
\hline Pac0800 & carbamazepina & & carbamazepina & C1 & $60 \mathrm{cp}(200 \mathrm{mg})$ & $2 \mathrm{cp} / \mathrm{dia}$ & 30 & 60 & -30 \\
\hline Pac1827 & $\begin{array}{l}\text { codeina; } \\
\text { paracetamol }\end{array}$ & & \begin{tabular}{|l} 
codeina; \\
paracetamol
\end{tabular} & \begin{tabular}{|c|} 
A2 - \\
adendo
\end{tabular} & $120 \mathrm{cp}(30 \mathrm{mg})$ & $4 \mathrm{cp} / \mathrm{dia}$ & 30 & 60 & -30 \\
\hline Pac1827 & amitriplilina & & amitriptilina & C1 & $60 \mathrm{cp}(25 \mathrm{mg})$ & $2 \mathrm{cp} / \mathrm{dia}$ & 30 & 60 & -30 \\
\hline Pac2268 & $\begin{array}{l}\text { codeina; } \\
\text { paracetamol }\end{array}$ & & \begin{tabular}{|l} 
codeina: \\
paracetamol
\end{tabular} & \begin{tabular}{|c|}
$\begin{array}{c}\text { A2 - } \\
\text { adendo }\end{array}$ \\
\end{tabular} & $50 \mathrm{cp}(30 \mathrm{mg})$ & $5 \mathrm{cp} / \mathrm{dia}$ & 10 & 60 & -50 \\
\hline Pac3978 & NIAR & Knoll & selegilina & C1 & $40 \mathrm{cp}(5 \mathrm{mg})$ & $1 \mathrm{cp} / \mathrm{dia}$ & 40 & 60 & -20 \\
\hline Pac4054 & $\begin{array}{l}\text { codeína; } \\
\text { paracetamol }\end{array}$ & & \begin{tabular}{|l} 
codeina; \\
paracetamol
\end{tabular} & \begin{tabular}{c|} 
A2 - \\
adendo
\end{tabular} & $120 \mathrm{cp}(30 \mathrm{mg})$ & $4 \mathrm{cp} / \mathrm{dia}$ & 30 & 60 & -30 \\
\hline Pac2310 & diazepam & & diazepam & B1 & $60 \mathrm{cp}(10 \mathrm{mg})$ & $2 \mathrm{cp} / \mathrm{dia}$ & 30 & 60 & -30 \\
\hline Pac2571 & clobazam & & clobazam & B1 & $60 \mathrm{cp}$ (10 mg) & $2 \mathrm{cp} / \mathrm{dia}$ & 30 & 60 & -30 \\
\hline Pac2942 & morfina & & morfina & A1 & $30 \mathrm{cp}(30 \mathrm{mg})$ & $4 \mathrm{cp} / \mathrm{dia}$ & 8 & 30 & -23 \\
\hline Pac0792 & SONEBON & Sigma Pharma & nitrazepam & B1 & $90 \mathrm{cp}(5 \mathrm{mg})$ & $3 \mathrm{cp} / \mathrm{dia}$ & 30 & 60 & -30 \\
\hline Pac3528 & URBANIL & Aventis & clobazam & B1 & $60 \mathrm{cp}(10 \mathrm{mg})$ & $2 \mathrm{cp} / \mathrm{dia}$ & 30 & 60 & -30 \\
\hline Pac2054 & clonazepam & & clonazepam & B1 & $60 \mathrm{cp}(2 \mathrm{mg})$ & $1,5 \mathrm{cp} / \mathrm{dia}$ & 40 & 60 & -20 \\
\hline Pac0060 & URBANIL & Aventis & clobazam & B1 & $40 \mathrm{cp}(10 \mathrm{mg})$ & $1 \mathrm{cp} / \mathrm{dia}$ & 40 & 60 & -20 \\
\hline Pac0732 & FRISIUM & Aventis & clobazam & B1 & $100 \mathrm{cp}(20 \mathrm{mg})$ & $1,5 \mathrm{cp} / \mathrm{dia}$ & 67 & 60 & 7 \\
\hline Pac1247 & clobazam & & clobazam & B1 & $40 \mathrm{cp}(10 \mathrm{mg})$ & $1 \mathrm{cp} / \mathrm{dia}$ & 40 & 60 & -20 \\
\hline Pac1960 & clobazam & & clobazam & B1 & $60 \mathrm{cp}(10 \mathrm{mg})$ & $2 \mathrm{cp} / \mathrm{dia}$ & 30 & 60 & -30 \\
\hline Pac1816 & diazepam & & diazepam & B1 & $60 \mathrm{cp}(10 \mathrm{mg})$ & $2 \mathrm{cp} / \mathrm{dia}$ & 30 & 60 & -30 \\
\hline Pac2579 & clobazam & & clobazam & B1 & $160 \mathrm{cp}(10 \mathrm{mg})$ & $5 \mathrm{cp} / \mathrm{dia}$ & 32 & 60 & -28 \\
\hline Pac2621 & clobazam & & clobazam & B1 & $60 \mathrm{cp}(10 \mathrm{mg})$ & $2 \mathrm{cp} / \mathrm{dia}$ & 30 & 60 & -30 \\
\hline Pac2636 & FRISIUM & Aventis & clobazam & B1 & $100 \mathrm{cp}$ (10 mg) & $3 \mathrm{cp} / \mathrm{dia}$ & 33 & 60 & -27 \\
\hline Pac3764 & URBANIL & Aventis & clobazam & B1 & $60 \mathrm{cp}(10 \mathrm{mg})$ & $2 \mathrm{cp} / \mathrm{dia}$ & 30 & 60 & 30 \\
\hline Pac1268 & nitrazepam & & nitrazepam & B1 & $60 \mathrm{cp}(5 \mathrm{mg})$ & $2 \mathrm{cp} / \mathrm{dia}$ & 30 & 60 & -30 \\
\hline Pac0467 & diazepam & & diazepam & B1 & $90 \mathrm{cp}(10 \mathrm{mg})$ & $3 \mathrm{cp} / \mathrm{dia}$ & 30 & 60 & -30 \\
\hline Pac3903 & diazepam & & diazepam & B1 & $30 \mathrm{cp}(10 \mathrm{mg})$ & $1 \mathrm{cp} / \mathrm{dia}$ & 30 & 60 & -30 \\
\hline Pac2939 & RIVOTRIL & Roche & clonazepam & B1 & $20 \mathrm{cp}(2 \mathrm{mg})$ & $0,5 \mathrm{cp} / \mathrm{dia}$ & 40 & 60 & -20 \\
\hline Pac0158 & nitrazepam & & nitrazepam & B1 & $210 \mathrm{cp}(5 \mathrm{mg})$ & $7 \mathrm{cp} / \mathrm{dia}$ & 30 & 60 & -30 \\
\hline Pac1957 & RIVOTRIL & Roche & clonazepam & B1 & $100 \mathrm{cp}(2 \mathrm{mg})$ & $3 \mathrm{cp} / \mathrm{dia}$ & 33 & 60 & -27 \\
\hline Pac2023 & diazepam & & diazepam & B1 & $90 \mathrm{cp}(10 \mathrm{mg})$ & $3 \mathrm{cp} / \mathrm{dia}$ & 30 & 60 & -30 \\
\hline Pac0795 & FRISIUM & Aventis & clobazam & B1 & $180 \mathrm{cp} \mathrm{(10} \mathrm{mg)}$ & $6 \mathrm{cp} / \mathrm{dia}$ & 30 & 60 & -30 \\
\hline Pac3587 & URBANL & Aventis & clobazam & B1 & $40 \mathrm{cp}(10 \mathrm{mg})$ & $1 \mathrm{cp} / \mathrm{dia}$ & 40 & 60 & -20 \\
\hline Pac1877 & nitrazepam & & nitrazepam & B1 & $120 \mathrm{cp}(5 \mathrm{mg})$ & $4 \mathrm{cp} / \mathrm{dia}$ & 30 & 60 & -30 \\
\hline Pac0141 & RIVOTRIL & Roche & clonazepam & B1 & $100 \mathrm{cp}(2 \mathrm{mg})$ & $3 \mathrm{cp} / \mathrm{dia}$ & 33 & 60 & -27 \\
\hline
\end{tabular}


$D T=$ Dias de tratamento fornecido $\quad L L=$ Limite legal

\begin{tabular}{|c|c|c|c|c|c|c|c|c|c|}
\hline $\begin{array}{l}\text { código } \\
\text { paciente }\end{array}$ & Prescrição & Indústria & Principio Ativo & Alinea & Fornecimento & Posologia & DT & LL & DT - LL \\
\hline Pac1113 & FRISIUM & Aventis & clobazam & 81 & $100 \mathrm{cp}(10 \mathrm{mg})$ & $3 \mathrm{cp} / \mathrm{dia}$ & 33 & 60 & -27 \\
\hline Pac2664 & clobazam & & clobazam & B1 & $100 \mathrm{cp}(10 \mathrm{mg})$ & $3 \mathrm{cp} / \mathrm{dia}$ & 33 & 60 & -27 \\
\hline Pac1537 & diazepam & & diazepam & B1 & $30 \mathrm{cp}(10 \mathrm{mg})$ & $1 \mathrm{cp} / \mathrm{dia}$ & 30 & 60 & -30 \\
\hline Pac2844 & diazepam & & diazepam & B1 & $30 \mathrm{cp}(10 \mathrm{mg})$ & $1 \mathrm{cp} / \mathrm{dia}$ & 30 & 60 & -30 \\
\hline Pac0313 & diazepam & & diazepam & B1 & $30 \mathrm{cp}(10 \mathrm{mg})$ & $1 \mathrm{cp} / \mathrm{dia}$ & 30 & 60 & -30 \\
\hline Pac4033 & URBANIL & Aventis & clobazam & B1 & $40 \mathrm{cp}(10 \mathrm{mg})$ & $1 \mathrm{cp} / \mathrm{dia}$ & 40 & 60 & -20 \\
\hline Pac3977 & DIMORF & Cristália & morina & A1 & $120 \mathrm{cp}(10 \mathrm{mg})$ & $4 \mathrm{cp} / \mathrm{dia}$ & 30 & 30 & 0 \\
\hline Pac2029 & morfina & & morfina & A1 & $120 \mathrm{cp}(30 \mathrm{mg})$ & $4 \mathrm{cp} / \mathrm{dia}$ & 30 & 30 & 0 \\
\hline Pac1595 & morfina & & morfina & A1 & $60 \mathrm{cp}(10 \mathrm{mg})$ & $2 \mathrm{cp} / \mathrm{dia}$ & 30 & 30 & 0 \\
\hline Pac2032 & RIVOTRIL & Roche & clonazepam & B1 & $100 \mathrm{cp}(2 \mathrm{mg})$ & $3 \mathrm{cp} / \mathrm{dia}$ & 33 & 60 & -27 \\
\hline Pac3418 & lluoxetina & & fuoxelina & C1 & $60 \mathrm{cp}(20 \mathrm{mg})$ & $3 \mathrm{cp} / \mathrm{dia}$ & 20 & 60 & -40 \\
\hline Pac1513 & $\begin{array}{l}\text { codeina; } \\
\text { paracetamol }\end{array}$ & & $\begin{array}{l}\text { codeína; } \\
\text { paracetamol }\end{array}$ & \begin{tabular}{|c|}
$\begin{array}{c}\text { A2 - } \\
\text { adendo }\end{array}$ \\
\end{tabular} & $30 \mathrm{cp}(30 \mathrm{mg})$ & $3 \mathrm{cp} / \mathrm{dia}$ & 10 & 60 & -50 \\
\hline Pac1977 & TRAMAL & $\begin{array}{l}\text { Pfizer- } \\
\text { Pharmacia }\end{array}$ & tramadol & $\begin{array}{c}\mathrm{A} 2- \\
\text { adendo }\end{array}$ & $30 \mathrm{cp}(50 \mathrm{mg})$ & $3 \mathrm{cp} / \mathrm{dia}$ & 10 & 60 & -50 \\
\hline Pac2911 & amitriptilina & & amitriptilina & $\mathrm{C1}$ & $60 \mathrm{cp}(25 \mathrm{mg})$ & $1 \mathrm{cp} / \mathrm{dia}$ & 60 & 60 & 0 \\
\hline Pac2768 & AMYTRIL & Cristália & amitriptilina & c1 & $15 \mathrm{cp}(25 \mathrm{mg})$ & $0,5 \mathrm{cp} / \mathrm{dia}$ & 30 & 60 & -30 \\
\hline Pac2768 & ARAVA & Aventis & leflunomida & C1 & $30 \mathrm{cp}(20 \mathrm{mg})$ & $1 \mathrm{cp} / \mathrm{dia}$ & 30 & 60 & -30 \\
\hline Pac0233 & fluoxeting & & fluoxetina & $\mathrm{Cl}$ & $40 \mathrm{cp}(20 \mathrm{mg})$ & $1 \mathrm{cp} / \mathrm{dia}$ & 40 & 60 & -20 \\
\hline Pac3542 & amitriptilina & & amitriptilina & C1 & $100 \mathrm{cp}(25 \mathrm{mg})$ & $3 \mathrm{cp} / \mathrm{dia}$ & 33 & 60 & -27 \\
\hline Pac3542 & AMPLICTIL & Aventis & clorpromazina & C1 & \begin{tabular}{|l|}
$20 \mathrm{ml}(0,4$ \\
$\mathrm{mg} / \mathrm{ml})$
\end{tabular} & $0,45 \mathrm{~m} / \mathrm{dia}$ & 44 & 60 & -16 \\
\hline Pac0911 & amitriptilina & & amitriptilina & C1 & $60 \mathrm{cp}(25 \mathrm{mg})$ & $2 \mathrm{cp} / \mathrm{dia}$ & 30 & 60 & -30 \\
\hline Pac2955 & TRAMAL & $\begin{array}{l}\text { Pfizer- } \\
\text { Pharmacia }\end{array}$ & framadol & $\begin{array}{c}\text { A2 - } \\
\text { adendo }\end{array}$ & $30 \mathrm{cp}(50 \mathrm{mg})$ & $3 \mathrm{cp} / \mathrm{dia}$ & 10 & 60 & -50 \\
\hline Pac0603 & amitriptilina & & amitriptitina & C1 & $20 \mathrm{cp}(25 \mathrm{mg})$ & $3 \mathrm{cp} / \mathrm{dia}$ & 7 & 60 & -53 \\
\hline Pac2832 & $\begin{array}{l}\text { DORLESS- } \\
\text { TRAMADOL }\end{array}$ & Uniāo Quimica & tramadol & $\begin{array}{c}\begin{array}{c}A 2- \\
\text { adendo }\end{array} \\
\end{array}$ & $30 \mathrm{cp}(50 \mathrm{mg})$ & $3 \mathrm{cp} / \mathrm{dia}$ & 10 & 60 & -50 \\
\hline Pac0960 & ANAFRANIL & Novartis & clomipramina & C1 & $60 \mathrm{cp} \mathrm{(25} \mathrm{mg)}$ & $1 \mathrm{cp} / \mathrm{dia}$ & 60 & 60 & 0 \\
\hline Pac0859 & sertralina & & sertralina & C1 & $9 \mathrm{cp}(50 \mathrm{mg})$ & $3 \mathrm{cp} / \mathrm{dia}$ & 3 & 60 & -57 \\
\hline Pac1994 & amitriptilina & & amitriptilina & C1 & $40 \mathrm{cp}(25 \mathrm{mg})$ & 1 cpidia & 40 & 60 & -20 \\
\hline Pac2471 & amitriptilina & & amitriptilina & C1 & $40 \mathrm{cp}$ (25 mg) & $1 \mathrm{cp} / \mathrm{dia}$ & 40 & 60 & -20 \\
\hline Pac1320 & fluoxetina & & Aluoxetina & C1 & $40 \mathrm{cp}(20 \mathrm{mg})$ & $1 \mathrm{cp} / \mathrm{dia}$ & 40 & 60 & -20 \\
\hline Pac1258 & carbamazepina & & carbamazepina & C1 & $120 \mathrm{cp}(200 \mathrm{mg})$ & $3.5 \mathrm{cp} / \mathrm{dia}$ & 34 & 60 & -26 \\
\hline Pac3370 & gabapentina & & gabapentina & C1 & $90 \mathrm{cp}(300 \mathrm{mg})$ & $3 \mathrm{cp} / \mathrm{dia}$ & 30 & 60 & -30 \\
\hline Pac3370 & amitriptitina & & amitriptilina & C1 & $40 \mathrm{cp}(25 \mathrm{mg})$ & $1 \mathrm{cp} / \mathrm{dia}$ & 40 & 60 & -20 \\
\hline Pac2892 & amitriptilina & & amitriptilina & C1 & $60 \mathrm{cp}(25 \mathrm{mg})$ & $2 \mathrm{cp} / \mathrm{dia}$ & 30 & 60 & -30 \\
\hline Pac2892 & fenobarbital & & fenobarbital & \begin{tabular}{|c|} 
B1 - \\
adendo
\end{tabular} & $40 \mathrm{cp}(100 \mathrm{mg})$ & $1 \mathrm{cp} / \mathrm{dia}$ & 40 & 60 & -20 \\
\hline Pac0846 & tramadol & & tramadot & \begin{tabular}{|c|}
$\mathrm{A} 2-$ \\
adendo
\end{tabular} & $120 \mathrm{cp}(50 \mathrm{mg})$ & $4 \mathrm{cp} / \mathrm{dia}$ & 30 & 60 & -30 \\
\hline Pac1537 & imipramina & & imipramina & C1 & $90 \mathrm{cp}(25 \mathrm{mg})$ & $3 \mathrm{cp} / \mathrm{dia}$ & 30 & 60 & -30 \\
\hline Pac3611 & DEPAKENE & Abbott & $\begin{array}{l}\text { ácido valpróico } \\
\text { (ou derivado) }\end{array}$ & C1 & $\begin{array}{l}100 \mathrm{ml}(50 \\
\mathrm{mg} / \mathrm{ml})\end{array}$ & $16 \mathrm{ml} / \mathrm{dia}$ & 6 & 60 & -54 \\
\hline Pac1892 & TRYPTANOL & Prodome & amitriptitina & C1 & $40 \mathrm{cp}$ (25 mg) & $1 \mathrm{cp} / \mathrm{dia}$ & 40 & 60 & -20 \\
\hline Pac2535 & TRAMAL & $\begin{array}{l}\text { Pfizer- } \\
\text { Pharmacia }\end{array}$ & tramadol & \begin{tabular}{c|}
$\begin{array}{c}A 2- \\
\text { adendo }\end{array}$ \\
\end{tabular} & $20 \mathrm{cp}(50 \mathrm{mg})$ & $3 \mathrm{cp} / \mathrm{dia}$ & 7 & 60 & -53 \\
\hline Pac2489 & $\begin{array}{l}\text { DORLESS- } \\
\text { TRAMADOL }\end{array}$ & Uniăo Quimica & tramadol & \begin{tabular}{|c|} 
A2 - \\
adendo
\end{tabular} & $60 \mathrm{cp}(50 \mathrm{mg})$ & $4 \mathrm{cpldia}$ & 15 & 60 & -45 \\
\hline Pac4082 & $\begin{array}{l}\text { codeina; } \\
\text { paracetamol }\end{array}$ & & $\begin{array}{l}\text { codeina; } \\
\text { paracetamol }\end{array}$ & \begin{tabular}{|c|}
$\mathrm{A} 2-$ \\
adendo
\end{tabular} & $30 \mathrm{cp}(30 \mathrm{mg})$ & $3 \mathrm{cp} / \mathrm{dia}$ & 10 & 60 & -50 \\
\hline Pac20033777 & $\begin{array}{l}\text { codeina; } \\
\text { paracetamol }\end{array}$ & & $\begin{array}{l}\text { codeina; } \\
\text { paracetamol }\end{array}$ & \begin{tabular}{|c|}
$\mathrm{A} 2-$ \\
adendo
\end{tabular} & $10 \mathrm{cp}(30 \mathrm{mg})$ & $3 \mathrm{cp} / \mathrm{dia}$ & 3 & 60 & -57 \\
\hline Pac4059 & LONGACTIL & Cristália & clorpromazina & C1 & $\begin{array}{l}60 \mathrm{ml}(0.4 \\
\mathrm{mg} / \mathrm{ml})\end{array}$ & $1.5 \mathrm{ml} / \mathrm{dia}$ & 40 & 60 & -20 \\
\hline Pac1315 & TRAMAL & $\begin{array}{l}\text { Plizer- } \\
\text { Pharmacia }\end{array}$ & tramadol & \begin{tabular}{|c|}
$\begin{array}{c}\text { A2 - } \\
\text { adendo }\end{array}$ \\
\end{tabular} & $40 \mathrm{cp}(50 \mathrm{mg})$ & $4 \mathrm{cp} / \mathrm{dia}$ & 10 & 60 & -50 \\
\hline Pac3206 & gabapentina & & gabapentina & C1 & $30 \mathrm{cp}(300 \mathrm{mg})$ & $1 \mathrm{cp} / \mathrm{dia}$ & 30 & 60 & -30 \\
\hline
\end{tabular}


$D T=$ Dias de tratamento fornecido $\quad L L=$ Limite legal

\begin{tabular}{|c|c|c|c|c|c|c|c|c|c|}
\hline $\begin{array}{l}\text { código } \\
\text { paciente }\end{array}$ & Prescrição & Indústria & Principio Ativo & Alinea & Fornecimento & Posologia & DT & LL & DT $-L L$ \\
\hline Pac3206 & amitriptilina & & amilriptilina & c1 & $40 \mathrm{cp}(25 \mathrm{mg})$ & $1 \mathrm{cp} / \mathrm{dia}$ & 40 & 60 & -20 \\
\hline Pac3919 & GARDENAL & Aventis & fenobarbital & \begin{tabular}{|c|} 
B1 - \\
adendo
\end{tabular} & $80 \mathrm{cp}(100 \mathrm{mg})$ & $2 \mathrm{cp} / \mathrm{dia}$ & 40 & 60 & -20 \\
\hline Pac0917 & carbamazepina & & carbamazepina & $c_{1}$ & $90 \mathrm{cp}(200 \mathrm{mg})$ & $3 \mathrm{cp} / \mathrm{dia}$ & 30 & 60 & -30 \\
\hline Pac3424 & $\begin{array}{l}\text { DORLESS- } \\
\text { TRAMADOL }\end{array}$ & Uniảo Quimica & tramadol & \begin{tabular}{c|}
$\begin{array}{c}A 2- \\
\text { adendo }\end{array}$ \\
\end{tabular} & $120 \mathrm{cp}(50 \mathrm{mg})$ & $4 \mathrm{cp} / \mathrm{dia}$ & 30 & 60 & -30 \\
\hline Pac3587 & DEPAKENE & Abbott & $\begin{array}{l}\text { ácido valpróico } \\
\text { (ou derivado) }\end{array}$ & C1 & $100 \mathrm{cp}(500 \mathrm{mg})$ & $3 \mathrm{cp} / \mathrm{dia}$ & 33 & 60 & -27 \\
\hline Pac1594 & LONGACTIL & Cristália & clorpromazina & C1 & $\begin{array}{l}20 \mathrm{ml}(0,4 \\
\mathrm{mg} / \mathrm{ml})\end{array}$ & $0,4 \mathrm{~m} / \mathrm{dia}$ & 50 & 60 & -10 \\
\hline Pac1594 & AMYTRIL & Cristália & amitriptilina & C1 & $20 \mathrm{cp}(25 \mathrm{mg})$ & $1 \mathrm{cp} / \mathrm{dia}$ & 20 & 60 & -40 \\
\hline Pac1594 & morlina & & morfina & A1 & $60 \mathrm{cp}$ (10 mg) & $6 \mathrm{cp} / \mathrm{dia}$ & 10 & 30 & -20 \\
\hline Pac2713 & AMYTRIL & Cristália & amitriptilina & $\overline{c 1}$ & $40 \mathrm{cp} \mathrm{(25} \mathrm{mg)}$ & $1 \mathrm{cp} / \mathrm{dia}$ & 40 & 60 & -20 \\
\hline Pac3558 & fenobarbital & & fenobarbital & \begin{tabular}{|c|}
$\begin{array}{c}\mathrm{B1}- \\
\text { adendo }\end{array}$ \\
\end{tabular} & $60 \mathrm{cp}(100 \mathrm{mg})$ & $2 \mathrm{cp} / \mathrm{dia}$ & 30 & 60 & -30 \\
\hline Pac3558 & carbamazepina & & carbamazepina & C1 & $240 \mathrm{cp}(200 \mathrm{mg})$ & $8 \mathrm{cp} / \mathrm{dia}$ & 30 & 60 & -30 \\
\hline Pac1233 & amitriptilina & & amitriplilina & C1 & $100 \mathrm{cp}(25 \mathrm{mg})$ & $3 \mathrm{cp} / \mathrm{dia}$ & 33 & 60 & -27 \\
\hline Pac3813 & amitriptilina & & amitriplitina & C1 & $60 \mathrm{cp}(25 \mathrm{mg})$ & $2 \mathrm{cp} / \mathrm{dia}$ & 30 & 60 & 30 \\
\hline Pac2621 & TRILEPTAL & Novartis & oxcarbazepina & C1 & $\begin{array}{l}200 \mathrm{ml}(40 \\
\mathrm{mg} / \mathrm{ml})\end{array}$ & $2 \mathrm{~m} / \mathrm{dia}$ & 100 & 60 & 40 \\
\hline Pac3450 & fenobarbital & & renobarbital & \begin{tabular}{|c|}
$\mathrm{B1}-$ \\
adendo
\end{tabular} & $60 \mathrm{cp}(100 \mathrm{mg})$ & $2 \mathrm{cp} / \mathrm{dia}$ & 30 & 60 & -30 \\
\hline Pac3450 & fenitoina & & $\begin{array}{l}\text { fenitoina } \\
\text { (hidantoina) }\end{array}$ & C1 & $75 \mathrm{cp}(100 \mathrm{mg})$ & $3 \mathrm{cp} / \mathrm{dia}$ & 25 & 60 & -35 \\
\hline Pac3436 & fluoxetina & & fluoxetina & C1 & $40 \mathrm{cp}(20 \mathrm{mg})$ & $1 \mathrm{cp} / \mathrm{dia}$ & 40 & 60 & -20 \\
\hline Pac1158 & TYLEX & Janssen-Cilag & $\begin{array}{l}\text { codeína; } \\
\text { paracetamol }\end{array}$ & \begin{tabular}{|c|} 
A2 - \\
adendo
\end{tabular} & $120 \mathrm{cp}(7,5 \mathrm{mg})$ & $4 \mathrm{cp} / \mathrm{dia}$ & 30 & 60 & -30 \\
\hline Pac3464 & TRAMAL & $\begin{array}{l}\text { Pfzer- } \\
\text { Pharmacia }\end{array}$ & tramadol & \begin{tabular}{|c|}
$\begin{array}{c}\text { A2 - } \\
\text { adendo }\end{array}$ \\
\end{tabular} & $30 \mathrm{cp}(50 \mathrm{mg})$ & $3 \mathrm{cp} / \mathrm{dia}$ & 10 & 60 & -50 \\
\hline Pac30032 & sertralina & & sertralina & C1 & $30 \mathrm{cp}$ (50 mg) & 1 cp/dia & 30 & 60 & -30 \\
\hline Pac3219 & TRILEPTAL & Novartis & oxcarbazepina & C1 & $90 \mathrm{cp}(300 \mathrm{mg})$ & $3 \mathrm{cp} / \mathrm{dia}$ & 30 & 60 & -30 \\
\hline Pac0996 & sertralina & & sertralina & C1 & $60 \mathrm{cp}(50 \mathrm{mg})$ & $1 \mathrm{cp} / \mathrm{dia}$ & 60 & 60 & 0 \\
\hline Pac0158 & carbamazepina & & carbamazepina & C1 & $290 \mathrm{cp}(200 \mathrm{mg})$ & $9,5 \mathrm{cp} / \mathrm{dia}$ & 31 & 60 & -29 \\
\hline Pac0158 & nitrazepam & & nitrazepam & $\overline{\text { B1 }}$ & $210 \mathrm{cp} \mathrm{(5} \mathrm{mg)}$ & $7 \mathrm{cp} / \mathrm{dia}$ & 30 & 60 & 30 \\
\hline Pac1951 & LONGACTIL & Cristália & clorpromazina & $c_{1}$ & \begin{tabular}{|l|}
$40 \mathrm{ml}(0,4$ \\
$\mathrm{mg} / \mathrm{mi})$
\end{tabular} & $0,6 \mathrm{mV} / \mathrm{dia}$ & 67 & 60 & 7 \\
\hline Pac1951 & carbamazepina & & carbamazepina & C1 & $160 \mathrm{cp}(200 \mathrm{mg})$ & $4 \mathrm{cp} / \mathrm{dia}$ & 40 & 60 & -20 \\
\hline Pac1951 & OXYCONTIN & Zodiac & oxicodona & A1 & $80 \mathrm{cp}(20 \mathrm{mg})$ & $2 \mathrm{cp} / \mathrm{dia}$ & 40 & 30 & 10 \\
\hline Pac1951 & AMYTRIL & Cristália & amitriptilina & C1 & $80 \mathrm{cp}(25 \mathrm{mg})$ & $2 \mathrm{cp} / \mathrm{dia}$ & 40 & 60 & -20 \\
\hline Pac2469 & $\begin{array}{l}\text { codeina; } \\
\text { paracetamol }\end{array}$ & $:$ & $\begin{array}{l}\text { codeína; } \\
\text { paracetamol }\end{array}$ & \begin{tabular}{|c|}
$A 2-$ \\
adendo
\end{tabular} & $90 \mathrm{cp}(30 \mathrm{mg})$ & $3 \mathrm{cp} / \mathrm{dia}$ & 30 & 60 & -30 \\
\hline Pac2546 & TRAMAL & $\begin{array}{l}\text { Pfizer- } \\
\text { Pharmacia }\end{array}$ & tramadol & \begin{tabular}{|c|}
$\begin{array}{c}\mathrm{A} 2- \\
\text { adendo }\end{array}$ \\
\end{tabular} & $90 \mathrm{cp}(50 \mathrm{mg})$ & $3 \mathrm{cp} / \mathrm{dia}$ & 30 & 60 & -30 \\
\hline Pac2054 & AKINETON & Knoll & biperideno & C1 & $150 \mathrm{cp}(2 \mathrm{mg})$ & $5 \mathrm{cp} / \mathrm{dia}$ & 30 & 60 & -30 \\
\hline Pac3352 & fenitoina & & $\begin{array}{l}\text { fenitoina } \\
\text { (hidantoina) }\end{array}$ & C1 & $90 \mathrm{cp}(100 \mathrm{mg})$ & $3 \mathrm{cp} / \mathrm{dia}$ & 30 & 60 & -30 \\
\hline Pac2515 & sertralina & & sertralina & C1 & $60 \mathrm{cp}(50 \mathrm{mg})$ & 2 cp/dia & 30 & 60 & -30 \\
\hline Pac1705 & $\begin{array}{l}\text { codeina; } \\
\text { paracetamol }\end{array}$ & & $\begin{array}{l}\text { codeina; } \\
\text { paracetamol }\end{array}$ & \begin{tabular}{|c|} 
A2 - \\
adendo \\
\end{tabular} & $30 \mathrm{cp}(30 \mathrm{mg})$ & 3 cpldia & 10 & 60 & -50 \\
\hline Pac0279 & \begin{tabular}{|l} 
codeina; \\
paracetamol
\end{tabular} & & $\begin{array}{l}\text { codeina; } \\
\text { paracetamol }\end{array}$ & \begin{tabular}{|c|}
$\begin{array}{c}\mathrm{A} 2- \\
\text { adendo }\end{array}$ \\
\end{tabular} & $40 \mathrm{cp}(30 \mathrm{mg})$ & $4 \mathrm{cp} / \mathrm{dia}$ & 10 & 60 & -50 \\
\hline Pac1688 & carbamazepina & & carbamazepina & C1 & $180 \mathrm{cp}$ (200 mg) & $6 \mathrm{cp} / \mathrm{dia}$ & 30 & 60 & -30 \\
\hline Pac2389 & Iestosterona & & testosterona & C5 & 0 ct $(0,05 \mathrm{mg} / \mathrm{g})$ & ct/dia & & 60 & \\
\hline Pac2590 & $\begin{array}{l}\text { codeina; } \\
\text { paracetamol }\end{array}$ & & \begin{tabular}{|l} 
codeina; \\
paracetamol
\end{tabular} & \begin{tabular}{c|}
$\mathrm{A} 2-$ \\
adendo
\end{tabular} & $60 \mathrm{cp}(30 \mathrm{mg})$ & $2 \mathrm{cp} / \mathrm{dia}$ & 30 & 60 & -30 \\
\hline Pac2539 & fluoxetina & & fluoxetina & C1 & $60 \mathrm{cp}(20 \mathrm{mg})$ & $2 \mathrm{cp} / \mathrm{dia}$ & 30 & 60 & -30 \\
\hline Pac3140 & Ienitolna & & $\begin{array}{l}\begin{array}{l}\text { fenitoina } \\
\text { (hidantoina) }\end{array} \\
\end{array}$ & C1 & $90 \mathrm{cp}(100 \mathrm{mg})$ & 3 cpidia & 30 & 60 & -30 \\
\hline Pac0677 & DEPAKENE & Abbott & $\begin{array}{l}\text { acido valpróico } \\
\text { (ou derivado) }\end{array}$ & C1 & $100 \mathrm{cp}(500 \mathrm{mg})$ & $4 \mathrm{cp} / \mathrm{dia}$ & 25 & 60 & -35 \\
\hline Pac1623 & fenobarbital & & fenobarbital & $\begin{array}{c}\begin{array}{c}\text { B1 - } \\
\text { adendo }\end{array} \\
\end{array}$ & $40 \mathrm{cp}(100 \mathrm{mg})$ & $1 \mathrm{cp} / \mathrm{dia}$ & 40 & 60 & -20 \\
\hline
\end{tabular}


DT = Dias de tratamento fornecido $\quad L L=$ Limite legal

\begin{tabular}{|c|c|c|c|c|c|c|c|c|c|}
\hline $\begin{array}{l}\text { código } \\
\text { paciente }\end{array}$ & Prescrição & Indústria & Principio Ativo & Alinea & Fornecimento & Posologia & DT & LL & DT $-\mathrm{LL}$ \\
\hline Pac2242 & carbamazepina & & carbamazepina & C1 & $80 \mathrm{cp}(200 \mathrm{mg})$ & $2,5 \mathrm{cp} / \mathrm{dia}$ & 32 & 60 & -28 \\
\hline Pac3583 & carbamazepina & & carbamazepina & C1 & $90 \mathrm{cp}(200 \mathrm{mg})$ & $3 \mathrm{cp} / \mathrm{dia}$ & 30 & 60 & -30 \\
\hline Pac2923 & fluoxetina & & fluoxetina & C1 & $40 \mathrm{cp}(20 \mathrm{mg})$ & $1 \mathrm{cp} / \mathrm{dia}$ & 40 & 60 & -20 \\
\hline Pac1384 & \begin{tabular}{|l} 
codeina; \\
paracetarnol
\end{tabular} & & \begin{tabular}{|l} 
codeina; \\
paracetamol
\end{tabular} & \begin{tabular}{|c|}
$\mathbf{A} 2-$ \\
adendo
\end{tabular} & $30 \mathrm{cp}(30 \mathrm{mg})$ & $3 \mathrm{cp} / \mathrm{dia}$ & 10 & 60 & -50 \\
\hline Pac1384 & AMVTRIL & Cristália & amitriptilina & C1 & $40 \mathrm{cp}(25 \mathrm{mg})$ & $1 \mathrm{cp} / \mathrm{dia}$ & 40 & 60 & -20 \\
\hline Pac1942 & pramipexol & & pramipexol & c1 & $\begin{array}{l}180 \mathrm{cp}(0,25 \\
\mathrm{mg})\end{array}$ & $6 \mathrm{cp} / \mathrm{dia}$ & 30 & 60 & -30 \\
\hline Pac1662 & NEULEPTIL & Aventis & periciazina & C1 & $\begin{array}{l}20 \mathrm{ml}(0,4 \\
\mathrm{mg} / \mathrm{mi})\end{array}$ & $0,15 \mathrm{ml} / \mathrm{dia}$ & 133 & 60 & 73 \\
\hline Pac2958 & sertralina & & sertralina & C1 & $90 \mathrm{cp}(50 \mathrm{mg})$ & $3 \mathrm{cp} / \mathrm{dia}$ & 30 & 60 & -30 \\
\hline Pac2974 & AROPAX & GlaxoSmithKline & paroxetina & C1 & $30 \mathrm{cp}$ (20 mg) & $1 \mathrm{cp} / \mathrm{dia}$ & 30 & 60 & -30 \\
\hline Pac1114 & TRAMAL & $\begin{array}{l}\text { Pfizer- } \\
\text { Pharmacia }\end{array}$ & tramadol & \begin{tabular}{c|} 
A2 - \\
adendo
\end{tabular} & $60 \mathrm{cp}(50 \mathrm{mg})$ & $3 \mathrm{cp} / \mathrm{dia}$ & 20 & 60 & -40 \\
\hline Pac1846 & sertralina & & sertralina & C1 & $60 \mathrm{cp}(50 \mathrm{mg})$ & $2 \mathrm{cp} / \mathrm{dia}$ & 30 & 60 & -30 \\
\hline Pac1267 & DEPAKENE & Abbott & $\begin{array}{l}\text { ácido vaipróico } \\
\text { (ou derivado) }\end{array}$ & C1 & $\begin{array}{l}200 \mathrm{ml}(50 \\
\mathrm{mg} / \mathrm{ml})\end{array}$ & $6 \mathrm{~m} / \mathrm{dia}$ & 33 & 60 & -27 \\
\hline Pac4063 & carbamazepina & & carbamazepina & c1 & $90 \mathrm{cp}(200 \mathrm{mg})$ & $3 \mathrm{cp} / \mathrm{dia}$ & 30 & 60 & -30 \\
\hline Pac4063 & TRYPTANOL & Prodome & amitriptilina & C1 & $40 \mathrm{cp}(25 \mathrm{mg})$ & $1 \mathrm{cp} / \mathrm{dia}$ & 40 & 60 & -20 \\
\hline Pac0344 & sertralina & & sertralina & C1 & $120 \mathrm{cp}(50 \mathrm{mg})$ & $1 \mathrm{cp} / \mathrm{dia}$ & 120 & 60 & 60 \\
\hline Pac1507 & AMVTRIL & Cristália & amitriptitina & C1 & $14 \mathrm{cp}(25 \mathrm{mg})$ & $1 \mathrm{cp} / \mathrm{dia}$ & 14 & 60 & -46 \\
\hline Pac2154 & TRYPTANOL & Prodome & amitriptilina & C1 & $40 \mathrm{cp}(25 \mathrm{mg})$ & $1 \mathrm{cp} / \mathrm{dia}$ & 40 & 60 & -20 \\
\hline Pac3387 & EPILENIL & Biolab-Sanus & \begin{tabular}{|l|}
$\begin{array}{l}\text { ácido valpróico } \\
\text { (ou derivado) }\end{array}$ \\
\end{tabular} & C1 & $\begin{array}{l}300 \mathrm{ml}(50 \\
\mathrm{mg} / \mathrm{ml})\end{array}$ & $8 \mathrm{~m}$ Vdia & 38 & 60 & -23 \\
\hline Pac0300 & DAFORIN & Sigma Pharma & Ruoxelina & C1 & $60 \mathrm{cp}(20 \mathrm{mg})$ & $2 \mathrm{cp} / \mathrm{dia}$ & 30 & 60 & -30 \\
\hline Pac0531 & primidona & & primidona & C1 & $90 \mathrm{cp}(250 \mathrm{mg})$ & $3 \mathrm{cp} / \mathrm{dia}$ & 30 & 60 & -30 \\
\hline Pac1421 & loperamida & & loperarnida & \begin{tabular}{|c|}
$\mathbf{C l}-$ \\
adendo
\end{tabular} & $180 \mathrm{cp}(2 \mathrm{mg})$ & $6 \mathrm{cp} / \mathrm{dia}$ & 30 & sem & \\
\hline Pac0733 & cartamazepina & & carbamazepina & C1 & $140 \mathrm{cp}(200 \mathrm{mg})$ & $4,5 \mathrm{cp} / \mathrm{dia}$ & 31 & 60 & -29 \\
\hline Pac3764 & carbamazepina & & carbamazepina & C1 & $240 \mathrm{cp}(200 \mathrm{mg})$ & $8 \mathrm{cp} / \mathrm{dia}$ & 30 & 60 & -30 \\
\hline Pac3764 & URBANIL & Aventis & clobazam & B1 & $30 \mathrm{cp}(20 \mathrm{mg})$ & $1 \mathrm{cp} / \mathrm{dia}$ & 30 & 60 & -30 \\
\hline Pac1021 & carbamazepina & & carbamazepina & C1 & $120 \mathrm{cp}(200 \mathrm{mg})$ & $4 \mathrm{cp} / \mathrm{dia}$ & 30 & 60 & -30 \\
\hline Pac1021 & fenitoina & & \begin{tabular}{|l|l} 
fenitoina \\
(hidantoina)
\end{tabular} & C1 & $100 \mathrm{cp}(100 \mathrm{mg})$ & $3 \mathrm{cp} / \mathrm{dia}$ & 33 & 60 & -27 \\
\hline Pac2460 & carbamazepina & & carbamazepina & C1 & $180 \mathrm{cp}(200 \mathrm{mg})$ & $6 \mathrm{cp} / \mathrm{dia}$ & 30 & 60 & -30 \\
\hline Pac3350 & fenobarbital & & fenotarbital & \begin{tabular}{|c|}
$\mathbf{B 1}-$ \\
adendo
\end{tabular} & $40 \mathrm{cp}(100 \mathrm{mg})$ & $1 \mathrm{cp} / \mathrm{dia}$ & 40 & 60 & -20 \\
\hline Pac2174 & DAFORIN & Sigma Pharma & fluoxetina & c1 & $40 \mathrm{cp}(20 \mathrm{mg})$ & $1 \mathrm{cp} / \mathrm{dia}$ & 40 & 60 & -20 \\
\hline Pac2639 & TOPAMAX & Janssen-Cilag & topiramato & $\mathrm{Cl}_{1}$ & $60 \mathrm{cp}(25 \mathrm{mg})$ & $2 \mathrm{cp} / \mathrm{dia}$ & 30 & 60 & -30 \\
\hline Pac2639 & amitriptilina & & amitriptilina & c1 & $60 \mathrm{cp}(25 \mathrm{mg})$ & $1 \mathrm{cp} / \mathrm{dia}$ & 60 & 60 & 0 \\
\hline Pac2534 & amitriptilina & & amitriptilina & $c_{1}$ & $40 \mathrm{cp}(25 \mathrm{mg})$ & $1 \mathrm{cp} / \mathrm{dia}$ & 40 & 60 & -20 \\
\hline Pac0797 & fluoxetina & & fluoxetina & C1 & $60 \mathrm{cp}(20 \mathrm{mg})$ & $2 \mathrm{cp} / \mathrm{dia}$ & 30 & 60 & -30 \\
\hline Pac3903 & AMYTRIL & Cristália & amitriptilina & C1 & $40 \mathrm{cp}(25 \mathrm{mg})$ & $1 \mathrm{cp} / \mathrm{dia}$ & 40 & 60 & -20 \\
\hline Pac1425 & carbamazepina & & carbamazepina & $\mathrm{Cl}_{1}$ & $90 \mathrm{cp} \mathrm{(200} \mathrm{mg)}$ & $3 \mathrm{cp} / \mathrm{dia}$ & 30 & 60 & -30 \\
\hline Pac0767 & sertralina & & sertralina & C1 & $60 \mathrm{cp}(50 \mathrm{mg})$ & 2 cp/dia & 30 & 60 & -30 \\
\hline Pac1277 & $\begin{array}{l}\text { codeina; } \\
\text { paracetamol }\end{array}$ & & $\begin{array}{l}\text { codeina; } \\
\text { paracetamol }\end{array}$ & \begin{tabular}{c|}
$\begin{array}{c}A 2- \\
\text { adendo }\end{array}$ \\
\end{tabular} & $120 \mathrm{cp}(30 \mathrm{mg})$ & $4 \mathrm{cp} / \mathrm{dia}$ & 30 & 60 & 30 \\
\hline Pac0289 & sertralina & & sertralina & C1 & $30 \mathrm{cp}(50 \mathrm{mg})$ & $1 \mathrm{cp} / \mathrm{dia}$ & 30 & 60 & -30 \\
\hline Pac0335 & sertralina & & sertralina & c1 & $30 \mathrm{cp}(50 \mathrm{mg})$ & $1 \mathrm{cp} / \mathrm{dia}$ & 30 & 60 & -30 \\
\hline Pac1497 & imipramina & & imipramina & $\mathrm{Ct}$ & $90 \mathrm{cp}(25 \mathrm{mg})$ & $3 \mathrm{cp} / \mathrm{dia}$ & 30 & 60 & -30 \\
\hline Pac2286 & carbarnazepina & & carbamazepina & $c 1$ & $180 \mathrm{cp}(200 \mathrm{mg})$ & $6 \mathrm{cp}$ idia & 30 & 60 & -30 \\
\hline Pac2516 & AMYTRIL & Cristália & amitriptilina & c1 & $40 \mathrm{cp}(25 \mathrm{mg})$ & $1 \mathrm{cp} / \mathrm{dia}$ & 40 & 60 & -20 \\
\hline Pac3776 & nuoxetina & & fluoxetina & C1 & $40 \mathrm{cp}(20 \mathrm{mg})$ & $1 \mathrm{cp} / \mathrm{dia}$ & 40 & 60 & -20 \\
\hline Pac0377 & DAFORIN & Sigma Pharma & fluoxetina & C1 & $10 \mathrm{cp}(20 \mathrm{mg})$ & $3 \mathrm{cp} / \mathrm{dia}$ & 3 & 60 & -57 \\
\hline
\end{tabular}


$D T=$ Dias de tratamento fornecido $\quad L L=$ Limite lega!

\begin{tabular}{|c|c|c|c|c|c|c|c|c|c|}
\hline $\begin{array}{l}\text { código } \\
\text { paciente }\end{array}$ & Prescrição & Indústria & Principio Ativo & Alinea & Fornecimento & Posologia & DT & $\mathbf{L L}$ & OT - LL \\
\hline Pac1487 & sertralina & & sertralina & C1 & $30 \mathrm{cp}(50 \mathrm{mg})$ & $1 \mathrm{cp} / \mathrm{dia}$ & 30 & 60 & -30 \\
\hline Pac3643 & AMYTRIL & Cristália & amitriptilina & C1 & $60 \mathrm{cp}(25 \mathrm{mg})$ & $2 \mathrm{cp} / \mathrm{dia}$ & 30 & 60 & -30 \\
\hline Pac4059 & AMYTRIL & Cristália & amitriptilina & c1 & $60 \mathrm{cp}(25 \mathrm{mg})$ & $2 \mathrm{cp} / \mathrm{dia}$ & 30 & 60 & -30 \\
\hline Pac4059 & TOPAMAX & Janssen-Cilag & topiramato & $c 1$ & $30 \mathrm{cp}(25 \mathrm{mg})$ & $1 \mathrm{cp} / \mathrm{dia}$ & 30 & 60 & -30 \\
\hline Pac1561 & AMYTRIL & Cristália & amitriptilina & $c 1$ & $60 \mathrm{cp}(25 \mathrm{mg})$ & $2 \mathrm{cp} / \mathrm{dia}$ & 30 & 60 & -30 \\
\hline Pac2379 & amitriptitina & & amitriptilina & c1 & $40 \mathrm{cp}(25 \mathrm{mg})$ & $1 \mathrm{cp} / \mathrm{dia}$ & 40 & 60 & -20 \\
\hline Pac3372 & LONGACTIL & Cristália & clorpromazina & C1 & $2 \mathrm{amp}(25 \mathrm{mg})$ & \begin{tabular}{|l|}
0,0475 \\
amp/dia
\end{tabular} & 42 & 60 & -18 \\
\hline Pac0918 & carbamazepina & & carbamazepina & $\mathrm{Ct}$ & $90 \mathrm{cp}(200 \mathrm{mg})$ & $3 \mathrm{cp} / \mathrm{dia}$ & 30 & 60 & -30 \\
\hline Pac3430 & carbamazepina & & carbamazepina & C1 & $120 \mathrm{cp}(200 \mathrm{mg})$ & $4 \mathrm{cp} / \mathrm{dia}$ & 30 & 60 & -30 \\
\hline Pac3686 & AMYTRIL & Cristália & amitriptilina & C1 & $40 \mathrm{cp}(25 \mathrm{mg})$ & $1 \mathrm{cp} / \mathrm{dia}$ & 40 & 60 & -20 \\
\hline Pac0935 & TRAMAL & $\begin{array}{l}\text { Pfizer- } \\
\text { Pharmacia }\end{array}$ & tramadol & $\begin{array}{c}\text { A2 - } \\
\text { adendo }\end{array}$ & $30 \mathrm{cp}(50 \mathrm{mg})$ & $3 \mathrm{cp} / \mathrm{dia}$ & 10 & 60 & -50 \\
\hline Pac0451 & amitriptilina & & amitriptilina & $c t$ & $40 \mathrm{cp}(25 \mathrm{mg})$ & $1 \mathrm{cp} / \mathrm{dia}$ & 40 & 60 & -20 \\
\hline Pac0395 & imipramina & & imipramina & $\mathrm{Cl}$ & $90 \mathrm{cp}(25 \mathrm{mg})$ & $3 \mathrm{cp} / \mathrm{dia}$ & 30 & 60 & -30 \\
\hline Pac1152 & amitriptilina & & amitriptilina & c1 & $40 \mathrm{cp}(25 \mathrm{mg})$ & 1 cpidia & 40 & 60 & -20 \\
\hline Pac2738 & fenobarbital & & fenobarbital & $\begin{array}{c}\text { B1 - } \\
\text { adendo }\end{array}$ & $6 \mathrm{cp}(100 \mathrm{mg})$ & $2 \mathrm{cp} / \mathrm{dia}$ & 3 & 60 & -57 \\
\hline Pac2738 & carbamazepina & & carbamazepina & C1 & $90 \mathrm{cp}(200 \mathrm{mg})$ & $3 \mathrm{cp} / \mathrm{dia}$ & 30 & 60 & -30 \\
\hline Pac2511 & $\begin{array}{l}\text { DORLESS- } \\
\text { TRAMADOL }\end{array}$ & Uniăo Quimica & tramadol & $\begin{array}{c}\text { A2 - } \\
\text { adendo }\end{array}$ & $90 \mathrm{cp}(50 \mathrm{mg})$ & $4 \mathrm{cp} / \mathrm{dia}$ & 23 & 60 & -38 \\
\hline Pac1484 & LORALERG-D & Farmasa & $\begin{array}{l}\text { loraladina; } \\
\text { pseudoefedrina }\end{array}$ & D1 & $60 \mathrm{ml}(10 \mathrm{mg})$ & $10 \mathrm{~m}$ Udia & 6 & & \\
\hline Pac1278 & $\begin{array}{l}\text { codeina; } \\
\text { paracetamol }\end{array}$ & & $\begin{array}{l}\text { codeina; } \\
\text { paracetamol }\end{array}$ & $\begin{array}{c}\text { A2 - } \\
\text { adendo }\end{array}$ & $90 \mathrm{cp}(30 \mathrm{mg})$ & $3 \mathrm{cp} / \mathrm{dia}$ & 30 & 60 & -30 \\
\hline Pac0307 & fluoxetina & & fluoxetina & C1 & $60 \mathrm{cp}(20 \mathrm{mg})$ & $2 \mathrm{cp} / \mathrm{dia}$ & 30 & 60 & -30 \\
\hline Pac1438 & carbamazepina & & carbamazepina & C1 & $110 \mathrm{cp}(250 \mathrm{mg})$ & $3,5 \mathrm{cp} / \mathrm{dia}$ & 31 & 60 & -29 \\
\hline Pac3846 & carbamazepina & & cartamazepina & C1 & $150 \mathrm{cp}$ (200 mg) & $5 \mathrm{cp} / \mathrm{dia}$ & 30 & 60 & -30 \\
\hline Pac2023 & fenobarbital & & fenobarbital & $\begin{array}{c}\text { B1 - } \\
\text { adendo }\end{array}$ & $100 \mathrm{cp}(100 \mathrm{mg})$ & $3 \mathrm{cp} / \mathrm{dia}$ & 33 & 60 & -27 \\
\hline Pac2023 & carbamazepina & & carbamazepina & C1 & $90 \mathrm{cp}(200 \mathrm{mg})$ & $3 \mathrm{cp} / \mathrm{dia}$ & 30 & 60 & -30 \\
\hline $\mathrm{Pac0237}$ & DEPAKENE & Abbott & $\begin{array}{l}\text { ácido valpróico } \\
\text { (ou derivado) }\end{array}$ & C1 & $100 \mathrm{cp}(500 \mathrm{mg})$ & $3 \mathrm{cp} / \mathrm{dia}$ & 33 & 60 & -27 \\
\hline Pac0237 & DEPAKENE & Abbott & $\begin{array}{l}\text { ácido valpróico } \\
\text { (ou derivado) }\end{array}$ & C1 & $50 \mathrm{cp}(250 \mathrm{mg})$ & $1 \mathrm{cp} / \mathrm{dia}$ & 50 & 60 & -10 \\
\hline Pac4044 & carbamazepina & & carbamazepina & C1 & $180 \mathrm{cp}(200 \mathrm{mg})$ & $6 \mathrm{cp} / \mathrm{dia}$ & 30 & 60 & -30 \\
\hline Pac4044 & AMYTRIL & Cristália & amitriptilina & C1 & $40 \mathrm{cp}(25 \mathrm{mg})$ & $1 \mathrm{cp} / \mathrm{dia}$ & 40 & 60 & -20 \\
\hline Pac1838 & fenobarbital & & fenobarbital & $\begin{array}{c}\text { B1 - } \\
\text { adendo }\end{array}$ & $40 \mathrm{cp}(100 \mathrm{mg})$ & $1 \mathrm{cp} / \mathrm{dia}$ & 40 & 60 & -20 \\
\hline Pac2166 & carbamazepina & & carbamazepina & C1 & $120 \mathrm{cp}(200 \mathrm{mg})$ & $4 \mathrm{cp} / \mathrm{dia}$ & 30 & 60 & -30 \\
\hline Pac2310 & carbamazepina & & carbamazepina & C1 & $180 \mathrm{cp}(200 \mathrm{mg})$ & $6 \mathrm{cp} / \mathrm{dia}$ & 30 & 60 & -30 \\
\hline Pac2310 & ANAFRANIL & Novartis & clomipramina & C1 & $60 \mathrm{cp}(25 \mathrm{mg})$ & 2 cp/dia & 30 & 60 & -30 \\
\hline Pac1699 & fenobarbital & & fenobarbital & $\begin{array}{c}\text { B1 - } \\
\text { adendo }\end{array}$ & $100 \mathrm{cp}(100 \mathrm{mg})$ & $3 \mathrm{cp} / \mathrm{dia}$ & 33 & 60 & -27 \\
\hline Pac1699 & fenitoina & & $\begin{array}{l}\text { fenitoina } \\
\text { (hidantoina) }\end{array}$ & C1 & $90 \mathrm{cp}(90 \mathrm{mg})$ & $3 \mathrm{cp} / \mathrm{dia}$ & 30 & 60 & -30 \\
\hline Pac2901 & haloperidol & & haloperidol & C1 & $100 \mathrm{cp}(5 \mathrm{mg})$ & $3 \mathrm{cp} / \mathrm{dia}$ & 33 & 60 & -27 \\
\hline Pac2901 & cartbamazepina & & carbarnazepina & C1 & $90 \mathrm{cp}(200 \mathrm{mg})$ & 3 cp/dia & 30 & 60 & -30 \\
\hline Pac2901 & fenobarbital & & fenobarbital & $\begin{array}{c}\text { B1 - } \\
\text { adendo }\end{array}$ & $60 \mathrm{cp}(100 \mathrm{mg})$ & $2 \mathrm{cp} / \mathrm{dia}$ & 30 & 60 & -30 \\
\hline Pac1046 & sertralina & & sertralina & C1 & $30 \mathrm{cp}(50 \mathrm{mg})$ & $1 \mathrm{cp} / \mathrm{dia}$ & 30 & 60 & -30 \\
\hline Pac3641 & amitriptilina & & amitriptilina & C1 & $40 \mathrm{cp}(25 \mathrm{mg})$ & $1 \mathrm{cp} / \mathrm{dia}$ & 40 & 60 & -20 \\
\hline Pac3727 & fluoxetina & & fluoxetina & C1 & $40 \mathrm{cp}(20 \mathrm{mg})$ & $1 \mathrm{cp} / \mathrm{dia}$ & 40 & 60 & -20 \\
\hline Pac3253 & \begin{tabular}{|l} 
codeina: \\
paracetamol
\end{tabular} & & $\begin{array}{l}\text { codeina; } \\
\text { paracotamol }\end{array}$ & $\begin{array}{c}\text { A2 - } \\
\text { adendo }\end{array}$ & $120 \mathrm{cp}(30 \mathrm{mg})$ & $4 \mathrm{cp} / \mathrm{dia}$ & 30 & 60 & -30 \\
\hline Pac2571 & carbamazepina & & cartamazepina & C1 & $150 \mathrm{cp}(200 \mathrm{mg})$ & $5 \mathrm{cp} / \mathrm{dia}$ & 30 & 60 & -30 \\
\hline Pac2571 & fenobarbital & & fenobarbital & \begin{tabular}{|c|} 
B1 - \\
adendo
\end{tabular} & $40 \mathrm{cp}(100 \mathrm{mg})$ & $1 \mathrm{cp} / \mathrm{dia}$ & 40 & 60 & -20 \\
\hline
\end{tabular}


$D T=$ Dias de tratamento fornecido $\quad L L=$ Limite legal

\begin{tabular}{|c|c|c|c|c|c|c|c|c|c|}
\hline \begin{tabular}{|l} 
código \\
paciente
\end{tabular} & Prescrição & Indústria & Principio Ativo & Alínea & Fornecimento & Posologia & DT & LL & DT - LL \\
\hline Pac1957 & DAFORIN & Sigma Pharma & fluoxetina & c1 & $40 \mathrm{cp}(20 \mathrm{mg})$ & $1,5 \mathrm{cp} / \mathrm{dia}$ & 27 & 60 & -33 \\
\hline Pac2181 & carbamazepina & & carbamazepina & C1 & $60 \mathrm{cp}(200 \mathrm{mg})$ & $2 \mathrm{cp} / \mathrm{dia}$ & 30 & 60 & -30 \\
\hline Pac3882 & DAFORIN & Sigma Pharma & fluoxetina & $\mathrm{cl}$ & $100 \mathrm{cp}(20 \mathrm{mg})$ & $3 \mathrm{cp} / \mathrm{dia}$ & 33 & 60 & -27 \\
\hline Pac1001 & sertralina & & sertralina & c1 & $30 \mathrm{cp}(50 \mathrm{mg})$ & $1 \mathrm{cp} / \mathrm{dia}$ & 30 & 60 & -30 \\
\hline Pac0806 & carbarnazepina & & carbamazepina & c1 & $120 \mathrm{cp} \mathrm{(200 \textrm {mg } )}$ & $2 \mathrm{cp} / \mathrm{dia}$ & 60 & 60 & 0 \\
\hline Pac0149 & DAFORIN & Sigma Pharma & Iluoxetina & $c t$ & $40 \mathrm{cp}(20 \mathrm{mg})$ & $1 \mathrm{cp} / \mathrm{dia}$ & 40 & 60 & -20 \\
\hline Pac3512 & $\begin{array}{l}\text { codeina: } \\
\text { paracetamol }\end{array}$ & & \begin{tabular}{|l} 
codeina; \\
paracetamol
\end{tabular} & $\begin{array}{c}\text { A2 - } \\
\text { adendo }\end{array}$ & $30 \mathrm{cp}(30 \mathrm{mg})$ & $3 \mathrm{cp} / \mathrm{dia}$ & 10 & 60 & -50 \\
\hline Pac0449 & carbamazepina & & carbamazepina & c1 & $90 \mathrm{cp}(200 \mathrm{mg})$ & $3 \mathrm{cp} / \mathrm{dia}$ & 30 & 60 & -30 \\
\hline Pac1893 & carbamazepina & & carbamazepina & C1 & $210 \mathrm{cp}(200 \mathrm{mg})$ & $6 \mathrm{cp} / \mathrm{dia}$ & 35 & 60 & -25 \\
\hline Pac1893 & fenitoina & & \begin{tabular}{|l|} 
fenitoina \\
(hidantoina)
\end{tabular} & C1 & $120 \mathrm{cp}(100 \mathrm{mg})$ & $4 \mathrm{cp} / \mathrm{dia}$ & 30 & 60 & -30 \\
\hline Pac0704 & \begin{tabular}{|l} 
codeina; \\
paracetamol
\end{tabular} & & \begin{tabular}{|l} 
codeina; \\
paracetamol
\end{tabular} & $\begin{array}{l}\text { A2- } \\
\text { adendo }\end{array}$ & $30 \mathrm{cp}(30 \mathrm{mg})$ & $3 \mathrm{cp} / \mathrm{dia}$ & 10 & .60 & -50 \\
\hline Pac1961 & DAFORIN & Sigma Pharma & nuoxetina & c1 & $40 \mathrm{cp}(20 \mathrm{mg})$ & $1 \mathrm{cp} / \mathrm{dia}$ & 40 & 60 & -20 \\
\hline Pac0990 & ARAVA & Aventis & leflunomida & $\mathrm{Cl}_{1}$ & $3 \mathrm{cp}$ (100 mg) & $3 \mathrm{cp} / \mathrm{dia}$ & 1 & 60 & -59 \\
\hline Pac0990 & ARAVA & Aventis & leflunomida & C1 & $30 \mathrm{cp}(20 \mathrm{mg})$ & $1 \mathrm{cp} / \mathrm{dia}$ & 30 & 60 & -30 \\
\hline Pac0256 & gabapentina & & gabapentina & c1 & $90 \mathrm{cp}(400 \mathrm{mg})$ & $3 \mathrm{cp} / \mathrm{dia}$ & 30 & 60 & -30 \\
\hline Pac0256 & nortriptilina & & nortriptilina & C1 & $30 \mathrm{cp}(10 \mathrm{mg})$ & $1 \mathrm{cp} / \mathrm{dia}$ & 30 & 60 & -30 \\
\hline Pac0256 & LONGACTIL & Cristália & clorpromazina & c1 & $\begin{array}{l}20 \mathrm{ml}(0,4 \\
\mathrm{mg} / \mathrm{ml})\end{array}$ & $0,5 \mathrm{~m} / \mathrm{dia}$ & 40 & 60 & -20 \\
\hline Pac0489 & fenobarbital & & fenobarbital & $\begin{array}{c}\text { B1- } \\
\text { adendo }\end{array}$ & $40 \mathrm{cp}(100 \mathrm{mg})$ & $1 \mathrm{cp} / \mathrm{dia}$ & 40 & 60 & -20 \\
\hline Pac0489 & fenitolna & & $\begin{array}{l}\begin{array}{l}\text { fenitoina } \\
\text { (hidantoina) }\end{array} \\
\end{array}$ & C1 & $60 \mathrm{cp}$ (100 mg) & $2 \mathrm{cp} / \mathrm{dia}$ & 30 & 60 & -30 \\
\hline Pac2183 & imipramina & & imipramina & $\mathrm{C} 4$ & $30 \mathrm{cp}$ (25 mg) & 1 cp/dia & 30 & 60 & -30 \\
\hline Pac2170 & DEPAKENE & Abbott & $\begin{array}{l}\text { ácido valpróico } \\
\text { (ou derivado) }\end{array}$ & $C_{1}$ & $100 \mathrm{cp}(500 \mathrm{mg})$ & $3 \mathrm{cp} / \mathrm{dia}$ & 33 & 60 & -27 \\
\hline Pac2170 & DEPAKENE & Abbott & \begin{tabular}{|l|} 
ácido valpróico \\
(ou derivado)
\end{tabular} & $\mathrm{C1}$ & $50 \mathrm{cp}(250 \mathrm{mg})$ & $1 \mathrm{cp} / \mathrm{dia}$ & 50 & 60 & -10 \\
\hline Pac0619 & carbamazepina & & carbamazepina & C1 & $90 \mathrm{cp}(200 \mathrm{mg})$ & 3 cpidia & 30 & 60 & -30 \\
\hline Pac0619 & fenobarbital & & fenobarbital & $\begin{array}{c}1- \\
\text { adendo }\end{array}$ & $20 \mathrm{cp}$ (100 mg) & $0,5 \mathrm{cp} / \mathrm{dia}$ & 40 & 60 & -20 \\
\hline Pac2636 & carbamazepina & & carbamazepina & $c_{1}$ & $230 \mathrm{cp}(200 \mathrm{mg})$ & $7,5 \mathrm{cp} / \mathrm{dia}$ & 31 & 60 & -29 \\
\hline Pac2636 & clobazam & & clobazam & B1 & $90 \mathrm{cp}(10 \mathrm{mg})$ & $3 \mathrm{cp} / \mathrm{dia}$ & 30 & 60 & -30 \\
\hline Pac1884 & carbamazepina & & carbamazepina & C1 & $90 \mathrm{cp}(200 \mathrm{mg})$ & $3 \mathrm{cp} / \mathrm{dia}$ & 30 & 60 & -30 \\
\hline Pac1107 & ácido valpróico & & $\begin{array}{l}\begin{array}{l}\text { ácido valpróico } \\
\text { (ou derivado) }\end{array} \\
\end{array}$ & C1 & $60 \mathrm{cp}$ (250 mg) & $2 \mathrm{cp} / \mathrm{dia}$ & 30 & 60 & -30 \\
\hline Pac1107 & carbamazepina & & carbamazepina & C1 & $150 \mathrm{cp}(200 \mathrm{mg})$ & $5 \mathrm{cp} / \mathrm{dia}$ & 30 & 60 & -30 \\
\hline Pac1107 & amitriptilina & & amitriptilina & $c 1$ & $40 \mathrm{cp} \mathrm{(25} \mathrm{mg)}$ & $1 \mathrm{cp} / \mathrm{dia}$ & 40 & 60 & -20 \\
\hline Pac3214 & sertralina & & sertralina & c1 & $60 \mathrm{cp}(50 \mathrm{mg})$ & $2 \mathrm{cp} / \mathrm{dia}$ & 30 & 60 & -30 \\
\hline Pac1254 & sertralina & & sertralina & C1 & $60 \mathrm{cp}(50 \mathrm{mg})$ & $2,5 \mathrm{cp} / \mathrm{dia}$ & 24 & 60 & -36 \\
\hline Pac1254 & $\begin{array}{l}\text { codeina; } \\
\text { paracetamol }\end{array}$ & & $\begin{array}{l}\text { codeina; } \\
\text { paracetamol }\end{array}$ & $\begin{array}{c}\text { A2 - } \\
\text { adendo }\end{array}$ & $60 \mathrm{cp}(30 \mathrm{mg})$ & $1,5 \mathrm{cp} / \mathrm{dia}$ & 40 & 60 & -20 \\
\hline Pac0060 & carbamazepina & & cartamazepina & c1 & $150 \mathrm{cp}(200 \mathrm{mg})$ & $7 \mathrm{cp} / \mathrm{dia}$ & 21 & 60 & -39 \\
\hline Pac3025 & $\begin{array}{l}\text { codeina: } \\
\text { paracetamol }\end{array}$ & & $\begin{array}{l}\text { codeina; } \\
\text { paracetamol }\end{array}$ & $\begin{array}{c}A 2- \\
\text { adendo }\end{array}$ & $90 \mathrm{cp}(30 \mathrm{mg})$ & $4 \mathrm{cp} / \mathrm{dia}$ & 23 & 60 & -38 \\
\hline Pac2010 & buspirona & & buspirona & $c_{1}$ & $30 \mathrm{cp}(5 \mathrm{mg})$ & $1 \mathrm{cp} / \mathrm{dia}$ & 30 & 60 & -30 \\
\hline Pac0287 & paroxetina & & paroxetina & C1 & $30 \mathrm{cp}(20 \mathrm{mg})$ & $1 \mathrm{cp} / \mathrm{dia}$ & 30 & 60 & -30 \\
\hline Pac3006 & amitriptilina & & amitriptilina & C1 & $40 \mathrm{cp}(25 \mathrm{mg})$ & $1 \mathrm{cp} / \mathrm{dia}$ & 40 & 60 & -20 \\
\hline Pac3338 & amitriptilina & & amitriptilina & C1 & $60 \mathrm{cp}(25 \mathrm{mg})$ & $2 \mathrm{cp} / \mathrm{dia}$ & 30 & 60 & -30 \\
\hline Pac3338 & AMPLICTIL & Aventis & clorpromazina & C1 & \begin{tabular}{|l|}
$60 \mathrm{ml}(0,4$ \\
$\mathrm{mg} / \mathrm{ml})$
\end{tabular} & $3,2 \mathrm{~m}$ Vdia & 19 & 60 & -41 \\
\hline Pac2346 & carbamazepina & & carbamazepina & $\mathrm{Cl}$ & $140 \mathrm{cp}(200 \mathrm{mg})$ & $4,5 \mathrm{cp} / \mathrm{dia}$ & 31 & 60 & -29 \\
\hline Pac2346 & AMYTRIL & Cristália & amitriptilina & $\mathrm{C1}$ & $40 \mathrm{cp}(25 \mathrm{mg})$ & $1 \mathrm{cp} / \mathrm{dia}$ & 40 & 60 & -20 \\
\hline Pac2375 & sertralina & & sertralina & C1 & $30 \mathrm{cp}(50 \mathrm{mg})$ & $1 \mathrm{cp} / \mathrm{dia}$ & 30 & 60 & -30 \\
\hline
\end{tabular}


$D T=$ Dias de tratamento fornecido $\quad L L=$ Limite legal

\begin{tabular}{|c|c|c|c|c|c|c|c|c|c|}
\hline $\begin{array}{l}\text { código } \\
\text { paciente }\end{array}$ & Prescrição & Indústria & Principio Ativo & Alínea & Fornecimento & Posologia & DT & $\mathbf{L L}$ & Dr. LL \\
\hline Pac0609 & amitriplilina & & amitriptilina & $\mathrm{C1}$ & $30 \mathrm{cp}(25 \mathrm{mg})$ & $1 \mathrm{cp} / \mathrm{dia}$ & 30 & 60 & .30 \\
\hline Pac1429 & TRYPTANOL & Prodome & amitriptilina & $\mathrm{Cl}$ & $40 \mathrm{cp}(25 \mathrm{mg})$ & $1 \mathrm{cp} / \mathrm{dia}$ & 40 & 60 & .20 \\
\hline Pac2939 & cisaprida & & cisaprida & $\mathrm{C1}$ & $90 \mathrm{cp}(10 \mathrm{mg})$ & $2 \mathrm{cp} / \mathrm{dia}$ & 45 & 60 & -15 \\
\hline Pac2939 & $\begin{array}{l}\text { codeina; } \\
\text { paracetamol }\end{array}$ & & $\begin{array}{l}\text { codeina; } \\
\text { paracetamol }\end{array}$ & \begin{tabular}{|c|}
$\mathrm{A} 2-$ \\
adendo
\end{tabular} & $90 \mathrm{cp}(30 \mathrm{mg})$ & $3 \mathrm{cp} / \mathrm{dia}$ & 30 & 60 & -30 \\
\hline Pac3935 & carbamazepina & & carbamazepina & $\mathrm{C} 1$ & $90 \mathrm{cp}(200 \mathrm{mg})$ & $3 \mathrm{cp} / \mathrm{dia}$ & 30 & 60 & -30 \\
\hline Pac2665 & sertralina & & sertralina & C1 & $90 \mathrm{cp}(50 \mathrm{mg})$ & $3 \mathrm{cp} / \mathrm{dia}$ & 30 & 60 & -30 \\
\hline Pac2665 & amitriptilina & & amitriptilina & C1 & $100 \mathrm{cp}(25 \mathrm{mg})$ & $3 \mathrm{cp} / \mathrm{dia}$ & 33 & 60 & -27 \\
\hline Pac3463 & fluoxetina & & fuoxetina & $\mathrm{C1}$ & $40 \mathrm{cp}(20 \mathrm{mg})$ & $1 \mathrm{cp} / \mathrm{dia}$ & 40 & 60 & -20 \\
\hline Pac0999 & DEPAKENE & Abbott & $\begin{array}{l}\text { ácido valpróico } \\
\text { (ou derivado) }\end{array}$ & C1 & $200 \mathrm{cp}(500 \mathrm{mg})$ & $6 \mathrm{cp} / \mathrm{dia}$ & 33 & 60 & -27 \\
\hline Pac2190 & TRILEPTAL & Novartis & oxcarbazepina & C1 & $120 \mathrm{cp}(300 \mathrm{mg})$ & $4 \mathrm{cp} / \mathrm{dia}$ & 30 & 60 & -30 \\
\hline Pac0664 & carbamazepina & & carbamazepina & C1 & $30 \mathrm{cp}(200 \mathrm{mg})$ & $2 \mathrm{cp} / \mathrm{dia}$ & 15 & 60 & -45 \\
\hline Pac0664 & amitriptilina & & amitriptilina & C1 & $60 \mathrm{cp}(25 \mathrm{mg})$ & $2 \mathrm{cp} / \mathrm{dia}$ & 30 & 60 & -30 \\
\hline Pac2664 & GARDENAL & Aventis & fenobarbital & $\begin{array}{c}\text { B1 - } \\
\text { adendo }\end{array}$ & $60 \mathrm{cp}(100 \mathrm{mg})$ & $2 \mathrm{cp} / \mathrm{dia}$ & 30 & 60 & -30 \\
\hline Pac2664 & HIDANTAL & Aventis & \begin{tabular}{|l|}
$\begin{array}{l}\text { fenitoina } \\
\text { (hidantoina) }\end{array}$ \\
\end{tabular} & C1 & $90 \mathrm{cp}(100 \mathrm{mg})$ & $3 \mathrm{cp} / \mathrm{dia}$ & 30 & 60 & -30 \\
\hline Pac2664 & sertralina & & sertralina & C1 & $30 \mathrm{cp}(50 \mathrm{mg})$ & $1 \mathrm{cp} / \mathrm{dia}$ & 30 & 60 & -30 \\
\hline Pac3037 & carbamazepina & & carbamazepina & C1 & $90 \mathrm{cp}(200 \mathrm{mg})$ & $3 \mathrm{cp} / \mathrm{dia}$ & 30 & 60 & -30 \\
\hline Pac0544 & sertralina & & sertratina & C1 & $60 \mathrm{cp}(50 \mathrm{mg})$ & $2 \mathrm{cp} / \mathrm{dia}$ & 30 & 60 & -30 \\
\hline Pac3963 & TRYPTANOL & Prodome & amitriplilina & C1 & $45 \mathrm{cp}(25 \mathrm{mg})$ & $1,5 \mathrm{cp} / \mathrm{dia}$ & 30 & 60 & -30 \\
\hline Pac2026 & $\begin{array}{l}\text { codeina; } \\
\text { paracetamol }\end{array}$ & & $\begin{array}{l}\text { codeina; } \\
\text { paracetamol }\end{array}$ & \begin{tabular}{c|}
$A 2-$ \\
adendo
\end{tabular} & $120 \mathrm{cp}(30 \mathrm{mg})$ & $4 \mathrm{cp} / \mathrm{dia}$ & 30 & 60 & -30 \\
\hline Pac2026 & TRYPTANOL & Prodome & amitriptilina & C1 & $40 \mathrm{cp}(25 \mathrm{mg})$ & $1 \mathrm{cp} / \mathrm{dia}$ & 40 & 60 & -20 \\
\hline Pac3532 & fluoxetina & & fluoxelina & C1 & $60 \mathrm{cp}(20 \mathrm{mg})$ & $2 \mathrm{cp} / \mathrm{dia}$ & 30 & 60 & -30 \\
\hline Pac0462 & amitriptilina & & amitriptilina & C1 & $40 \mathrm{cp}(25 \mathrm{mg})$ & $1 \mathrm{cp} / \mathrm{dia}$ & 40 & 60 & -20 \\
\hline Pac2768 & amitriptitina & & amitriptilina & C1 & $15 \mathrm{cp}(25 \mathrm{mg})$ & $0,5 \mathrm{cp} / \mathrm{dia}$ & 30 & 60 & -30 \\
\hline Pac2768 & ARAVA & Aventis & leflunomida & C1 & $30 \mathrm{cp}(20 \mathrm{mg})$ & $1 \mathrm{cp} /$ dia & 30 & 60 & -30 \\
\hline Pac0625 & amitriptilina & & amitriptilina & C1 & $40 \mathrm{cp}(25 \mathrm{mg})$ & $1 \mathrm{cp} / \mathrm{dia}$ & 40 & 60 & -20 \\
\hline Pac2280 & amitriptilina & & amitriptilina & C1 & $60 \mathrm{cp}(25 \mathrm{mg})$ & $2 \mathrm{cp} / \mathrm{dia}$ & 30 & 60 & -30 \\
\hline Pac3168 & ACTIFEDRIN & Zest & $\begin{array}{l}\begin{array}{l}\text { triprolidina; } \\
\text { pseudoefedrina }\end{array} \\
\end{array}$ & D1 & $60 \mathrm{cp}(2,5 \mathrm{mg})$ & $2 \mathrm{cp} / \mathrm{dia}$ & 30 & & \\
\hline Pac3168 & tramadol & & tramadol & \begin{tabular}{|c|}
$\begin{array}{c}\text { A2 - } \\
\text { adendo }\end{array}$ \\
\end{tabular} & $30 \mathrm{cp}(50 \mathrm{mg})$ & $3 \mathrm{cp} / \mathrm{dia}$ & 10 & 60 & -50 \\
\hline Pac3168 & carbamazepina & & carbamazepina & C1 & $120 \mathrm{cp}(200 \mathrm{mg})$ & $4 \mathrm{cp} / \mathrm{dia}$ & 30 & 60 & -30 \\
\hline Pac3168 & fluoxetina & & fluoxetina & C1 & $60 \mathrm{cp}(20 \mathrm{mg})$ & $2 \mathrm{cp} / \mathrm{dia}$ & 30 & 60 & -30 \\
\hline Pac3168 & fluoxetina & & fluoxetina & C1 & $40 \mathrm{cp}(20 \mathrm{mg})$ & $1 \mathrm{cp} / \mathrm{dia}$ & 40 & 60 & -20 \\
\hline Pac2501 & TRAMAL & $\begin{array}{l}\text { Phizer- } \\
\text { Pharmacia }\end{array}$ & tramadol & \begin{tabular}{|c|} 
A2 - \\
adendo
\end{tabular} & $40 \mathrm{cp}(50 \mathrm{mg})$ & $4 \mathrm{cp} / \mathrm{dia}$ & 10 & 60 & -50 \\
\hline Pac1470 & TRIPSOL & Cazi & amitriptilina & C1 & $4 \mathrm{cp}$ (100 mg) & $0,15 \mathrm{cp} / \mathrm{dia}$ & 27 & 60 & -33 \\
\hline Pac2391 & fluoxetina & & fluoxetina & C1 & $90 \mathrm{cp}(20 \mathrm{mg})$ & $3 \mathrm{cp} / \mathrm{dia}$ & 30 & 60 & -30 \\
\hline Pac1134 & TRYPTANOL & Prodome & amitriptilina & C1 & $60 \mathrm{cp}$ (25 mg) & $2 \mathrm{cp} / \mathrm{dia}$ & 30 & 60 & -30 \\
\hline Pac3330 & AMTTRIL & Cristália & amitriptilina & C1 & $60 \mathrm{cp}(25 \mathrm{mg})$ & $2 \mathrm{cp} / \mathrm{dia}$ & 30 & 60 & -30 \\
\hline Pac3330 & $\begin{array}{l}\text { codeina; } \\
\text { paracetamol }\end{array}$ & & $\begin{array}{l}\text { codeína; } \\
\text { paracetamol }\end{array}$ & \begin{tabular}{|c|} 
A2 - \\
adendo
\end{tabular} & $60 \mathrm{cp}(30 \mathrm{mg})$ & $2 \mathrm{cp} / \mathrm{dia}$ & 30 & 60 & -30 \\
\hline Pac3299 & CINETOL & Cristália & biperideno & C1 & $180 \mathrm{cp}(2 \mathrm{mg})$ & $6 \mathrm{cp} / \mathrm{dia}$ & 30 & 60 & -30 \\
\hline Pac1311 & TRYPTANOL & Prodome & amitriptilina & $\mathrm{C1}$ & $40 \mathrm{cp}$ (25 mg) & $1 \mathrm{cp} / \mathrm{dia}$ & 40 & 60 & -20 \\
\hline Pac1339 & carbamazepina & & carbamazepina & c1 & $50 \mathrm{cp}(200 \mathrm{mg})$ & $1 \mathrm{cp} / \mathrm{dia}$ & 50 & 60 & -10 \\
\hline Pac3841 & carbamazepina & & carbamazepina & $\mathrm{Cl}$ & $90 \mathrm{cp}(200 \mathrm{mg})$ & $3 \mathrm{cp} / \mathrm{dia}$ & 30 & 60 & -30 \\
\hline Pac3841 & AMYTRIL & Cristália & amitriptilina & C1 & $40 \mathrm{cp}(25 \mathrm{mg})$ & $3 \mathrm{cp} / \mathrm{dia}$ & 13 & 60 & -47 \\
\hline Pac1191 & amantadina & & amantadina & C1 & $90 \mathrm{cp}(100 \mathrm{mg})$ & $3 \mathrm{cp} / \mathrm{dia}$ & 30 & 60 & -30 \\
\hline Pac1191 & amitriptilina & & amitriptilina & C1 & $40 \mathrm{cp}(25 \mathrm{mg})$ & $1 \mathrm{cp} / \mathrm{dia}$ & 40 & 60 & -20 \\
\hline Pac1149 & $\begin{array}{l}\text { codeina; } \\
\text { paracetamol }\end{array}$ & & $\begin{array}{l}\text { codeina; } \\
\text { paracetamol }\end{array}$ & $\begin{array}{c}\text { A2 - } \\
\text { adendo }\end{array}$ & $90 \mathrm{cp}(30 \mathrm{mg})$ & $3 \mathrm{cp} / \mathrm{dia}$ & 30 & 60 & -30 \\
\hline
\end{tabular}


DT = Dias de tratamento fornecido $\quad L L=$ Limite legal

\begin{tabular}{|c|c|c|c|c|c|c|c|c|c|}
\hline $\begin{array}{l}\text { código } \\
\text { paciente }\end{array}$ & Prescrição & Indústria & Principio Ativo & Alinea & Fomecimento & Posologia & DT & LL & DT $-\mathrm{LL}$ \\
\hline Pac1149 & fenobarbital & & fenobarbital & \begin{tabular}{|c|} 
B1- \\
adendo
\end{tabular} & $40 \mathrm{cp}(100 \mathrm{mg})$ & $1 \mathrm{cp} / \mathrm{dia}$ & 40 & 60 & -20 \\
\hline Pac1149 & amitriptilina & & amitriptilina & $\mathrm{Cl}$ & $40 \mathrm{cp}(25 \mathrm{mg})$ & $1 \mathrm{cp} / \mathrm{dia}$ & 40 & 60 & -20 \\
\hline Pac2398 & carbamazepina & & carbamazepina & C1 & $90 \mathrm{cp}(200 \mathrm{mg})$ & $3 \mathrm{cp} / \mathrm{dia}$ & 30 & 60 & -30 \\
\hline Pac3746 & fenitoina & & \begin{tabular}{|l|}
$\begin{array}{l}\text { fenitoina } \\
\text { (hidantoina) }\end{array}$ \\
\end{tabular} & C1 & $100 \mathrm{cp}(100 \mathrm{mg})$ & $3 \mathrm{cp} / \mathrm{dia}$ & 33 & 60 & -27 \\
\hline Pac3602 & lluoxetina & & fuoxelina & C1 & $40 \mathrm{cp}(20 \mathrm{mg})$ & $1 \mathrm{cp} / \mathrm{dia}$ & 40 & 60 & -20 \\
\hline Pac3602 & MnEX & Janssen-Cilag & \begin{tabular}{|l|} 
Codeina; \\
paracetamol
\end{tabular} & $\begin{array}{c}A 2- \\
\text { adendo }\end{array}$ & $12 \mathrm{cp}(30 \mathrm{mg})$ & $4 \mathrm{cp} / \mathrm{dia}$ & 3 & 60 & -57 \\
\hline Pac1830 & TRILEPTAL & Novartis & oxcarbazepina & $\mathrm{Cl}$ & $150 \mathrm{cp}(300 \mathrm{mg})$ & $5 \mathrm{cp} / \mathrm{dia}$ & 30 & 60 & -30 \\
\hline Pac1830 & carbamazepina & & carbamazepina & C1 & $60 \mathrm{cp}(200 \mathrm{mg})$ & 2 cp/dia & 30 & 60 & -30 \\
\hline Pac1899 & fenobarbital & & fenobarbital & $\begin{array}{c}\text { B1- } \\
\text { adendo }\end{array}$ & $40 \mathrm{cp}(100 \mathrm{mg})$ & $1 \mathrm{cp} / \mathrm{dia}$ & 40 & 60 & -20 \\
\hline Pac1208 & PROZAC & Eli Lilly & fluoxetina & C1 & $30 \mathrm{cp}(20 \mathrm{mg})$ & $1 \mathrm{cp} / \mathrm{dia}$ & 30 & 60 & -30 \\
\hline Pac3315 & sertralina & & sertralina & C1 & $90 \mathrm{cp}(50 \mathrm{mg})$ & $3 \mathrm{cp} / \mathrm{dia}$ & 30 & 60 & -30 \\
\hline Pac1664 & amitriptilina & & amitriptilina & C1 & $4 \mathrm{cp}(25 \mathrm{mg})$ & $1 \mathrm{cp} / \mathrm{dia}$ & 4 & 60 & -56 \\
\hline Pac3720 & $\begin{array}{l}\text { codeina; } \\
\text { paracetamol }\end{array}$ & & \begin{tabular}{|l} 
codeina; \\
paracetamol
\end{tabular} & $\begin{array}{c}\text { A2 - } \\
\text { adendo }\end{array}$ & $90 \mathrm{cp}(30 \mathrm{mg})$ & $3 \mathrm{cp} / \mathrm{dia}$ & 30 & 60 & -30 \\
\hline Pac2909 & amitriptilina & & amitriptilina & c1 & $25 \mathrm{cp}$ (25 mg) & $1 \mathrm{cp} / \mathrm{dia}$ & 25 & 60 & -35 \\
\hline Pac2762 & TRAMAL & $\begin{array}{l}\text { Pfizer- } \\
\text { Pharmacia }\end{array}$ & Iramadol & $\begin{array}{c}\text { A2 - } \\
\text { adendo }\end{array}$ & $120 \mathrm{cp}(50 \mathrm{mg})$ & $4 \mathrm{cp} / \mathrm{dia}$ & 30 & 60 & -30 \\
\hline Pac3697 & amitriptilina & & amitriptilina & c1 & $60 \mathrm{cp}(25 \mathrm{mg})$ & $2 \mathrm{cp} / \mathrm{dia}$ & 30 & 60 & -30 \\
\hline Pac3697 & $\begin{array}{l}\text { codeina: } \\
\text { paracetamol }\end{array}$ & & $\begin{array}{l}\text { Codeina; } \\
\text { paracetamol }\end{array}$ & $\begin{array}{c}\text { A2:- } \\
\text { adendo }\end{array}$ & $90 \mathrm{cp}(30 \mathrm{mg})$ & $3 \mathrm{cp} / \mathrm{dia}$ & 30 & 60 & -30 \\
\hline Pac4061 & DEPAKENE & Abbott & $\begin{array}{l}\text { acido valpróico } \\
\text { (ou derivado) }\end{array}$ & C1 & $100 \mathrm{cp}(500 \mathrm{mg})$ & $2 \mathrm{cp} / \mathrm{dia}$ & 50 & 60 & -10 \\
\hline Pac2915 & amitriptilina & & amitriptilina & $C_{1}$ & $60 \mathrm{cp}(25 \mathrm{mg})$ & $2 \mathrm{cp} / \mathrm{dia}$ & 30 & 60 & -30 \\
\hline Pac1119 & amitriptilina & & amitriptilina & C1 & $100 \mathrm{cp}(25 \mathrm{mg})$ & $3 \mathrm{cp} / \mathrm{dia}$ & 33 & 60 & -27 \\
\hline Pac0430 & DAFORIN & Sigma Pharma & fluoxetina & C1 & $40 \mathrm{cp}(20 \mathrm{mg})$ & $1 \mathrm{cp} / \mathrm{dia}$ & 40 & 60 & -20 \\
\hline Pac2394 & carbamazepina & & carbamazepina & C1 & $180 \mathrm{cp}(200 \mathrm{mg})$ & $6 \mathrm{cp} / \mathrm{dia}$ & 30 & 60 & -30 \\
\hline Pac3342 & fenitoina & & \begin{tabular}{|l} 
fenitoina \\
(hidantoina)
\end{tabular} & C1 & $90 \mathrm{cp}(100 \mathrm{mg})$ & $3 \mathrm{cp} / \mathrm{dia}$ & 30 & 60 & -30 \\
\hline Pac0710 & PROLOPA & Roche & \begin{tabular}{|l|} 
levodopa $\theta$ \\
benserazida
\end{tabular} & C1 & \begin{tabular}{|l|}
$30 \mathrm{cp} \mathrm{(200/50}$ \\
$\mathrm{mg})$
\end{tabular} & $1 \mathrm{cp} / \mathrm{dia}$ & 30 & 60 & -30 \\
\hline Pac1544 & fenitolna & & \begin{tabular}{|l|}
$\begin{array}{l}\text { fenitoina } \\
\text { (hidantoina) }\end{array}$ \\
\end{tabular} & C1 & $6 \mathrm{cp}(100 \mathrm{mg})$ & 2 cpldia & 3 & 60 & -57 \\
\hline Pac1544 & FENOCRIS & Cristália & lenobarbital & $\begin{array}{c}\text { B1 - } \\
\text { adendo }\end{array}$ & $60 \mathrm{ml}(40 \mathrm{mg} / \mathrm{ml})$ & $2 \mathrm{~m} / \mathrm{dia}$ & 30 & 60 & -30 \\
\hline Pac2311 & HIPOFAGIN S & Sigma Pharma & \begin{tabular}{|l|} 
anfepramona \\
(dietilpropiona)
\end{tabular} & B2 & 00 & $1 / \mathrm{dia}$ & 0 & 60 & -60 \\
\hline Pac2966 & TRAMAL & \begin{tabular}{|l|} 
Pfizer- \\
Pharmacia \\
\end{tabular} & tramadol & $\begin{array}{c}\mathrm{A} 2 \text { - } \\
\text { adendo }\end{array}$ & $90 \mathrm{cp}(50 \mathrm{mg})$ & $3 \mathrm{cp} / \mathrm{dia}$ & 30 & 60 & -30 \\
\hline Pac2966 & LONGACTIL & Cristália & clorpromazina & C1 & $\begin{array}{l}20 \mathrm{ml}(0,4 \\
\mathrm{mg} / \mathrm{ml})\end{array}$ & $0,4 \mathrm{ml} / \mathrm{dia}$ & 50 & 60 & -10 \\
\hline Pac2966 & DAFORIN & Sigma Pharma & nuoxetina & c1 & $20 \mathrm{cp}(20 \mathrm{mg})$ & $1 \mathrm{cp} / \mathrm{dia}$ & 20 & 60 & -40 \\
\hline Pac2255 & DEPAKENE & Abbott & \begin{tabular}{|l|} 
ácido valpróico \\
(ou derivado)
\end{tabular} & c1 & $100 \mathrm{cp}(500 \mathrm{mg})$ & $3 \mathrm{cp} / \mathrm{dia}$ & 33 & 60 & -27 \\
\hline Pac3604 & AMVTRIL & Cristália & amitriptilina & c1 & $40 \mathrm{cp}(25 \mathrm{mg})$ & $1 \mathrm{cp} / \mathrm{dia}$ & 40 & 60 & -20 \\
\hline Pac3557 & fenobarbital & & fenobarbital & $\begin{array}{c}1- \\
\text { adendo }\end{array}$ & $60 \mathrm{cp}(100 \mathrm{mg})$ & $2 \mathrm{cp} / \mathrm{dia}$ & 30 & 60 & -30 \\
\hline Pac3557 & NEOZINE & Aventis & $\begin{array}{l}\text { levomepromazina } \\
\text { (metotrimeprazina) }\end{array}$ & $\mathrm{C1}$ & $60 \mathrm{cp}(10 \mathrm{mg})$ & $2 \mathrm{cp} / \mathrm{dia}$ & 30 & 60 & -30 \\
\hline Pac2483 & amitriptilina & & amitriptilina & C1 & $4025(25 \mathrm{mg})$ & $125 /$ dia & 40 & 60 & -20 \\
\hline Pac2682 & fluoxetina & & fluoxetina & C1 & $40 \mathrm{cp}(20 \mathrm{mg})$ & $1 \mathrm{cp} / \mathrm{dia}$ & 40 & 60 & -20 \\
\hline Pac3138 & ANAFRANIL & Novartis & clomipramina & C1 & $40 \mathrm{cp}(25 \mathrm{mg})$ & $1 \mathrm{cp} / \mathrm{dia}$ & 40 & 60 & -20 \\
\hline Pac0112 & DAFORIN & Sigma Pharma & fluoxetina & C1 & $40 \mathrm{cp}(20 \mathrm{mg})$ & $1 \mathrm{cp} / \mathrm{dia}$ & 40 & 60 & -20 \\
\hline Pac3227 & imipramina & & imipramina & C1 & $30 \mathrm{cp}(25 \mathrm{mg})$ & $1 \mathrm{cp} / \mathrm{dia}$ & 30 & 60 & -30 \\
\hline Pac0407 & carbamazepina & & cartamazepina & $\mathrm{C1}$ & $60 \mathrm{cp}$ (200 mg) & 2 cp/dia & 30 & 60 & -30 \\
\hline Pac1457 & imipramina & & imipramina & $c 1$ & $30 \mathrm{cp}(25 \mathrm{mg})$ & $1 \mathrm{cp} / \mathrm{dia}$ & 30 & 60 & -30 \\
\hline
\end{tabular}


$D T=$ Dias de tratamento fornecido $\quad L L=$ Limite legal

\begin{tabular}{|c|c|c|c|c|c|c|c|c|c|}
\hline $\begin{array}{l}\text { código } \\
\text { paciente }\end{array}$ & Prescrição & Indústria & Principio Ativo & Alinea & Fornecimento & Posologia & DT & LL & DT $-L L$ \\
\hline Pac1457 & AMNTRIL & Cristália & amitriptilina & c1 & $30 \mathrm{cp}(25 \mathrm{mg})$ & $1 \mathrm{cp} / \mathrm{dia}$ & 30 & 60 & -30 \\
\hline Pac3241 & fenitoina & & $\begin{array}{l}\text { fenitoina } \\
\text { (hidantoina) }\end{array}$ & C1 & $30 \mathrm{cp}(100 \mathrm{mg})$ & $1 \mathrm{cp} / \mathrm{dia}$ & 30 & 60 & -30 \\
\hline Pac0406 & carbamazepina & & carbamazepina & C1 & $180 \mathrm{cp}(200 \mathrm{mg})$ & $6 \mathrm{cp} / \mathrm{dia}$ & 30 & 60 & -30 \\
\hline Pac0406 & nitrazepam & & nitrazepam & B1 & $90 \mathrm{cp}(5 \mathrm{mg})$ & $3 \mathrm{cp} / \mathrm{dia}$ & 30 & 60 & -30 \\
\hline Pac3020 & AMYTRIL & Cristália & amitriptilina & C1 & $120 \mathrm{cp}(25 \mathrm{mg})$ & $4 \mathrm{cp} / \mathrm{dia}$ & 30 & 60 & -30 \\
\hline Pac3020 & LONGACTIL & Cristália & clorpromazina & c1 & $\begin{array}{l}60 \mathrm{ml}(0,4 \\
\mathrm{mg} / \mathrm{ml})\end{array}$ & $2 \mathrm{~m} / \mathrm{dia}$ & 30 & 60 & -30 \\
\hline Pac3289 & AMYTRIL & Cristália & amitriptilina & C1 & $60 \mathrm{cp}(25 \mathrm{mg})$ & $2 \mathrm{cp} / \mathrm{dia}$ & 30 & 60 & -30 \\
\hline Pac3289 & morfina & & morfina & A1 & $100 \mathrm{cp}(30 \mathrm{mg})$ & $8 \mathrm{cp} / \mathrm{dia}$ & 13 & 30 & -18 \\
\hline Pac3182 & loperamida & & loperamida & $\begin{array}{c}\text { C1- } \\
\text { adendo }\end{array}$ & $240 \mathrm{cp}(2 \mathrm{mg})$ & $8 \mathrm{cp} / \mathrm{dia}$ & 30 & sem & \\
\hline Pac1777 & carbamazepina & & carbamazepina & C1 & $240 \mathrm{cp}(200 \mathrm{mg})$ & $3 \mathrm{cp} / \mathrm{dia}$ & 80 & 60 & 20 \\
\hline Pac1722 & fenobarbital & & fenobarbital & \begin{tabular}{|c|}
81 - \\
adendo
\end{tabular} & $40 \mathrm{cp}(100 \mathrm{mg})$ & $1 \mathrm{cp} / \mathrm{dia}$ & 40 & 60 & -20 \\
\hline Pac1722 & carbamazepina & & carbamazepina & c1 & $120 \mathrm{cp}(200 \mathrm{mg})$ & $4 \mathrm{cp} / \mathrm{dia}$ & 30 & 60 & -30 \\
\hline Pac1722 & clobazam & & clobazam & B1 & $30 \mathrm{cp}(10 \mathrm{mg})$ & $1 \mathrm{cp} / \mathrm{dia}$ & 30 & 60 & -30 \\
\hline Pac0728 & carbamazepina & & carbamazepina & C1 & $150 \mathrm{cp}(200 \mathrm{mg})$ & $5 \mathrm{cp} / \mathrm{dia}$ & 30 & 60 & -30 \\
\hline Pac2289 & amitriptilina & & amitriptilina & C1 & $120 \mathrm{cp}(25 \mathrm{mg})$ & $4 \mathrm{cp} / \mathrm{dia}$ & 30 & 60 & .30 \\
\hline Pac2289 & LONGACTIL & Cristália & clorpromazina & c1 & $\begin{array}{l}60 \mathrm{ml}(0,4 \\
\mathrm{mg} / \mathrm{ml})\end{array}$ & $1,6 \mathrm{~m} / \mathrm{dia}$ & 38 & 60 & -23 \\
\hline Pac3165 & fluoxetina & & fluoxetina & C1 & $150 \mathrm{cp}$ (20 mg) & $5 \mathrm{cp} / \mathrm{dia}$ & 30 & 60 & -30 \\
\hline Pac0264 & amitriptilina & & amitriptilina & C1 & $60 \mathrm{cp}(25 \mathrm{mg})$ & $2 \mathrm{cp} / \mathrm{dia}$ & 30 & 60 & 30 \\
\hline Pac2541 & AMYTRIL & Cristália & amitriptilina & $\mathrm{C}_{1}$ & $60 \mathrm{cp}(25 \mathrm{mg})$ & $2 \mathrm{cp} / \mathrm{dia}$ & 30 & 60 & -30 \\
\hline Pac3353 & AMYTRIL & Cristália & amitriptilina & C1 & $60 \mathrm{cp}(25 \mathrm{mg})$ & $2 \mathrm{cp} / \mathrm{dia}$ & 30 & 60 & -30 \\
\hline Pac0989 & sertralina & & sertratina & C1 & $30 \mathrm{cp}(50 \mathrm{mg})$ & $1 \mathrm{cp} / \mathrm{dia}$ & 30 & 60 & -30 \\
\hline Pac2129 & DEPAKENE & Abbott & \begin{tabular}{|l|} 
ácido valpróico \\
(ou derivado)
\end{tabular} & C1 & $75 \mathrm{cp}(250 \mathrm{mg})$ & $2 \mathrm{cp} / \mathrm{dia}$ & 38 & 60 & -23 \\
\hline Pac3117 & imipramina & & imipramina & c1 & $60 \mathrm{cp}$ (25 mg) & $2 \mathrm{cp} / \mathrm{dia}$ & 30 & 60 & -30 \\
\hline Pac3454 & carbamazepina & & carbamazepina & C1 & $90 \mathrm{cp}(200 \mathrm{mg})$ & $3 \mathrm{cp} / \mathrm{dia}$ & 30 & 60 & -30 \\
\hline Pac3480 & DEPAKENE & Abbott & \begin{tabular}{|l|}
$\begin{array}{l}\text { ácido valpróico } \\
\text { (ou derivado) }\end{array}$ \\
\end{tabular} & C1 & $125 \mathrm{cp}(250 \mathrm{mg})$ & $1 \mathrm{cp} / \mathrm{dia}$ & 125 & 60 & 65 \\
\hline Pac3205 & amitriptilina & & amitriptilina & c1 & $100 \mathrm{cp}(25 \mathrm{mg})$ & $3 \mathrm{cp} / \mathrm{dia}$ & 33 & 60 & -27 \\
\hline Pac1682 & sertralina & & sertralina & C1 & $30 \mathrm{cp}(10 \mathrm{mg})$ & $1 \mathrm{cp} / \mathrm{dia}$ & 30 & 60 & -30 \\
\hline Pac1115 & TRAMAL & \begin{tabular}{|l} 
Prizer- \\
Pharmacia
\end{tabular} & tramadol & $\begin{array}{c}A 2- \\
\text { adendo }\end{array}$ & $120 \mathrm{cp}(50 \mathrm{mg})$ & $4 \mathrm{cp} / \mathrm{dia}$ & 30 & 60 & 30 \\
\hline Pac0008 & carbonato de lítio & & litio (e derivado) & $\mathrm{Cl}$ & $30 \mathrm{cp}$ (300 mg) & $1 \mathrm{cp} / \mathrm{dia}$ & 30 & 60 & .30 \\
\hline Pac2258 & AMYTRRIL & Cristália & amitriptilina & $\mathrm{Cl}$ & $60 \mathrm{cp}(25 \mathrm{mg})$ & $2 \mathrm{cp} / \mathrm{dia}$ & 30 & 60 & -30 \\
\hline Pac3168 & DEPAKENE & Abbott & \begin{tabular}{|l|} 
ácido valpróico \\
(ou derivado)
\end{tabular} & C1 & $75 \mathrm{cp} \mathrm{(250} \mathrm{mg)}$ & $2 \mathrm{cp} / \mathrm{dia}$ & 38 & 60 & -23 \\
\hline Pac1732 & RIVOTRIL & Rocho & clonazepam & B1 & $30 \mathrm{cp}(2 \mathrm{mg})$ & $1 \mathrm{cp} / \mathrm{dia}$ & 30 & 60 & .30 \\
\hline Pac1571 & Auoxetina & & fluoxetina & $\mathbf{C 1}$ & $40 \mathrm{cp}(20 \mathrm{mg})$ & 1 cp/dia & 40 & 60 & -20 \\
\hline Pac2272 & DAFORIN & Sigma Pharma & fuoxetina & $\mathrm{Cl}$ & $100 \mathrm{cp}(20 \mathrm{mg})$ & $3 \mathrm{cp} / \mathrm{dia}$ & 33 & 60 & -27 \\
\hline Pac3892 & TRYPTANOL & Prodome & amitriptilina & C1 & $40 \mathrm{cp}(25 \mathrm{mg})$ & $1 \mathrm{cp} / \mathrm{dia}$ & 40 & 60 & -20 \\
\hline Pac3892 & AMPLICTIL & Aventis & clorpromazina & $\mathrm{C} 1$ & \begin{tabular}{|l|}
$40 \mathrm{ml}(0,4$ \\
$\mathrm{mg} / \mathrm{ml})$ \\
\end{tabular} & $0,6 \mathrm{mV} / \mathrm{dia}$ & 67 & 60 & 7 \\
\hline Pac3168 & fluoxetina & & fluoxetina & C1 & $60 \mathrm{cp}(20 \mathrm{mg})$ & 2 cp/dia & 30 & 60 & -30 \\
\hline Pac1611 & AMYTRIL & Cristália & amitriptilina & C1 & 4025 (25 mg) & $125 /$ dia & 40 & 60 & -20 \\
\hline Pac2678 & DEPAKENE & Abbott & $\begin{array}{l}\text { ácido valpróico } \\
\text { (ou derivado) }\end{array}$ & C1 & $25 \mathrm{cp}(250 \mathrm{mg})$ & $4 \mathrm{cp} / \mathrm{dia}$ & 6 & 60 & -54 \\
\hline Pac3410 & gabapentina & & gabapentina & $\mathrm{Cl}$ & $70 \mathrm{cp}(300 \mathrm{mg})$ & $3 \mathrm{cp} / \mathrm{dia}$ & 23 & 60 & -37 \\
\hline Pac2414 & TRIPSOL & Cazi & amitriptilina & c1 & $0(1$ & $2 /$ dia & 0 & 60 & -60 \\
\hline Pac1696 & DAFORIN & Sigma Pharma & fluoxetina & C1 & $60 \mathrm{cp}(20 \mathrm{mg})$ & $2 \mathrm{cp} / \mathrm{dia}$ & 30 & 60 & 30 \\
\hline Pac1648 & carbamazepina & & carbamazepina & C1 & $30 \mathrm{cp}(200 \mathrm{mg})$ & $1 \mathrm{cp} / \mathrm{dia}$ & 30 & 60 & -30 \\
\hline Pac2845 & AMYTRIL & Cristália & amitriptilina & C1 & $100 \mathrm{cp}(25 \mathrm{mg})$ & $3 \mathrm{cp} / \mathrm{dia}$ & 33 & 60 & -27 \\
\hline
\end{tabular}


$D T=$ Dias de tratamento fornecido $\quad L L=$ Limite legal

\begin{tabular}{|c|c|c|c|c|c|c|c|c|c|}
\hline $\begin{array}{l}\text { código } \\
\text { paciente }\end{array}$ & Prescrição & Indústria & Principio Ativo & Alinea & Fornecimento & Posologia & DT & LL & DT - LL \\
\hline Pac2848 & $\begin{array}{l}\text { codeina; } \\
\text { beladona }\end{array}$ & & codeina; beladona & $\begin{array}{c}\mathrm{A} 2- \\
\text { adendo }\end{array}$ & $\begin{array}{l}20 \mathrm{ml}(30 / 500 \\
\mathrm{mg} / \mathrm{ml})\end{array}$ & $1,5 \mathrm{ml} / \mathrm{dia}$ & 13 & 60 & -47 \\
\hline Pac0261 & AMVTRIL & Cristália & amitriptilina & C1 & $120 \mathrm{cp}(25 \mathrm{mg})$ & $4 \mathrm{cp} / \mathrm{dia}$ & 30 & 60 & -30 \\
\hline Pac0261 & $\begin{array}{l}\text { codeina; } \\
\text { paracetamol }\end{array}$ & & $\begin{array}{l}\text { codeina: } \\
\text { paracelamol }\end{array}$ & $\begin{array}{c}\text { A2 - } \\
\text { adendo }\end{array}$ & $120 \mathrm{cp}(30 \mathrm{mg})$ & $4 \mathrm{cp} / \mathrm{dia}$ & 30 & 60 & -30 \\
\hline Pac3168 & fenobarbital & & fenobarbital & \begin{tabular}{|c|}
$\mathrm{B1}-$ \\
adendo
\end{tabular} & $40 \mathrm{cp}$ (100 mg) & $1 \mathrm{cp} / \mathrm{dia}$ & 40 & 60 & -20 \\
\hline Pac3168 & tramadol & & tramadol & $\begin{array}{c}\mathrm{A} 2- \\
\text { adendo }\end{array}$ & $30 \mathrm{cp}(50 \mathrm{mg})$ & $4 \mathrm{cp} / \mathrm{dia}$ & 8 & 60 & -53 \\
\hline Pac3168 & TRAMAL & $\begin{array}{l}\text { Pfizer- } \\
\text { Pharmacia }\end{array}$ & tramadol & $\begin{array}{c}\text { A2 - } \\
\text { adendo }\end{array}$ & $20 \mathrm{cp}(50 \mathrm{mg})$ & $3 \mathrm{cp} / \mathrm{dia}$ & 7 & 60 & -53 \\
\hline Pac2689 & $\begin{array}{l}\text { codeina; } \\
\text { paracetamol }\end{array}$ & & $\begin{array}{l}\text { codeina; } \\
\text { paracetamol }\end{array}$ & $\begin{array}{c}\mathrm{A2}- \\
\text { adendo }\end{array}$ & $30 \mathrm{cp}(30 \mathrm{mg})$ & $3 \mathrm{cp} / \mathrm{dia}$ & 10 & 60 & -50 \\
\hline Pac1035 & AMYTRIL & Cristália & amitriptilina & $\mathrm{c} 1$ & $120 \mathrm{cp}(25 \mathrm{mg})$ & $4 \mathrm{cp} / \mathrm{dia}$ & 30 & 60 & -30 \\
\hline Pac1035 & carbamazepina & & carbamazepina & c1 & $90 \mathrm{cp}(200 \mathrm{mg})$ & $3 \mathrm{cp} / \mathrm{dia}$ & 30 & 60 & -30 \\
\hline Pac1035 & LONGACTIL & Cristália & clorpromazina & $\mathrm{Cl}_{1}$ & $\begin{array}{l}20 \mathrm{ml}(0,4 \\
\mathrm{mg} / \mathrm{ml})\end{array}$ & $0,6 \mathrm{ml} / \mathrm{dia}$ & 33 & 60 & -27 \\
\hline Pac3931 & fenitoina & & \begin{tabular}{|l} 
fenitoina \\
(hidantoina)
\end{tabular} & $\mathrm{C}_{1}$ & $100 \mathrm{cp}(100 \mathrm{mg})$ & $3 \mathrm{cp} / \mathrm{dia}$ & 33 & 60 & -27 \\
\hline Pac0282 & AMYTRIL & Cristália & amitriptilina & C1 & $100 \mathrm{cp}(25 \mathrm{mg})$ & $3 \mathrm{cp} / \mathrm{dia}$ & 33 & 60 & -27 \\
\hline Pac0282 & CINETOL & Cristália & biperideno & $\mathrm{ci}$ & $100 \mathrm{cp}(2 \mathrm{mg})$ & $3 \mathrm{cp} / \mathrm{dia}$ & 33 & 60 & -27 \\
\hline Pac0282 & RIVOTRIL & Roche & clonazepam & B1 & $60 \mathrm{cp}(2 \mathrm{mg})$ & 2 cp/dia & 30 & 60 & -30 \\
\hline Pac0183 & fenitoina & & \begin{tabular}{|l} 
fenitoina \\
(hidantoina)
\end{tabular} & C1 & $60 \mathrm{cp}(100 \mathrm{mg})$ & $2 \mathrm{cp} / \mathrm{dia}$ & 30 & 60 & .30 \\
\hline Pac2838 & fenitoina & & \begin{tabular}{|l} 
fenitoina \\
(hidantoina)
\end{tabular} & C1 & $60 \mathrm{cp}(100 \mathrm{mg})$ & $2 \mathrm{cp} / \mathrm{dia}$ & 30 & 60 & .30 \\
\hline Pac2838 & AMYTRIL & Cristália & amitriptilina & $\mathrm{C}_{1}$ & $40 \mathrm{cp}(25 \mathrm{mg})$ & $1 \mathrm{cp} / \mathrm{dia}$ & 40 & 60 & -20 \\
\hline Pac0250 & AMYTRIL & Cristália & amitriptilina & $\mathrm{C1}$ & $40 \mathrm{cp}(25 \mathrm{mg})$ & 1 cpidia & 40 & 60 & .20 \\
\hline Pac3790 & AMNTRIL & Cristália & amitriptilina & C1 & $60 \mathrm{cp}(25 \mathrm{mg})$ & $2 \mathrm{cp} / \mathrm{dia}$ & 30 & 60 & -30 \\
\hline Pac2614 & DAFORIN & Sigma Pharma & fluoxetina & $\mathrm{Cl}$ & $60 \mathrm{cp}(20 \mathrm{mg})$ & $2 \mathrm{cp} / \mathrm{dia}$ & 30 & 60 & -30 \\
\hline Pac4034 & amitriptilina & & amitriptilina & C1 & $60 \mathrm{cp}(25 \mathrm{mg})$ & 2 cp/dia & 30 & 60 & -30 \\
\hline Pac3472 & AMYTRIL & Cristália & amitriplilina & C1 & $40 \mathrm{cp}(25 \mathrm{mg})$ & $1 \mathrm{cp} / \mathrm{dia}$ & 40 & 60 & -20 \\
\hline Pac1805 & PROLOPA & Roche & \begin{tabular}{|l|} 
levodopa $\mathrm{a}$ \\
benserazida
\end{tabular} & $\mathrm{Cl}$ & $90 \mathrm{cp}(250 \mathrm{mg})$ & 1,5 cp/dia & 60 & 60 & 0 \\
\hline Pac1805 & PROLOPA HBS & Roche & $\begin{array}{l}\text { levodopa e } \\
\text { benserazida - } \\
\text { assoc. }\end{array}$ & $\mathrm{cl}$ & $30 \mathrm{cp}(125 \mathrm{mg})$ & $1 \mathrm{cp} / \mathrm{dia}$ & 30 & 60 & -30 \\
\hline Pac1053 & sertralina & & sertralina & C1 & $30 \mathrm{cp}(50 \mathrm{mg})$ & $1 \mathrm{cp} / \mathrm{dia}$ & 30 & 60 & -30 \\
\hline Pac1455 & imipramina & & imipramina & $\mathrm{Cl}$ & $30 \mathrm{cp}(25 \mathrm{mg})$ & $1 \mathrm{cp} / \mathrm{dia}$ & 30 & 60 & -30 \\
\hline Pac4102 & AMYTRIL & Cristália & amitriptilina & C1 & $60 \mathrm{cp}(25 \mathrm{mg})$ & $2 \mathrm{cp} / \mathrm{dia}$ & 30 & 60 & -30 \\
\hline Pac3634 & carbamazepina & & carbamazepina & c1 & $180 \mathrm{cp}(200 \mathrm{mg})$ & $4,5 \mathrm{cp} / \mathrm{dia}$ & 40 & 60 & -20 \\
\hline Pac3634 & fenobarbital & & fenobarbital & $\begin{array}{c}\text { B1 - } \\
\text { adendo }\end{array}$ & $40 \mathrm{cp}$ (100 mg) & $1 \mathrm{cp} / \mathrm{dia}$ & 40 & 60 & -20 \\
\hline Pac2149 & carbamazepina & & carbamazepina & C1 & $60 \mathrm{cp}(200 \mathrm{mg})$ & $2 \mathrm{cp} / \mathrm{dia}$ & 30 & 60 & -30 \\
\hline Pac2149 & DAFORIN & Sigma Pharma & nuoxetina & c1 & $60 \mathrm{cp}(20 \mathrm{mg})$ & $2 \mathrm{cp} / \mathrm{dia}$ & 30 & 60 & -30 \\
\hline Pac2978 & sertralina & & sertralina & $\mathrm{C1}$ & $6 \mathrm{cp}(50 \mathrm{mg})$ & 1 cp/dia & 6 & 60 & -54 \\
\hline Pac1926 & $\begin{array}{l}\text { codeina; } \\
\text { paracetamol }\end{array}$ & & \begin{tabular}{|l} 
codeina; \\
paracetamol
\end{tabular} & $\begin{array}{c}\text { A2 - } \\
\text { adendo }\end{array}$ & $120 \mathrm{cp}$ (30 mg) & 4 cp/dia & 30 & 60 & -30 \\
\hline Pac1669 & AMYTRIL & Cristália & amitriptilina & c1 & $60 \mathrm{cp}(25 \mathrm{mg})$ & $2 \mathrm{cp} / \mathrm{dia}$ & 30 & 60 & -30 \\
\hline Pac1930 & AMYTRIL & Cristália & amitriptilina & C1 & $40 \mathrm{cp}(25 \mathrm{mg})$ & $1 \mathrm{cp} / \mathrm{dia}$ & 40 & 60 & -20 \\
\hline Pac1930 & PROLOPA & Roche & $\begin{array}{l}\text { levodopa e } \\
\text { benserazida }\end{array}$ & c1 & $30 \mathrm{cp}(200 \mathrm{mg})$ & $1,5 \mathrm{co} / \mathrm{dia}$ & 20 & 60 & -40 \\
\hline Pac1930 & amantadina & & amantadina & $\mathrm{Cl}$ & $90 \mathrm{cp}(100 \mathrm{mg})$ & $3 \mathrm{cp} / \mathrm{dia}$ & 30 & 60 & -30 \\
\hline Pac3861 & AMITRIL & Cristália & amitriptilina & $\mathrm{C1}$ & $40 \mathrm{cp}(25 \mathrm{mg})$ & $1 \mathrm{cp} / \mathrm{dia}$ & 40 & 60 & -20 \\
\hline Pac3861 & clorpromazina & & clorpromazina & C1 & $\begin{array}{l}40 \mathrm{ml}(0,4 \\
\mathrm{mg} / \mathrm{ml})\end{array}$ & $0,6 \mathrm{~m} / \mathrm{dia}$ & 67 & 60 & 7 \\
\hline Pac1176 & \begin{tabular}{|l} 
codeina; \\
paracetamol
\end{tabular} & & $\begin{array}{l}\text { codeina; } \\
\text { paracetamol }\end{array}$ & $\begin{array}{c}\text { A2 - } \\
\text { adendo }\end{array}$ & $30 \mathrm{cp}(30 \mathrm{mg})$ & $3 \mathrm{cp} / \mathrm{dia}$ & 10 & 60 & -50 \\
\hline Pac0503 & sertralina & & sertralina & $\mathrm{c1}$ & $30 \mathrm{cp}(50 \mathrm{mg})$ & $1 \mathrm{cp} / \mathrm{dia}$ & 30 & 60 & -30 \\
\hline Pac2620 & primidona & & primidona & $\mathrm{Cl}$ & $60 \mathrm{cp}(250 \mathrm{mg})$ & $1,5 \mathrm{cp} / \mathrm{dia}$ & 40 & 60 & -20 \\
\hline
\end{tabular}


$D T=$ Dias de tratamento fornecido $\quad L L=$ Limite legal

\begin{tabular}{|c|c|c|c|c|c|c|c|c|c|}
\hline $\begin{array}{l}\text { código } \\
\text { paciente }\end{array}$ & Prescrição & Indústria & Principio Ativo & Alinea & Fornecimento & Posologia & DT & LL & DT - LL \\
\hline Pac2620 & sertralina & & sertralina & C1 & $120 \mathrm{cp}(50 \mathrm{mg})$ & $3 \mathrm{cp} / \mathrm{dia}$ & 40 & 60 & -20 \\
\hline Pac2620 & $\begin{array}{l}\text { codeina; } \\
\text { paracetamol }\end{array}$ & & $\begin{array}{l}\text { codeína; } \\
\text { paracetamol }\end{array}$ & \begin{tabular}{|c|} 
A2 - \\
adendo
\end{tabular} & $80 \mathrm{cp}(30 \mathrm{mg})$ & $2 \mathrm{cp} / \mathrm{dia}$ & 40 & 60 & -20 \\
\hline Pac3626 & fenobarbital & & fenobarbital & \begin{tabular}{|c|}
$\mathrm{B1}-$ \\
adendo
\end{tabular} & $40 \mathrm{cp}(100 \mathrm{mg})$ & $1 \mathrm{cp} / \mathrm{dia}$ & 40 & 60 & -20 \\
\hline Pac1269 & nortriptilina & & nortriptilina & $\mathrm{C1}$ & $30 \mathrm{cp}(25 \mathrm{mg})$ & $1 \mathrm{cp} / \mathrm{dia}$ & 30 & 60 & -30 \\
\hline Pac0431 & fenobarbital & & fenobarbital & $\begin{array}{c}\text { B1- } \\
\text { adendo }\end{array}$ & $40 \mathrm{cp}(100 \mathrm{mg})$ & $1 \mathrm{cp} / \mathrm{dia}$ & 40 & 60 & -20 \\
\hline Pac0431 & selegilina & & selegilina & C1 & $40 \mathrm{cp}(5 \mathrm{mg})$ & $1 \mathrm{cp} / \mathrm{dia}$ & 40 & 60 & -20 \\
\hline Pac0431 & pramipexol & & pramipexol & $\mathrm{C1}$ & $40 \mathrm{cp}(1 \mathrm{mg})$ & $3 \mathrm{cp} / \mathrm{dia}$ & 13 & 60 & -47 \\
\hline Pac2984 & $\begin{array}{l}\text { Codeina; } \\
\text { paracetamol }\end{array}$ & & $\begin{array}{l}\text { codeina; } \\
\text { paracetamol }\end{array}$ & $\begin{array}{c}\mathrm{A} 2- \\
\text { adendo }\end{array}$ & $90 \mathrm{cp}(30 \mathrm{mg})$ & $3 \mathrm{cp} / \mathrm{dia}$ & 30 & 60 & -30 \\
\hline Pac0983 & imipramina & & imipramina & C1 & $150 \mathrm{cp}(25 \mathrm{mg})$ & $5 \mathrm{cp} / \mathrm{dia}$ & 30 & 60 & -30 \\
\hline Pac2146 & DAFORIN & Sigma Pharma & fluoxetina & $c 1$ & $40 \mathrm{cp}(20 \mathrm{mg})$ & $1 \mathrm{cp} / \mathrm{dia}$ & 40 & 60 & -20 \\
\hline Pac2146 & PROGRESSE & Biosintética & gabapentina & $\mathrm{c} 1$ & $30 \mathrm{cp}(300 \mathrm{mg})$ & $1 \mathrm{cp} / \mathrm{dia}$ & 30 & 60 & -30 \\
\hline Pac2481 & sertralina & & sertralina & C1 & $30 \mathrm{cp}(50 \mathrm{mg})$ & $1 \mathrm{cp} / \mathrm{dia}$ & 30 & 60 & -30 \\
\hline Pac1940 & fenobarbital & & fenobarbital & \begin{tabular}{|c|} 
B1 - \\
adendo
\end{tabular} & $60 \mathrm{cp}(100 \mathrm{mg})$ & $2 \mathrm{cp} / \mathrm{dia}$ & 30 & 60 & -30 \\
\hline Pac3168 & fluoxetina & & fluoxetina & $\mathrm{C1}$ & $30 \mathrm{cp}(20 \mathrm{mg})$ & $1 \mathrm{cp} / \mathrm{dia}$ & 30 & 60 & -30 \\
\hline Pac1223 & TEGRETOL & Novartis & carbamazepina & C1 & $30 \mathrm{cp}(200 \mathrm{mg})$ & $1 \mathrm{cp} / \mathrm{dia}$ & 30 & 60 & -30 \\
\hline Pac3053 & imipramina & & imipramina & c1 & $90 \mathrm{cp}(25 \mathrm{mg})$ & 3 cp/dia & 30 & 60 & -30 \\
\hline Pac3053 & LONGACTIL & Cristália & clorpromazina & $\mathrm{C1}$ & $\begin{array}{l}60 \mathrm{ml}(0,4 \\
\mathrm{mg} / \mathrm{ml}) \\
\end{array}$ & $1,6 \mathrm{~m} / \mathrm{dia}$ & 38 & 60 & -23 \\
\hline Pac1587 & ACTIFEDRIN & Zest & $\begin{array}{l}\text { triprolidina; } \\
\text { pseudoefedrina }\end{array}$ & D1 & $\begin{array}{l}100 \mathrm{ml}(0,5 / 5 \\
\mathrm{mg} / \mathrm{ml})\end{array}$ & $2,5 \mathrm{mU} / \mathrm{dia}$ & 40 & & \\
\hline Pac0413 & fenobarbital & & fenobarbital & \begin{tabular}{|c|} 
B1 - \\
adendo
\end{tabular} & $40 \mathrm{cp}(100 \mathrm{mg})$ & $1 \mathrm{cp} / \mathrm{dia}$ & 40 & 60 & -20 \\
\hline Pac0413 & clobazam & & clobazam & B1 & $60 \mathrm{cp}(10 \mathrm{mg})$ & $2 \mathrm{cp} / \mathrm{dia}$ & 30 & 60 & .30 \\
\hline Pac0413 & carbarnazepina & & carbamazepina & $\mathrm{Cl}$ & $50 \mathrm{cp}(200 \mathrm{mg})$ & $1,5 \mathrm{cp} / \mathrm{dia}$ & 33 & 60 & -27 \\
\hline Pac1309 & clobazam & & clobazam & B1 & $80 \mathrm{cp}(10 \mathrm{mg})$ & $2,5 \mathrm{cp} / \mathrm{dia}$ & 32 & 60 & -28 \\
\hline Pac1309 & carbamazepina & & carbamazepina & c1 & $90 \mathrm{cp}(200 \mathrm{mg})$ & $3 \mathrm{cp} / \mathrm{dia}$ & 30 & 60 & -30 \\
\hline Pac1309 & imipramina & & imipramina & C1 & $120 \mathrm{cp}(25 \mathrm{mg})$ & $4 \mathrm{cp} / \mathrm{dia}$ & 30 & 60 & -30 \\
\hline $\mathrm{Pac} 0273$ & $\begin{array}{l}\text { OORLESS- } \\
\text { TRAMADOL }\end{array}$ & Uniāo Quimica & tramadol & $\begin{array}{c}\mathrm{A} 2- \\
\text { adendo }\end{array}$ & $90 \mathrm{cp}(50 \mathrm{mg})$ & $3 \mathrm{cp} / \mathrm{dia}$ & 30 & 60 & -30 \\
\hline Pac1898 & morfina & & morfina & A1 & $60 \mathrm{cp}(10 \mathrm{mg})$ & $2 \mathrm{cp} / \mathrm{dia}$ & 30 & 30 & 0 \\
\hline Pac1898 & amitriptilina & & amitriptilina & C1 & $60 \mathrm{cp}(25 \mathrm{mg})$ & $2 \mathrm{cp} / \mathrm{dia}$ & 30 & 60 & -30 \\
\hline Pac1898 & AMPLICTIL & Aventis & clorpromazina & $\mathrm{C1}$ & $\begin{array}{l}20 \mathrm{ml}(0,4 \\
\mathrm{mg} / \mathrm{ml})\end{array}$ & $0,8 \mathrm{ml} / \mathrm{dia}$ & 25 & 60 & -35 \\
\hline Pac1120 & imipramina & & imipramina & $\mathrm{C1}$ & $30 \mathrm{cp}(150 \mathrm{mg})$ & $1 \mathrm{cp} / \mathrm{dia}$ & 30 & 60 & -30 \\
\hline Pac1120 & LONGACTIL & Cristália & clorpromazina & $\mathrm{Cl}$ & \begin{tabular}{|l|}
$40 \mathrm{ml}(0,4$ \\
$\mathrm{mg} / \mathrm{ml})$
\end{tabular} & $0,6 \mathrm{~m} / \mathrm{dia}$ & 67 & 60 & 7 \\
\hline Pac3947 & AMYTRIL & Cristália & amitriptilina & C1 & $60 \mathrm{cp}(25 \mathrm{mg})$ & $2 \mathrm{cp} / \mathrm{dia}$ & 30 & 60 & -30 \\
\hline Pac3947 & LONGACTIL & Cristália & clorpromazina & $\mathrm{C1}$ & \begin{tabular}{|l|}
$40 \mathrm{ml}(0,4$ \\
$\mathrm{mg} / \mathrm{ml})$
\end{tabular} & $1,2 \mathrm{ml} / \mathrm{dia}$ & 33 & 60 & -27 \\
\hline Pac0567 & AMYTRIL & Cristália & amitriptilina & C1 & $40 \mathrm{cp}$ (25 mg) & $1 \mathrm{cp} / \mathrm{dia}$ & 40 & 60 & -20 \\
\hline Pac0567 & LONGACTIL & Cristália & clorpromazina & $\mathrm{Cl}$ & $\begin{array}{l}40 \mathrm{ml}(0,4 \\
\mathrm{mg} / \mathrm{ml})\end{array}$ & $1 \mathrm{~m}$ Udia & 40 & 60 & -20 \\
\hline Pac2716 & AMVTRIL & Cristália & amitriptilina & c1 & $100 \mathrm{cp}(25 \mathrm{mg})$ & $3 \mathrm{cp} / \mathrm{dia}$ & 33 & 60 & -27 \\
\hline Pac0902 & fluoxetina & & fluoxetina & $\mathrm{C1}$ & $40 \mathrm{cp}(20 \mathrm{mg})$ & $1 \mathrm{cp} / \mathrm{dia}$ & 40 & 60 & -20 \\
\hline Pac0492 & $\begin{array}{l}\text { DORLESS- } \\
\text { TRAMADOL } \\
\end{array}$ & Uniāo Química & tramadol & $\begin{array}{c}\text { A2 - } \\
\text { adendo }\end{array}$ & $90 \mathrm{cp}(50 \mathrm{mg})$ & $3 \mathrm{cp} / \mathrm{dia}$ & 30 & 60 & -30 \\
\hline Pac3101 & amitriptilina & & amitriptitina & C1 & $40 \mathrm{cp}(25 \mathrm{mg})$ & $1 \mathrm{cp} / \mathrm{dia}$ & 40 & 60 & -20 \\
\hline Pac2587 & DAFORIN & Sigma Pharma & fluoxetina & C1 & $60 \mathrm{cp}(20 \mathrm{mg})$ & $2 \mathrm{cp} / \mathrm{dia}$ & 30 & 60 & -30 \\
\hline Pac3451 & primidona & & primidona & C1 & $30 \mathrm{cp}(250 \mathrm{mg})$ & $1 \mathrm{cp} / \mathrm{dia}$ & 30 & 60 & -30 \\
\hline Pac1072 & carbamazepina & & carbamazepina & C1 & $90 \mathrm{cp}(200 \mathrm{mg})$ & $1 \mathrm{cp} / \mathrm{dia}$ & 90 & 60 & 30 \\
\hline Pac1072 & amitriptilina & & amitriptilina & C1 & $40 \mathrm{cp} \mathrm{(25 \textrm {mg } )}$ & $1 \mathrm{cp} / \mathrm{dia}$ & 40 & 60 & -20 \\
\hline Pac2952 & PROLOPA & Roche & $\begin{array}{l}\text { levodopa } \theta \\
\text { benserazida }\end{array}$ & C1 & $60 \mathrm{cp}(250 \mathrm{mg})$ & $0,75 \mathrm{cp} / \mathrm{dia}$ & 80 & 60 & 20 \\
\hline
\end{tabular}


$\mathrm{DT}=$ Dias de tratamento fornecido $\quad \mathrm{LL}=$ Limite legal

\begin{tabular}{|c|c|c|c|c|c|c|c|c|c|}
\hline $\begin{array}{l}\text { código } \\
\text { paciente }\end{array}$ & Prescrição & Indústria & Princípio Ativo & Alínea & Fornecimento & Posologia & DT & LL & DT - LL \\
\hline Pac2952 & selegilina & & selegilina & C1 & $60 \mathrm{cp}(5 \mathrm{mg})$ & $2 \mathrm{cp} / \mathrm{dia}$ & 30 & 60 & -30 \\
\hline Pac2952 & SIFROL & Boehringer & pramipexol & $\mathrm{Cl}$ & $\begin{array}{l}150 \mathrm{cp}(0,25 \\
\mathrm{mg})\end{array}$ & $5 \mathrm{cp} / \mathrm{dia}$ & 30 & 60 & -30 \\
\hline Pac0074 & sentralina & & sertralina & $c_{1}$ & $15 \mathrm{cp}(50 \mathrm{mg})$ & $0,5 \mathrm{cp} / \mathrm{dia}$ & 30 & 60 & .30 \\
\hline Pac3881 & sertralina & & sertralina & $\mathrm{c1}$ & $30 \mathrm{cp}(50 \mathrm{mg})$ & $1 \mathrm{cp} / \mathrm{dia}$ & 30 & 60 & -30 \\
\hline Pac3692 & TRAMAL & $\begin{array}{l}\text { Pfizer- } \\
\text { Pharmacia }\end{array}$ & tramadol & \begin{tabular}{|c|}
$\mathrm{A} 2-$ \\
adendo
\end{tabular} & $60 \mathrm{cp}(50 \mathrm{mg})$ & $4 \mathrm{cp} / \mathrm{dia}$ & 15 & 60 & -45 \\
\hline Pac3692 & AMYTRIL & Cristália & amitriptilina & $\mathrm{C1}$ & $40 \mathrm{cp}(25 \mathrm{mg})$ & $1 \mathrm{cp} / \mathrm{dia}$ & 40 & 60 & -20 \\
\hline Pac2440 & TRAMAL & $\begin{array}{l}\text { Pfizer- } \\
\text { Pharmacia }\end{array}$ & tramadol & $\begin{array}{c}\mathrm{A} 2- \\
\text { adendo }\end{array}$ & $40 \mathrm{cp}(50 \mathrm{mg})$ & $4 \mathrm{cp} / \mathrm{dia}$ & 10 & 60 & -50 \\
\hline Pac0841 & sertralina & & sertralina & C1 & $30 \mathrm{cp}(50 \mathrm{mg})$ & $1 \mathrm{cp} / \mathrm{dia}$ & 30 & 60 & -30 \\
\hline Pac0770 & AMYTRIL & Cristália & amitriptilina & C1 & $40 \mathrm{cp}(25 \mathrm{mg})$ & $1 \mathrm{cp} / \mathrm{dia}$ & 40 & 60 & -20 \\
\hline Pac0770 & TRAMAL & $\begin{array}{l}\text { Pfizer- } \\
\text { Pharmacia }\end{array}$ & tramadol & \begin{tabular}{|c|}
$\begin{array}{c}A 2 \\
\text { adendo }\end{array}$ \\
\end{tabular} & $60 \mathrm{cp}(50 \mathrm{mg})$ & $3 \mathrm{cp} / \mathrm{dia}$ & 20 & 60 & -40 \\
\hline Pac1325 & $\begin{array}{l}\text { codeina; } \\
\text { paracelamol }\end{array}$ & & $\begin{array}{l}\text { codeina; } \\
\text { paracetamol }\end{array}$ & $\begin{array}{c}\text { A2 - } \\
\text { adendo }\end{array}$ & $120 \mathrm{cp}(30 \mathrm{mg})$ & $4 \mathrm{cp} / \mathrm{dia}$ & 30 & 60 & -30 \\
\hline Pac2062 & fenobarbital & & fenobarbital & $\begin{array}{c}\mathrm{B1}- \\
\text { adendo }\end{array}$ & $60 \mathrm{cp}(100 \mathrm{mg})$ & $2 \mathrm{cp} / \mathrm{dia}$ & 30 & 60 & -30 \\
\hline Pac3840 & imipramina & & imipramina & $\mathrm{Cl}_{1}$ & $180 \mathrm{cp}(25 \mathrm{mg})$ & $6 \mathrm{cp} / \mathrm{dia}$ & 30 & 60 & -30 \\
\hline Pac2078 & $\begin{array}{l}\text { DORLESS- } \\
\text { TRAMADOL }\end{array}$ & Uniāo Quimica & tramadol & $\begin{array}{c}\begin{array}{c}A 2- \\
\text { adendo }\end{array} \\
\end{array}$ & $30 \mathrm{cp}(50 \mathrm{mg})$ & $3 \mathrm{cp} / \mathrm{dia}$ & 10 & 60 & -50 \\
\hline Pac3404 & carbamazepina & & carbamazepina & C1 & $60 \mathrm{cp}(200 \mathrm{mg})$ & $2 \mathrm{cp} / \mathrm{dia}$ & 30 & 60 & -30 \\
\hline Pac3404 & DEPAKENE & Abbott & $\begin{array}{l}\text { ácido valpróico } \\
\text { (ou derivado) }\end{array}$ & C1 & $100 \mathrm{cp}(500 \mathrm{mg})$ & $3 \mathrm{cp} / \mathrm{dia}$ & 33 & 60 & -27 \\
\hline Pac3399 & TRAMAL & \begin{tabular}{|l|} 
Pfizer- \\
Pharmacia \\
\end{tabular} & tramadol & \begin{tabular}{|c|}
$\mathrm{A} 2-$ \\
adendo
\end{tabular} & $80 \mathrm{cp} \mathrm{(50} \mathrm{mg)}$ & $8 \mathrm{cp} / \mathrm{dia}$ & 10 & 60 & -50 \\
\hline Pac3399 & clorpromazina & & clorpromazina & c1 & $\begin{array}{l}20 \mathrm{ml}(0,4 \\
\mathrm{mg} / \mathrm{ml})\end{array}$ & $0.8 \mathrm{~m} / \mathrm{dia}$ & 25 & 60 & -35 \\
\hline Pac3767 & $\begin{array}{l}\text { DORLESS- } \\
\text { TRAMADOL }\end{array}$ & Uniäo Quimica & tramadol & $\begin{array}{c}\text { A2 - } \\
\text { adendo }\end{array}$ & $30 \mathrm{cp}(50 \mathrm{mg})$ & $3 \mathrm{cp} / \mathrm{dia}$ & 10 & 60 & -50 \\
\hline Pac2475 & GARDENAL & Aventis & fenobarbital & \begin{tabular}{|c|} 
B1 - \\
adendo
\end{tabular} & $60 \mathrm{cp}(50 \mathrm{mg})$ & $2 \mathrm{cp} / \mathrm{dia}$ & 30 & 60 & -30 \\
\hline Pac2058 & cartamazepina & & carbamazepina & $\mathrm{Cl}$ & $40 \mathrm{cp} \mathrm{(200} \mathrm{mg)}$ & $2 \mathrm{cp} / \mathrm{dia}$ & 20 & 60 & -40 \\
\hline Pac4072 & HIDANTAL & Aventis & \begin{tabular}{|l}
$\begin{array}{l}\text { fenitoina } \\
\text { (hidantoina) }\end{array}$ \\
\end{tabular} & C1 & $60 \mathrm{cp}(100 \mathrm{mg})$ & $2 \mathrm{cp} / \mathrm{dia}$ & 30 & 60 & -30 \\
\hline Pac2506 & amitriptitina & & amitriptilina & c1 & $120 \mathrm{cp}(25 \mathrm{mg})$ & $4 \mathrm{cp} / \mathrm{dia}$ & 30 & 60 & -30 \\
\hline Pac3236 & fluoxetina & & fluoxelina & C1 & $40 \mathrm{cp}(20 \mathrm{mg})$ & $1 \mathrm{cp} / \mathrm{dia}$ & 40 & 60 & -20 \\
\hline Pac0608 & amitriptilina & & amitriptilina & C1 & $40 \mathrm{cp}$ (25 mg) & 1 cp'dia & 40 & 60 & -20 \\
\hline Pac0919 & amitriptilina & & amitriptilina & C1 & $100 \mathrm{cp}(25 \mathrm{mg})$ & $3 \mathrm{cp} / \mathrm{dia}$ & 33 & 60 & -27 \\
\hline Pac0858 & carbamazepina & & carbamazepina & C1 & $270 \mathrm{cp}(200 \mathrm{mg})$ & $9 \mathrm{cp} / \mathrm{dia}$ & 30 & 60 & -30 \\
\hline Pac0858 & URBANIL & Aventis & clobazam & B1 & $60 \mathrm{cp}(20 \mathrm{mg})$ & $2 \mathrm{cp} / \mathrm{dia}$ & 30 & 60 & -30 \\
\hline Pac3920 & PROLOPA & Roche & $\begin{array}{l}\text { levodopa } \mathrm{e} \\
\text { benserazida }\end{array}$ & C1 & $120 \mathrm{cp}(250 \mathrm{mg})$ & $4 \mathrm{cp} / \mathrm{dia}$ & 30 & 60 & -30 \\
\hline Pac2477 & $\begin{array}{l}\text { DORLESS- } \\
\text { TRAMADOL }\end{array}$ & Uniāo Química & tramadol & $\begin{array}{c}\text { A2 - } \\
\text { adendo }\end{array}$ & $30 \mathrm{cp}(50 \mathrm{mg})$ & $3 \mathrm{cp} / \mathrm{dia}$ & 10 & 60 & -50 \\
\hline Pac3875 & fenobarbital & & fenobarbital & \begin{tabular}{|c|}
$\begin{array}{c}\text { B1 - } \\
\text { adendo }\end{array}$ \\
\end{tabular} & $40 \mathrm{cp}(100 \mathrm{mg})$ & $1 \mathrm{cp} / \mathrm{dia}$ & 40 & 60 & -20 \\
\hline Pac3875 & carbamazepina & & carbamazepina & $\mathrm{Cl}$ & $90 \mathrm{cp}(200 \mathrm{mg})$ & $3 \mathrm{cp} / \mathrm{dia}$ & 30 & 60 & -30 \\
\hline Pac2848 & $\begin{array}{l}\text { Codeina; } \\
\text { beladona }\end{array}$ & & codeina; beladona & $\begin{array}{c}2- \\
\text { adendo }\end{array}$ & \begin{tabular}{|l|}
$20 \mathrm{ml}(30 / 500$ \\
$\mathrm{mg} / \mathrm{ml})$
\end{tabular} & $1,5 \mathrm{ml} / \mathrm{dia}$ & 13 & 60 & -47 \\
\hline Pac2784 & PROLOPA & Roche & \begin{tabular}{|l|} 
levodopa $a$ \\
benserazida
\end{tabular} & C1 & $50 \mathrm{cp}(250 \mathrm{mg})$ & $2 \mathrm{cp} / \mathrm{dia}$ & 25 & 60 & -35 \\
\hline Pac2640 & DAFORIN & Sigma Pharma & fluoxetina & C1 & $40 \mathrm{cp}(20 \mathrm{mg})$ & $1 \mathrm{cp} / \mathrm{dia}$ & 40 & 60 & -20 \\
\hline Pac2663 & NEULEPTIL & Aventis & periciazina & C1 & $\begin{array}{l}20 \mathrm{ml}(0,4 \\
\mathrm{mg} / \mathrm{ml})\end{array}$ & $0,2 \mathrm{mV} / \mathrm{dia}$ & 100 & 60 & 40 \\
\hline Pac0065 & $\begin{array}{l}\text { DORLESS- } \\
\text { TRAMADOL }\end{array}$ & Uniāo Quimica & tramadol & $\begin{array}{c}\text { A2 - } \\
\text { adendo }\end{array}$ & $30 \mathrm{cp}(50 \mathrm{mg})$ & $3 \mathrm{cp} / \mathrm{dia}$ & 10 & 60 & -50 \\
\hline Pac0840 & AMYTRIL & Cristália & amitriptilina & C1 & $150 \mathrm{cp}(25 \mathrm{mg})$ & $5 \mathrm{cp} / \mathrm{dia}$ & 30 & 60 & -30 \\
\hline Pac1041 & TRAMAL & $\begin{array}{l}\text { Pfizer- } \\
\text { Pharmacia }\end{array}$ & tramadol & $\begin{array}{c}\text { A2 - } \\
\text { adendo }\end{array}$ & $40 \mathrm{cp}(50 \mathrm{mg})$ & $4 \mathrm{cp} / \mathrm{dia}$ & 10 & 60 & -50 \\
\hline Pac0681 & sertratina & & sertralina & $\mathrm{Cl}$ & $30 \mathrm{cp}(50 \mathrm{mg})$ & $1 \mathrm{cp} / \mathrm{dia}$ & 30 & 60 & -30 \\
\hline
\end{tabular}


$\mathrm{DT}=$ Dias de tratamento fornecido $\quad \mathrm{LL}=$ Limite legal

\begin{tabular}{|c|c|c|c|c|c|c|c|c|c|}
\hline $\begin{array}{l}\text { código } \\
\text { paciente }\end{array}$ & Prescrição & Indústria & Principio Ativo & Alinea & Fornecimento & Posologia & DT & LL & DT - LL \\
\hline Pac1125 & \begin{tabular}{|l|} 
codeina; \\
paracetamol
\end{tabular} & & \begin{tabular}{|l|} 
codeina; \\
paracetamol
\end{tabular} & $\begin{array}{c}\text { A2 - } \\
\text { adendo }\end{array}$ & $90 \mathrm{cp}(30 \mathrm{mg})$ & $3 \mathrm{cp} / \mathrm{dia}$ & 30 & 60 & -30 \\
\hline Pac3932 & ARAVA & Aventis & leftunomida & $\mathrm{C} 1$ & $3 \mathrm{cp}(100 \mathrm{mg})$ & $3 \mathrm{cp} / \mathrm{dia}$ & 1 & 60 & -59 \\
\hline Pac3932 & ARAVA & Aventis & leflunomida & $\mathrm{Cl}$ & $30 \mathrm{cp}(20 \mathrm{mg})$ & $3 \mathrm{cp} / \mathrm{dia}$ & 10 & 60 & -50 \\
\hline Pac1008 & fenitoina & & \begin{tabular}{|l|} 
fenitoina \\
(hidantoina) \\
\end{tabular} & C1 & $40 \mathrm{cp}(100 \mathrm{mg})$ & $3 \mathrm{cp} / \mathrm{dia}$ & 13 & 60 & -47 \\
\hline Pac1008 & RIVOTRIL & Roche & clonazepam & B1 & $30 \mathrm{cp}(2 \mathrm{mg})$ & $1 \mathrm{cp} / \mathrm{dia}$ & 30 & 60 & -30 \\
\hline Pac0807 & DAFORIN & Sigma Pharma & fluoxetina & C1 & $40 \mathrm{cp}(20 \mathrm{mg})$ & $1 \mathrm{cp} / \mathrm{dia}$ & 40 & 60 & -20 \\
\hline Pac2415 & amitriptilina & & amitriptilina & C1 & $60 \mathrm{cp}(25 \mathrm{mg})$ & $2 \mathrm{cp} / \mathrm{dia}$ & 30 & 60 & -30 \\
\hline Pac2415 & LONGACTIL & Cristália & clorpromazina & C1 & $\begin{array}{l}40 \mathrm{ml}(0,4 \\
\mathrm{mg} / \mathrm{ml})\end{array}$ & $1 \mathrm{~m} / \mathrm{dia}$ & 40 & 60 & -20 \\
\hline Pac2919 & DAFORIN & Sigma Pharma & fluoxetina & C1 & $40 \mathrm{cp}(20 \mathrm{mg})$ & $1 \mathrm{cp} / \mathrm{dia}$ & 40 & 60 & -20 \\
\hline Pac3364 & AMYTRIL & Cristália & amitriptilina & C1 & $40 \mathrm{cp}(25 \mathrm{mg})$ & $1 \mathrm{cp} / \mathrm{dia}$ & 40 & 60 & -20 \\
\hline Pac3520 & fenobarbital & & fenobarbital & $\begin{array}{c}\mathrm{B} 1- \\
\text { adendo }\end{array}$ & $40 \mathrm{cp}(100 \mathrm{mg})$ & $1 \mathrm{cp} / \mathrm{dia}$ & 40 & 60 & -20 \\
\hline Pac3520 & carbamazepina & & carbamazepina & C1 & $150 \mathrm{cp}(200 \mathrm{mg})$ & $4 \mathrm{cp} / \mathrm{dia}$ & 38 & 60 & -23 \\
\hline Pac3520 & amitriptilina & & amitriptilina & $\mathrm{Ct}$ & $100 \mathrm{cp}(25 \mathrm{mg})$ & $3 \mathrm{cp} / \mathrm{dia}$ & 33 & 60 & -27 \\
\hline Pac3520 & AMPLICTIL & Aventis & clorpromazina & C1 & $\begin{array}{l}20 \mathrm{ml}(0,4 \\
\mathrm{mg} / \mathrm{mi})\end{array}$ & $0,5 \mathrm{~m} / \mathrm{dia}$ & 40 & 60 & -20 \\
\hline Pac2470 & clobazam & & clobazam & B1 & $120 \mathrm{cp}(10 \mathrm{mg})$ & $4 \mathrm{cp} / \mathrm{dia}$ & 30 & 60 & -30 \\
\hline Pac3292 & diazepam & & diazepam & B1 & $60 \mathrm{cp}(10 \mathrm{mg})$ & $2 \mathrm{cp} / \mathrm{dia}$ & 30 & 60 & -30 \\
\hline Pac3333 & RIVOTRIL & Roche & clonazepam & B1 & $40 \mathrm{cp}(2 \mathrm{mg})$ & $1 \mathrm{cp} / \mathrm{dia}$ & 40 & 60 & -20 \\
\hline Pac4012 & diazepam & & diazepam & B1 & $30 \mathrm{cp}(10 \mathrm{mg})$ & $0,5 \mathrm{cp} / \mathrm{dia}$ & 60 & 60 & 0 \\
\hline Pac1875 & nitrazepam & & nitrazepam & B1 & $90 \mathrm{cp}(5 \mathrm{mg})$ & $3 \mathrm{cp} / \mathrm{dia}$ & 30 & 60 & -30 \\
\hline Pac2036 & diazepam & & diazepam & B1 & $90 \mathrm{cp}(10 \mathrm{mg})$ & $3 \mathrm{cp} / \mathrm{dia}$ & 30 & 60 & -30 \\
\hline Pac1106 & clobazam & & clobazam & B1 & $100 \mathrm{cp}(10 \mathrm{mg})$ & $3 \mathrm{cp} / \mathrm{dia}$ & 33 & 60 & -27 \\
\hline Pac0679 & RIVOTRIL & Roche & clonazepam & B1 & $40 \mathrm{cp} \mathrm{(2} \mathrm{mg)}$ & $1 \mathrm{cp} / \mathrm{dia}$ & 40 & 60 & -20 \\
\hline Pac3451 & diazepam & & diazepam & B1 & $60 \mathrm{cp}(10 \mathrm{mg})$ & $2 \mathrm{cp} / \mathrm{dia}$ & 30 & 60 & -30 \\
\hline Pac0951 & diazepam & & diazepam & B1 & $60 \mathrm{cp}(10 \mathrm{mg})$ & $2 \mathrm{cp} / \mathrm{dia}$ & 30 & 60 & -30 \\
\hline Pac2537 & clonazepam & & clonazepam & $B 1$ & $50 \mathrm{cp}(2 \mathrm{mg})$ & $1,5 \mathrm{cp} / \mathrm{dia}$ & 33 & 60 & -27 \\
\hline Pac1940 & FRISIUM & Aventis & clobazam & B1 & $60 \mathrm{cp}(10 \mathrm{mg})$ & $1,5 \mathrm{cp} / \mathrm{dia}$ & 40 & 60 & -20 \\
\hline Pac2168 & diazepam & & diazepam & B1 & $90 \mathrm{cp}(10 \mathrm{mg})$ & $3 \mathrm{cp} / \mathrm{dia}$ & 30 & 60 & 30 \\
\hline Pac0282 & RIVOTRIL & Roche & clonazepam & B1 & $60 \mathrm{cp}(2 \mathrm{mg})$ & $2 \mathrm{cp} / \mathrm{dia}$ & 30 & 60 & -30 \\
\hline Pac1308 & FRISIUM & Aventis & clobazam & B1 & $80 \mathrm{cp}(10 \mathrm{mg})$ & $2,5 \mathrm{cp} / \mathrm{dia}$ & 32 & 60 & -28 \\
\hline Pac3479 & nitrazepam & & nitrazepam & B1 & $120 \mathrm{cp}(5 \mathrm{mg})$ & $4 \mathrm{cp} / \mathrm{dia}$ & 30 & 60 & -30 \\
\hline Pac0262 & FRISIUM & Aventis & clobazam & B1 & $60 \mathrm{cp}(10 \mathrm{mg})$ & $2 \mathrm{cp} / \mathrm{dia}$ & 30 & 60 & -30 \\
\hline Pac0406 & nitrazepam & & nitrazepam & B1 & $90 \mathrm{cp}(5 \mathrm{mg})$ & $3 \mathrm{cp} / \mathrm{dia}$ & 30 & 60 & -30 \\
\hline Pac1008 & RIVOTRIL & Roche & clonazepam & B1 & $40 \mathrm{cp}(2 \mathrm{mg})$ & $1 \mathrm{cp} / \mathrm{dia}$ & 40 & 60 & -20 \\
\hline Pac2142 & RIVOTRIL & Roche & clonazepam & B1 & $60 \mathrm{cp}(2 \mathrm{mg})$ & $2 \mathrm{cp} / \mathrm{dia}$ & 30 & 60 & -30 \\
\hline Pac0454 & FRISIUM & Aventis & clobazam & B1 & $60 \mathrm{cp}(10 \mathrm{mg})$ & $2 \mathrm{cp} / \mathrm{dia}$ & 30 & 60 & -30 \\
\hline Pac0858 & FRISIUM & Aventis & clobazam & B1 & $120 \mathrm{cp}(10 \mathrm{mg})$ & $4 \mathrm{cp} / \mathrm{dia}$ & 30 & 60 & -30 \\
\hline Pac0527 & nitrazepam & & nitrazepam & B1 & $90 \mathrm{cp}(5 \mathrm{mg})$ & $3 \mathrm{cp} / \mathrm{dia}$ & 30 & 60 & -30 \\
\hline Pac2986 & RIVOTRIL & Roche & clonazepam & B1 & $20 \mathrm{cp}(2 \mathrm{mg})$ & $0,75 \mathrm{cp} / \mathrm{dia}$ & 27 & 60 & -33 \\
\hline Pac3229 & FRISIUM & Aventis & clobazam & B1 & $180 \mathrm{cp}(10 \mathrm{mg})$ & $6 \mathrm{cp} / \mathrm{dia}$ & 30 & 60 & -30 \\
\hline Pac0813 & FRISIUM & Aventis & clobazam & B1 & $180 \mathrm{cp}(10 \mathrm{mg})$ & $6 \mathrm{cp} / \mathrm{dia}$ & 30 & 60 & -30 \\
\hline Pac1722 & FRISIUM & Aventis & clobazam & B1 & $40 \mathrm{cp}(10 \mathrm{mg})$ & $1 \mathrm{cp} / \mathrm{dia}$ & 40 & 60 & -20 \\
\hline Pac2680 & FRISIUM & Aventis & clobazam & B1 & $100 \mathrm{cp}(10 \mathrm{mg})$ & $3 \mathrm{cp} / \mathrm{dia}$ & 33 & 60 & -27 \\
\hline Pac1966 & nitrazepam & & nitrazepam & 81 & $150 \mathrm{cp}(5 \mathrm{mg})$ & $4,5 \mathrm{cp} / \mathrm{dia}$ & 33 & 60 & -27 \\
\hline Pac2245 & nitrazepam & & nitrazepam & B1 & $20 \mathrm{cp}$ (5 mg) & $0,5 \mathrm{cp} / \mathrm{dia}$ & 40 & 60 & -20 \\
\hline Pac1223 & RIVOTRIL & Roche & clonazepam & B1 & $40 \mathrm{cp}(2 \mathrm{mg})$ & $1 \mathrm{cp} / \mathrm{dia}$ & 40 & 60 & -20 \\
\hline Pac0884 & diazepam & & diazepam & B1 & $30 \mathrm{cp}(10 \mathrm{mg})$ & $1 \mathrm{cp} / \mathrm{dia}$ & 30 & 60 & -30 \\
\hline Pac2065 & RIVOTRIL & Roche & clonazepam & B1 & $40 \mathrm{cp}(2 \mathrm{mg})$ & $1 \mathrm{cp} / \mathrm{dia}$ & 40 & 60 & -20 \\
\hline
\end{tabular}


$\mathrm{DT}=$ Dias de tratamento fornecido $\quad \mathrm{LL}=$ Limite legal

\begin{tabular}{|c|c|c|c|c|c|c|c|c|c|}
\hline \begin{tabular}{|l} 
código \\
paciente
\end{tabular} & Prescrição & Indủstria & Principio Ativo & Alinea & Fornecimento & Posologia & DT & $L L$ & DT-LL. \\
\hline Pac2492 & URBANIL & Aventis & clobazam & B1 & $120 \mathrm{cp}(10 \mathrm{mg})$ & $2 \mathrm{cp} / \mathrm{dia}$ & 60 & 60 & 0 \\
\hline Pac0109 & diazepam & & diazepam & B1 & $30 \mathrm{cp}(10 \mathrm{mg})$ & $1 \mathrm{cp} / \mathrm{dia}$ & 30 & 60 & -30 \\
\hline Pac4042 & RIVOTRIL & Roche & clonazepam & B1 & $210 \mathrm{cp}(2 \mathrm{mg})$ & $7 \mathrm{cp} / \mathrm{dia}$ & 30 & 60 & -30 \\
\hline Pac3851 & RIVOTRIL & Roche & clonazepam & B1 & $180 \mathrm{cp}(2 \mathrm{mg})$ & $6 \mathrm{cp} / \mathrm{dia}$ & 30 & 60 & -30 \\
\hline Pac0666 & RIVOTRIL & Roche & clonazepam & B1 & $60 \mathrm{cp}(2 \mathrm{mg})$ & $2 \mathrm{cp} / \mathrm{dia}$ & 30 & 60 & -30 \\
\hline Pac1201 & nitrazepam & & nitrazepam & B1 & $60 \mathrm{cp}(5 \mathrm{mg})$ & $2 \mathrm{cp} / \mathrm{dia}$ & 30 & 60 & -30 \\
\hline Pac3425 & diazepam & & diazepam & B1 & $20 \mathrm{cp}(5 \mathrm{mg})$ & $0,5 \mathrm{cp} / \mathrm{dia}$ & 40 & 60 & -20 \\
\hline Pac2536 & morfina & & morfina & A1 & $100 \mathrm{cp}(30 \mathrm{mg})$ & $4 \mathrm{cp} / \mathrm{dia}$ & 25 & 30 & -5 \\
\hline Pac3544 & morfina & & morfina & A1 & $120 \mathrm{cp}(30 \mathrm{mg})$ & $4 \mathrm{cp} / \mathrm{dia}$ & 30 & 30 & 0 \\
\hline Pac3240 & mortina & & morfina & A1 & $120 \mathrm{cp}(30 \mathrm{mg})$ & $4 \mathrm{cp} / \mathrm{dia}$ & 30 & 30 & 0 \\
\hline Pac3308 & NEULEPTIL & Aventis & periciazina & C1 & \begin{tabular}{|l|}
$20 \mathrm{ml}(0,4$ \\
$\mathrm{mg} / \mathrm{ml})$
\end{tabular} & $0,6 \mathrm{ml} / \mathrm{dia}$ & 33 & 60 & -27 \\
\hline Pac2992 & amitriptilina & & amitriptilina & C1 & $60 \mathrm{cp}(25 \mathrm{mg})$ & $2 \mathrm{cp} / \mathrm{dia}$ & 30 & 60 & -30 \\
\hline Pac0494 & carbamazepina & & carbamazepina & $c 1$ & $30 \mathrm{cp}(200 \mathrm{mg})$ & $3 \mathrm{cp} / \mathrm{dia}$ & 10 & 60 & -50 \\
\hline Pac0494 & FRISIUM & Aventis & clobazam & B1 & $100 \mathrm{cp}(10 \mathrm{mg})$ & $3 \mathrm{cp} / \mathrm{dia}$ & 33 & 60 & -27 \\
\hline Pac2320 & sertralina & & sertralina & C1 & $30 \mathrm{cp}(25 \mathrm{mg})$ & $1 \mathrm{cp} / \mathrm{dia}$ & 30 & 60 & -30 \\
\hline Pac1460 & TRAMAL & \begin{tabular}{|l|} 
Pfizer- \\
Pharmacia
\end{tabular} & tramadol & $\begin{array}{c}\text { A2- } \\
\text { adendo }\end{array}$ & $60 \mathrm{cp}(50 \mathrm{mg})$ & $3 \mathrm{cp} / \mathrm{dia}$ & 20 & 60 & -40 \\
\hline Pac0220 & NEULEPTIL & Aventis & periciazina & C1 & $\begin{array}{l}20 \mathrm{ml}(0,4 \\
\mathrm{mg} / \mathrm{ml})\end{array}$ & $0,2 \mathrm{ml} / \mathrm{dia}$ & 100 & 60 & 40 \\
\hline Pac0494 & DEPAKENE & Abbott & \begin{tabular}{|l|}
$\begin{array}{l}\text { acido valpróico } \\
\text { (ou derivado) }\end{array}$ \\
\end{tabular} & C1 & $100 \mathrm{cp}(250 \mathrm{mg})$ & $3 \mathrm{cp} / \mathrm{dia}$ & 33 & 60 & -27 \\
\hline Pac3937 & $\begin{array}{l}\text { DORLESS- } \\
\text { TRAMADOL }\end{array}$ & União Quimica & tramadol & $\begin{array}{c}A 2- \\
\text { adendo }\end{array}$ & $60 \mathrm{cp}(50 \mathrm{mg})$ & $4 \mathrm{cp} / \mathrm{dia}$ & 15 & 60 & -45 \\
\hline Pac2651 & \begin{tabular}{|l} 
codeina; \\
paracetamol
\end{tabular} & & $\begin{array}{l}\text { codeina; } \\
\text { paracetamol }\end{array}$ & $\begin{array}{c}\text { A2 - } \\
\text { adendo }\end{array}$ & $120 \mathrm{cp}(30 \mathrm{mg})$ & $4 \mathrm{cp} / \mathrm{dia}$ & 30 & 60 & -30 \\
\hline Pac3145 & \begin{tabular}{|l|} 
DORLESS- \\
TRAMADOL \\
\end{tabular} & Uniẫo Quimica & tramadol & $\begin{array}{c}\mathrm{A} 2- \\
\text { adendo }\end{array}$ & $120 \mathrm{cp}(50 \mathrm{mg})$ & $4 \mathrm{cp} / \mathrm{dia}$ & 30 & 60 & -30 \\
\hline Pac2264 & morfina & & morfina & A1 & $70 \mathrm{cp}(10 \mathrm{mg})$ & $7 \mathrm{cp} / \mathrm{dia}$ & 10 & 30 & -20 \\
\hline Pac3878 & sertralina & & sertmalina & c1 & $60 \mathrm{cp}(50 \mathrm{mg})$ & $2 \mathrm{cp} / \mathrm{dia}$ & 30 & 60 & -30 \\
\hline Paco160 & fenobarbital & & fenobarbital & \begin{tabular}{|c|} 
B1 - \\
adendo
\end{tabular} & $40 \mathrm{cp}(100 \mathrm{mg})$ & $1 \mathrm{cp} / \mathrm{dia}$ & 40 & 60 & -20 \\
\hline Pac0855 & \begin{tabular}{|l} 
codeina; \\
paracetamol
\end{tabular} & & $\begin{array}{l}\text { codeina; } \\
\text { paracetamol }\end{array}$ & $\begin{array}{c}\mathrm{A2} \text { - } \\
\text { adendo }\end{array}$ & $60 \mathrm{cp}(30 \mathrm{mg})$ & $3 \mathrm{cp} / \mathrm{dia}$ & 20 & 60 & -40 \\
\hline Pac0229 & ANAFRANIL & Novartis & clomipramina & C1 & $80 \mathrm{cp}(25 \mathrm{mg})$ & $1 \mathrm{cp} / \mathrm{dia}$ & 80 & 60 & 20 \\
\hline Pac1448 & DEPAKENE & Abbott & \begin{tabular}{|l|}
$\begin{array}{l}\text { ácido valpróico } \\
\text { (ou dervivado) }\end{array}$ \\
\end{tabular} & C1 & $200 \mathrm{cp}(500 \mathrm{mg})$ & $4 \mathrm{cp} / \mathrm{dia}$ & 50 & 60 & -10 \\
\hline Pac3996 & \begin{tabular}{|l} 
DORLESS- \\
TRAMADOL \\
\end{tabular} & Uniäo Quimica & tramadol & $\begin{array}{c}\mathrm{A} 2- \\
\text { adendo }\end{array}$ & $20 \mathrm{cp}(50 \mathrm{mg})$ & $2 \mathrm{cp} / \mathrm{dia}$ & 10 & 60 & -50 \\
\hline Pac2085 & DEPAKENE & Abbott & \begin{tabular}{|l} 
ácido valpróico \\
(ou derivado)
\end{tabular} & C1 & $250 \mathrm{cp}(500 \mathrm{mg})$ & $8 \mathrm{cp} / \mathrm{dia}$ & 31 & 60 & -29 \\
\hline Pac2085 & sertralina & & sertralina & C1 & $60 \mathrm{cp}(50 \mathrm{mg})$ & $2 \mathrm{cp} / \mathrm{dia}$ & 30 & 60 & -30 \\
\hline Pact953 & DEPAKENE & Abbott & $\begin{array}{l}\text { ácido valpróico } \\
\text { (ou derivado) }\end{array}$ & c1 & $100 \mathrm{cp}(500 \mathrm{mg})$ & $2 \mathrm{cp} / \mathrm{dia}$ & 50 & 60 & -10 \\
\hline Pac2264 & morlina & & morfina & A1 & $70 \mathrm{cp}(10 \mathrm{mg})$ & $7 \mathrm{cp} / \mathrm{dia}$ & 10 & 30 & -20 \\
\hline Pac2905 & RIVOTRIL & Roche & clonazepam & B1 & $40 \mathrm{cp}(2 \mathrm{mg})$ & $1 \mathrm{cp} / \mathrm{dia}$ & 40 & 60 & -20 \\
\hline Pac1089 & FRISIUM & Aventis & clobazam & B1 & $120 \mathrm{cp}$ (10 mg) & $4 \mathrm{cp} / \mathrm{dia}$ & 30 & 60 & -30 \\
\hline Pac4004 & URBANL & Aventis & clobazam & B1 & $80 \mathrm{cp}(10 \mathrm{mg})$ & $2,5 \mathrm{cp} / \mathrm{dia}$ & 32 & 60 & -28 \\
\hline Pac1336 & RIVOTRIL & Roche & clonazepam & B1 & $40 \mathrm{cp}(2 \mathrm{mg})$ & $1 \mathrm{cp} / \mathrm{dia}$ & 40 & 60 & -20 \\
\hline Pac2749 & FRISIUM & Aventis & clobazam & B1 & $40 \mathrm{cp}(10 \mathrm{mg})$ & $1 \mathrm{cp} / \mathrm{dia}$ & 40 & 60 & -20 \\
\hline Pac1680 & diazepam & & diazepam & B1 & $40 \mathrm{cp}$ (10 mg) & $1 \mathrm{cp} / \mathrm{dia}$ & 40 & 60 & -20 \\
\hline Pac2313 & RIVOTRIL & Roche & clonazepam & B1 & $40 \mathrm{cp}(2 \mathrm{mg})$ & $1 \mathrm{cp} / \mathrm{dia}$ & 40 & 60 & -20 \\
\hline Pac0560 & diazepam & & diazepam & B1 & $30 \mathrm{c}(10 \mathrm{mg})$ & 1 c/dia & 30 & 60 & -30 \\
\hline Pac1902 & nitrazepam & & nitrazepam & B1 & $240 \mathrm{cp}(5 \mathrm{mg})$ & $8 \mathrm{cp} / \mathrm{dia}$ & 30 & 60 & -30 \\
\hline Pac1557 & clonazepam & & clonazepam & B1 & $40 \mathrm{cp}(2 \mathrm{mg})$ & $1 \mathrm{cp} / \mathrm{dia}$ & 40 & 60 & -20 \\
\hline Pac3565 & FRISIUM & Aventis & clobazam & 81 & $40 \mathrm{cp}(10 \mathrm{mg})$ & $1 \mathrm{cp} / \mathrm{dia}$ & 40 & 60 & -20 \\
\hline Pac1999 & FRISIUM & Aventis & clobazam & B1 & $100 \mathrm{cp}(10 \mathrm{mg})$ & $3 \mathrm{cp} / \mathrm{dia}$ & 33 & 60 & -27 \\
\hline
\end{tabular}


$D T=$ Dias de tratamento fornecido $\quad L L=$ Limite legal

\begin{tabular}{|c|c|c|c|c|c|c|c|c|c|}
\hline $\begin{array}{l}\text { código } \\
\text { paciente }\end{array}$ & Prescrição & Indústria & Princípio Ativo & Alínea & Fornecimento & Posologia & DT & L.L. & DT - LL \\
\hline Pac3613 & FRISIUM & Aventis & clobazam & B1 & $150 \mathrm{cp}(10 \mathrm{mg})$ & $2 \mathrm{cp} / \mathrm{dia}$ & 75 & 60 & 15 \\
\hline Pac0979 & diazepam & & diazepam & B1 & $30 \mathrm{cp}(10 \mathrm{mg})$ & $1 \mathrm{cp} / \mathrm{dia}$ & 30 & 60 & -30 \\
\hline Pac3606 & nitrazepam & & nitrazepam & B1 & $30 \mathrm{cp}(5 \mathrm{mg})$ & $1 \mathrm{cp} / \mathrm{dia}$ & 30 & 60 & -30 \\
\hline Pac0912 & RIVOTRIL & Roche & clonazepam & B1 & $20 \mathrm{cp}(2 \mathrm{mg})$ & $0,5 \mathrm{cp} / \mathrm{dia}$ & 40 & 60 & -20 \\
\hline Pac1464 & RIVOTRIL & Roche & clonazepam & B1 & $240 \mathrm{cp}(2 \mathrm{mg})$ & $8 \mathrm{cp} / \mathrm{dia}$ & 30 & 60 & -30 \\
\hline Pac2076 & RIVOTRIL & Roche & clonazepam & B1 & $40 \mathrm{cp}(2 \mathrm{mg})$ & $1 \mathrm{cp} / \mathrm{dia}$ & 40 & 60 & -20 \\
\hline Pac3545 & RIVOTRIL & Roche & clonazepam & B1 & $40 \mathrm{cp}(2 \mathrm{mg})$ & $1 \mathrm{cp} / \mathrm{dia}$ & 40 & 60 & -20 \\
\hline Pac0392 & RIVOTRIL & Roche & clonazepam & B1 & $120 \mathrm{cp}(2 \mathrm{mg})$ & $4 \mathrm{cp} / \mathrm{dia}$ & 30 & 60 & -30 \\
\hline Pac0494 & FRISIUM & Aventis & clobazam & B1 & $100 \mathrm{cp}(10 \mathrm{mg})$ & $3 \mathrm{cp} / \mathrm{dia}$ & 33 & 60 & -27 \\
\hline Pac2365 & FRISIUM & Aventis & clobazam & B1 & $60 \mathrm{cp}(10 \mathrm{mg})$ & $1,5 \mathrm{cp} / \mathrm{dia}$ & 40 & 60 & -20 \\
\hline Pac3878 & diazepam & & diazepam & B1 & $30 \mathrm{cp}(10 \mathrm{mg})$ & $1 \mathrm{cp} / \mathrm{dia}$ & 30 & 60 & -30 \\
\hline Pac0229 & diazepam & & diazepam & B1 & $30 \mathrm{cp}(10 \mathrm{mg})$ & $1 \mathrm{cp} / \mathrm{dia}$ & 30 & 60 & -30 \\
\hline Pac0229 & RIVOTRIL & Roche & clonazepam & B1 & $40 \mathrm{cp}(2 \mathrm{mg})$ & $1 \mathrm{cp} / \mathrm{dia}$ & 40 & 60 & -20 \\
\hline Pac3752 & diazepam & & diazepam & B1 & $30 \mathrm{cp}(10 \mathrm{mg})$ & $3 \mathrm{cp} / \mathrm{dia}$ & 10 & 60 & -50 \\
\hline Pac0260 & RIVOTRIL & Roche & clonazepam & B1 & $100 \mathrm{cp}(2 \mathrm{mg})$ & $3 \mathrm{cp} / \mathrm{dia}$ & 33 & 60 & -27 \\
\hline Pac1288 & RIVOTRIL & Roche & clonazepam & 81 & $160 \mathrm{cp}(2 \mathrm{mg})$ & $5 \mathrm{cp} / \mathrm{dia}$ & 32 & 60 & -28 \\
\hline Pac1918 & FRISIUM & Aventis & clobazam & B1 & $60 \mathrm{cp}(10 \mathrm{mg})$ & $1,5 \mathrm{cp} / \mathrm{dia}$ & 40 & 60 & -20 \\
\hline Pac0599 & nitrazepam & & nitrazepam & B1 & $30 \mathrm{cp}(5 \mathrm{mg})$ & $2 \mathrm{cp} / \mathrm{dia}$ & 15 & 60 & -45 \\
\hline Pac3793 & diazepam & & diazepam & B1 & $30 \mathrm{cp}(10 \mathrm{mg})$ & $1 \mathrm{cp} / \mathrm{dia}$ & 30 & 60 & -30 \\
\hline Pac0042 & RIVOTRIL & Roche & clonazepam & B1 & $40 \mathrm{cp}(2 \mathrm{mg})$ & $1 \mathrm{cp} / \mathrm{dia}$ & 40 & 60 & -20 \\
\hline Pac3747 & RIVOTRIL & Roche & clonazepam & B1 & $40 \mathrm{cp}(2 \mathrm{mg})$ & $1 \mathrm{cp} / \mathrm{dia}$ & 40 & 60 & -20 \\
\hline Pac2667 & AMYTRLL & Cristália & amitriptilina & C1 & $40 \mathrm{cp}(25 \mathrm{mg})$ & $1 \mathrm{cp} / \mathrm{dia}$ & 40 & 60 & -20 \\
\hline Pac1693 & $\begin{array}{l}\text { codeina; } \\
\text { paracetamol }\end{array}$ & & $\begin{array}{l}\text { codeina; } \\
\text { paracetamol }\end{array}$ & $\begin{array}{c}\text { A2:- } \\
\text { adendo }\end{array}$ & $30 \mathrm{cp}$ (30 mg) & $1,5 \mathrm{cp} / \mathrm{dia}$ & 20 & 60 & -40 \\
\hline Pac2962 & fenitoina & & $\begin{array}{l}\text { fenitoina } \\
\text { (hidantoina) }\end{array}$ & C1 & $100 \mathrm{cp}(100 \mathrm{mg})$ & $3 \mathrm{cp} / \mathrm{dia}$ & 33 & 60 & -27 \\
\hline Pac2180 & $\begin{array}{l}\text { codeina; } \\
\text { paracetamol }\end{array}$ & & $\begin{array}{l}\text { codeina; } \\
\text { paracetamol }\end{array}$ & \begin{tabular}{|c|} 
A2 - \\
adendo
\end{tabular} & $160 \mathrm{cp}(30 \mathrm{mg})$ & $4 \mathrm{cp} / \mathrm{dia}$ & 40 & 60 & -20 \\
\hline Pac2180 & sertralina & & sertralina & C1 & $45 \mathrm{cp}$ (50 mg) & $1 \mathrm{cp} / \mathrm{dia}$ & 45 & 60 & -15 \\
\hline Pac0474 & $\begin{array}{l}\text { codeina; } \\
\text { paracetamol }\end{array}$ & & $\begin{array}{l}\text { codeina: } \\
\text { paracetamol }\end{array}$ & $\begin{array}{c}\text { A2 - } \\
\text { adendo }\end{array}$ & $60 \mathrm{cp}(30 \mathrm{mg})$ & $2 \mathrm{cp} / \mathrm{dia}$ & 30 & 60 & -30 \\
\hline Pac1965 & $\begin{array}{l}\text { codeina; } \\
\text { paracetamol }\end{array}$ & & $\begin{array}{l}\text { codeina; } \\
\text { paracetamol }\end{array}$ & \begin{tabular}{|c|} 
A2 - \\
adendo
\end{tabular} & $40 \mathrm{cp}(30 \mathrm{mg})$ & $4 \mathrm{cp} / \mathrm{dia}$ & 10 & 60 & -50 \\
\hline Pac2675 & AMYTRL & Cristália & amitriptilina & c1 & $40 \mathrm{cp}(25 \mathrm{mg})$ & $3 \mathrm{cp} / \mathrm{dia}$ & 13 & 60 & -47 \\
\hline Pac0629 & fentoina & & $\begin{array}{l}\text { fenitoina } \\
\text { (hidanloina) }\end{array}$ & c1 & $30 \mathrm{cp}(100 \mathrm{mg})$ & $3 \mathrm{cp} / \mathrm{dia}$ & 10 & 60 & -50 \\
\hline Pac3899 & DEPAKENE & Abbott & $\begin{array}{l}\text { ácido valpróico } \\
\text { (ou derivado) }\end{array}$ & c1 & $100 \mathrm{cp}(250 \mathrm{mg})$ & $3 \mathrm{cp} / \mathrm{dia}$ & 33 & 60 & -27 \\
\hline Pac3722 & $\begin{array}{l}\text { DORLESS- } \\
\text { TRAMADOL }\end{array}$ & Uniăo Quimica & tramadol & $\begin{array}{c}\text { A2- } \\
\text { adendo }\end{array}$ & $30 \mathrm{cp}(50 \mathrm{mg})$ & $3 \mathrm{cp} / \mathrm{dia}$ & 10 & 60 & -50 \\
\hline Pac2088 & carbamazepina & & carbamazepina & C1 & $90 \mathrm{cp}$ (200 mg) & 3 cpidia & 30 & 60 & -30 \\
\hline Pac2088 & fenitoina & & $\begin{array}{l}\text { fenitoína } \\
\text { (hidantoina) }\end{array}$ & C1 & $90 \mathrm{cp}(100 \mathrm{mg})$ & $3 \mathrm{cp} / \mathrm{dia}$ & 30 & 60 & -30 \\
\hline Pac3078 & carbamezepina & & carbamazepina & C1 & $100 \mathrm{cp}(200 \mathrm{mg})$ & $2 \mathrm{cp} / \mathrm{dia}$ & 50 & 60 & -10 \\
\hline Pac2039 & fenobarbital & & fenobarbital & \begin{tabular}{|c|} 
B1- \\
adendo
\end{tabular} & $80 \mathrm{cp}(100 \mathrm{mg})$ & $1 \mathrm{cp} / \mathrm{dia}$ & 80 & 60 & 20 \\
\hline Pac3623 & amitriptilina & & amitriptilina & C1 & $40 \mathrm{cp}(25 \mathrm{mg})$ & $1 \mathrm{cp} / \mathrm{dia}$ & 40 & 60 & -20 \\
\hline Pac0576 & sertralina & & sertralina & C1 & $160 \mathrm{cp}(50 \mathrm{mg})$ & $4 \mathrm{cp} / \mathrm{dia}$ & 40 & 60 & -20 \\
\hline Pac2360 & TRYPTANOL & Prodome & amitriptilina & C1 & $20 \mathrm{cp}(25 \mathrm{mg})$ & $0,5 \mathrm{cp} / \mathrm{dia}$ & 40 & 60 & -20 \\
\hline Pac3777 & carbamazepina & & carbamazepina & ci & $140 \mathrm{cp}(200 \mathrm{mg})$ & $4 \mathrm{cp} / \mathrm{dia}$ & 35 & 60 & -25 \\
\hline Pac3958 & amitriptilina & & amitriptilina & $\mathrm{C}_{1}$ & $8 \mathrm{cp}(25 \mathrm{mg})$ & $2 \mathrm{cp} / \mathrm{dia}$ & 4 & 60 & -56 \\
\hline Pac3958 & LONGACTIL & Cristália & clorpromazina & C1 & \begin{tabular}{|l|}
$40 \mathrm{ml}(0,4$ \\
$\mathrm{mg} / \mathrm{ml})$
\end{tabular} & $0,6 \mathrm{~m} / / \mathrm{dia}$ & 67 & 60 & 7 \\
\hline Pac3063 & fuoxetina & & fluoxetina & C1 & $60 \mathrm{cp}(20 \mathrm{mg})$ & $1 \mathrm{cp} / \mathrm{dia}$ & 60 & 60 & 0 \\
\hline Pac1560 & carbamazepina & & carbamazepina & C1 & $120 \mathrm{cp}(200 \mathrm{mg})$ & $3 \mathrm{cp} / \mathrm{dia}$ & 40 & 60 & -20 \\
\hline Pac1560 & amitriptilina & & amitriptilina & C1 & $40 \mathrm{cp}(25 \mathrm{mg})$ & $0,5 \mathrm{cp} / \mathrm{dia}$ & 80 & 60 & 20 \\
\hline
\end{tabular}


$D T=$ Dias de tratamento fornecido $\quad L L=$ Limite legal

\begin{tabular}{|c|c|c|c|c|c|c|c|c|c|}
\hline $\begin{array}{l}\text { código } \\
\text { paciente }\end{array}$ & Prescrição & Indústria & Princípio Ativo & Alínea & Fornecimento & Posologia & DT & LL & DT - LL \\
\hline Pac3199 & sertralina & & sertralina & $\mathrm{c1}$ & $30 \mathrm{cp} \mathrm{(50} \mathrm{mg)}$ & $0,5 \mathrm{cp} / \mathrm{dia}$ & 60 & 60 & 0 \\
\hline Pac1495 & $\begin{array}{l}\text { codeina; } \\
\text { paracetamol }\end{array}$ & & $\begin{array}{l}\text { codeina: } \\
\text { paracetamol }\end{array}$ & \begin{tabular}{c|} 
A2 - \\
adendo
\end{tabular} & $10 \mathrm{cp}(30 \mathrm{mg})$ & $1 \mathrm{cp} / \mathrm{dia}$ & 10 & 60 & -50 \\
\hline Pac2849 & carbamazepina & & carbamazepina & $\mathrm{Cl}_{1}$ & $45 \mathrm{cp}(200 \mathrm{mg})$ & $2 \mathrm{cp} / \mathrm{dia}$ & 23 & 60 & -38 \\
\hline Pac2849 & carbamazepina & & carbamazepina & $\mathrm{C} 1$ & $180 \mathrm{cp}(200 \mathrm{mg})$ & $6 \mathrm{cp} / \mathrm{dia}$ & 30 & 60 & -30 \\
\hline Pac1612 & sertralina & & sertralina & $c 1$ & $30 \mathrm{cp}(50 \mathrm{mg})$ & $1 \mathrm{cp} / \mathrm{dia}$ & 30 & 60 & -30 \\
\hline Pac1679 & amitriptilina & & amitriptilina & $\mathrm{CI}$ & $120 \mathrm{cp}(25 \mathrm{mg})$ & $3 \mathrm{cp} / \mathrm{dia}$ & 40 & 60 & -20 \\
\hline Pac3898 & amitriptilina & & amitriptilina & $\mathrm{C1}$ & $40 \mathrm{cp}(25 \mathrm{mg})$ & $1 \mathrm{cp} / \mathrm{dia}$ & 40 & 60 & -20 \\
\hline Pac3898 & carbamazepina & & carbamazepina & c1 & $60 \mathrm{cp}(200 \mathrm{mg})$ & $2 \mathrm{cp} / \mathrm{dia}$ & 30 & 60 & -30 \\
\hline Pac1361 & diazepam & & diazeparn & 81 & $20 \mathrm{cp}(5 \mathrm{mg})$ & $1 \mathrm{cp} / \mathrm{dia}$ & 20 & 60 & -40 \\
\hline Pac3521 & amitriptilina & & amitriptilina & C1 & $40 \mathrm{cp}(120 \mathrm{mg})$ & $1 \mathrm{cp} / \mathrm{dia}$ & 40 & 60 & -20 \\
\hline Pac0634 & carbamazepina & & carbamazepina & C1 & $320 \mathrm{cp}(200 \mathrm{mg})$ & $8 \mathrm{cp} / \mathrm{dia}$ & 40 & 60 & -20 \\
\hline Pac1434 & amitriptilina & & amitriptilina & C1 & $120 \mathrm{cp}(25 \mathrm{mg})$ & $4 \mathrm{cp} / \mathrm{dia}$ & 30 & 60 & -30 \\
\hline Pac3672 & TEGRETOL & Novartis & carbamazepina & $\mathrm{C}_{1}$ & $200 \mathrm{cp}(200 \mathrm{mg})$ & $5 \mathrm{cp} / \mathrm{dia}$ & 40 & 60 & -20 \\
\hline Pac3672 & GARDENAL & Aventis & fenobarbital & $\begin{array}{c}\text { B1 - } \\
\text { adendo }\end{array}$ & $40 \mathrm{cp}(100 \mathrm{mg})$ & $1 \mathrm{cp} / \mathrm{dia}$ & 40 & 60 & -20 \\
\hline Pac1445 & carbamazepina & & carbamazepina & $C_{1}$ & $120 \mathrm{cp}(200 \mathrm{mg})$ & $3 \mathrm{cp} / \mathrm{dia}$ & 40 & 60 & -20 \\
\hline Pac1445 & amitriptilina & & amitriptilina & C1 & $40 \mathrm{cp}$ (25 mg) & $1 \mathrm{cp} / \mathrm{dia}$ & 40 & 60 & -20 \\
\hline Pac0938 & JUMEXIL & Farmalab & selegilina & $C_{1}$ & $120 \mathrm{cp}(5 \mathrm{mg})$ & $3 \mathrm{cp} / \mathrm{dia}$ & 40 & 60 & -20 \\
\hline Pac0938 & CINETOL & Cristália & biperideno & $\mathrm{Cl}$ & $110 \mathrm{cp}(2 \mathrm{mg})$ & $3 \mathrm{cp} / \mathrm{dia}$ & 37 & 60 & -23 \\
\hline Pac2427 & imipramina & & imipramina & C1 & $30 \mathrm{cp}(25 \mathrm{mg})$ & $1 \mathrm{cp} / \mathrm{dia}$ & 30 & 60 & -30 \\
\hline Pac3192 & imipramina & & imipramina & c1 & $30 \mathrm{cp}(25 \mathrm{mg})$ & $1 \mathrm{cp} / \mathrm{dia}$ & 30 & 60 & 30 \\
\hline Pac1305 & carbamazepina & & carbamazepina & C1 & $90 \mathrm{cp}(200 \mathrm{mg})$ & $3 \mathrm{cp} / \mathrm{dia}$ & 30 & 60 & -30 \\
\hline Pac1291 & DEPAKENE & Abbott & $\begin{array}{l}\text { ácido valpróico } \\
\text { (ou derivado) }\end{array}$ & $\mathrm{c} 1$ & $100 \mathrm{cp}(500 \mathrm{mg})$ & $3 \mathrm{cp} / \mathrm{dia}$ & 33 & 60 & -27 \\
\hline Pac3346 & amitriptilina & & amitriptilina & $\mathrm{C1}_{1}$ & $14 \mathrm{cp}(25 \mathrm{mg})$ & $0,5 \mathrm{cp} / \mathrm{dia}$ & 28 & 60 & 32 \\
\hline Pac2371 & amitriptilina & & amitriptitina & C1 & $40 \mathrm{cp}$ (25 mg) & $1 \mathrm{cp} / \mathrm{dia}$ & 40 & 60 & -20 \\
\hline Pac2371 & AMPLICTIL & Aventis & clorpromazina & C1 & $\begin{array}{l}40 \mathrm{ml}(0,4 \\
\mathrm{mg} / \mathrm{ml})\end{array}$ & $1 \mathrm{~m} / \mathrm{dia}$ & 40 & 60 & -20 \\
\hline Pac4075 & sertralina & & sertratina & $C_{1}$ & $90 \mathrm{cp}(50 \mathrm{mg})$ & $3 \mathrm{cp} / \mathrm{dia}$ & 30 & 60 & -30 \\
\hline Pac1620 & gabapentina & & gabapentina & C1 & $120 \mathrm{cp}(300 \mathrm{mg})$ & $4 \mathrm{cp} / \mathrm{dia}$ & 30 & 60 & -30 \\
\hline Pac1620 & LONGACTIL & Cristalia & clorpromazina & $\mathrm{C1}$ & $\begin{array}{l}60 \mathrm{ml}(0,4 \\
\mathrm{mg} / \mathrm{ml})\end{array}$ & $2 \mathrm{~m} /$ dia & 30 & 60 & -30 \\
\hline Pac0320 & fenitoina & & $\begin{array}{l}\text { fenitoína } \\
\text { (hidantoina) }\end{array}$ & $\mathrm{C}_{1}$ & $120 \mathrm{cp}(100 \mathrm{mg})$ & $3 \mathrm{cp} / \mathrm{dia}$ & 40 & 60 & -20 \\
\hline Pac0320 & primidona & & primidona & C1 & $90 \mathrm{cp}(250 \mathrm{mg})$ & $3 \mathrm{cp} / \mathrm{dia}$ & 30 & 60 & -30 \\
\hline Pac0518 & cisaprida & & cisaprida & C1 & $60 \mathrm{cp}(10 \mathrm{mg})$ & $2 \mathrm{cp} / \mathrm{dia}$ & 30 & 60 & -30 \\
\hline Pac2464 & pramipexol & & pramipexol & $\mathrm{C1}$ & $40 \mathrm{cp}(0,25 \mathrm{mg})$ & $1.5 \mathrm{cp} / \mathrm{dia}$ & 27 & 60 & -33 \\
\hline Pac2464 & pramipexol & & pramipexol & $c 1$ & $40 \mathrm{cp}(1 \mathrm{mg})$ & $3 \mathrm{cp} / \mathrm{dia}$ & 13 & 60 & -47 \\
\hline Pac0534 & amitriptilina & & amitriptilina & C1 & $40 \mathrm{cp}(25 \mathrm{mg})$ & $1 \mathrm{cp} / \mathrm{dia}$ & 40 & 60 & -20 \\
\hline Pac0534 & amantadina & & amantadina & C1 & $50 \mathrm{cp}(100 \mathrm{mg})$ & $1,5 \mathrm{cp} / \mathrm{dia}$ & 33 & 60 & -27 \\
\hline Pac0534 & PROLOPA & Roche & $\begin{array}{l}\text { levodopa e } \\
\text { benserazida }\end{array}$ & C1 & $120 \mathrm{cp}(250 \mathrm{mg})$ & $4 \mathrm{cp} / \mathrm{dia}$ & 30 & 60 & -30 \\
\hline Pac3316 & sertralina & & sertralina & C1 & $30 \mathrm{cp}(50 \mathrm{mg})$ & $1 \mathrm{cp} / \mathrm{dia}$ & 30 & 60 & -30 \\
\hline Pac2562 & sertralina & & sertralina & C1 & $75 \mathrm{cp}(50 \mathrm{mg})$ & $2,5 \mathrm{cp} / \mathrm{dia}$ & 30 & 60 & 30 \\
\hline Pac2562 & \begin{tabular}{|l|} 
codeina: \\
paracetamol
\end{tabular} & & $\begin{array}{l}\text { codeina; } \\
\text { paracetamol }\end{array}$ & $\begin{array}{c}\text { A2 - } \\
\text { adendo }\end{array}$ & $60 \mathrm{cp}(30 \mathrm{mg})$ & $2 \mathrm{cp} / \mathrm{dia}$ & 30 & 60 & -30 \\
\hline Pac3160 & clorpromazina & & clorpromazina & C1 & $\begin{array}{l}20 \mathrm{mi}(0,4 \\
\mathrm{mg} / \mathrm{ml})\end{array}$ & $0,25 \mathrm{~m}$ Vdia & 80 & 60 & 20 \\
\hline Pac3160 & amitriptitina & & amitriptilina & c1 & $40 \mathrm{cp}(25 \mathrm{mg})$ & $1 \mathrm{cp} / \mathrm{dia}$ & 40 & 60 & -20 \\
\hline Pac0018 & diazepam & & diazepam & 81 & $20 \mathrm{cp}(10 \mathrm{mg})$ & $2 \mathrm{cp} / \mathrm{dia}$ & 10 & 60 & -50 \\
\hline Pac2704 & carbamazepina & & carbamazepina & C1 & $90 \mathrm{cp}(200 \mathrm{mg})$ & $3 \mathrm{cp} / \mathrm{dia}$ & 30 & 60 & -30 \\
\hline Pac0832 & sertralina & & sertralina & C1 & $60 \mathrm{cp}(50 \mathrm{mg})$ & $2 \mathrm{cp} / \mathrm{dia}$ & 30 & 60 & -30 \\
\hline Pac4062 & DEPAKENE & Abbott & $\begin{array}{l}\text { ácido valpróico } \\
\text { (ou derivado) }\end{array}$ & C1 & $150 \mathrm{cp}$ (250 mg) & $4 \mathrm{cp} / \mathrm{dia}$ & 38 & 60 & -23 \\
\hline
\end{tabular}


DT = Dias de tratamento fornecido $\quad \mathrm{LL}=$ Limite legal

\begin{tabular}{|c|c|c|c|c|c|c|c|c|c|}
\hline $\begin{array}{l}\text { código } \\
\text { paciente }\end{array}$ & Prescrição & Indústria & Principio Ativo & Alinea & Fornecimento & Posologia & DT & LL & DT - LL \\
\hline Pac4062 & fenobarbital & & fenobarbital & $\begin{array}{c}\text { B1 - } \\
\text { adendo }\end{array}$ & $40 \mathrm{cp}(100 \mathrm{mg})$ & $1 \mathrm{cp} / \mathrm{dia}$ & 40 & 60 & -20 \\
\hline Pac1220 & $\begin{array}{l}\text { Codeina; } \\
\text { paracetamol }\end{array}$ & & $\begin{array}{l}\text { codeina; } \\
\text { paracetamol }\end{array}$ & $\begin{array}{c}\text { A2 - } \\
\text { adendo }\end{array}$ & $120 \mathrm{cp}(30 \mathrm{mg})$ & $4 \mathrm{cp} / \mathrm{dia}$ & 30 & 60 & -30 \\
\hline Pac1980 & carbamazepina & & carbamazepina & $\mathrm{C1}$ & $250 \mathrm{cp}(200 \mathrm{mg})$ & $7 \mathrm{cp} / \mathrm{dia}$ & 36 & 60 & -24 \\
\hline Pac2728 & carbamazepina & & carbamazepina & C1 & $240 \mathrm{cp}(200 \mathrm{mg})$ & $6 \mathrm{cp} / \mathrm{dia}$ & 40 & 60 & -20 \\
\hline Pac2728 & clobazam & & clobazam & B1 & $90 \mathrm{cp}(10 \mathrm{mg})$ & $3 \mathrm{cp} / \mathrm{dia}$ & 30 & 60 & -30 \\
\hline Pac1508 & TOPAMAX & Janssen-Cilag & topiramato & $\mathrm{C}_{1}$ & $60 \mathrm{cp}(100 \mathrm{mg})$ & $2 \mathrm{cp} / \mathrm{dia}$ & 30 & 60 & .30 \\
\hline Pac1508 & LONGACTIL & Cristália & clorpromazina & $\mathrm{Cl}$ & $\begin{array}{l}60 \mathrm{ml}(0,4 \\
\mathrm{mg} / \mathrm{ml})\end{array}$ & $1,5 \mathrm{ml} / \mathrm{dia}$ & 40 & 60 & .20 \\
\hline Pac1508 & fluoxetina & & fluoxetina & $\mathrm{C1}$ & $60 \mathrm{cp}(20 \mathrm{mg})$ & $2 \mathrm{cp} / \mathrm{dia}$ & 30 & 60 & -30 \\
\hline Pac1329 & amitriptilina & & amitriptilina & C1 & $20 \mathrm{cp}(25 \mathrm{mg})$ & $1 \mathrm{cp} / \mathrm{dia}$ & 20 & 60 & -40 \\
\hline Pac3373 & amitriptilina & & amitriptilina & $\mathrm{C1}$ & $80 \mathrm{cp}(25 \mathrm{mg})$ & $2 \mathrm{cp} / \mathrm{dia}$ & 40 & 60 & -20 \\
\hline Pac3373 & AMPLICTIL & Aventis & clorpromazina & C1 & $\begin{array}{l}20 \mathrm{ml}(0,4 \\
\mathrm{mg} / \mathrm{ml})\end{array}$ & $0,45 \mathrm{~m} / \mathrm{dia}$ & 44 & 60 & -16 \\
\hline Pac3942 & amitriptilina & & amitriptilina & C1 & $40 \mathrm{cp}(25 \mathrm{mg})$ & $1 \mathrm{cp} / \mathrm{dia}$ & 40 & 60 & -20 \\
\hline Pac1070 & amitriptilina & & amitriptilina & $\mathrm{C1}$ & $40 \mathrm{cp}(25 \mathrm{mg})$ & $1 \mathrm{cp} / \mathrm{dia}$ & 40 & 60 & -20 \\
\hline Pac0772 & amitriptilina & & amitriptilina & $\mathrm{Cl}$ & $40 \mathrm{cp}(25 \mathrm{mg})$ & $1 \mathrm{cp} / \mathrm{dia}$ & 40 & 60 & -20 \\
\hline Pac0839 & imipramina & & imipramina & C1 & $40 \mathrm{cp}(25 \mathrm{mg})$ & $1 \mathrm{cp} /$ dia & 40 & 60 & -20 \\
\hline Pac1349 & AMVTRIL & Cristália & amitriptilina & $\mathrm{c} 1$ & $40 \mathrm{cp}(25 \mathrm{mg})$ & $1 \mathrm{cp} / \mathrm{dia}$ & 40 & 60 & -20 \\
\hline Pac2731 & sertralina & & sertralina & $\mathrm{C1}$ & $30 \mathrm{cp}(50 \mathrm{mg})$ & $1 \mathrm{cp} / \mathrm{dia}$ & 30 & 60 & -30 \\
\hline Pac3527 & DEPAKENE & Abbott & $\begin{array}{l}\text { ácido valpróico } \\
\text { (ou derivado) }\end{array}$ & C1 & $225 \mathrm{cp}(250 \mathrm{mg})$ & $6 \mathrm{cp} / \mathrm{dia}$ & 38 & 60 & -23 \\
\hline Pac2656 & amitriptilina & & amitriptilina & $\mathrm{C}_{1}$ & $280 \mathrm{cp}(25 \mathrm{mg})$ & $7 \mathrm{cp} /$ dia & 40 & 60 & -20 \\
\hline Pac2877 & amitriptilina & & amitriptilina & C1 & $40 \mathrm{cp}(25 \mathrm{mg})$ & $1 \mathrm{cp} / \mathrm{dia}$ & 40 & 60 & -20 \\
\hline Pac2877 & LONGACTIL & Cristália & clorpromazina & C1 & $\begin{array}{l}20 \mathrm{ml}(0,4 \\
\mathrm{mg} / \mathrm{ml})\end{array}$ & $0,45 \mathrm{~m} / \mathrm{dia}$ & 44 & 60 & -16 \\
\hline Pac1370 & AMYTRIL & Cristália & amitriptilina & C1 & $180 \mathrm{cp}(25 \mathrm{mg})$ & $6 \mathrm{cp} / \mathrm{dia}$ & 30 & 60 & -30 \\
\hline Pac1992 & carbamazepina & & carbamazepina & C1 & $80 \mathrm{cp}(200 \mathrm{mg})$ & $2 \mathrm{cp} / \mathrm{dia}$ & 40 & 60 & -20 \\
\hline Pac1992 & LONGACTLL & Cristália & clorpromazina & $c_{1}$ & $\begin{array}{l}60 \mathrm{ml}(0,4 \\
\mathrm{mg} / \mathrm{ml}) \\
\end{array}$ & $1,5 \mathrm{mUdia}$ & 40 & 60 & -20 \\
\hline Pac1992 & imipramina & & imipramina & $C_{1}$ & $40 \mathrm{cp}(25 \mathrm{mg})$ & $1 \mathrm{cp} / \mathrm{dia}$ & 40 & 60 & -20 \\
\hline Pac0477 & PROLOPA & Roche & \begin{tabular}{|l} 
levodopa e \\
benserazida
\end{tabular} & C1 & $110 \mathrm{cp}(250 \mathrm{mg})$ & $3 \mathrm{cp} / \mathrm{dia}$ & 37 & 60 & -23 \\
\hline Pac0477 & selegilina & & selegilina & C1 & $40 \mathrm{cp}(5 \mathrm{mg})$ & $1 \mathrm{cp} / \mathrm{dia}$ & 40 & 60 & -20 \\
\hline Pac0477 & amantadina & & amantadina & $C 1$ & $120 \mathrm{cp}(100 \mathrm{mg})$ & $3 \mathrm{cp} / \mathrm{dia}$ & 40 & 60 & -20 \\
\hline Pac3939 & gabapentina & & gabapentina & C1 & $210 \mathrm{cp}(300 \mathrm{mg})$ & $6 \mathrm{cp} / \mathrm{dia}$ & 35 & 60 & -25 \\
\hline Pac3420 & carbamazepina & & carbamazepina & C1 & $280 \mathrm{cp}(200 \mathrm{mg})$ & $7 \mathrm{cp} / \mathrm{dia}$ & 40 & 60 & -20 \\
\hline Pac1202 & fenobarbital & & fenobarbital & \begin{tabular}{|c|} 
B1- \\
adendo \\
\end{tabular} & $80 \mathrm{cp}(100 \mathrm{mg})$ & $2 \mathrm{cp} / \mathrm{dia}$ & 40 & 60 & -20 \\
\hline Pac1202 & carbamazepina & & carbamazepina & c1 & $140 \mathrm{cp}(200 \mathrm{mg})$ & $6 \mathrm{cp} / \mathrm{dia}$ & 23 & 60 & -37 \\
\hline Pac1004 & $\begin{array}{l}\text { codeina; } \\
\text { paracetamol }\end{array}$ & & $\begin{array}{l}\text { codeina; } \\
\text { paracetamol }\end{array}$ & $\begin{array}{c}\text { A2 - } \\
\text { adendo }\end{array}$ & $40 \mathrm{cp}(30 \mathrm{mg})$ & $0,5 \mathrm{cp} / \mathrm{dia}$ & 80 & 60 & 20 \\
\hline Pac3168 & carbamazepina & & carbamazepina & C1 & $240 \mathrm{cp}(200 \mathrm{mg})$ & $3 \mathrm{cp} / \mathrm{dia}$ & 80 & 60 & 20 \\
\hline Pac3168 & DEPAKENE & Abbolt & \begin{tabular}{|l|} 
ácido valpróico \\
(ou derivado) \\
\end{tabular} & $c 1$ & $\begin{array}{l}700 \mathrm{ml}(50 \\
\mathrm{mg} / \mathrm{ml})\end{array}$ & $30 \mathrm{~m} / \mathrm{dia}$ & 23 & 60 & -37 \\
\hline Pac3168 & NEULEPTIL & Aventis & periciazina & C1 & $\begin{array}{l}80 \mathrm{ml}(0,4 \\
\mathrm{mg} / \mathrm{ml})\end{array}$ & $1,2 \mathrm{mUdia}$ & 67 & 60 & 7 \\
\hline Pac2416 & amitriptilina & & amitriptilina & C1 & $100 \mathrm{cp}(25 \mathrm{mg})$ & $3 \mathrm{cp} / \mathrm{dia}$ & 33 & 60 & -27 \\
\hline Pac2416 & AMPLICTIL & Aventis & clorpromazina & C1 & $\begin{array}{l}6 \mathrm{ml}(0.4 \\
\mathrm{mg} / \mathrm{ml}) \\
\end{array}$ & 2 mUdia & 30 & 60 & -30 \\
\hline Pac2559 & amitriptilina & & emilriptilina & C1 & $100 \mathrm{cp}(25 \mathrm{mg})$ & $3 \mathrm{cp} / \mathrm{dia}$ & 33 & 60 & -27 \\
\hline Pac2559 & NEURONTIN & Pfizer & gabapentina & C1 & $120 \mathrm{cp}(400 \mathrm{mg})$ & $4 \mathrm{cp} / \mathrm{dia}$ & 30 & 60 & -30 \\
\hline Pac3231 & AMMTRIL & Cristália & amitriptilina & C1 & $100 \mathrm{cp}(25 \mathrm{mg})$ & $3 \mathrm{cp} / \mathrm{dia}$ & 33 & 60 & -27 \\
\hline Pac3231 & LONGACTIL & Cristália & clorpromazina & C1 & $\begin{array}{l}60 \mathrm{ml}(0,4 \\
\mathrm{mg} / \mathrm{ml}) \\
\end{array}$ & $1,6 \mathrm{ml} / \mathrm{dia}$ & 38 & 60 & -23 \\
\hline Pac2779 & AMVTRLL & Cristália & amitriptilina & c1 & $100 \mathrm{cp}(25 \mathrm{mg})$ & $3 \mathrm{cp} / \mathrm{dia}$ & 33 & 60 & -27 \\
\hline Pac2779 & LONGACTIL & Cristália & clorpromazina & C1 & $\begin{array}{l}40 \mathrm{ml}(0,4 \\
\mathrm{mg} / \mathrm{ml})\end{array}$ & $1 \mathrm{~m} /$ dia & 40 & 60 & -20 \\
\hline
\end{tabular}


$D T=$ Dias de tratamento fornecido $\quad L L=$ Limite legal

\begin{tabular}{|c|c|c|c|c|c|c|c|c|c|}
\hline $\begin{array}{l}\text { código } \\
\text { paciente }\end{array}$ & Prescrição & Indústria & Princípio Ativo & Alínea & Fornecimento & Posologia & DT & LL & DT - LL \\
\hline Pac2043 & gabapentina & & gabapentina & $\mathrm{c1}$ & $90 \mathrm{cp}(300 \mathrm{mg})$ & $3 \mathrm{cp} / \mathrm{dia}$ & 30 & 60 & -30 \\
\hline Pac2043 & imipramina & & imipramina & C1 & $60 \mathrm{cp}(25 \mathrm{mg})$ & $2 \mathrm{cp} / \mathrm{dia}$ & 30 & 60 & -30 \\
\hline Pac2043 & LONGACTIL & Cristália & clorpromazina & $\mathrm{C1}$ & $\begin{array}{l}60 \mathrm{ml}(0,4 \\
\mathrm{mg} / \mathrm{ml})\end{array}$ & $2 \mathrm{~m} / \mathrm{dia}$ & 30 & 60 & -30 \\
\hline Pac3005 & sertralina & & sertralina & C1 & $60 \mathrm{cp}(50 \mathrm{mg})$ & $2 \mathrm{cp} / \mathrm{dia}$ & 30 & 60 & -30 \\
\hline Pac3284 & carbamazepina & & carbamazepina & c1 & $60 \mathrm{cp}(200 \mathrm{mg})$ & $2 \mathrm{cp} / \mathrm{dia}$ & 30 & 60 & -30 \\
\hline Pac1683 & diazepam & & diazepam & $\overline{B 1}$ & $20 \mathrm{cp}(5 \mathrm{mg})$ & $1 \mathrm{cp} / \mathrm{dia}$ & 20 & 60 & -40 \\
\hline Pac2887 & TRYPTANOL & Prodome & amitriptilina & C1 & 40 cp (25 mg) & $1 \mathrm{cp} / \mathrm{dia}$ & 40 & 60 & -20 \\
\hline Pac3744 & PROGRESSE & Biosintètica & gabapentina & $\mathrm{C1}$ & $20 \mathrm{cp}(300 \mathrm{mg})$ & $2 \mathrm{cp} / \mathrm{dia}$ & 10 & 60 & -50 \\
\hline Pac2405 & $\begin{array}{l}\text { codeina; } \\
\text { paracetamol }\end{array}$ & & $\begin{array}{l}\text { codeina; } \\
\text { paracetamol }\end{array}$ & $\begin{array}{c}2- \\
\text { adendo }\end{array}$ & $60 \mathrm{cp}(30 \mathrm{mg})$ & $2 \mathrm{cp} / \mathrm{dia}$ & 30 & 60 & -30 \\
\hline Pac2429 & ANAFRANIL & Novartis & clomipramina & $\mathrm{C1}$ & $120 \mathrm{cp}(25 \mathrm{mg})$ & $4 \mathrm{cp} / \mathrm{dia}$ & 30 & 60 & -30 \\
\hline Pac2429 & CINETOL & Cristália & biperideno & $\mathrm{c1}$ & $90 \mathrm{cp}(2 \mathrm{mg})$ & $3 \mathrm{cp} / \mathrm{dia}$ & 30 & 60 & -30 \\
\hline Pac1727 & AMMTRIL & Cristália & amitriptilina & c1 & $20 \mathrm{cp}(25 \mathrm{mg})$ & $2 \mathrm{cp} / \mathrm{dia}$ & 10 & 60 & -50 \\
\hline Pac0373 & AMYTRIL & Cristália & amitriptilina & $\mathrm{ct}$ & $100 \mathrm{cp} \mathrm{(25} \mathrm{mg)}$ & $3 \mathrm{cp} / \mathrm{dia}$ & 33 & 60 & -27 \\
\hline Pac2972 & tramadol & & tramadol & $\begin{array}{c}\mathrm{A2}- \\
\text { adendo }\end{array}$ & $\begin{array}{l}30 \mathrm{cp}(30 / 500 \\
\mathrm{mg})\end{array}$ & $1 \mathrm{cp} / \mathrm{dia}$ & 30 & 60 & -30 \\
\hline Pac1526 & amitriptilina & & amitriptilina & c1 & $40 \mathrm{cp}(25 \mathrm{mg})$ & $1 \mathrm{cp} / \mathrm{dia}$ & 40 & 60 & -20 \\
\hline Pac2435 & tramadol & & tramadol & $\begin{array}{c}A 2- \\
\text { adendo }\end{array}$ & $50 \mathrm{cp}(50 \mathrm{mg})$ & $4 \mathrm{cp} / \mathrm{dia}$ & 13 & 60 & -48 \\
\hline Pac0992 & sertralina & & sertralina & $\mathrm{Ct}$ & $60 \mathrm{cp}(50 \mathrm{mg})$ & $2 \mathrm{cp} / \mathrm{dia}$ & 30 & 60 & -30 \\
\hline Pac1168 & PROLOPA & Roche & $\begin{array}{l}\text { levodopa e } \\
\text { benserazida }\end{array}$ & C1 & $30 \mathrm{cp}$ (200 mg) & $1 \mathrm{cp} / \mathrm{dia}$ & 30 & 60 & -30 \\
\hline Pac1168 & AKINETON & Knoll & biperideno & C1 & $60 \mathrm{cp}(2 \mathrm{mg})$ & $2 \mathrm{cp} / \mathrm{dia}$ & 30 & 60 & -30 \\
\hline Pac1168 & amantadina & & amantadina & C1 & $90 \mathrm{cp}(100 \mathrm{mg})$ & $3 \mathrm{cp} / \mathrm{dia}$ & 30 & 60 & -30 \\
\hline Pac4008 & fluoxetina & & fluoxetina & $\mathrm{c} 1$ & $40 \mathrm{cp}(20 \mathrm{mg})$ & $1 \mathrm{cp} / \mathrm{dia}$ & 40 & 60 & -20 \\
\hline Pac0984 & TRAMAL & $\begin{array}{l}\text { Plizer- } \\
\text { Pharmacia }\end{array}$ & tramadol & \begin{tabular}{|c|}
$\begin{array}{c}A 2- \\
\text { adendo }\end{array}$ \\
\end{tabular} & $30 \mathrm{cp}(50 \mathrm{mg})$ & $3 \mathrm{cp} / \mathrm{dia}$ & 10 & 60 & -50 \\
\hline Pac3969 & AMYTRIL & Cristália & amitriptilina & $\overline{c 1}$ & $40 \mathrm{cp}(25 \mathrm{mg})$ & 1 cp/dia & 40 & 60 & -20 \\
\hline Pac1234 & carbamazepina & & carbamazepina & C1 & $120 \mathrm{cp}(200 \mathrm{mg})$ & $4 \mathrm{cp} / \mathrm{dia}$ & 30 & 60 & -30 \\
\hline Pac2967 & fluoxetina & & fluoxetina & $\mathrm{C1}$ & $60 \mathrm{cp}(20 \mathrm{mg})$ & $1 \mathrm{cp} / \mathrm{dia}$ & 60 & 60 & 0 \\
\hline Pac2003 & $\begin{array}{l}\text { codeína; } \\
\text { paracetamol }\end{array}$ & & $\begin{array}{l}\text { codeina; } \\
\text { paracetamol }\end{array}$ & \begin{tabular}{|c|}
$\begin{array}{c}A 2- \\
\text { adendo }\end{array}$ \\
\end{tabular} & $30 \mathrm{cp}(30 \mathrm{mg})$ & $3 \mathrm{cp} / \mathrm{dia}$ & 10 & 60 & -50 \\
\hline Pac0555 & $\begin{array}{l}\text { codeina; } \\
\text { paracelamol }\end{array}$ & & $\begin{array}{l}\text { codeina; } \\
\text { paracetamol }\end{array}$ & $\begin{array}{c}A 2- \\
\text { adendo }\end{array}$ & $30 \mathrm{cp}(30 \mathrm{mg})$ & $3 \mathrm{cp} / \mathrm{dia}$ & 10 & 60 & -50 \\
\hline Pac3232 & AMYTRIL & Cristália & amitriptilina & C1 & $60 \mathrm{cp}(25 \mathrm{mg})$ & $1 \mathrm{cp} / \mathrm{dia}$ & 60 & 60 & $\overline{0}$ \\
\hline Pac3258 & amantadina & & amantadina & C1 & $60 \mathrm{cp}(100 \mathrm{mg})$ & $2 \mathrm{cp} / \mathrm{dia}$ & 30 & 60 & -30 \\
\hline Pac2481 & SIFROL. & Boehringer & pramipexol & C1 & $30 \mathrm{cp}(0,25 \mathrm{mg})$ & $1 \mathrm{cp} / \mathrm{dia}$ & 30 & 60 & -30 \\
\hline Pac0605 & OXYCONTIN & Zodiac & oxicodona & $\overline{A 1}$ & $120 \mathrm{cp}(20 \mathrm{mg})$ & $4 \mathrm{cp} / \mathrm{dia}$ & 30 & 30 & 0 \\
\hline Pac0605 & AMYTRIL & Cristália & amitriptilina & $c 1$ & $40 \mathrm{cp}(25 \mathrm{mg})$ & $1 \mathrm{cp} / \mathrm{dia}$ & 40 & 60 & -20 \\
\hline Pac0528 & sertralina & & sertralina & C1 & $60 \mathrm{cp}(50 \mathrm{mg})$ & $2 \mathrm{cp} / \mathrm{dia}$ & 30 & 60 & -30 \\
\hline Pac0679 & AMYTRIL & Cristália & amitriptilina & C1 & $100 \mathrm{cp}(25 \mathrm{mg})$ & $3 \mathrm{cp} / \mathrm{dia}$ & 33 & 60 & -27 \\
\hline Pac0526 & carbamazepina & & carbamazepina & C1 & $90 \mathrm{cp}(200 \mathrm{mg})$ & $3 \mathrm{cp} / \mathrm{dia}$ & 30 & 60 & -30 \\
\hline Pac2163 & carbamazepina & & carbamazepina & $c 1$ & $90 \mathrm{cp}(200 \mathrm{mg})$ & $3 \mathrm{cp} / \mathrm{dia}$ & 30 & 60 & -30 \\
\hline Pac2557 & $\begin{array}{l}\text { codeina; } \\
\text { paracetamol }\end{array}$ & & $\begin{array}{l}\text { codeína; } \\
\text { paracetamol }\end{array}$ & $\begin{array}{c}\text { A2- } \\
\text { adendo }\end{array}$ & 30 cp (30 mg) & $4 \mathrm{cp} / \mathrm{dia}$ & 8 & 60 & -53 \\
\hline Pac0475 & $\begin{array}{l}\text { codeína; } \\
\text { paracetamol }\end{array}$ & & $\begin{array}{l}\text { codeina; } \\
\text { paracetamol }\end{array}$ & \begin{tabular}{|c|} 
A2 - \\
adendo
\end{tabular} & $100 \mathrm{cp}(30 \mathrm{mg})$ & $3 \mathrm{cp} / \mathrm{dia}$ & 33 & 60 & -27 \\
\hline Pac1375 & DEPAKENE & Abbott & $\begin{array}{l}\text { ácido valpróico } \\
\text { (ou derivado) }\end{array}$ & $\mathrm{Cl}$ & $50 \mathrm{cp}(500 \mathrm{mg})$ & $6 \mathrm{cp} / \mathrm{dia}$ & 8 & 60 & -52 \\
\hline Pac1375 & fenitoina & & $\begin{array}{l}\text { fenitoina } \\
\text { (hidantoina) }\end{array}$ & $\mathrm{Cl}$ & $30 \mathrm{cp}(100 \mathrm{mg})$ & $3 \mathrm{cp} / \mathrm{dia}$ & 10 & 60 & -50 \\
\hline Pac2045 & tramadol & & tramadol & $\begin{array}{c}2- \\
\text { adendo }\end{array}$ & $60 \mathrm{cp}(50 \mathrm{mg})$ & $4 \mathrm{cp} / \mathrm{dia}$ & 15 & 60 & -45 \\
\hline Pac2324 & TRAMAL & $\begin{array}{l}\text { Prizer- } \\
\text { Pharmacia }\end{array}$ & tramadol & $\begin{array}{c}\text { A2 - } \\
\text { adendo }\end{array}$ & $30 \mathrm{cp}(50 \mathrm{mg})$ & $3 \mathrm{cp} / \mathrm{dia}$ & 10 & 60 & -50 \\
\hline Pac1844 & $\begin{array}{l}\text { codeina; } \\
\text { paracetamol }\end{array}$ & & $\begin{array}{l}\text { codeína: } \\
\text { paracetamol }\end{array}$ & $\begin{array}{c}\text { A2- } \\
\text { adendo }\end{array}$ & $30 \mathrm{cp}(30 \mathrm{mg})$ & $3 \mathrm{cp} / \mathrm{dia}$ & 10 & 60 & -50 \\
\hline
\end{tabular}


$D T=$ Dias de tratamento fornecido $\quad L L=$ Limite legal

\begin{tabular}{|c|c|c|c|c|c|c|c|c|c|}
\hline $\begin{array}{l}\text { código } \\
\text { paciente }\end{array}$ & Prescrição & Indústria & Principio Ativo & Alínea & Fornecimento & Posologia & DT & LL & DT - LL \\
\hline Pac1469 & amitriptilina & & amitriptilina & C1 & $60 \mathrm{cp}(25 \mathrm{mg})$ & $2 \mathrm{cp} / \mathrm{dia}$ & 30 & 60 & -30 \\
\hline Pac3786 & DAFORIN & Sigma Pharma & fluoxetina & $\mathrm{C1}$ & $60 \mathrm{cp}(20 \mathrm{mg})$ & $1 \mathrm{cp} / \mathrm{dia}$ & 60 & 60 & 0 \\
\hline Pac3639 & tramadol & & tramadol & $\begin{array}{c}\text { A2 - } \\
\text { adendo }\end{array}$ & $30 \mathrm{cp}(50 \mathrm{mg})$ & $3 \mathrm{cp} / \mathrm{dia}$ & 10 & 60 & -50 \\
\hline Pac0457 & $\begin{array}{l}\text { codeina; } \\
\text { paracetamol }\end{array}$ & & $\begin{array}{l}\text { codeina; } \\
\text { paracetamol }\end{array}$ & \begin{tabular}{|c|} 
A2 - \\
adendo
\end{tabular} & $30 \mathrm{cp}(30 \mathrm{mg})$ & $3 \mathrm{cp} / \mathrm{dia}$ & 10 & 60 & -50 \\
\hline Pac4053 & LONGACTIL & Cristália & clorpromazina & c1 & $\begin{array}{l}40 \mathrm{ml}(0.4 \\
\mathrm{mg} / \mathrm{ml})\end{array}$ & $0,75 \mathrm{ml} / \mathrm{dia}$ & 53 & 60 & -7 \\
\hline Pac0745 & carbamazepina & & carbamazepina & $\mathrm{C1}$ & $450 \mathrm{cp}(200 \mathrm{mg})$ & $10 \mathrm{cp} / \mathrm{dia}$ & 45 & 60 & .15 \\
\hline Pac0782 & carbamazepina & & carbamazepina & $\mathrm{C1}$ & $40 \mathrm{cp}(200 \mathrm{mg})$ & $0,5 \mathrm{cp} / \mathrm{dia}$ & 80 & 60 & 20 \\
\hline Pac4046 & arnitriptilina & & amitriptilina & $\mathrm{C1}$ & $60 \mathrm{cp}$ (25 mg) & $1,5 \mathrm{cp} / \mathrm{dia}$ & 40 & 60 & -20 \\
\hline Pac2378 & amitriptitina & & amitriptilina & $\overline{C 1}$ & $30 \mathrm{cp}(25 \mathrm{mg})$ & $1 \mathrm{cp} / \mathrm{dia}$ & 30 & 60 & -30 \\
\hline Pac2370 & carbamazepina & & carbamazepina & $\mathrm{Cl}$ & $60 \mathrm{cp}(200 \mathrm{mg})$ & $1 \mathrm{cp} / \mathrm{dia}$ & 60 & 60 & 0 \\
\hline Pac1199 & amitriptilina & & amitriptilina & $c_{1}$ & $60 \mathrm{cp}(25 \mathrm{mg})$ & $2 \mathrm{cp} / \mathrm{dia}$ & 30 & 60 & -30 \\
\hline Pac2446 & amitriptilina & & amitriptilina & $\mathrm{C1}$ & $180 \mathrm{cp}(25 \mathrm{mg})$ & $6 \mathrm{cp} / \mathrm{dia}$ & 30 & 60 & 30 \\
\hline Pac2444 & $\begin{array}{l}\text { codeina: } \\
\text { paracelamol }\end{array}$ & & $\begin{array}{l}\text { codeina: } \\
\text { paracetamol }\end{array}$ & $\begin{array}{c}\begin{array}{c}A 2- \\
\text { adendo }\end{array} \\
\end{array}$ & $30 \mathrm{cp}$ (30 mg) & $3 \mathrm{cp} / \mathrm{dia}$ & 10 & 60 & -50 \\
\hline Pac3940 & amitriptifina & & amitriptilina & $\mathrm{c} 1$ & $30 \mathrm{cp}(25 \mathrm{mg})$ & $1 \mathrm{cp} / \mathrm{dia}$ & 30 & 60 & -30 \\
\hline Pac3868 & fenitoina & & $\begin{array}{l}\text { fenitoina } \\
\text { (hidantoina) }\end{array}$ & $\mathrm{C1}$ & $120 \mathrm{cp}(100 \mathrm{mg})$ & $4 \mathrm{cp} / \mathrm{dia}$ & 30 & 60 & -30 \\
\hline Pac0559 & DEPAKENE & Abbott & $\begin{array}{l}\text { ácido valpróico } \\
\text { (ou derivado) }\end{array}$ & $\mathrm{Cl}$ & $50 \mathrm{cp}(250 \mathrm{mg})$ & $1 \mathrm{cp} / \mathrm{dia}$ & 50 & 60 & -10 \\
\hline Pac2719 & amitriptilina & & amitriptilina & C1 & $120 \mathrm{cp} \mathrm{(25} \mathrm{mg)}$ & $4 \mathrm{cp} / \mathrm{dia}$ & 30 & 60 & -30 \\
\hline Pac1982 & DEPAKENE & Abbott & $\begin{array}{l}\text { ácido valpróico } \\
\text { (ou derivado) }\end{array}$ & $\mathrm{c} 1$ & $250 \mathrm{cp}(500 \mathrm{mg})$ & $8 \mathrm{cp} / \mathrm{dia}$ & 31 & 60 & -29 \\
\hline Pac2376 & carbamazepina & & carbamazepina & $\mathrm{C1}_{1}$ & $120 \mathrm{cp}(200 \mathrm{mg})$ & $2 \mathrm{cp} / \mathrm{dia}$ & 60 & 60 & 0 \\
\hline Pac2376 & amitriptilina & & amitriptilina & C1 & $100 \mathrm{cp}(25 \mathrm{mg})$ & 2 cp/dia & 50 & 60 & -10 \\
\hline Pac1340 & TRAMAL & $\begin{array}{l}\text { Pfizer- } \\
\text { Pharmacia }\end{array}$ & tramadol & \begin{tabular}{c|}
$\begin{array}{c}A 2- \\
\text { adendo }\end{array}$ \\
\end{tabular} & $40 \mathrm{cp}(50 \mathrm{mg})$ & $4 \mathrm{cp} / \mathrm{dia}$ & 10 & 60 & -50 \\
\hline Pac0714 & carbamazepina & & carbamazepina & C1 & $20 \mathrm{cp}(200 \mathrm{mg})$ & $1 \mathrm{cp} / \mathrm{dia}$ & 20 & 60 & -40 \\
\hline Pac1697 & amitriptilina & & amitriptilina & $\mathrm{Cl}$ & $60 \mathrm{cp}(25 \mathrm{mg})$ & $2 \mathrm{cp} / \mathrm{dia}$ & 30 & 60 & -30 \\
\hline Pac4080 & AMYTRIL & Cristália & amitriptilina & C1 & $40 \mathrm{cp}(25 \mathrm{mg})$ & $1 \mathrm{cp} / \mathrm{dia}$ & 40 & 60 & -20 \\
\hline Pac3159 & DEPAKENE & Abbott & $\begin{array}{l}\text { ácido valpróico } \\
\text { (ou derivado) }\end{array}$ & $\mathrm{C} 1$ & $100 \mathrm{cp}(500 \mathrm{mg})$ & $8 \mathrm{cp} / \mathrm{dia}$ & 13 & 60 & -48 \\
\hline Pac3159 & fenobarbital & & fenobarbital & \begin{tabular}{|c|}
$\begin{array}{c}\text { B1 - } \\
\text { adendo }\end{array}$ \\
\end{tabular} & $40 \mathrm{cp}(100 \mathrm{mg})$ & $1 \mathrm{cp} / \mathrm{dia}$ & 40 & 60 & -20 \\
\hline Pac0947 & carbamazepina & & carbamazepina & $\mathrm{C1}$ & $60 \mathrm{cp}(200 \mathrm{mg})$ & $3 \mathrm{cp} / \mathrm{dia}$ & 20 & 60 & -40 \\
\hline Pac0947 & TOPAMAX & Janssen-Cilag & topiramato & C1 & $60 \mathrm{cp}(100 \mathrm{mg})$ & $3 \mathrm{cp} / \mathrm{dia}$ & 20 & 60 & -40 \\
\hline Pac3986 & amitriptilina & & amitriptilina & c1 & $100 \mathrm{cp} \mathrm{(25} \mathrm{mg)}$ & $3 \mathrm{cp} / \mathrm{dia}$ & 33 & 60 & -27 \\
\hline Pac0054 & fenobarbital & & fenobarbital & \begin{tabular}{|c|}
$\mathrm{B1}-$ \\
adendo
\end{tabular} & $40 \mathrm{cp}(100 \mathrm{mg})$ & $1 \mathrm{cp} / \mathrm{dia}$ & 40 & 60 & -20 \\
\hline Pac2786 & amitriptitina & & amitriptilina & C1 & $60 \mathrm{cp}(25 \mathrm{mg})$ & $2 \mathrm{cp} / \mathrm{dia}$ & 30 & 60 & -30 \\
\hline Pac1370 & LONGACTIL & Cristália & clorpromazina & C1 & $\begin{array}{l}20 \mathrm{ml}(0,4 \\
\mathrm{mg} / \mathrm{ml})\end{array}$ & $0,85 \mathrm{~m} / \mathrm{dia}$ & 24 & 60 & 36 \\
\hline Pac1370 & amitriptilina & & amitriptilina & C1 & $60 \mathrm{cp}(25 \mathrm{mg})$ & $2 \mathrm{cp} / \mathrm{dia}$ & 30 & 60 & -30 \\
\hline Pac3998 & fenobarbilal & & fenobarbital & $\begin{array}{c}\mathrm{B1}- \\
\text { adendo } \\
\end{array}$ & $40 \mathrm{cp}(100 \mathrm{mg})$ & $1 \mathrm{cp} / \mathrm{dia}$ & 40 & 60 & -20 \\
\hline Pac2421 & imipramina & & imipramina & $\mathrm{C1}$ & $60 \mathrm{cp}(25 \mathrm{mg})$ & $1 \mathrm{cp} / \mathrm{dia}$ & 60 & 60 & o \\
\hline Pac1390 & sertralina & & sertralina & C1 & $30 \mathrm{cp}(50 \mathrm{mg})$ & $1 \mathrm{cp} / \mathrm{dia}$ & 30 & 60 & -30 \\
\hline Pac1955 & LONGACTIL & Cristália & clorpromazina & C1 & $\begin{array}{l}60 \mathrm{ml}(0,4 \\
\mathrm{mg} / \mathrm{mi})\end{array}$ & $2 \mathrm{ml} / \mathrm{dia}$ & 30 & 60 & 30 \\
\hline Pac1418 & $\begin{array}{l}\text { DORLESS- } \\
\text { TRAMADOL }\end{array}$ & União Química & tramadol & $\begin{array}{c}\text { A2 - } \\
\text { adendo }\end{array}$ & $60 \mathrm{cp}(50 \mathrm{mg})$ & $4 \mathrm{cp} / \mathrm{dia}$ & 15 & 60 & -45 \\
\hline Pac2496 & amitriptilina & & amitriptilina & C1 & $40 \mathrm{cp}(25 \mathrm{mg})$ & $1 \mathrm{cp} / \mathrm{dia}$ & 40 & 60 & -20 \\
\hline Pac2888 & AMTTRIL & Cristália & amitriptilina & C1 & $40 \mathrm{cp}(25 \mathrm{mg})$ & $1 \mathrm{cp} / \mathrm{dia}$ & 40 & 60 & -20 \\
\hline Pac2878 & amitriptilina & & amitriptilina & C1 & $60 \mathrm{cp}(25 \mathrm{mg})$ & $2 \mathrm{cp} / \mathrm{dia}$ & 30 & 60 & .30 \\
\hline Pac2260 & sertralina & & sertralina & C1 & $30 \mathrm{cp}(50 \mathrm{mg})$ & $1 \mathrm{cp} / \mathrm{dia}$ & 30 & 60 & -30 \\
\hline
\end{tabular}


$D T=$ Dias de tratamento fornecido $\quad \mathrm{LL}=$ Limite legal

\begin{tabular}{|c|c|c|c|c|c|c|c|c|c|}
\hline $\begin{array}{l}\text { código } \\
\text { paciente }\end{array}$ & Prescrição & Indústria & Principio Ativo & Alinea & Fornecimento & Posologia & DT & LL & OT - LL \\
\hline Pac1337 & tramadol & & Iramadol & \begin{tabular}{c|} 
A2- \\
adendo
\end{tabular} & $30 \mathrm{cp}(50 \mathrm{mg})$ & $3 \mathrm{cp} / \mathrm{dia}$ & 10 & 60 & -50 \\
\hline Pac0337 & carbamazepina & & carbamazepina & $\mathrm{C1}$ & $150 \mathrm{cp}(200 \mathrm{mg})$ & $3 \mathrm{cp} / \mathrm{dia}$ & 50 & 60 & -10 \\
\hline Pac0337 & AMYTRIL & Cristália & amitriptilina & $\mathrm{C1}$ & $100 \mathrm{cp}(25 \mathrm{mg})$ & $2 \mathrm{cp} / \mathrm{dia}$ & 50 & 60 & -10 \\
\hline Pac3668 & fenobarbital & & fenobarbital & \begin{tabular}{|c|} 
B1- \\
adendo
\end{tabular} & $20 \mathrm{cp}(100 \mathrm{mg})$ & $3 \mathrm{cp} / \mathrm{dia}$ & 7 & 60 & -53 \\
\hline Pac3668 & carbamazepina & & carbarnazepina & C1 & $60 \mathrm{cp} \mathrm{(200} \mathrm{mg)}$ & $6 \mathrm{cp} / \mathrm{dia}$ & 10 & 60 & -50 \\
\hline Pac1685 & DOLOXENE-A & Eli Lilly & $\begin{array}{l}\text { propoxifeno; ácido } \\
\text { acetilsalicilico }\end{array}$ & $\begin{array}{c}\text { A2:- } \\
\text { adendo }\end{array}$ & $\begin{array}{l}30 \mathrm{cp}(77 / 325 \\
\mathrm{mg})\end{array}$ & $2 \mathrm{cp} / \mathrm{dia}$ & 15 & 60 & -45 \\
\hline Pac0072 & amitriptilina & & amitriptilina & $\mathrm{C1}$ & $100 \mathrm{cp}(25 \mathrm{mg})$ & $3 \mathrm{cp} / \mathrm{dia}$ & 33 & 60 & -27 \\
\hline Pac2780 & clorpromazina & & clorpromazina & C1 & $60 \mathrm{cp}(25 \mathrm{mg})$ & $2 \mathrm{cp} / \mathrm{dia}$ & 30 & 60 & -30 \\
\hline Pac0605 & gabapentina & & gabapentina & C1 & $120 \mathrm{cp}(400 \mathrm{mg})$ & $4 \mathrm{cp} / \mathrm{dia}$ & 30 & 60 & -30 \\
\hline Pac0334 & amitriptilina & & amitriptilina & $\mathrm{C1}$ & $80 \mathrm{cp}(20 \mathrm{mg})$ & $3 \mathrm{cp} / \mathrm{dia}$ & 27 & 60 & -33 \\
\hline Pac3917 & sertralina & & sertralina & C1 & $60 \mathrm{cp}(50 \mathrm{mg})$ & $2 \mathrm{cp} / \mathrm{dia}$ & 30 & 60 & -30 \\
\hline Pac3739 & gabapentina & & gabapentina & C1 & $60 \mathrm{cp}(400 \mathrm{mg})$ & $2 \mathrm{cp} / \mathrm{dia}$ & 30 & 60 & -30 \\
\hline Pac3739 & AMYTRIL & Cristália & amitriptilina & C1 & $40 \mathrm{cp}$ (25 mg) & $1 \mathrm{cp} / \mathrm{dia}$ & 40 & 60 & -20 \\
\hline Pac3739 & OXYCONTIN & Zodiac & oxicodona & A1 & $60 \mathrm{cp}(20 \mathrm{mg})$ & $2 \mathrm{cp} / \mathrm{dia}$ & 30 & 30 & 0 \\
\hline Pac3637 & PSICOSEDIN & Farmasa & clordiazepóxido & B1 & $30 \mathrm{cp}(10 \mathrm{mg})$ & $1 \mathrm{cp} / \mathrm{dia}$ & 30 & 60 & .30 \\
\hline Pac2262 & carbamazepina & & carbamazepina & C1 & $120 \mathrm{cp}(200 \mathrm{mg})$ & $2 \mathrm{cp} / \mathrm{dia}$ & 60 & 60 & 0 \\
\hline Pac2262 & sertralina & & sertralina & $C 1$ & $120 \mathrm{cp}(50 \mathrm{mg})$ & $2 \mathrm{cp} / \mathrm{dia}$ & 60 & 60 & 0 \\
\hline Pac2285 & diazepam & & diazepam & 81 & $20 \mathrm{cp}(10 \mathrm{mg})$ & $1 \mathrm{cp} / \mathrm{dia}$ & 20 & 60 & -40 \\
\hline Pac0337 & LONGACTIL & Cristália & clorpromazina & c1 & $\begin{array}{l}140 \mathrm{ml}(0,4 \\
\mathrm{mg} / \mathrm{ml})\end{array}$ & $2,5 \mathrm{mV}$ dia & 56 & 60 & -4 \\
\hline Pac3763 & fluoxetina & & fluoxetina & C1 & $30 \mathrm{cp}(20 \mathrm{mg})$ & $1 \mathrm{cp} / \mathrm{dia}$ & 30 & 60 & 30 \\
\hline Pac1955 & RIVOTRIL & Roche & clonazepam & B1 & $90 \mathrm{cp}(2 \mathrm{mg})$ & $1 \mathrm{cp} / \mathrm{dia}$ & 90 & 60 & 30 \\
\hline Pac0536 & AMVTRIL & Cristália & amitriplilina & C1 & $60 \mathrm{cp}(25 \mathrm{mg})$ & $2 \mathrm{cp} / \mathrm{dia}$ & 30 & 60 & -30 \\
\hline Pac0636 & amitriptilina & & amitriptilina & C1 & $40 \mathrm{cp}(25 \mathrm{mg})$ & $1 \mathrm{cp} / \mathrm{dia}$ & 40 & 60 & -20 \\
\hline Pac0636 & LONGACTIL & Cristália & clorpromazina & C1 & \begin{tabular}{|l|}
$20 \mathrm{ml}(0,4$ \\
$\mathrm{mg} / \mathrm{ml})$
\end{tabular} & $0,3 \mathrm{ml} / \mathrm{dia}$ & 67 & 60 & 7 \\
\hline Pac2954 & CLARITIN D & Schering Plough & $\begin{array}{l}\text { loratadina; } \\
\text { pseudoefedrina }\end{array}$ & D1 & $60 \mathrm{cp}(5 \mathrm{mg})$ & $2 \mathrm{cp} / \mathrm{dia}$ & 30 & & \\
\hline Pac3458 & imipramina & & imipramina & C1 & $30 \mathrm{cp}$ (25 mg) & $1 \mathrm{cp} / \mathrm{dia}$ & 30 & 60 & -30 \\
\hline Pac2063 & AMYTRIL. & Cristália & amitriptilina & C1 & $60 \mathrm{cp}$ (25 mg) & $2 \mathrm{cp} / \mathrm{dia}$ & 30 & 60 & -30 \\
\hline Pac2063 & gabapentina & & gabapentina & $c_{1}$ & $90 \mathrm{cp}(300 \mathrm{mg})$ & $3 \mathrm{cp} / \mathrm{dia}$ & 30 & 60 & -30 \\
\hline Pac2888 & NEURONTIN & Prizer & gabapentina & $C 1$ & $90 \mathrm{cp}$ (400 mg) & $3 \mathrm{cp} / \mathrm{dia}$ & 30 & 60 & 30 \\
\hline Pac2888 & OXYCONTIN & Zodiac & oxicodona & A1 & $120 \mathrm{cp}(20 \mathrm{mg})$ & $4 \mathrm{cp} / \mathrm{dia}$ & 30 & 30 & 0 \\
\hline Pac3210 & AMYTRIL & Cristália & amitriptilina & $\mathrm{Cl}$ & $40 \mathrm{cp}(25 \mathrm{mg})$ & $1 \mathrm{cp} / \mathrm{dia}$ & 40 & 60 & -20 \\
\hline Pac0017 & TRAMAL & \begin{tabular}{|l|} 
Pfizer- \\
Pharmacia
\end{tabular} & tramadol & \begin{tabular}{|c|} 
A2:- \\
adendo
\end{tabular} & $60 \mathrm{cp}(50 \mathrm{mg})$ & $3 \mathrm{cp} / \mathrm{dia}$ & 20 & 60 & -40 \\
\hline Pac2204 & \begin{tabular}{|l|} 
codeina; \\
paracetamol
\end{tabular} & & $\begin{array}{l}\text { codeina; } \\
\text { paracetamol }\end{array}$ & $\begin{array}{c}\text { A2:- } \\
\text { adendo }\end{array}$ & $60 \mathrm{cp}(30 \mathrm{mg})$ & $4 \mathrm{cp} / \mathrm{dia}$ & 15 & 60 & -45 \\
\hline Pac3964 & ANAFRANIL & Novartis & clomipramina & C1 & $120 \mathrm{cp}(25 \mathrm{mg})$ & $4 \mathrm{cp} / \mathrm{dia}$ & 30 & 60 & .30 \\
\hline Pac3964 & imipramina & & imipramina & C1 & $90 \mathrm{cp}(25 \mathrm{mg})$ & $3 \mathrm{cp} / \mathrm{dia}$ & 30 & 60 & -30 \\
\hline Pac0176 & amitriptilina & & amiiniptilina & $c 1$ & $180 \mathrm{cp}(25 \mathrm{mg})$ & $6 \mathrm{cp} / \mathrm{dia}$ & 30 & 60 & -30 \\
\hline Pac0176 & AMVTRIL & Cristália & amitriptitina & C1 & $45 \mathrm{cp}(25 \mathrm{mg})$ & $1,5 \mathrm{cp} / \mathrm{dia}$ & 30 & 60 & -30 \\
\hline Pac0176 & gabapentina & & gabapentina & C1 & $90 \mathrm{cp}(300 \mathrm{mg})$ & $3 \mathrm{cp} / \mathrm{dia}$ & 30 & 60 & 30 \\
\hline Pac1040 & \begin{tabular}{|l} 
codeina; \\
paracetamol
\end{tabular} & & \begin{tabular}{|l|} 
codeina: \\
paracetamol
\end{tabular} & $\begin{array}{c}\text { A2 - } \\
\text { adendo }\end{array}$ & $30 \mathrm{cp}(30 \mathrm{mg})$ & $3 \mathrm{cp} / \mathrm{dia}$ & 10 & 60 & -50 \\
\hline Pac0285 & \begin{tabular}{|l|} 
codeina: \\
paracetamol
\end{tabular} & & \begin{tabular}{|l} 
codeina: \\
paracetamol
\end{tabular} & $\begin{array}{c}\text { A2- } \\
\text { adendo }\end{array}$ & $160 \mathrm{cp}(30 \mathrm{mg})$ & $4 \mathrm{cp} / \mathrm{dia}$ & 40 & 60 & -20 \\
\hline Pac0285 & amitriptilina & & amitriptilina & C1 & $120 \mathrm{cp}(25 \mathrm{mg})$ & $3 \mathrm{cp} / \mathrm{dia}$ & 40 & 60 & -20 \\
\hline Pac3254 & cisaprida & & cisaprida & $\mathrm{Cl}$ & $120 \mathrm{cp}(10 \mathrm{mg})$ & $3 \mathrm{cp} / \mathrm{dia}$ & 40 & 60 & -20 \\
\hline Pac3486 & gabapentina & & gabapentina & $c_{1}$ & $60 \mathrm{cp}(300 \mathrm{mg})$ & $2 \mathrm{cp} / \mathrm{dia}$ & 30 & 60 & -30 \\
\hline Pac.3533 & imipramina & & imipramina & C1 & $90 \mathrm{cp}(25 \mathrm{mg})$ & $3 \mathrm{cp} / \mathrm{dia}$ & 30 & 60 & -30 \\
\hline $\operatorname{Pac} 2914$ & amitriptilina & & amitnptilina & C1 & $40 \mathrm{cp}(25 \mathrm{mg})$ & $1 \mathrm{cp} / \mathrm{dia}$ & 40 & 60 & -20 \\
\hline
\end{tabular}


$D T=$ Dias de tratamento fornecido $\quad L L=$ Limite legal

\begin{tabular}{|c|c|c|c|c|c|c|c|c|c|}
\hline $\begin{array}{l}\text { código } \\
\text { paciente }\end{array}$ & Prescrição & Indústria & Princípio Ativo & Alínea & Fornecimento & Posalogia & DT & LL & DT - LL \\
\hline Pac1131 & carbamazepina & & carbamazepina & C1 & $450 \mathrm{cp}(200 \mathrm{mg})$ & $5 \mathrm{cp} / \mathrm{dia}$ & 90 & 60 & 30 \\
\hline Pac1131 & fenobarbital & & fenobarbital & \begin{tabular}{|c|} 
B1- \\
adendo
\end{tabular} & $60 \mathrm{cp}(100 \mathrm{mg})$ & $1,5 \mathrm{cp} / \mathrm{dia}$ & 40 & 60 & -20 \\
\hline Pac1131 & TOPAMAX & Janssen-Cilag & topiramato & c1 & $20 \mathrm{cp}(100 \mathrm{mg})$ & $0,5 \mathrm{cp} / \mathrm{dia}$ & 40 & 60 & -20 \\
\hline Pac1518 & TRAMAL & $\begin{array}{l}\text { Pfizer- } \\
\text { Pharmacia }\end{array}$ & tramadot & \begin{tabular}{|c|} 
A2 - \\
adendo
\end{tabular} & $30 \mathrm{cp}(30 \mathrm{mg})$ & $3 \mathrm{cp} / \mathrm{dia}$ & 10 & 60 & -50 \\
\hline Pac2228 & $\begin{array}{l}\text { codeina: } \\
\text { paracetamol }\end{array}$ & & \begin{tabular}{|l|} 
codeina; \\
paracetamol
\end{tabular} & $\begin{array}{c}\text { A2 - } \\
\text { adendo }\end{array}$ & $30 \mathrm{cp}(30 \mathrm{mg})$ & $3 \mathrm{cp} / \mathrm{dia}$ & 10 & 60 & -50 \\
\hline Pac1009 & TOPAMAX & Janssen-Cilag & topiramato & c1 & $140 \mathrm{cp}(100 \mathrm{mg})$ & $4,5 \mathrm{cp} / \mathrm{dia}$ & 31 & 60 & -29 \\
\hline Pac1009 & carbamazepina & & carbamazepina & C1 & $90 \mathrm{cp}(200 \mathrm{mg})$ & $3 \mathrm{cp} / \mathrm{dia}$ & 30 & 60 & -30 \\
\hline Pac1009 & nitrazepam & & nitrazepam & B1 & $270 \mathrm{cp}(5 \mathrm{mg})$ & $9 \mathrm{cp} / \mathrm{dia}$ & 30 & 60 & -30 \\
\hline Pac1823 & PROLOPA & Roche & $\begin{array}{l}\text { levodopa e } \\
\text { benserazida }\end{array}$ & $\mathrm{C1}$ & $90 \mathrm{cp}(250 \mathrm{mg})$ & $3 \mathrm{cp} / \mathrm{dia}$ & 30 & 60 & -30 \\
\hline Pac0413 & FRISIUM & Aventis & clobazam & B1 & $60 \mathrm{cp}(10 \mathrm{mg})$ & $2 \mathrm{cp} / \mathrm{dia}$ & 30 & 60 & -30 \\
\hline Pac2362 & clobazam & & clobazam & B1 & $60 \mathrm{cp}(40 \mathrm{mg})$ & $2 \mathrm{cp} / \mathrm{dia}$ & 30 & 60 & -30 \\
\hline Pac0567 & diazepam & & diazepam & B1 & $30 \mathrm{cp}(10 \mathrm{mg})$ & $1 \mathrm{cp} / \mathrm{dia}$ & 30 & 60 & -30 \\
\hline Pac0657 & FRISIUM & Aventis & clobazam & B1 & $60 \mathrm{cp}(10 \mathrm{mg})$ & $2 \mathrm{cp} / \mathrm{dia}$ & 30 & 60 & -30 \\
\hline Pac1599 & FRISIUM & Aventis & clobazam & B1 & $40 \mathrm{cp}(10 \mathrm{mg})$ & $1 \mathrm{cp} / \mathrm{dia}$ & 40 & 60 & -20 \\
\hline Pac3761 & FRISIUM & Aventis & clobazam & $B 1$ & $80 \mathrm{cp}$ (10 mg) & $2,5 \mathrm{cp} / \mathrm{dia}$ & 32 & 60 & -28 \\
\hline Pac2095 & clobazam & & clobazam & B1 & $60 \mathrm{cp}(10 \mathrm{mg})$ & $1 \mathrm{cp} / \mathrm{dia}$ & 60 & 60 & 0 \\
\hline Pac0357 & FRISIUM & Aventis & clobazam & B1 & $100 \mathrm{cp}(10 \mathrm{mg})$ & $3 \mathrm{cp} / \mathrm{dia}$ & 33 & 60 & -27 \\
\hline Pac2728 & clobazam & & clobazam & B1 & $100 \mathrm{cp}(10 \mathrm{mg})$ & $3 \mathrm{cp} / \mathrm{dia}$ & 33 & 60 & -27 \\
\hline Pac0947 & FRISIUM & Aventis & clobazam & 81 & $180 \mathrm{cp}$ (10 mg) & $4 \mathrm{cp} / \mathrm{dia}$ & 45 & 60 & -15 \\
\hline Pac3615 & FRISIUM & Aventis & clobazam & 81 & $100 \mathrm{cp}(10 \mathrm{mg})$ & $3 \mathrm{cp} / \mathrm{dia}$ & 33 & 60 & -27 \\
\hline Pac0670 & FRISIUM & Aventis & clobezam & B1 & $60 \mathrm{cp}(10 \mathrm{mg})$ & $6 \mathrm{cp} / \mathrm{dia}$ & 10 & 60 & .50 \\
\hline Pac3385 & FRISIUM & Aventis & clobazam & B1 & $60 \mathrm{cp}$ (10 mg) & $2 \mathrm{cp} / \mathrm{dia}$ & 30 & 60 & -30 \\
\hline Pac1508 & FRISIUM & Aventis & clobazam & B1 & $60 \mathrm{cp}(10 \mathrm{mg})$ & $2 \mathrm{cp} / \mathrm{dia}$ & 30 & 60 & -30 \\
\hline Pac1151 & FRISIUM & Aventis & clobazam & B1 & $78 \mathrm{cp}(10 \mathrm{mg})$ & $5 \mathrm{cp} / \mathrm{dia}$ & 16 & 60 & -44 \\
\hline Pac3874 & clobazam & & clobazam & B1 & $60 \mathrm{cp}(10 \mathrm{mg})$ & $2 \mathrm{cp} / \mathrm{dia}$ & 30 & 60 & -30 \\
\hline Pac1906 & RIVOTRIL & Roche & clonazepam & B1 & $60 \mathrm{cp}(2 \mathrm{mg})$ & $2 \mathrm{cp} / \mathrm{dia}$ & 30 & 60 & -30 \\
\hline Pac0610 & diazepam & & diazepam & B1 & $30 \mathrm{cp}(10 \mathrm{mg})$ & $1 \mathrm{cp} / \mathrm{dia}$ & 30 & 60 & -30 \\
\hline Pac1361 & diazepam & & diazepam & B1 & $20 \mathrm{cp}(5 \mathrm{mg})$ & $0,5 \mathrm{cp} / \mathrm{dia}$ & 40 & 60 & -20 \\
\hline Pac2843 & RIVOTRIL & Roche & clonazepam & B1 & $40 \mathrm{cp}(2 \mathrm{mg})$ & $1 \mathrm{cp} / \mathrm{dia}$ & 40 & 60 & -20 \\
\hline Pac1955 & RIVOTRIL & Roche & clonazepam & B1 & $40 \mathrm{cp}(2 \mathrm{mg})$ & $1 \mathrm{cp} / \mathrm{dia}$ & 40 & 60 & -20 \\
\hline Pac2459 & diazepam & & diazepam & B1 & $210 \mathrm{cp}$ (10 mg) & $7 \mathrm{cp} / \mathrm{dia}$ & 30 & 60 & -30 \\
\hline Pac0055 & RIVOTRIL & Roche & clonazepam & B1 & $60 \mathrm{cp}(2 \mathrm{mg})$ & $2 \mathrm{cp} / \mathrm{dia}$ & 30 & 60 & -30 \\
\hline $\mathrm{PaC0203}$ & RIVOTRIL & Roche & clonazepam & B1 & $40 \mathrm{cp}(2 \mathrm{mg})$ & $1 \mathrm{cp} / \mathrm{dia}$ & 40 & 60 & -20 \\
\hline Pac0066 & RIVOTRIL & Roche & clonazepam & B1 & $40 \mathrm{cp}(2 \mathrm{mg})$ & $1 \mathrm{cp} / \mathrm{dia}$ & 40 & 60 & -20 \\
\hline Pac3672 & RIVOTRIL & Roche & clonazepam & B1 & $40 \mathrm{cp}(2 \mathrm{mg})$ & $1 \mathrm{cp} / \mathrm{dia}$ & 40 & 60 & -20 \\
\hline Pac1009 & nitrazepam & & nitrazepam & B1 & $90 \mathrm{cp}(5 \mathrm{mg})$ & $3 \mathrm{cp} / \mathrm{dia}$ & 30 & 60 & -30 \\
\hline Pac1157 & RIVOTRIL & Roche & clonazepam & B1 & $40 \mathrm{cp}(2 \mathrm{mg})$ & $1 \mathrm{cp} / \mathrm{dia}$ & 40 & 60 & -20 \\
\hline Pac2063 & RIVOTRIL & Roche & clonazepam & B1 & $40 \mathrm{cp}(2 \mathrm{mg})$ & $1 \mathrm{cp} / \mathrm{dia}$ & 40 & 60 & -20 \\
\hline Pac1370 & RIVOTRIL & Roche & clonazepam & B1 & $40 \mathrm{cp}(2 \mathrm{mg})$ & $1 \mathrm{cp} / \mathrm{dia}$ & 40 & 60 & -20 \\
\hline Pac1597 & diazepan & & diazepam & B1 & $40 \mathrm{cp}(10 \mathrm{mg})$ & $1 \mathrm{cp} / \mathrm{dia}$ & 40 & 60 & -20 \\
\hline Pac2159 & diazepam & & diazepam & B1 & $40 \mathrm{cp}(10 \mathrm{mg})$ & $1 \mathrm{cp} / \mathrm{dia}$ & 40 & 60 & -20 \\
\hline Pac2519 & RIVOTRIL & Roche & clonazepam & B1 & $40 \mathrm{cp}(2 \mathrm{mg})$ & $1 \mathrm{cp} / \mathrm{dia}$ & 40 & 60 & -20 \\
\hline Pac0152 & RIVOTRIL & Roche & clonazepam & B1 & $40 \mathrm{cp}(2 \mathrm{mg})$ & $1 \mathrm{cp} / \mathrm{dia}$ & 40 & 60 & -20 \\
\hline Pac0745 & RIVOTRIL & Roche & clonazepam & B1 & $40 \mathrm{cp}(2 \mathrm{mg})$ & $1 \mathrm{cp} / \mathrm{dia}$ & 40 & 60 & -20 \\
\hline Pac2554 & RIVOTRIL & Roche & clonazepam & B1 & $40 \mathrm{cp}(2 \mathrm{mg})$ & $1 \mathrm{cp} / \mathrm{dia}$ & 40 & 60 & -20 \\
\hline Pac1435 & RIVOTRIL & Roche & clonazepam & B1 & $40 \mathrm{cp}(2 \mathrm{mg})$ & $1 \mathrm{cp} / \mathrm{dia}$ & 40 & 60 & -20 \\
\hline
\end{tabular}


$\mathrm{DT}=$ Dias de tratamento fornecido $\mathrm{LL}=$ Limite legal

\begin{tabular}{|c|c|c|c|c|c|c|c|c|c|}
\hline $\begin{array}{l}\text { código } \\
\text { paciente }\end{array}$ & Prescrição & Indústria & Principio Ativo & Alínea & Fornecimento & Posologia & DT & $\mathbf{L L}$ & DT - LL \\
\hline Pac0945 & RIVOTRIL & Roche & clonazepam & B1 & $60 \mathrm{cp}(2 \mathrm{mg})$ & $2 \mathrm{cp} / \mathrm{dia}$ & 30 & 60 & -30 \\
\hline Pac2009 & RIVOTRIL & Roche & clonazepam & B1 & $20 \mathrm{cp}(2 \mathrm{mg})$ & $0,5 \mathrm{cp} / \mathrm{dia}$ & 40 & 60 & .20 \\
\hline Pac0018 & diazepam & & diazepam & B1 & $30 \mathrm{cp}$ (10 mg) & $1 \mathrm{cp} / \mathrm{dia}$ & 30 & 60 & -30 \\
\hline Pac3386 & nitrazepam & & nitrazepam & B1 & $150 \mathrm{cp}(5 \mathrm{mg})$ & $3 \mathrm{cp} / \mathrm{dia}$ & 50 & 60 & -10 \\
\hline Pac1077 & fuoxetina & & fluoxetina & C1 & $60 \mathrm{cp}(20 \mathrm{mg})$ & $2 \mathrm{cp} / \mathrm{dia}$ & 30 & 60 & -30 \\
\hline Pac2910 & $\begin{array}{l}\text { DORLESS- } \\
\text { TRAMADOL }\end{array}$ & União Quimica & tramadol & $\begin{array}{c}\text { A2 - } \\
\text { adendo }\end{array}$ & $40 \mathrm{cp}(50 \mathrm{mg})$ & $4 \mathrm{cp} / \mathrm{dia}$ & 10 & 60 & -50 \\
\hline Pac2910 & clorpromazina & & clorpromazina & C1 & $\begin{array}{l}20 \mathrm{ml}(0,4 \\
\mathrm{mg} / \mathrm{ml})\end{array}$ & $0,1 \mathrm{~m} / \mathrm{dia}$ & 200 & 60 & 140 \\
\hline Pac2910 & FRONTAL & $\begin{array}{l}\text { Pfizer- } \\
\text { Pharmacia }\end{array}$ & alprazolam & B1 & $90 \mathrm{cp}(400 \mathrm{mg})$ & $3 \mathrm{cp} / \mathrm{dia}$ & 30 & 60 & -30 \\
\hline Pac2288 & AMYTRIL & Cristália & amitriptilina & C1 & $20 \mathrm{cp}(25 \mathrm{mg})$ & $1 \mathrm{cp} / \mathrm{dia}$ & 20 & 60 & -40 \\
\hline Pac3131 & amitriptitina & & amitriptilina & C1 & $14 \mathrm{cp}(25 \mathrm{mg})$ & $0,5 \mathrm{cp} / \mathrm{dia}$ & 28 & 60 & -32 \\
\hline Pac2518 & \begin{tabular}{|l|} 
codeina: \\
paracetamol
\end{tabular} & & $\begin{array}{l}\text { codeina: } \\
\text { paracetamol }\end{array}$ & $\begin{array}{c}\text { A2:- } \\
\text { adendo }\end{array}$ & $20 \mathrm{cp}$ (30 mg) & $4,5 \mathrm{cp} / \mathrm{dia}$ & 4 & 60 & -56 \\
\hline Pac2295 & amantadina & & amantadina & C1 & $110 \mathrm{cp}(200 \mathrm{mg})$ & $2 \mathrm{cp} / \mathrm{dia}$ & 55 & 60 & -5 \\
\hline Pac2208 & sertralina & & sertralina & C1 & $30 \mathrm{cp}(50 \mathrm{mg})$ & $2 \mathrm{cp} / \mathrm{dia}$ & 15 & 60 & -45 \\
\hline Pac3891 & AMVTRIL & Cristália & amitriptilina & C1 & $120 \mathrm{cp}(25 \mathrm{mg})$ & $1 \mathrm{cp} / \mathrm{dia}$ & 120 & 60 & 60 \\
\hline Pac3891 & LONGACTIL & Cristália & clorpromazina & C1 & $\begin{array}{l}40 \mathrm{ml}(0,4 \\
\mathrm{mg} / \mathrm{ml})\end{array}$ & $1,5 \mathrm{ml} / \mathrm{dia}$ & 27 & 60 & -33 \\
\hline Pac2605 & TRYPTANOL & Prodome & amitriptilina & c1 & $100 \mathrm{cp}(25 \mathrm{mg})$ & $3 \mathrm{cp} / \mathrm{dia}$ & 33 & 60 & -27 \\
\hline Pac1607 & $\begin{array}{l}\text { codeina; } \\
\text { paracetamol }\end{array}$ & & $\begin{array}{l}\text { codeina; } \\
\text { paracetamol }\end{array}$ & $\begin{array}{l}\text { A2- } \\
\text { adendo }\end{array}$ & $60 \mathrm{cp}(30 \mathrm{mg})$ & 2 cp/dia & 30 & 60 & -30 \\
\hline Pac0507 & sertralina & & sertralina & C1 & $30 \mathrm{cp}(50 \mathrm{mg})$ & $1 \mathrm{cp} / \mathrm{dia}$ & 30 & 60 & -30 \\
\hline Pac2050 & LONGACTIL & Cristália & clorpromazina & C1 & \begin{tabular}{|l|}
$20 \mathrm{ml}(0,4$ \\
$\mathrm{mg} / \mathrm{ml})$ \\
\end{tabular} & $1,2 \mathrm{mUdia}$ & 17 & 60 & -43 \\
\hline Pac2050 & AMYTRL & Cristália & amitriptilina & $\mathrm{C1}$ & $60 \mathrm{cp}(25 \mathrm{mg})$ & $2 \mathrm{cp} / \mathrm{dia}$ & 30 & 60 & -30 \\
\hline Pac0298 & \begin{tabular}{|l} 
codeina; \\
paracetamol
\end{tabular} & & \begin{tabular}{|l|} 
codeina; \\
paracetamol
\end{tabular} & $\begin{array}{c}\text { A2 - } \\
\text { adendo }\end{array}$ & $30 \mathrm{cp}(30 \mathrm{mg})$ & $3 \mathrm{cp} / \mathrm{dia}$ & 10 & 60 & -50 \\
\hline Pac2926 & sertralina & & sertralina & C1 & $30 \mathrm{cp}(50 \mathrm{mg})$ & $1 \mathrm{c} / \mathrm{dia}$ & 30 & 60 & -30 \\
\hline Pac0920 & carbamazepina & & carbamazepina & C1 & $120 \mathrm{cp}(200 \mathrm{mg})$ & $4 \mathrm{cp} / \mathrm{dla}$ & 30 & 60 & -30 \\
\hline Pac0920 & Nuoxetina & & fluoxetina & C1 & $120 \mathrm{cp}(200 \mathrm{mg})$ & $4 \mathrm{cp} / \mathrm{dia}$ & 30 & 60 & -30 \\
\hline Pac3147 & imipramina & & imipramina & C1 & $40 \mathrm{cp}(25 \mathrm{mg})$ & $0,5 \mathrm{cp} / \mathrm{dia}$ & 80 & 60 & 20 \\
\hline Pac3147 & LONGACTIL & Cristália & clorpromazina & C1 & $\begin{array}{l}40 \mathrm{ml}(0,4 \\
\mathrm{mg} / \mathrm{ml}) \\
\end{array}$ & $0,6 \mathrm{mu} / \mathrm{dia}$ & 67 & 60 & 7 \\
\hline Pac3246 & amitriptilina & & amitriptilina & C1 & $40 \mathrm{cp}(25 \mathrm{mg})$ & $1 \mathrm{cp} / \mathrm{dia}$ & 40 & 60 & -20 \\
\hline Pac3493 & amitriptilina & & amitriptilina & C1 & $100 \mathrm{cp}(25 \mathrm{mg})$ & $3 \mathrm{cp} / \mathrm{dia}$ & 33 & 60 & -27 \\
\hline Pac3493 & clorpromazina & & clorpromazina & C1 & $\begin{array}{l}60 \mathrm{ml}(0,4 \\
\mathrm{mg} / \mathrm{ml}) \\
\end{array}$ & $0,8 \mathrm{~m} / \mathrm{dia}$ & 75 & 60 & 15 \\
\hline Pac3282 & PROLOPA & Roche & $\begin{array}{l}\text { levodopa e } \\
\text { benserazida - } \\
\text { assoc. }\end{array}$ & C1 & $30 \mathrm{cp}(250 \mathrm{mg})$ & $0,75 \mathrm{cp} / \mathrm{dia}$ & 40 & 60 & -20 \\
\hline Pac3771 & sertralina & & sertralina & $c_{1}$ & $60 \mathrm{cp}(50 \mathrm{mg})$ & $2 \mathrm{cp} / \mathrm{dia}$ & 30 & 60 & -30 \\
\hline Pac2913 & amitriptilina & & amitriptilina & C1 & $120 \mathrm{cp}(25 \mathrm{mg})$ & $4 \mathrm{cp} / \mathrm{dia}$ & 30 & 60 & -30 \\
\hline Pac3168 & \begin{tabular}{|l} 
codeina; \\
paracetamol
\end{tabular} & & $\begin{array}{l}\text { codeina; } \\
\text { paracetamol }\end{array}$ & $\begin{array}{l}\text { A2 - } \\
\text { adendo }\end{array}$ & $80 \mathrm{cp}(30 \mathrm{mg})$ & $3 \mathrm{cp} / \mathrm{dia}$ & 27 & 60 & -33 \\
\hline Pac2175 & AMMTRIL & Cristália & amitriptilina & C1 & $100 \mathrm{cp} \mathrm{(25} \mathrm{mg)}$ & $3 \mathrm{cp} / \mathrm{dia}$ & 33 & 60 & -27 \\
\hline Pac2175 & LONGACTL & Cristália & clorpromazina & C1 & $\begin{array}{l}60 \mathrm{ml}(0,4 \\
\mathrm{mg} / \mathrm{ml})\end{array}$ & $1,5 \mathrm{ml} / \mathrm{dia}$ & 40 & 60 & -20 \\
\hline Pac2175 & $\begin{array}{l}\text { codeina; } \\
\text { paracetamol }\end{array}$ & & $\begin{array}{l}\text { codeina; } \\
\text { paracetamol }\end{array}$ & $\begin{array}{c}\text { A2 - } \\
\text { adendo }\end{array}$ & $60 \mathrm{cp}(30 \mathrm{mg})$ & $2 \mathrm{cp} / \mathrm{dia}$ & 30 & 60 & -30 \\
\hline Pac1970 & $\begin{array}{l}\text { DORLESS- } \\
\text { TRAMADOL }\end{array}$ & Uniāo Quimica & tramadol & $\begin{array}{c}A 2- \\
\text { adendo }\end{array}$ & $30 \mathrm{cp}(50 \mathrm{mg})$ & $3 \mathrm{cp} / \mathrm{dia}$ & 10 & 60 & -50 \\
\hline Pac3077 & sertralina & & sertralina & $C_{1}$ & $60 \mathrm{cp}(50 \mathrm{mg})$ & $1,5 \mathrm{cp} / \mathrm{dia}$ & 40 & 60 & -20 \\
\hline Pac3266 & amitriptitina & & amitriptilina & C1 & $30 \mathrm{cp}(25 \mathrm{mg})$ & $0,5 \mathrm{cp} / \mathrm{dia}$ & 60 & 60 & 0 \\
\hline Pac2611 & RISPERIDON & Cristália & risperidona & C1 & $30 \mathrm{cp}(2 \mathrm{mg})$ & $1 \mathrm{cp} / \mathrm{dia}$ & 30 & 60 & -30 \\
\hline Pac0868 & AMTIRIL & Cristalia & amitriptilina & C1 & $100 \mathrm{cp}(25 \mathrm{mg})$ & $3 \mathrm{cp} / \mathrm{dia}$ & 33 & 60 & -27 \\
\hline Pac0868 & imipramina & & imipramina & C1 & $30 \mathrm{cp}(25 \mathrm{mg})$ & $1 \mathrm{cp} / \mathrm{dia}$ & 30 & 60 & -30 \\
\hline Pac2996 & fuoxetina & & fluoxetina & C1 & $30 \mathrm{cp} \mathrm{(20 \textrm {mg } )}$ & $1 \mathrm{cp} / \mathrm{dia}$ & 30 & 60 & -30 \\
\hline
\end{tabular}


$\mathrm{DT}=$ Dias de tratamento fornecido $\quad \mathrm{LL}=$ Limite legal

\begin{tabular}{|c|c|c|c|c|c|c|c|c|c|}
\hline $\begin{array}{l}\text { código } \\
\text { paciente }\end{array}$ & Prescrição & Indústria & Principio Ativo & Alinea & Fornecimento & Posologia & DT & LL & $D T-L L$ \\
\hline Pac3866 & amitriptilina & & amitriptilina & C1 & $40 \mathrm{cp}(25 \mathrm{mg})$ & $1 \mathrm{cp} / \mathrm{dia}$ & 40 & 60 & -20 \\
\hline Pac0394 & carbamazepina & & carbamazepina & C1 & $210 \mathrm{cp}(200 \mathrm{mg})$ & $7 \mathrm{cp} / \mathrm{dia}$ & 30 & 60 & -30 \\
\hline Pac0394 & TOPAMAX & Janssen-Cilag & topiramato & C1 & $180 \mathrm{cp}(100 \mathrm{mg})$ & $6 \mathrm{cp} / \mathrm{dia}$ & 30 & 60 & -30 \\
\hline Pac0394 & FRISIUM & Aventis & clobazam & $B 1$ & $60 \mathrm{cp}(10 \mathrm{mg})$ & $2 \mathrm{cp} / \mathrm{dia}$ & 30 & 60 & -30 \\
\hline Pac3819 & amitriptilina & & amitriptilina & c1 & $40 \mathrm{cp}$ (25 mg) & $0,5 \mathrm{cp} / \mathrm{dia}$ & 80 & 60 & 20 \\
\hline Pac1198 & CARBOLITIUM & Eurofarma & lítio (e derivado) & $\mathrm{C}_{1}$ & $80 \mathrm{cp}(300 \mathrm{mg})$ & $2 \mathrm{cp} / \mathrm{dia}$ & 40 & 60 & -20 \\
\hline Pac0600 & EPILENIL & Biolab-Sanus & $\begin{array}{l}\text { ácido valpróico } \\
\text { (ou derivado) }\end{array}$ & C1 & $\begin{array}{l}600 \mathrm{ml}(50 \\
\mathrm{mg} / \mathrm{ml})\end{array}$ & $15 \mathrm{ml} / \mathrm{dia}$ & 40 & 60 & -20 \\
\hline Pac1544 & EPILENIL. & Biolab-Sanus & $\begin{array}{l}\text { ácido valpróico } \\
\text { (ou derivado) }\end{array}$ & C1 & $\begin{array}{l}300 \mathrm{ml}(50 \\
\mathrm{mg} / \mathrm{ml})\end{array}$ & $9 \mathrm{ml} / \mathrm{dia}$ & 33 & 60 & -27 \\
\hline Pac2186 & sertralina & & sertralina & C1 & $60 \mathrm{cp}(50 \mathrm{mg})$ & $2 \mathrm{cp} / \mathrm{dia}$ & 30 & 60 & -30 \\
\hline Pac3083 & DEPAKENE & Abbott & \begin{tabular}{|l|} 
ácido valpróico \\
(ou derivado)
\end{tabular} & C1 & $\begin{array}{l}500 \mathrm{ml}(50 \\
\mathrm{mg} / \mathrm{ml})\end{array}$ & 15 mudia & 33 & 60 & -27 \\
\hline Pac3386 & TRILEPTAL & Novartis & oxcarbazepina & $\mathrm{Cl}$ & $320 \mathrm{cp}(300 \mathrm{mg})$ & $8 \mathrm{cp} / \mathrm{dia}$ & 40 & 60 & -20 \\
\hline Pac3386 & TOPAMAX & Janssen-Cilag & topiramato & $\mathrm{C1}$ & $240 \mathrm{cp}(100 \mathrm{mg})$ & $6 \mathrm{cp} / \mathrm{dia}$ & 40 & 60 & -20 \\
\hline Pac3888 & AMYTRIL & Cristália & amitriptilina & C1 & $40 \mathrm{cp}(25 \mathrm{mg})$ & $1 \mathrm{cp} / \mathrm{dia}$ & 40 & 60 & -20 \\
\hline Pac2288 & ARAVA & Aventis & leflunomida & C1 & $30 \mathrm{cp}(20 \mathrm{mg})$ & $1 \mathrm{cp} / \mathrm{dia}$ & 30 & 60 & -30 \\
\hline Pac1670 & $\begin{array}{l}\text { codeins: } \\
\text { paracetamol }\end{array}$ & & $\begin{array}{l}\text { codeina; } \\
\text { paracetamol }\end{array}$ & $\begin{array}{c}A 2- \\
\text { adendo }\end{array}$ & $30 \mathrm{cp}$ (30 mg) & $3 \mathrm{cp} / \mathrm{dia}$ & 10 & 60 & -50 \\
\hline Pac0069 & imipramina & & imipramina & C1 & $30 \mathrm{cp}$ (25 mg) & $1 \mathrm{cp} / \mathrm{dia}$ & 30 & 60 & -30 \\
\hline Pac0069 & TRAMAL & $\begin{array}{l}\text { Pfizer- } \\
\text { Pharmacia }\end{array}$ & tramadol & $\begin{array}{c}\text { A2 - } \\
\text { adendo }\end{array}$ & $30 \mathrm{cp}(50 \mathrm{mg})$ & $4 \mathrm{cp} / \mathrm{dia}$ & 8 & 60 & -53 \\
\hline Pac2808 & clorpromazina & & clorpromazina & $\mathrm{C}_{1}$ & $90 \mathrm{cp}(25 \mathrm{mg})$ & $2 \mathrm{cp} / \mathrm{dia}$ & 45 & 60 & -15 \\
\hline Pac2808 & MVEX & Janssen-Cilag & $\begin{array}{l}\text { codeina: } \\
\text { paracetamol }\end{array}$ & $\begin{array}{c}\text { A2 - } \\
\text { adendo }\end{array}$ & $90 \mathrm{cp}(30 \mathrm{mg})$ & $2 \mathrm{cp} / \mathrm{dia}$ & 45 & 60 & -15 \\
\hline Pac1847 & fluoxetina & & fluoxetina & $c_{1}$ & $30 \mathrm{cp}(20 \mathrm{mg})$ & $1 \mathrm{cp} / \mathrm{dia}$ & 30 & 60 & -30 \\
\hline Pac0956 & carbamazepina & & carbamazepina & c1 & $120 \mathrm{cp}(200 \mathrm{mg})$ & $4 \mathrm{cp} / \mathrm{dia}$ & 30 & 60 & -30 \\
\hline Pac0872 & AMYRRIL & Cristália & amitriptilina & C1 & $60 \mathrm{cp}(25 \mathrm{mg})$ & $2 \mathrm{cp} / \mathrm{dia}$ & 30 & 60 & -30 \\
\hline Pac0597 & amantadina & & amantadina & C1 & $120 \mathrm{cp}(100 \mathrm{mg})$ & $3 \mathrm{cp} / \mathrm{dja}$ & 40 & 60 & -20 \\
\hline Pac0597 & CINETOL & Cristália & biperideno & $C_{1}$ & $80 \mathrm{cp}(2 \mathrm{mg})$ & $2 \mathrm{cp} / \mathrm{dia}$ & 40 & 60 & -20 \\
\hline Pac2287 & sertralina & & sertralina & C1 & $30 \mathrm{cp}(50 \mathrm{mg})$ & $1 \mathrm{cp} / \mathrm{dia}$ & 30 & 60 & -30 \\
\hline Pac2884 & AMMTRIL & Cristália & amitriptilina & C1 & $40 \mathrm{cp}$ (25 rm) & $1 \mathrm{cp} / \mathrm{dia}$ & 40 & 60 & -20 \\
\hline Pac0747 & fenobarbital & & fenobarbital & $\begin{array}{c}\text { B1 - } \\
\text { adendo }\end{array}$ & $120 \mathrm{cp}(100 \mathrm{mg})$ & $4 \mathrm{cp} / \mathrm{dia}$ & 30 & 60 & -30 \\
\hline Pac3305 & $\begin{array}{l}\text { codeina; } \\
\text { paracetamol }\end{array}$ & & $\begin{array}{l}\text { codeina; } \\
\text { paracetamol }\end{array}$ & adendo & $120 \mathrm{cp}(30 \mathrm{mg})$ & $4 \mathrm{cp} / \mathrm{dia}$ & 30 & 60 & -30 \\
\hline Pac1106 & carbamazepina & & carbamazepina & C1 & $180 \mathrm{cp}(200 \mathrm{mg})$ & $6 \mathrm{cp} / \mathrm{dia}$ & 30 & 60 & -30 \\
\hline Pac2470 & FENOCRIS & Cristália & fenobarbital & $\begin{array}{c}\text { B1- } \\
\text { adendo }\end{array}$ & $\begin{array}{l}120 \mathrm{ml}(40 \\
\mathrm{mg} / \mathrm{md})\end{array}$ & $3,5 \mathrm{ml} / \mathrm{dia}$ & 34 & 60 & -26 \\
\hline Pac2470 & NEULEPTIL & Aventis & periciazina & C1 & $\begin{array}{l}20 \mathrm{ml}(0,4 \\
\mathrm{mg} / \mathrm{m} /)\end{array}$ & 0.15 mVdia & 133 & 60 & 73 \\
\hline Pac0070 & $\begin{array}{l}\text { codeina; } \\
\text { paracetamol }\end{array}$ & & $\begin{array}{l}\text { codeina: } \\
\text { paracetamol }\end{array}$ & $\begin{array}{l}\text { A2 - } \\
\text { adendo }\end{array}$ & $30 \mathrm{cp}$ (30 mg) & $3 \mathrm{cp} / \mathrm{dia}$ & 10 & 60 & -50 \\
\hline Pac0690 & DEPAKENE & Abbott & $\begin{array}{l}\text { ácido valpróico } \\
\text { (ou derivado) }\end{array}$ & C1 & $125 \mathrm{cp}$ (250 mg) & $3 \mathrm{cp} / \mathrm{dia}$ & 42 & 60 & -18 \\
\hline Pac3775 & nitrazepam & & nitrezepam & B1 & $30 \mathrm{cp}$ (5 mg) & $1 \mathrm{cp} / \mathrm{dia}$ & 30 & 60 & -30 \\
\hline Pac0973 & TOFRANIL & Novartis & imipramina & C1 & $40 \mathrm{cp}(25 \mathrm{mg})$ & $1 \mathrm{cp} / \mathrm{dia}$ & 40 & 60 & -20 \\
\hline Pac2467 & carbarnazepina & & carbamazepina & Ct & $60 \mathrm{cp}(200 \mathrm{mg})$ & $3 \mathrm{cp} / \mathrm{dia}$ & 20 & 60 & -40 \\
\hline Pac2467 & AMYTRIL & Cristália & amitriptilina & C1 & $20 \mathrm{cp}(25 \mathrm{mg})$ & $1 \mathrm{cp} / \mathrm{dia}$ & 20 & 60 & -40 \\
\hline Pac3143 & $\begin{array}{l}\text { DORLESS- } \\
\text { TRAMADOLL }\end{array}$ & Uniāo Quimica & tramadol & $\begin{array}{c}\text { A2 - } \\
\text { adendo }\end{array}$ & $90 \mathrm{cp}(50 \mathrm{mg})$ & $3 \mathrm{cp} / \mathrm{dia}$ & 30 & 60 & -30 \\
\hline $\mathrm{Pac} 2282$ & fenitoina & & $\begin{array}{l}\text { fenitoina } \\
\text { (hidantoina) }\end{array}$ & C1 & $50 \mathrm{cp}(100 \mathrm{mg})$ & $1 \mathrm{cp} / \mathrm{dia}$ & 50 & 60 & -10 \\
\hline Pac2747 & AMYTRIL & Cristália & amitriptifina & C1 & $20 \mathrm{cp}(25 \mathrm{mg})$ & $1 \mathrm{cp} / \mathrm{dia}$ & 20 & 60 & -40 \\
\hline Pac0991 & $\begin{array}{l}\text { DORLESS- } \\
\text { TRAMADOL }\end{array}$ & Uniāo Química & tramadol & $\begin{array}{c}\text { A2 - } \\
\text { adendo }\end{array}$ & $30 \mathrm{cp}(50 \mathrm{mg})$ & $3 \mathrm{cp} / \mathrm{dia}$ & 10 & 60 & -50 \\
\hline Pac2540 & $\begin{array}{l}\text { codeina; } \\
\text { paracetamol }\end{array}$ & & $\begin{array}{l}\text { codeina; } \\
\text { paracotamol }\end{array}$ & $\begin{array}{c}\text { A2 - } \\
\text { adendo }\end{array}$ & $30 \mathrm{cp}(30 \mathrm{mg})$ & $3 \mathrm{cp} / \mathrm{dia}$ & 10 & 60 & -50 \\
\hline
\end{tabular}


$D T=$ Dias de tratamento fornecido $\quad L L=$ Limite legal

\begin{tabular}{|c|c|c|c|c|c|c|c|c|c|}
\hline $\begin{array}{l}\text { código } \\
\text { paciente }\end{array}$ & Prescrição & Indústria & Princípio Ativo & Alinea & Fornecimento & Posologia & DT & 느 & DT - LL \\
\hline Pac2188 & amitriptilina & & amitriptilina & $\mathrm{C1}$ & $40 \mathrm{cp}(25 \mathrm{mg})$ & $1 \mathrm{cp} / \mathrm{dia}$ & 40 & 60 & -20 \\
\hline Pac0522 & TRYPTANOL & Prodome & amitriptilina & $\mathrm{C1}$ & $40 \mathrm{cp}(25 \mathrm{mg})$ & $1 \mathrm{cp} / \mathrm{dia}$ & 40 & 60 & -20 \\
\hline Pac1855 & $\begin{array}{l}\text { DORLESS- } \\
\text { TRAMADOL }\end{array}$ & Uniảo Quimica & tramadol & $\begin{array}{c}\text { A2 - } \\
\text { adendo }\end{array}$ & $90 \mathrm{cp}(50 \mathrm{mg})$ & $3 \mathrm{cp} / \mathrm{dia}$ & 30 & 60 & -30 \\
\hline Pac1855 & sertralina & & sertralina & $\mathrm{C1}$ & $60 \mathrm{cp}(50 \mathrm{mg})$ & $2 \mathrm{cp} / \mathrm{dia}$ & 30 & 60 & -30 \\
\hline Pac1540 & AMYTRIL & Cristália & amitriptilina & $\mathrm{C1}$ & $60 \mathrm{cp}(25 \mathrm{mg})$ & $2 \mathrm{cp} / \mathrm{dia}$ & 30 & 60 & -30 \\
\hline Pac0177 & $\begin{array}{l}\text { codeina; } \\
\text { paracetamol }\end{array}$ & & $\begin{array}{l}\text { codeina; } \\
\text { paracetamol }\end{array}$ & $\begin{array}{c}A 2- \\
\text { adendo }\end{array}$ & $30 \mathrm{cp}(30 \mathrm{mg})$ & $3 \mathrm{cp} / \mathrm{dia}$ & 10 & 60 & -50 \\
\hline Pac3653 & tramadol & & tramadol & $\begin{array}{c}\text { A2 - } \\
\text { adendo }\end{array}$ & $30 \mathrm{cp}(50 \mathrm{mg})$ & $3 \mathrm{cp} / \mathrm{dia}$ & 10 & 60 & -50 \\
\hline Pac0750 & gabapentina & & gabapentina & $\mathrm{Ct}$ & $90 \mathrm{cp} \mathrm{(400 \textrm {mg } )}$ & $3 \mathrm{cp} / \mathrm{dia}$ & 30 & 60 & -30 \\
\hline Pac3524 & carbamazepina & & carbamazepina & $\mathrm{Cl}$ & $120 \mathrm{cp}(200 \mathrm{mg})$ & $3 \mathrm{cp} / \mathrm{dia}$ & 40 & 60 & -20 \\
\hline Pac0657 & DEPAKENE & Abbott & $\begin{array}{l}\text { ácido valpróico } \\
\text { (ou derivado) }\end{array}$ & $\mathrm{Cl}$ & $75 \mathrm{cp}(250 \mathrm{mg})$ & $7 \mathrm{cp} / \mathrm{dia}$ & 11 & 60 & -49 \\
\hline Pac0657 & carbamazepina & & carbamazepina & $\mathrm{Cl}$ & $40 \mathrm{cp}(200 \mathrm{mg})$ & $2 \mathrm{cp} / \mathrm{dia}$ & 20 & 60 & -40 \\
\hline Pac0657 & URBANIL & Aventis & clobazam & B1 & $60 \mathrm{cp}(10 \mathrm{mg})$ & $2 \mathrm{cp} / \mathrm{dia}$ & 30 & 60 & -30 \\
\hline Pac3157 & imipramina & & imipramina & C1 & $110 \mathrm{cp}(25 \mathrm{mg})$ & $3 \mathrm{cp} / \mathrm{dia}$ & 37 & 60 & -23 \\
\hline Pac2852 & amitriptilina & & amitriptilina & C1 & $80 \mathrm{cp}(25 \mathrm{mg})$ & $2 \mathrm{cp} / \mathrm{dia}$ & 40 & 60 & -20 \\
\hline Pac2852 & LONGACTIL & Cristália & clorpromazina & C1 & $\begin{array}{l}40 \mathrm{ml}(0,4 \\
\mathrm{mg} / \mathrm{ml})\end{array}$ & $0,9 \mathrm{~m} / \mathrm{dia}$ & 44 & 60 & -16 \\
\hline Pac2575 & AMYTRIL & Cristália & amitriptilina & $c 1$ & $100 \mathrm{cp}(25 \mathrm{mg})$ & $3 \mathrm{cp} / \mathrm{dia}$ & 33 & 60 & -27 \\
\hline Pac2575 & gabapentina & & gabapentina & c1 & $120 \mathrm{cp}(300 \mathrm{mg})$ & $3 \mathrm{cp} / \mathrm{dia}$ & 40 & 60 & -20 \\
\hline Pac3277 & fenobarbital & & fenobarbital & $\begin{array}{c}\text { B1 - } \\
\text { adendo }\end{array}$ & $120 \mathrm{cp}(100 \mathrm{mg})$ & $3 \mathrm{cp} / \mathrm{dia}$ & 40 & 60 & -20 \\
\hline Pac3277 & TEGRETOL & Novartis & carbamazepina & C1 & $160 \mathrm{cp}(200 \mathrm{mg})$ & $4 \mathrm{cp} / \mathrm{dia}$ & 40 & 60 & -20 \\
\hline Pac2707 & fenitoina & & $\begin{array}{l}\text { fenitoina } \\
\text { (hidantoina) }\end{array}$ & C1 & $80 \mathrm{cp}(100 \mathrm{mg})$ & $1 \mathrm{cp} / \mathrm{dia}$ & 80 & 60 & 20 \\
\hline Pac2767 & cartamazepina & & carbamazepina & C1 & $120 \mathrm{cp}(200 \mathrm{mg})$ & $3 \mathrm{cp} / \mathrm{dia}$ & 40 & 60 & -20 \\
\hline Pac2070 & amitriptilina & & amitriptilina & C1 & $40 \mathrm{cp}$ (25 mg) & $1 \mathrm{cp} / \mathrm{dia}$ & 40 & 60 & -20 \\
\hline Pac2770 & carbamazepina & & carbamazepina & C1 & $20 \mathrm{cp}(200 \mathrm{mg})$ & $1 \mathrm{cp} / \mathrm{dia}$ & 20 & 60 & -40 \\
\hline Pac0988 & amitriptilina & & amiltiptilina & C1 & $40 \mathrm{cp}(25 \mathrm{mg})$ & $1 \mathrm{cp} / \mathrm{dia}$ & 40 & 60 & -20 \\
\hline Pac0711 & amitriptilina & & amitriptilina & C1 & $100 \mathrm{cp}(25 \mathrm{mg})$ & $3 \mathrm{cp} / \mathrm{dia}$ & 33 & 60 & -27 \\
\hline Pac1587 & LORALERG-D & Farmasa & $\begin{array}{l}\text { loratadina; } \\
\text { pseudoefedrina }\end{array}$ & D1 & $60 \mathrm{ml}(10 \mathrm{mg})$ & 7 mVdia & 9 & & \\
\hline Pac2259 & fenobarbital & & fenobarbital & $\begin{array}{c}\text { B1- } \\
\text { adendo }\end{array}$ & $40 \mathrm{cp}(100 \mathrm{mg})$ & $1 \mathrm{cp} / \mathrm{dia}$ & 40 & 60 & -20 \\
\hline Pac2259 & carbamazepina & & carbamazepina & C1 & $180 \mathrm{cp}(200 \mathrm{mg})$ & $5 \mathrm{cp} / \mathrm{dia}$ & 36 & 60 & -24 \\
\hline Pac0227 & AUVTRIL & Cristália & amitriptilina & C1 & $40 \mathrm{cp}(25 \mathrm{mg})$ & $1 \mathrm{cp} / \mathrm{dia}$ & 40 & 60 & -20 \\
\hline Pac3614 & carbamazepina & & carbamazepina & C1 & $90 \mathrm{cp}(200 \mathrm{mg})$ & $3 \mathrm{cp} / \mathrm{dia}$ & 30 & 60 & -30 \\
\hline Pac3614 & GARDENAL & Aventis & fenobarbital & $\begin{array}{c}\text { B1- } \\
\text { adendo }\end{array}$ & $100 \mathrm{cp}(100 \mathrm{mg})$ & $3 \mathrm{cp} / \mathrm{dia}$ & 33 & 60 & -27 \\
\hline Pac3614 & clobazam & & clobazam & B1 & $90 \mathrm{cp}(10 \mathrm{mg})$ & $3 \mathrm{cp} / \mathrm{dia}$ & 30 & 60 & -30 \\
\hline Pac0046 & ANAFRANIL & Novartis & clomipramina & C1 & $100 \mathrm{cp}(25 \mathrm{mg})$ & $1 \mathrm{cp} / \mathrm{dia}$ & 100 & 60 & 40 \\
\hline Pac3084 & carbamazepina & & carbamazepina & C1 & $120 \mathrm{cp}(200 \mathrm{mg})$ & $3 \mathrm{cp} / \mathrm{dia}$ & 40 & 60 & -20 \\
\hline Pac3084 & fenobarbital & & fenobarbital & $\begin{array}{c}\text { B1- } \\
\text { adendo }\end{array}$ & $40 \mathrm{cp}(100 \mathrm{mg})$ & $1 \mathrm{cp} / \mathrm{dia}$ & 40 & 60 & -20 \\
\hline Pac2437 & AMYTRIL & Cristália & amitriptilina & C1 & $240 \mathrm{cp}(25 \mathrm{mg})$ & $4 \mathrm{cp} / \mathrm{dia}$ & 60 & 60 & 0 \\
\hline Pac2437 & tramadol & & tramadol & $\begin{array}{c}\text { A2- } \\
\text { adendo }\end{array}$ & $180 \mathrm{cp}(50 \mathrm{mg})$ & $3 \mathrm{cp} / \mathrm{dia}$ & 60 & 60 & 0 \\
\hline Pac0121 & TRILEPTAL & Novartis & oxcartazepina & $\mathrm{C1}$ & $90 \mathrm{cp}(300 \mathrm{mg})$ & $2 \mathrm{cp} / \mathrm{dia}$ & 45 & 60 & -15 \\
\hline Pac0623 & $\begin{array}{l}\text { DORLESS- } \\
\text { TRAMADOL }\end{array}$ & Unižo Quimica & tramadol & $\begin{array}{c}\text { A2 - } \\
\text { adendo }\end{array}$ & $30 \mathrm{cp}(50 \mathrm{mg})$ & $3 \mathrm{cp} / \mathrm{dia}$ & 10 & 60 & .50 \\
\hline Pac3311 & tramadol & & tramadol & $\begin{array}{c}A 2- \\
\text { adendo }\end{array}$ & $60 \mathrm{cp}(50 \mathrm{mg})$ & $2 \mathrm{cp} / \mathrm{dia}$ & 30 & 60 & -30 \\
\hline Pac2550 & fenitoina & & \begin{tabular}{|l}
$\begin{array}{l}\text { fenitoina } \\
\text { (hidantoina) }\end{array}$ \\
\end{tabular} & C1 & $30 \mathrm{cp}$ (100 mg) & $1 \mathrm{cp} / \mathrm{dia}$ & 30 & 60 & 30 \\
\hline Pac1572 & DEPAKENE & Abbott & $\begin{array}{l}\text { ácido valpróico } \\
\text { (ou derivado) }\end{array}$ & c1 & $100 \mathrm{cp}(500 \mathrm{mg})$ & $2 \mathrm{cp} / \mathrm{dia}$ & 50 & 60 & -10 \\
\hline Pac2368 & fenobarbital & & fenobarbital & $\begin{array}{c}\mathrm{B1}- \\
\text { adendo }\end{array}$ & $120 \mathrm{ml}(1 \mathrm{mg})$ & $3,5 \mathrm{~m} / \mathrm{dia}$ & 34 & 60 & -26 \\
\hline
\end{tabular}


$D T=$ Dias de tratamento fornecido $\quad L L=$ Limite legal

\begin{tabular}{|c|c|c|c|c|c|c|c|c|c|}
\hline $\begin{array}{l}\text { código } \\
\text { paciente }\end{array}$ & Prescriçăo & Indústria & Principio Ativo & Alínea & Fornecimento & Posologia & DT & ㄴ․ & DT - LL \\
\hline Pac0206 & ANAFRANIL & Novartis & clomipramina & C1 & $40 \mathrm{cp}(25 \mathrm{mg})$ & $1 \mathrm{cp} / \mathrm{dia}$ & 40 & 60 & -20 \\
\hline Pac3486 & OXYCONTIN & Zodiac & oxicodona & A1 & $120 \mathrm{cp}(20 \mathrm{mg})$ & $4 \mathrm{cp} / \mathrm{dia}$ & 30 & 30 & 0 \\
\hline Pac3234 & $\begin{array}{l}\text { codeina: } \\
\text { beladona }\end{array}$ & & codeina: beladona & $\begin{array}{c}A 2- \\
\text { adendo }\end{array}$ & $30 \mathrm{ml}(30 \mathrm{mg} / \mathrm{ml})$ & $1 \mathrm{ml} / \mathrm{dia}$ & 30 & 60 & 30 \\
\hline Pac0703 & carbamazepina & & carbamazepina & C1 & $200 \mathrm{cp}$ (200 mg) & $5 \mathrm{cp} / \mathrm{dia}$ & 40 & 60 & -20 \\
\hline Pact 1440 & $\begin{array}{l}\text { codeina; } \\
\text { paracetamol }\end{array}$ & & \begin{tabular}{|l} 
codeina; \\
paracetamol
\end{tabular} & $\begin{array}{c}\mathrm{A} 2- \\
\text { adendo }\end{array}$ & $90 \mathrm{cp}(30 \mathrm{mg})$ & $3 \mathrm{cp} / \mathrm{dia}$ & 30 & 60 & -30 \\
\hline Pac2697 & OXYCONTIN & Zodiac & oxicodona & A1 & $90 \mathrm{cp}(20 \mathrm{mg})$ & $2 \mathrm{cp} / \mathrm{dia}$ & 45 & 30 & 15 \\
\hline Pac0630 & imipramina & & imipramina & $\mathrm{Cl}$ & $30 \mathrm{cp}(25 \mathrm{mg})$ & $1 \mathrm{cp} / \mathrm{dia}$ & 30 & 60 & .30 \\
\hline Pac0390 & AMITRIL & Cristália & amitriptilina & C1 & $40 \mathrm{cp}(25 \mathrm{mg})$ & $1 \mathrm{cp} / \mathrm{dia}$ & 40 & 60 & -20 \\
\hline Pac1596 & amitriptilina & & amitriptilina & C1 & $40 \mathrm{cp}(25 \mathrm{mg})$ & $1 \mathrm{cp} / \mathrm{dia}$ & 40 & 60 & -20 \\
\hline Pac0486 & TRAMAL & $\begin{array}{l}\text { Pfizer- } \\
\text { Pharmacia }\end{array}$ & tramadol & $\begin{array}{c}2- \\
\text { adendo }\end{array}$ & $30 \mathrm{cp}(50 \mathrm{mg})$ & $3 \mathrm{cp} / \mathrm{dia}$ & 10 & 60 & -50 \\
\hline Pac2900 & sertralina & & sertralina & C1 & $60 \mathrm{cp}(50 \mathrm{mg})$ & $2 \mathrm{cp} / \mathrm{dia}$ & 30 & .60 & -30 \\
\hline Pac0333 & $\begin{array}{l}\text { codeina; } \\
\text { paracetamol }\end{array}$ & & $\begin{array}{l}\text { codeina; } \\
\text { paracetamol }\end{array}$ & $\begin{array}{c}2- \\
\text { adendo }\end{array}$ & $90 \mathrm{cp}(30 \mathrm{mg})$ & $3 \mathrm{cp} / \mathrm{dia}$ & 30 & 60 & -30 \\
\hline Pac2936 & fluoxetina & & fluoxetina & $\mathrm{C1}_{1}$ & $60 \mathrm{cp}(20 \mathrm{mg})$ & $2 \mathrm{cp} / \mathrm{dia}$ & 30 & 60 & -30 \\
\hline Pac0393 & sertralina & & sertralina & C1 & $30 \mathrm{cp}(50 \mathrm{mg})$ & $1 \mathrm{cp} / \mathrm{dia}$ & 30 & 60 & -30 \\
\hline Pac0639 & fluoxetina & & fluoxetina & C1 & $120 \mathrm{cp}(20 \mathrm{mg})$ & $1 \mathrm{cp} / \mathrm{dia}$ & 120 & 60 & 60 \\
\hline Pac0639 & DEPAKENE & Abbott & $\begin{array}{l}\text { ácido valpróico } \\
\text { (ou derivado) }\end{array}$ & C1 & $100 \mathrm{cp}(250 \mathrm{mg})$ & $3 \mathrm{cp} / \mathrm{dia}$ & 33 & 60 & -27 \\
\hline Pac0639 & ANAFRANIL & Novartis & clomipramina & $\mathrm{Cl}$ & $60 \mathrm{cp}(25 \mathrm{mg})$ & $2 \mathrm{cp} / \mathrm{dia}$ & 30 & 60 & -30 \\
\hline Pac1257 & carbamazepina & & carbamazepina & C1 & $30 \mathrm{cp}(200 \mathrm{mg})$ & $3 \mathrm{cp} / \mathrm{dia}$ & 10 & 60 & -50 \\
\hline Pac0245 & PROLOPA & Roche & \begin{tabular}{|l} 
levodopa $\theta$ \\
benserazida
\end{tabular} & C1 & $120 \mathrm{cp}(250 \mathrm{mg})$ & $2,5 \mathrm{cp} / \mathrm{dia}$ & 48 & 60 & -12 \\
\hline Pac0245 & CINETOL & Cristália & biperideno & C1 & $160 \cos (2 \mathrm{mg})$ & 3 co/dia & 53 & 60 & -7 \\
\hline Pac0245 & fluoxetina & & fluoxetina & C1 & $60 \mathrm{cp}(20 \mathrm{mg})$ & $1 \mathrm{cp} / \mathrm{dia}$ & 60 & 60 & 0 \\
\hline Pac0789 & TRAMAL & $\begin{array}{l}\text { Pfizer- } \\
\text { Pharmacia }\end{array}$ & tramadol & $\begin{array}{c}A 2- \\
\text { adendo }\end{array}$ & $60 \mathrm{cp}(50 \mathrm{mg})$ & $4 \mathrm{cp} / \mathrm{dia}$ & 15 & 60 & -45 \\
\hline Pac0280 & loperamida & & loperamida & $\begin{array}{c}\mathrm{C1}- \\
\text { adendo }\end{array}$ & $90 \mathrm{cp}(2 \mathrm{mg})$ & $3 \mathrm{cp} / \mathrm{dia}$ & 30 & sem & \\
\hline Pac4018 & \begin{tabular}{|l} 
codelna; \\
paracetamol
\end{tabular} & & \begin{tabular}{|l|} 
codeina; \\
paracetamol
\end{tabular} & $\begin{array}{c}\text { A2 - } \\
\text { adendo }\end{array}$ & $30 \mathrm{cp}(30 \mathrm{mg})$ & $3 \mathrm{cp} / \mathrm{dia}$ & 10 & 60 & -50 \\
\hline Pac0140 & tramadol & & tramadol & $\begin{array}{c}\text { A2 - } \\
\text { adendo }\end{array}$ & $40 \mathrm{cp}(500 \mathrm{mg})$ & $4 \mathrm{cp} / \mathrm{dia}$ & 10 & 60 & -50 \\
\hline Pac0967 & carbonato de litio & & litio (o derivado) & c1 & $30 \mathrm{cp}(300 \mathrm{mg})$ & $0,5 \mathrm{cp} / \mathrm{dia}$ & 60 & 60 & 0 \\
\hline Pac2525 & amitriptilina & & amitriptilina & C1 & $15 \mathrm{cp}(25 \mathrm{mg})$ & $0,5 \mathrm{cp} / \mathrm{dia}$ & 30 & 60 & -30 \\
\hline Pac2213 & sertralina & & sertralina & C1 & $30 \mathrm{cp}(50 \mathrm{mg})$ & $1 \mathrm{cp} / \mathrm{dia}$ & 30 & 60 & -30 \\
\hline Pac3731 & amitriptilina & & amitriptilina & $\mathrm{c1}$ & $40 \mathrm{cp}(25 \mathrm{mg})$ & $1 \mathrm{cp} / \mathrm{dia}$ & 40 & 60 & -20 \\
\hline Pac3731 & $\begin{array}{l}\text { codeina; } \\
\text { paracetamol }\end{array}$ & & \begin{tabular}{|l} 
codeina; \\
paracetamol
\end{tabular} & $\begin{array}{c}\text { A2 - } \\
\text { adendo }\end{array}$ & $90 \mathrm{cp}(30 \mathrm{mg})$ & $3 \mathrm{cp} / \mathrm{dia}$ & 30 & 60 & -30 \\
\hline Pac2523 & imipramina & & imipramina & C1 & $60 \mathrm{cp}(150 \mathrm{mg})$ & $2 \mathrm{cp} / \mathrm{dia}$ & 30 & 60 & 30 \\
\hline Pac2829 & DAFORIN & Sigma Pharma & fluoxetina & C1 & $40 \mathrm{cp}(20 \mathrm{mg})$ & $1 \mathrm{cp} / \mathrm{dia}$ & 40 & 60 & -20 \\
\hline Pac0374 & DAFORIN & Sigma Pharma & nuoxetina & c1 & $60 \mathrm{cp}(20 \mathrm{mg})$ & $2 \mathrm{cp} / \mathrm{dia}$ & 30 & 60 & -30 \\
\hline Pac0943 & AMYTRIL & Cristália & amitriptilina & C1 & $40 \mathrm{cp}(25 \mathrm{mg})$ & $1 \mathrm{cp} / \mathrm{dia}$ & 40 & 60 & -20 \\
\hline Pac0943 & AMPLICTIL & Aventis & clorpromazina & c1 & $\begin{array}{l}40 \mathrm{ml}(0,4 \\
\mathrm{mg} / \mathrm{ml})\end{array}$ & $1 \mathrm{~m} / \mathrm{dia}$ & 40 & 60 & -20 \\
\hline Pac1286 & carbamazepina & & carbamazepina & C1 & $90 \mathrm{cp}(200 \mathrm{mg})$ & $3 \mathrm{cp} / \mathrm{dia}$ & 30 & 60 & -30 \\
\hline Pac1954 & TRAMAL & $\begin{array}{l}\text { Plizer- } \\
\text { Pharmacia }\end{array}$ & tramadol & $\begin{array}{c}\text { A2 - } \\
\text { adendo }\end{array}$ & $20 \mathrm{cp}(100 \mathrm{mg})$ & $2 \mathrm{cp} / \mathrm{dia}$ & 10 & 60 & -50 \\
\hline Pac2542 & DAFORIN & Sigma Pharma & fluoxetina & C1 & $140 \mathrm{cp}$ (20 mg) & $2 \mathrm{cp} / \mathrm{dia}$ & 70 & 60 & 10 \\
\hline Pac1626 & $\begin{array}{l}\text { codeina; } \\
\text { paracetamol }\end{array}$ & & $\begin{array}{l}\text { codeina; } \\
\text { paracetamol }\end{array}$ & $\begin{array}{c}\text { A2- } \\
\text { adendo }\end{array}$ & $30 \mathrm{cp}(30 \mathrm{mg})$ & $3 \mathrm{cp} / \mathrm{dia}$ & 10 & 60 & -50 \\
\hline Pac2198 & AMYTRL & Cristália & amitriptilina & c1 & $40 \mathrm{cp}(25 \mathrm{mg})$ & $1 \mathrm{cp} / \mathrm{dia}$ & 40 & 60 & -20 \\
\hline Pac2657 & DAFORIN & Sigma Pharma & fluoxelina & c1 & $30 \mathrm{cp}(20 \mathrm{mg})$ & $1 \mathrm{cp} / \mathrm{dia}$ & 30 & 60 & -30 \\
\hline Pac0325 & gabapentina & & gabapentina & C1 & $90 \mathrm{cp}(400 \mathrm{mg})$ & $3 \mathrm{cp} / \mathrm{dia}$ & 30 & 60 & -30 \\
\hline
\end{tabular}


$D T=$ Dias de tratamento fornecido $\quad L L=$ Limite legal

\begin{tabular}{|c|c|c|c|c|c|c|c|c|c|}
\hline $\begin{array}{l}\text { código } \\
\text { paciente }\end{array}$ & Prescrição & Indústria & Principio Ativo & Alinea & Fornecimento & Posologia & DT & LL & OT - LL \\
\hline Pac0325 & amitriptilina & & amitriptilina & C1 & $100 \mathrm{cp}(25 \mathrm{mg})$ & $3 \mathrm{cp} / \mathrm{dia}$ & 33 & 60 & -27 \\
\hline Pac3478 & amitriptilina & & amitriptilina & C1 & $120 \mathrm{cp}(25 \mathrm{mg})$ & $4 \mathrm{cp} / \mathrm{dia}$ & 30 & 60 & -30 \\
\hline Pac2117 & AMYTRIL & Cristália & amitriptilina & $C_{1}$ & $40 \mathrm{cp}(25 \mathrm{mg})$ & $1 \mathrm{cp} / \mathrm{dia}$ & 40 & 60 & -20 \\
\hline Pac2117 & carbamazepina & & carbamazepina & C1 & $30 \mathrm{cp}(200 \mathrm{mg})$ & $1 \mathrm{cp} / \mathrm{dia}$ & 30 & 60 & -30 \\
\hline Pac1983 & fenitoina & & \begin{tabular}{|l|}
$\begin{array}{l}\text { fenitoina } \\
\text { (hidantoina) }\end{array}$ \\
\end{tabular} & C1 & $90 \mathrm{cp}(100 \mathrm{mg})$ & $3 \mathrm{cp} / \mathrm{dia}$ & 30 & 60 & -30 \\
\hline Pac3621 & sertralina & & sertralina & C1 & $30 \mathrm{cp}(50 \mathrm{mg})$ & $1 \mathrm{cp} / \mathrm{dia}$ & 30 & 60 & -30 \\
\hline Pac3621 & diazepam & & diazepam & B1 & $20 \mathrm{cp}(5 \mathrm{mg})$ & $1 \mathrm{cp} / \mathrm{dia}$ & 20 & 60 & -40 \\
\hline Pac1139 & amitriptilina & & amitriptilina & C1 & $40 \mathrm{cp}(25 \mathrm{mg})$ & $1 \mathrm{cp} / \mathrm{dia}$ & 40 & 60 & -20 \\
\hline Pac3871 & TRAMAL & $\begin{array}{l}\text { Pfizer- } \\
\text { Pharmacia } \\
\end{array}$ & tramadol & $\begin{array}{c}\text { A2- } \\
\text { adendo }\end{array}$ & $30 \mathrm{cp}(50 \mathrm{mg})$ & 3 cp/dia & 10 & 60 & -50 \\
\hline Pac0645 & DAFORIN & Sigma Pharma & Muoxetina & c1 & $20 \mathrm{cp}(20 \mathrm{mg})$ & $1 \mathrm{cp} / \mathrm{dia}$ & 20 & 60 & -40 \\
\hline Pac0255 & \begin{tabular}{|l|} 
codeina; \\
paracetamol
\end{tabular} & & \begin{tabular}{|l|} 
codeina; \\
paracetamol
\end{tabular} & $\begin{array}{c}\text { A2 - } \\
\text { adendo }\end{array}$ & $30 \mathrm{cp}(30 \mathrm{mg})$ & $3 \mathrm{cp} / \mathrm{dia}$ & 10 & 60 & -50 \\
\hline Pac2613 & DAFORIN & Sigma Pharma & fluoxelina & C1 & $100 \mathrm{cp}(20 \mathrm{mg})$ & $2 \mathrm{cp} / \mathrm{dia}$ & 50 & 60 & -10 \\
\hline Pac1098 & $\begin{array}{l}\text { codeina; } \\
\text { paracetarnol }\end{array}$ & & $\begin{array}{l}\text { codeina; } \\
\text { paracetamol }\end{array}$ & $\begin{array}{c}\text { A2 - } \\
\text { adendo }\end{array}$ & 30 cp (30 mg) & $3 \mathrm{cp} / \mathrm{dia}$ & 10 & 60 & -50 \\
\hline Pac0296 & paroxelina & & paroxetina & C1 & $60 \mathrm{cp}(20 \mathrm{mg})$ & $2 \mathrm{cp} / \mathrm{dia}$ & 30 & 60 & -30 \\
\hline Pac1255 & morlina & & morfina & A1 & $360 \mathrm{cp}(30 \mathrm{mg})$ & $16 \mathrm{cp} / \mathrm{dia}$ & 23 & 30 & -8 \\
\hline Pac1255 & AMVTRIL & Cristalia & amitriptilina & $\mathrm{Cl}$ & $100 \mathrm{cp}(25 \mathrm{mg})$ & $3 \mathrm{cp} / \mathrm{dia}$ & 33 & 60 & -27 \\
\hline Pac1255 & gabapentina & & gabapentina & $\mathrm{C1}$ & $80 \mathrm{cp}(400 \mathrm{mg})$ & $3 \mathrm{cp} / \mathrm{dia}$ & 27 & 60 & -33 \\
\hline Pac1255 & LONGACTL & Cristália & clorpromazina & $\mathrm{Cl}$ & $\begin{array}{l}40 \mathrm{ml}(0,4 \\
\mathrm{mg} / \mathrm{ml})\end{array}$ & $1,2 \mathrm{ml} / \mathrm{dia}$ & 33 & 60 & -27 \\
\hline Pac2123 & amitriptilina & & amitriptilina & $\mathrm{C1}$ & $20 \mathrm{cp}(25 \mathrm{mg})$ & $0,25 \mathrm{cp} / \mathrm{dia}$ & 80 & 60 & 20 \\
\hline Pac2123 & LONGACTIL & Cristália & clorpromazina & C1 & $\begin{array}{l}20 \mathrm{ml}(0,4 \\
\mathrm{mg} / \mathrm{ml})\end{array}$ & $0,3 \mathrm{~m} / \mathrm{dia}$ & 67 & 60 & 7 \\
\hline Pac3369 & fenitoina & & \begin{tabular}{|l|l} 
fenitoina \\
(hidantoina)
\end{tabular} & $\mathrm{C1}$ & $30 \mathrm{cp}(100 \mathrm{mg})$ & $3 \mathrm{cp} / \mathrm{dia}$ & 10 & 60 & -50 \\
\hline Pac1369 & \begin{tabular}{|l} 
Codeina; \\
paracetamol
\end{tabular} & & $\begin{array}{l}\text { codeina; } \\
\text { paracetamol }\end{array}$ & $\begin{array}{c}\text { A2 - } \\
\text { adendo }\end{array}$ & $30 \mathrm{cp}(30 \mathrm{mg})$ & $3 \mathrm{cp} / \mathrm{dia}$ & 10 & 60 & -50 \\
\hline Pac2134 & DAFORIN & Sigma Pharma & fluoxetina & $\mathrm{C1}$ & $40 \mathrm{cp}(20 \mathrm{mg})$ & $1 \mathrm{cp} / \mathrm{dia}$ & 40 & 60 & -20 \\
\hline Pac1239 & imipramina & & imipramina & $C 1$ & $30 \mathrm{cp}(75 \mathrm{mg})$ & 1 cp/dia & 30 & 60 & -30 \\
\hline Pac0293 & fenttoina & & \begin{tabular}{|l|l|} 
fenitoina \\
(hidantoina) \\
\end{tabular} & C1 & $90 \mathrm{cp}(100 \mathrm{mg})$ & $3 \mathrm{cp} / \mathrm{dia}$ & 30 & 60 & -30 \\
\hline Pac0293 & amitriptifina & & amitriptilina & C1 & $60 \mathrm{cp}(25 \mathrm{mg})$ & $2 \mathrm{cp} / \mathrm{dia}$ & 30 & 60 & -30 \\
\hline Pac0293 & LONGACTIL & Cristália & clorpromazina & C1 & $\begin{array}{l}20 \mathrm{ml}(0.4 \\
\mathrm{mg} / \mathrm{ml})\end{array}$ & $0.6 \mathrm{ml} / \mathrm{dia}$ & 33 & 60 & -27 \\
\hline Pac0135 & gabapentina & & gabapentina & C1 & $90 \mathrm{cp}(300 \mathrm{mg})$ & $3 \mathrm{cp} / \mathrm{dia}$ & 30 & 60 & -30 \\
\hline Pac0135 & \begin{tabular}{|l|} 
DORLESS- \\
TRAMADOL \\
\end{tabular} & Uniāo Química & tramadol & $\begin{array}{c}\text { A2 - } \\
\text { adendo }\end{array}$ & $60 \mathrm{cp}(50 \mathrm{mg})$ & $4 \mathrm{cp} / \mathrm{dia}$ & 15 & 60 & -45 \\
\hline Pac0135 & talidomida & & talidomida & $\mathrm{C3}$ & $60 \mathrm{cp}(100 \mathrm{mg})$ & $2 \mathrm{cp} / \mathrm{dia}$ & 30 & 30 & 0 \\
\hline Pac1140 & Iluoxetina & & fluoxetina & C1 & $40 \mathrm{cp}(20 \mathrm{mg})$ & $1 \mathrm{cp} / \mathrm{dia}$ & 40 & 60 & -20 \\
\hline Pac1439 & $\begin{array}{l}\text { codeina; } \\
\text { paracetamol }\end{array}$ & & $\begin{array}{l}\text { codeina; } \\
\text { paracetamol }\end{array}$ & $\begin{array}{c}\text { A2- } \\
\text { adendo }\end{array}$ & $120 \mathrm{cp}(30 \mathrm{mg})$ & $4 \mathrm{cp} / \mathrm{dia}$ & 30 & 60 & 30 \\
\hline Pac2578 & DAFORIN & Sigma Pharma & fluoxetina & C1 & $120 \mathrm{cp}(20 \mathrm{mg})$ & $3 \mathrm{cp} / \mathrm{dia}$ & 40 & 60 & -20 \\
\hline Pac2578 & carbonato de lítio & & lítio (e derivado) & C1 & $120 \mathrm{cp}(300 \mathrm{mg})$ & $3 \mathrm{cp} / \mathrm{dia}$ & 40 & 60 & -20 \\
\hline Pac2578 & amilriptilina & & amitriptilina & C1 & $60 \mathrm{cp}(25 \mathrm{mg})$ & $1 \mathrm{cp} / \mathrm{dia}$ & 60 & 60 & 0 \\
\hline Pac2418 & amitriptilina & & amitriptiline & C1 & $80 \mathrm{cp}(25 \mathrm{mg})$ & $4 \mathrm{cp} / \mathrm{dia}$ & 20 & 60 & -40 \\
\hline Pac2418 & clorpromazina & & clorpromazina & $\mathrm{C1}_{1}$ & $\begin{array}{l}20 \mathrm{ml}(0.4 \\
\mathrm{mg} / \mathrm{ml})\end{array}$ & $0,5 \mathrm{~m} / \mathrm{dia}$ & 40 & 60 & -20 \\
\hline Pac0412 & $\begin{array}{l}\text { DORLESS- } \\
\text { TRAMADOL }\end{array}$ & Uniåo Qulmica & tramadol & $\begin{array}{c}\text { A2 - } \\
\text { adendo }\end{array}$ & $50 \mathrm{cp}(50 \mathrm{mg})$ & $1 \mathrm{cp} / \mathrm{dia}$ & 50 & 60 & -10 \\
\hline Pac0702 & AMYTRIL & Cristalia & amitriptilina & c1 & $40 \mathrm{cp}(25 \mathrm{mg})$ & $1 \mathrm{cp} / \mathrm{dia}$ & 40 & 60 & -20 \\
\hline Pac0702 & LONGACTLL & Cristália & clorpromazina & c1 & $\begin{array}{l}20 \mathrm{~m} /(0,4 \\
\mathrm{mg} / \mathrm{m})\end{array}$ & $0,3 \mathrm{~m}$ Vdia & 67 & 60 & 7 \\
\hline Pac2807 & carbamazepina & & carbamazepina & C1 & $210 \mathrm{cp}(20 \mathrm{mg})$ & $7 \mathrm{cp} / \mathrm{dia}$ & 30 & 60 & -30 \\
\hline Pac2807 & fenobarbital & & fenobarbital & $\begin{array}{c}\text { B1- } \\
\text { adendo }\end{array}$ & $60 \mathrm{cp}(100 \mathrm{mg})$ & $2 \mathrm{cp} / \mathrm{dia}$ & 30 & 60 & -30 \\
\hline
\end{tabular}


$D T=$ Dias de tratamento fornecido $\quad L L=$ Limite legal

\begin{tabular}{|c|c|c|c|c|c|c|c|c|c|}
\hline $\begin{array}{l}\text { código } \\
\text { paciente }\end{array}$ & Prescriçāo & Indústria & Principio Ativo & Alínea & Fornecimento & Posologia & DT & $\mathbf{L}$ & DT - L \\
\hline Pac2244 & amitriptilina & & amitriptilina & C1 & $60 \mathrm{cp}(25 \mathrm{mg})$ & $2 \mathrm{cp} / \mathrm{dia}$ & 30 & 60 & -30 \\
\hline Pac2727 & $\begin{array}{l}\text { DORLESS- } \\
\text { TRAMADOL }\end{array}$ & Uniảo Química & tramadol & $\begin{array}{c}\text { A2 - } \\
\text { adendo }\end{array}$ & $30 \mathrm{cp}(50 \mathrm{mg})$ & $3 \mathrm{cp} / \mathrm{dia}$ & 10 & 60 & -50 \\
\hline Pac1395 & OXYCONTIN & Zodiac & oxicodona & A1 & $30 \mathrm{cp}(10 \mathrm{mg})$ & $2 \mathrm{cp} / \mathrm{dia}$ & 15 & 30 & -15 \\
\hline Pac1593 & sertralina & & sertralina & C1 & $30 \mathrm{cp}(50 \mathrm{mg})$ & $1 \mathrm{cp} / \mathrm{dia}$ & 30 & 60 & -30 \\
\hline Pac1382 & $\begin{array}{l}\text { DORLESS- } \\
\text { TRAMADOL }\end{array}$ & Uniāo Quimica & tramadol & $\begin{array}{c}\text { A2 - } \\
\text { adendo }\end{array}$ & $30 \mathrm{cp}(50 \mathrm{mg})$ & $3 \mathrm{cp} / \mathrm{dia}$ & 10 & 60 & -50 \\
\hline Pac0844 & sertralina & & sertralina & c1 & $30 \mathrm{cp}(50 \mathrm{mg})$ & $1 \mathrm{cp} / \mathrm{dia}$ & 30 & 60 & -30 \\
\hline Pac1712 & amitriptilina & & amitriptilina & C1 & $40 \mathrm{cp}(25 \mathrm{mg})$ & $1 \mathrm{cp} / \mathrm{dia}$ & 40 & 60 & -20 \\
\hline Pac1712 & OXYCONTIN & Zodiac & oxicodona & A1 & $60 \mathrm{cp}(20 \mathrm{mg})$ & $2 \mathrm{cp} / \mathrm{dia}$ & 30 & 30 & 0 \\
\hline Pac2823 & $\begin{array}{l}\text { DORLESS- } \\
\text { TRAMADOL }\end{array}$ & União Quimica & tramadol & $\begin{array}{c}\text { A2- } \\
\text { adendo }\end{array}$ & $120 \mathrm{cp}(50 \mathrm{mg})$ & $4 \mathrm{cp} / \mathrm{dia}$ & 30 & 60 & -30 \\
\hline Pac0730 & fluoxetina & & fluoxetina & C1 & $140 \mathrm{cp}(20 \mathrm{mg})$ & $3 \mathrm{cp} / \mathrm{dia}$ & 47 & 60 & -13 \\
\hline Pac3953 & $\begin{array}{l}\text { Codeina; } \\
\text { paracetamol }\end{array}$ & & \begin{tabular}{|l|} 
codeina; \\
paracetamol
\end{tabular} & $\begin{array}{c}\text { A2- } \\
\text { adendo }\end{array}$ & $30 \mathrm{cp}(30 \mathrm{mg})$ & $3 \mathrm{cp} / \mathrm{dia}$ & 10 & 60 & -50 \\
\hline Pac1715 & AMYTRIL & Cristália & amitriptilina & C1 & $40 \mathrm{cp}(25 \mathrm{mg})$ & $1 \mathrm{cp} / \mathrm{dia}$ & 40 & 60 & -20 \\
\hline Pac1715 & clorpromazina & & clorpromazina & $\mathrm{C}_{1}$ & $30 \mathrm{cp}(100 \mathrm{mg})$ & $1 \mathrm{cp} / \mathrm{dia}$ & 30 & 60 & -30 \\
\hline Pac3064 & $\begin{array}{l}\text { Codeina: } \\
\text { paracetamol }\end{array}$ & & \begin{tabular}{|l} 
codeina; \\
paracetamol
\end{tabular} & $\begin{array}{c}\text { A2 - } \\
\text { adendo }\end{array}$ & $120 \mathrm{cp}(30 \mathrm{mg})$ & $4 \mathrm{cp} / \mathrm{dia}$ & 30 & 60 & -30 \\
\hline Pac3578 & AMYTRIL & Cristália & amitriptilina & C1 & $40 \mathrm{cp}(25 \mathrm{mg})$ & $1 \mathrm{cp} / \mathrm{dia}$ & 40 & 60 & -20 \\
\hline Pac0850 & $\begin{array}{l}\text { codeina: } \\
\text { paracetamol }\end{array}$ & & \begin{tabular}{|l} 
codeina; \\
paracetamol
\end{tabular} & $\begin{array}{c}\text { A2 - } \\
\text { adendo }\end{array}$ & $30 \mathrm{cp}(30 \mathrm{mg})$ & $3 \mathrm{cp} / \mathrm{dia}$ & 10 & 60 & .50 \\
\hline Pac0613 & AMTTRIL & Cristália & amitriptilina & C1 & $40 \mathrm{cp}(25 \mathrm{mg})$ & $1 \mathrm{cp} / \mathrm{dia}$ & 40 & 60 & -20 \\
\hline Pac2417 & carbamazepina & & carbamazepina & C1 & $120 \mathrm{cp}(200 \mathrm{mg})$ & $4 \mathrm{cp} / \mathrm{dia}$ & 30 & 60 & -30 \\
\hline Pac2461 & diazepam & & diazepam & B1 & $30 \mathrm{cp}$ (10 mg) & $1 \mathrm{cp} / \mathrm{dia}$ & 30 & 60 & 30 \\
\hline Pac0166 & amitriptitina & & amitriptilina & C1 & $40 \mathrm{cp}(25 \mathrm{mg})$ & $1 \mathrm{cp} / \mathrm{dia}$ & 40 & 60 & -20 \\
\hline Pac3889 & DEPAKENE & Abbott & $\begin{array}{l}\text { ácido valpróico } \\
\text { (ou derivado) }\end{array}$ & $\mathrm{c1}$ & $\begin{array}{l}500 \mathrm{ml}(50 \\
\mathrm{mg} / \mathrm{ml})\end{array}$ & $15 \mathrm{~m} / \mathrm{dia}$ & 33 & 60 & -27 \\
\hline Pac3413 & cartzamazepina & & carbamazepina & C1 & $60 \mathrm{cp}(200 \mathrm{mg})$ & $2 \mathrm{cp} / \mathrm{dia}$ & 30 & 60 & -30 \\
\hline Pac0499 & OXYCONTIN & Zodiac & oxicodona & A1 & $30 \mathrm{cp}(20 \mathrm{mg})$ & $2 \mathrm{cp} / \mathrm{dia}$ & 15 & 30 & -15 \\
\hline Pac2789 & OXYCONTIN & Zodiac & oxicodona & A1 & $30 \mathrm{cp}(20 \mathrm{mg})$ & $2 \mathrm{cp} / \mathrm{dia}$ & 15 & 30 & -15 \\
\hline Pac2789 & amitriptilina & & amitriptilina & C1 & $20 \mathrm{cp}(20 \mathrm{mg})$ & $1 \mathrm{cp} / \mathrm{dia}$ & 20 & 60 & -40 \\
\hline Pac1047 & AMYTRIL & Cristália & amitriptilina & C1 & $40 \mathrm{cp}(25 \mathrm{mg})$ & $1 \mathrm{cp} / \mathrm{dia}$ & 40 & 60 & -20 \\
\hline Pac2263 & $\begin{array}{l}\text { DORLESS- } \\
\text { TRAMADOL }\end{array}$ & Uniảo Quimica & tramadol & $\begin{array}{c}\text { A2- } \\
\text { adendo }\end{array}$ & $90 \mathrm{cp}(50 \mathrm{mg})$ & $3 \mathrm{cp} / \mathrm{dia}$ & 30 & 60 & -30 \\
\hline Pac3062 & amantadina & & amantadina & C1 & $60 \mathrm{cp}(100 \mathrm{mg})$ & $2 \mathrm{cp} / \mathrm{dia}$ & 30 & 60 & -30 \\
\hline Pac0201 & AMITRIL & Cristália & amilriptilina & c1 & $40 \mathrm{cp}$ (25 mg) & 1 cp/dia & 40 & 60 & -20 \\
\hline Pac3566 & $\begin{array}{l}\text { codeina; } \\
\text { paracetamol }\end{array}$ & & \begin{tabular}{|l} 
codeina; \\
paracetamol
\end{tabular} & $\begin{array}{c}\text { A2 - } \\
\text { adendo }\end{array}$ & $30 \mathrm{cp}(30 \mathrm{mg})$ & $2 \mathrm{cp} / \mathrm{dia}$ & 15 & 60 & -45 \\
\hline Pac2693 & $\begin{array}{l}\text { codeina; } \\
\text { paracetamol }\end{array}$ & & \begin{tabular}{|l|} 
codeina; \\
paracetamol
\end{tabular} & $\begin{array}{c}\text { A2- } \\
\text { adendo }\end{array}$ & $120 \mathrm{cp}(30 \mathrm{mg})$ & $4 \mathrm{cp} / \mathrm{dia}$ & 30 & 60 & -30 \\
\hline Pac1293 & OXYCONTIN & Zodiac & oxicodona & A1 & $150 \mathrm{cp}(10 \mathrm{mg})$ & $3 \mathrm{cp} / \mathrm{dia}$ & 50 & 30 & 20 \\
\hline Pac1293 & carbamazepina & & carbamazepina & c1 & $50 \mathrm{cp}(200 \mathrm{mg})$ & $1 \mathrm{cp} / \mathrm{dia}$ & 50 & 60 & -10 \\
\hline Pac4036 & imipramina & & imipramina & C1 & $30 \mathrm{cp}(25 \mathrm{mg})$ & $1 \mathrm{cp} / \mathrm{dia}$ & 30 & 60 & 30 \\
\hline Pac4036 & LONGACTIL & Cristália & clorpromazina & C1 & \begin{tabular}{|l|}
$20 \mathrm{ml}(0,4$ \\
$\mathrm{mg} / \mathrm{ml})$
\end{tabular} & 0,3 mVdia & 67 & 60 & 7 \\
\hline $\operatorname{Pac} 2560$ & amitriptilina & & amitriptilina & c1 & $60 \mathrm{cp}(25 \mathrm{mg})$ & $2 \mathrm{cp} /$ dia & 30 & 60 & -30 \\
\hline Pac3877 & ANAFRANIL & Novartis & clomipramina & C1 & $60 \mathrm{cp}(25 \mathrm{mg})$ & $2 \mathrm{cp} / \mathrm{dia}$ & 30 & 60 & 30 \\
\hline Pac3877 & LONGACTIL & Cristália & clorpromazina & c1 & $\begin{array}{l}20 \mathrm{ml}(0,4 \\
\mathrm{mg} / \mathrm{mi}) \\
\end{array}$ & 0,6 mudia & 33 & 60 & -27 \\
\hline Paco776 & DAFORIN & Sigma Pharma & fluoxetina & C1 & $60 \mathrm{cp}(20 \mathrm{mg})$ & $2 \mathrm{cp} / \mathrm{dia}$ & 30 & 60 & -30 \\
\hline Pac0230 & $\begin{array}{l}\text { DORLESS- } \\
\text { TRAMADOL }\end{array}$ & Uniảo Quimica & tramadol & $\begin{array}{c}\text { A2 - } \\
\text { adendo }\end{array}$ & $60 \mathrm{cp}(50 \mathrm{mg})$ & $3 \mathrm{cp} / \mathrm{dia}$ & 20 & 60 & -40 \\
\hline Pac2646 & $\begin{array}{l}\text { codeina; } \\
\text { paracetamol }\end{array}$ & & \begin{tabular}{|l} 
codeina; \\
paracetamol
\end{tabular} & $\begin{array}{c}\text { A2 - } \\
\text { adendo }\end{array}$ & $90 \mathrm{cp}(30 \mathrm{mg})$ & $3 \mathrm{cp} / \mathrm{dia}$ & 30 & 60 & 30 \\
\hline Pac1496 & TRAMAL & \begin{tabular}{|l|} 
Pfozer- \\
Pharmacia \\
\end{tabular} & tramadol & $\begin{array}{c}\text { A2 - } \\
\text { adendo }\end{array}$ & $120 \mathrm{cp}$ (50 mg) & $4 \mathrm{cp} / \mathrm{dia}$ & 30 & 60 & 30 \\
\hline Pac1496 & haloperidol & & haloperidol & C1 & $40 \mathrm{ml}(2 \mathrm{mg})$ & $0,8 \mathrm{~m} / \mathrm{dia}$ & 50 & 60 & -10 \\
\hline
\end{tabular}


$\mathrm{DT}=$ Dias de tratamento fornecido $\quad \mathrm{LL}=$ Limite legal

\begin{tabular}{|c|c|c|c|c|c|c|c|c|c|}
\hline $\begin{array}{l}\text { código } \\
\text { paciente }\end{array}$ & Prescrição & Indústria & Principio Ativo & Alínea & Fornecimento & Posologia & DT & $L L$ & $D T-L L$ \\
\hline Pac1496 & imipramina & & imipramina & C1 & $30 \mathrm{cp}(25 \mathrm{mg})$ & $1 \mathrm{cp} / \mathrm{dia}$ & 30 & 60 & 30 \\
\hline Pac3711 & \begin{tabular}{|l|} 
codeina; \\
paracetamol
\end{tabular} & & $\begin{array}{l}\text { codeina; } \\
\text { paracetamol }\end{array}$ & $\begin{array}{c}\text { A2 - } \\
\text { adendo }\end{array}$ & $30 \mathrm{cp}$ (30 mg) & $1 \mathrm{cp} / \mathrm{dia}$ & 30 & 60 & -30 \\
\hline Pac3711 & PROGRESSE & Biosintética & gabapentina & C1 & $30 \mathrm{cp}$ (300 mg) & $1 \mathrm{cp} / \mathrm{dia}$ & 30 & 60 & -30 \\
\hline Pac3734 & OXYCONTIN & Zodiac & oxicodona & A1 & $60 \mathrm{cp}(20 \mathrm{mg})$ & $2 \mathrm{cp} / \mathrm{dia}$ & 30 & 30 & 0 \\
\hline Pac3734 & PROGRESSE & Biosintètica & gabapentina & C1 & $90 \mathrm{cp}(400 \mathrm{mg})$ & $3 \mathrm{cp} / \mathrm{dia}$ & 30 & 60 & -30 \\
\hline Pac3927 & \begin{tabular}{|l|} 
codeina; \\
paracetamol
\end{tabular} & & \begin{tabular}{|l|} 
codeina; \\
paracetamol
\end{tabular} & $\begin{array}{c}\text { A2 - } \\
\text { adendo }\end{array}$ & $30 \mathrm{cp}(30 \mathrm{mg})$ & $3 \mathrm{cp} / \mathrm{dia}$ & 10 & 60 & -50 \\
\hline Pac0173 & gabapentina & & gabapentina & c1 & $90 \mathrm{cp}(400 \mathrm{mg})$ & $3 \mathrm{cp} / \mathrm{dia}$ & 30 & 60 & -30 \\
\hline Pac2138 & TEGRETOL & Novartis & carbamazepina & c1 & $210 \mathrm{cp}(200 \mathrm{mg})$ & $7 \mathrm{cp} / \mathrm{dia}$ & 30 & 60 & -30 \\
\hline \begin{tabular}{|l} 
Pac1998 \\
\end{tabular} & cartamazepina & & carbamazepina & C1 & $120 \mathrm{cp}(200 \mathrm{mg})$ & $4 \mathrm{cp} / \mathrm{dia}$ & 30 & 60 & 30 \\
\hline Pac1880 & \begin{tabular}{|l|} 
codeina; \\
paracetamol
\end{tabular} & & $\begin{array}{l}\text { codeina: } \\
\text { paracetamol }\end{array}$ & $\begin{array}{c}A 2- \\
\text { adendo }\end{array}$ & $90 \mathrm{cp}(7,5 \mathrm{mg})$ & $3 \mathrm{cp} / \mathrm{dia}$ & 30 & 60 & -30 \\
\hline Pac1726 & AMYTRIL & Cristália & amitriptilina & C1 & $60 \mathrm{cp}(25 \mathrm{mg})$ & $2 \mathrm{cp} / \mathrm{dia}$ & 30 & 60 & -30 \\
\hline Pac1979 & PROLOPA & Roche & $\begin{array}{l}\text { levodopa e } \\
\text { benserazida }\end{array}$ & C1 & $180 \mathrm{cp}(250 \mathrm{mg})$ & $1,5 \mathrm{cp} / \mathrm{dia}$ & 120 & 60 & 60 \\
\hline Pac2746 & imipramina & & imipramina & C1 & $90 \mathrm{cp}(25 \mathrm{mg})$ & $3 \mathrm{cp} / \mathrm{dia}$ & 30 & 60 & -30 \\
\hline Pac2746 & LONGACTL & Cristália & clorpromazina & C1 & $\begin{array}{l}40 \mathrm{ml}(0,4 \\
\mathrm{mg} / \mathrm{ml})\end{array}$ & $1 \mathrm{~m} / \mathrm{dia}$ & 40 & 60 & -20 \\
\hline Pac1193 & femproporex & & femproporex & $\mathrm{B2}$ & $30 \mathrm{cp}(25 \mathrm{mg})$ & $1 \mathrm{cp} / \mathrm{dia}$ & 30 & 60 & 30 \\
\hline Pac0442 & gabapentina & & gabapentina & C1 & $90 \mathrm{cp}(400 \mathrm{mg})$ & $3 \mathrm{cp} / \mathrm{dia}$ & 30 & 60 & -30 \\
\hline Pac0442 & carbamazepina & & carbamazepina & C1 & $60 \mathrm{cp}(200 \mathrm{mg})$ & $2 \mathrm{cp} / \mathrm{dia}$ & 30 & 60 & -30 \\
\hline Pac0442 & AMYTRIL & Cristália & amitriptilina & C1 & $40 \mathrm{cp}(25 \mathrm{mg})$ & $1 \mathrm{cp} / \mathrm{dia}$ & 40 & 60 & -20 \\
\hline Pac1638 & AMYTRIL & Cristália & amitriptilina & $c 1$ & $40 \mathrm{cp}(25 \mathrm{mg})$ & $1 \mathrm{cp} / \mathrm{dia}$ & 40 & 60 & -20 \\
\hline Pac1638 & LONGACTIL & Cristália & clorpromazina & C1 & $\begin{array}{l}20 \mathrm{ml}(0,4 \\
\mathrm{mg} / \mathrm{ml})\end{array}$ & $0,45 \mathrm{~m}$ Vdia & 44 & 60 & -16 \\
\hline Pac1638 & carbamazepina & & carbamazepina & C1 & $90 \mathrm{cp}(200 \mathrm{mg})$ & 3 cp/dia & 30 & 60 & -30 \\
\hline Pac0742 & EFEXOR & Wyoth & venlafaxina & C1 & $30 \mathrm{cp}(75 \mathrm{mg})$ & $1 \mathrm{cp} / \mathrm{dia}$ & 30 & 60 & 30 \\
\hline Pac2249 & AMYTRIL & Cristália & amitriptilina & C1 & $120 \mathrm{cp}(25 \mathrm{mg})$ & $3 \mathrm{cp} / \mathrm{dia}$ & 40 & 60 & -20 \\
\hline Pac2249 & LONGACTIL & Cristália & clorpromazina & C1 & $\begin{array}{l}80 \mathrm{ml}(0,4 \\
\mathrm{mg} / \mathrm{ml})\end{array}$ & $2 \mathrm{~m} / \mathrm{dia}$ & 40 & 60 & -20 \\
\hline Pac3689 & carbamazepina & & carbamazepina & C1 & $120 \mathrm{cp}(200 \mathrm{mg})$ & $3 \mathrm{cp} / \mathrm{dia}$ & 40 & 60 & -20 \\
\hline Pac1933 & AMYTRIL & Cristália & amitriptilina & C1 & $40 \mathrm{cp}(25 \mathrm{mg})$ & $1 \mathrm{cp} / \mathrm{dia}$ & 40 & 60 & -20 \\
\hline Pac3606 & carbamazepina & & cartamazepina & C1 & $240 \mathrm{cp}(200 \mathrm{mg})$ & $6 \mathrm{cp} / \mathrm{dia}$ & 40 & 60 & -20 \\
\hline Pac1409 & carbarnazepina & & carbamazepina & C1 & $80 \mathrm{cp}(200 \mathrm{mg})$ & $2 \mathrm{cp} / \mathrm{dia}$ & 40 & 60 & -20 \\
\hline Pac1721 & diazepam & & diazepam & B1 & $20 \mathrm{cp}(10 \mathrm{mg})$ & $1 \mathrm{cp} / \mathrm{dia}$ & 20 & 60 & -40 \\
\hline Pac2724 & HALDOL & Janssen-Cilag & haloperidol & c1 & $60 \mathrm{cp}(5 \mathrm{mg})$ & $2 \mathrm{cp} / \mathrm{dia}$ & 30 & 60 & -30 \\
\hline Pac2724 & carbamazepina & & carbamazepina & c1 & $60 \mathrm{cp}(200 \mathrm{mg})$ & $2 \mathrm{cp} / \mathrm{dia}$ & 30 & 60 & 30 \\
\hline Pac0530 & PROGRESSE & Biosintética & gabapentina & C1 & $200 \mathrm{cp}$ (400 mg) & $5 \mathrm{cp} / \mathrm{dia}$ & 40 & 60 & -20 \\
\hline Pac3577 & carbamazepina & & carbarnazepina & $c 1$ & $80 \mathrm{cp}(200 \mathrm{mg})$ & $2 \mathrm{cp} / \mathrm{dia}$ & 40 & 60 & -20 \\
\hline Pac2102 & imipramina & & imipramina & C1 & $90 \mathrm{cp}(25 \mathrm{mg})$ & $3 \mathrm{cp} / \mathrm{dia}$ & 30 & 60 & -30 \\
\hline Pac0653 & AMYTRRIL & Cristália & amitriptilina & C1 & $180 \mathrm{cp}(25 \mathrm{mg})$ & $6 \mathrm{cp} / \mathrm{dia}$ & 30 & 60 & -30 \\
\hline Pac0979 & AMYTRIL & Cristália & amitriptilina & C1 & $140 \mathrm{cp}(25 \mathrm{mg})$ & $3 \mathrm{cp} / \mathrm{dia}$ & 47 & 60 & -13 \\
\hline Pac1352 & fenitoina & & \begin{tabular}{|l|} 
fenitoina \\
(hidantoina)
\end{tabular} & C1 & $120 \mathrm{cp}(100 \mathrm{mg})$ & $4 \mathrm{cp} / \mathrm{dia}$ & 30 & 60 & -30 \\
\hline Pac1089 & carbamazepina & & cartamazepina & c1 & $270 \mathrm{cp}(200 \mathrm{mg})$ & $9 \mathrm{cp} / \mathrm{dia}$ & 30 & 60 & -30 \\
\hline Pac1089 & TOPAMAX & Janssen-Cilag & topiramato & C1 & $30 \mathrm{cp}(25 \mathrm{mg})$ & $1 \mathrm{cp} / \mathrm{dia}$ & 30 & 60 & -30 \\
\hline Pac0389 & carbamazepina & & carbamazepina & C1 & $60 \mathrm{cp}(200 \mathrm{mg})$ & $1 \mathrm{cp} / \mathrm{dia}$ & 60 & 60 & 0 \\
\hline Pac2513 & carbamazepina & & cartamazepina & c1 & $280 \mathrm{cp}(200 \mathrm{mg})$ & 7 cp/dia & 40 & 60 & -20 \\
\hline Pac0804 & fenitoina & & \begin{tabular}{|l|}
$\begin{array}{l}\text { fenitoina } \\
\text { (hidantoina) }\end{array}$ \\
\end{tabular} & c1 & $160 \mathrm{cp}(100 \mathrm{mg})$ & 3,75 cp/dia & 43 & 60 & -17 \\
\hline Pac3948 & AMYTRIL & Cristália & amitriptilina & C1 & $60 \mathrm{cp}(25 \mathrm{mg})$ & $2 \mathrm{cp} / \mathrm{dia}$ & 30 & 60 & -30 \\
\hline Pac3948 & carbamazepina & & carbamazepina & C1 & $90 \mathrm{cp}(200 \mathrm{mg})$ & 3 cpidia & 30 & 60 & 30 \\
\hline
\end{tabular}


$\mathrm{DT}=$ Dias de tratamento fornecido $\quad \mathrm{LL}=$ Limite legal

\begin{tabular}{|c|c|c|c|c|c|c|c|c|c|}
\hline $\begin{array}{l}\text { código } \\
\text { paciente }\end{array}$ & Prescriçāo & Indústria & Princípio Ativo & Alínea & Fornecimento & Posologia & DT & LL & DT - UL \\
\hline Pac1820 & $\begin{array}{l}\text { DORLESS- } \\
\text { TRAMADOL }\end{array}$ & Uniảo Quimica & tramadol & $\begin{array}{c}\text { A2 - } \\
\text { adendo }\end{array}$ & $60 \mathrm{cp}(50 \mathrm{mg})$ & $4 \mathrm{cp} / \mathrm{dia}$ & 15 & 60 & -45 \\
\hline Pac1820 & \begin{tabular}{|l} 
codeina: \\
paracetamol
\end{tabular} & & \begin{tabular}{|l} 
codeina; \\
paracetamol
\end{tabular} & $\begin{array}{c}\text { A2 - } \\
\text { adendo }\end{array}$ & $40 \mathrm{cp}(30 \mathrm{mg})$ & $4 \mathrm{cp} / \mathrm{dia}$ & 10 & 60 & -50 \\
\hline Pac1042 & \begin{tabular}{|l|} 
codeina; \\
paracetamol
\end{tabular} & & $\begin{array}{l}\text { codeina; } \\
\text { paracetamol }\end{array}$ & $\begin{array}{c}\text { A2 - } \\
\text { adendo }\end{array}$ & $60 \mathrm{cp}(30 \mathrm{mg})$ & 1,5 cp/dia & 40 & 60 & -20 \\
\hline Pac1042 & AMYTRIL & Cristália & amitriptilina & C1 & $100 \mathrm{cp}(25 \mathrm{mg})$ & $3 \mathrm{cp} / \mathrm{dia}$ & 33 & 60 & -27 \\
\hline Pac1849 & \begin{tabular}{|l|} 
codeina: \\
paracetamol
\end{tabular} & & \begin{tabular}{|l} 
codeina; \\
paracetamol
\end{tabular} & $\begin{array}{c}\text { A2 - } \\
\text { adendo }\end{array}$ & $120 \mathrm{cp}(30 \mathrm{mg})$ & $4 \mathrm{cp} / \mathrm{dia}$ & 30 & 60 & 30 \\
\hline Pac1294 & carbamazepina & & carbamazepina & $\mathrm{C}_{1}$ & $240 \mathrm{cp}(200 \mathrm{mg})$ & $8 \mathrm{cp} / \mathrm{dia}$ & 30 & 60 & -30 \\
\hline Pac1294 & fenobarbital & & fenobarbital & $\begin{array}{c}\text { B1 - } \\
\text { adendo }\end{array}$ & $60 \mathrm{cp}(100 \mathrm{mg})$ & $2 \mathrm{cp} / \mathrm{dia}$ & 30 & 60 & -30 \\
\hline Pac2131 & \begin{tabular}{|l|} 
codeina; \\
paracetamol
\end{tabular} & & \begin{tabular}{|l} 
codeina; \\
paracetamol
\end{tabular} & $\begin{array}{c}A 2- \\
\text { adendo }\end{array}$ & $60 \mathrm{cp}(30 \mathrm{mg})$ & $2 \mathrm{cp} / \mathrm{dia}$ & 30 & 60 & -30 \\
\hline Pac2422 & fluoxetina & & fluoxetina & C1 & $30 \mathrm{cp}(20 \mathrm{mg})$ & $1 \mathrm{cp} / \mathrm{dia}$ & 30 & 60 & -30 \\
\hline Pac0371 & AMYTRIL & Cristália & amitriptilina & C1 & $40 \mathrm{cp}(25 \mathrm{mg})$ & $1 \mathrm{cp} / \mathrm{dia}$ & 40 & 60 & -20 \\
\hline Pac0775 & fluoxotina & & fluoxetina & C1 & $60 \mathrm{cp}(20 \mathrm{mg})$ & $2 \mathrm{cp} / \mathrm{dia}$ & 30 & 60 & -30 \\
\hline Pac1681 & carbamazepina & & carbamazepina & C1 & $90 \mathrm{cp}(200 \mathrm{mg})$ & $3 \mathrm{cp} / \mathrm{dia}$ & 30 & 60 & -30 \\
\hline Pac1681 & AMVTRIL & Cristália & amitriptilina & c1 & $40 \mathrm{cp}(25 \mathrm{mg})$ & $1 \mathrm{cp} / \mathrm{dia}$ & 40 & 60 & -20 \\
\hline Pac2079 & carbamazepina & & cartamazepina & C1 & $60 \mathrm{cp}(200 \mathrm{mg})$ & $2 \mathrm{cp} / \mathrm{dia}$ & 30 & 60 & 30 \\
\hline Pac2079 & ANYTRRL & Cristália & amitriptilina & $c_{1}$ & $90 \mathrm{cp}(25 \mathrm{mg})$ & $3 \mathrm{cp} / \mathrm{dia}$ & 30 & 60 & -30 \\
\hline Pac3168 & $\begin{array}{l}\text { codeina: } \\
\text { paracetamol }\end{array}$ & & $\begin{array}{l}\text { codeina: } \\
\text { paracetamol }\end{array}$ & $\begin{array}{c}\text { A2 - } \\
\text { adendo }\end{array}$ & $30 \mathrm{cp}(30 \mathrm{mg})$ & $3 \mathrm{cp} / \mathrm{dia}$ & 10 & 60 & -50 \\
\hline Pac0972 & fluoxetina & & fuoxetina & C1 & $30 \mathrm{cp}(20 \mathrm{mg})$ & $1 \mathrm{cp} / \mathrm{dia}$ & 30 & 60 & -30 \\
\hline Pac1419 & imipramina & & imipramina & C1 & $30 \mathrm{cp}(25 \mathrm{mg})$ & $1 \mathrm{cp} / \mathrm{dia}$ & 30 & 60 & -30 \\
\hline Pac2081 & AMYTRIL & Cristália & amitriptilina & C1 & $180 \mathrm{cp}(25 \mathrm{mg})$ & $5 \mathrm{cp} / \mathrm{dia}$ & 36 & 60 & -24 \\
\hline Pac2081 & LONGACTIL & Cristália & clorpromazina & C1 & $\begin{array}{l}40 \mathrm{ml}(0,4 \\
\mathrm{mg} / \mathrm{ml})\end{array}$ & $0.6 \mathrm{~m} / \mathrm{dia}$ & 67 & 60 & 7 \\
\hline Pac0146 & PROLOPAHBS & Roche & $\begin{array}{l}\text { lewodopa e } \\
\text { benserazida }\end{array}$ & C1 & $60 \mathrm{cp}(60 \mathrm{mg})$ & $1 \mathrm{cp} / \mathrm{dia}$ & 60 & 60 & 0 \\
\hline Pac0146 & PROLOPA & Roche & $\begin{array}{l}\text { levodopa o } \\
\text { benserazida }\end{array}$ & C1 & $90 \mathrm{cp}(250 \mathrm{mg})$ & $2 \mathrm{cp} / \mathrm{dia}$ & 45 & 60 & -15 \\
\hline Pac0146 & selegilina & & selegilina & C1 & $40 \mathrm{cp}(5 \mathrm{mg})$ & $1 \mathrm{cp} / \mathrm{dia}$ & 40 & 60 & -20 \\
\hline Pac2365 & DEPAKENE & Abbott & $\begin{array}{l}\text { ácido valpróico } \\
\text { (ou derivado) }\end{array}$ & C1 & $150 \mathrm{cp}(500 \mathrm{mg})$ & $3 \mathrm{cp} / \mathrm{dia}$ & 50 & 60 & -10 \\
\hline Pac2365 & TOPAMAX & Janssen-Clag & topiramato & $c_{1}$ & $30 \mathrm{cp}(100 \mathrm{mg})$ & $1 \mathrm{cp} / \mathrm{dia}$ & 30 & 60 & -30 \\
\hline Pac0764 & $\begin{array}{l}\text { DORLESS- } \\
\text { TRANADOL }\end{array}$ & Uniảo Quimica & tramadol & $\begin{array}{c}\text { A2 - } \\
\text { adendo }\end{array}$ & $90 \mathrm{cp}(50 \mathrm{mg})$ & $3 \mathrm{cp} / \mathrm{dia}$ & 30 & 60 & -30 \\
\hline Pac0764 & AMYTRIL & Cristália & amitriptilina & C1 & $120 \mathrm{cp}(25 \mathrm{mg})$ & $4 \mathrm{cp} / \mathrm{dia}$ & 30 & 60 & -30 \\
\hline Pac0764 & LONGACTIL & Cristália & clorpromazina & C1 & $\begin{array}{l}60 \mathrm{ml}(0,4 \\
\mathrm{mg} / \mathrm{ml})\end{array}$ & $1 \mathrm{ml} / \mathrm{dia}$ & 60 & 60 & 0 \\
\hline Pac3087 & sertralina & & sertralina & C1 & $45 \mathrm{cp}(50 \mathrm{mg})$ & $1 \mathrm{cp} / \mathrm{dia}$ & 45 & 60 & -15 \\
\hline Pac2364 & amitriptikna & & amitriptilina & C1 & $60 \mathrm{cp}(25 \mathrm{mg})$ & $2 \mathrm{cp} / \mathrm{dia}$ & 30 & 60 & -30 \\
\hline Pac2364 & LONGACTIL & Cristália & clorpromazina & C1 & $\begin{array}{l}60 \mathrm{ml}(0,4 \\
\mathrm{mg} / \mathrm{m})\end{array}$ & $2 \mathrm{ml} / \mathrm{dia}$ & 30 & 60 & -30 \\
\hline Pac2364 & carbamazepina & & cartamazepina & C1 & $90 \mathrm{cp}(200 \mathrm{mg})$ & $3 \mathrm{cp} / \mathrm{dia}$ & 30 & 60 & -30 \\
\hline Pac1433 & sertralina & & sertralina & C1 & $60 \mathrm{cp}(50 \mathrm{mg})$ & $2 \mathrm{cp} / \mathrm{dia}$ & 30 & 60 & -30 \\
\hline Pac2386 & sertralina & & sertralina & C1 & $60 \mathrm{cp}(50 \mathrm{mg})$ & $2 \mathrm{cp} / \mathrm{dia}$ & 30 & 60 & .30 \\
\hline Pac0581 & fenitoina & & \begin{tabular}{|l}
$\begin{array}{l}\text { fenitoina } \\
\text { (hidantoina) }\end{array}$ \\
\end{tabular} & C1 & $80 \mathrm{cp}(100 \mathrm{mg})$ & $2 \mathrm{cp} / \mathrm{dia}$ & 40 & 60 & -20 \\
\hline Pac0581 & fenobarbital & & fenobarbital & $\begin{array}{c}\text { B1- } \\
\text { adendo }\end{array}$ & $40 \mathrm{cp}(100 \mathrm{mg})$ & $1 \mathrm{cp} / \mathrm{dia}$ & 40 & 60 & -20 \\
\hline Pac3629 & AMYTRIL & Cristália & amitriptitine & C1 & $60 \mathrm{cp}(25 \mathrm{mg})$ & $2 \mathrm{cp} / \mathrm{dia}$ & 30 & 60 & -30 \\
\hline Pac0378 & ORAP & Janssen-Cilag & pimozida & c1 & $60 \mathrm{cp}(1 \mathrm{mg})$ & $2 \mathrm{cp} / \mathrm{dia}$ & 30 & 60 & 30 \\
\hline Pac0520 & AMYTRIL & Cristália & amitriptilina & C1 & $40 \mathrm{cp}(25 \mathrm{mg})$ & $1 \mathrm{cp} / \mathrm{dia}$ & 40 & 60 & -20 \\
\hline Pac1016 & fluoxetina & & fluoxetina & C1 & $60 \mathrm{cp}(20 \mathrm{mg})$ & 2 cp/dia & 30 & 60 & -30 \\
\hline Pac0196 & fenobarbital & & fenobarbital & \begin{tabular}{|c|} 
B1- \\
adendo
\end{tabular} & $20 \mathrm{cp}(100 \mathrm{mg})$ & $0.5 \mathrm{cp} / \mathrm{dia}$ & 40 & 60 & -20 \\
\hline Pac0509 & $\begin{array}{l}\text { DORLESS- } \\
\text { TRAMADOL }\end{array}$ & Uniåo Química & tramadol & $\begin{array}{c}\text { A2 - } \\
\text { adendo }\end{array}$ & $30 \mathrm{cp}(50 \mathrm{mg})$ & $3 \mathrm{cp} / \mathrm{dla}$ & 10 & 60 & -50 \\
\hline
\end{tabular}


$D T=$ Dias de tratamento fornecido $\quad L L=$ Limite legal

\begin{tabular}{|c|c|c|c|c|c|c|c|c|c|}
\hline $\begin{array}{l}\text { código } \\
\text { paciente }\end{array}$ & Prescriçāo & Indústria & Principio Ativo & Alinea & Fornecimento & Posologia & DT & LL & DT-LL \\
\hline Pac0831 & haloperidol & & haloperidol & C1 & $80 \mathrm{cp}(5 \mathrm{mg})$ & $2 \mathrm{cp} / \mathrm{dia}$ & 40 & 60 & -20 \\
\hline Pac2201 & sertralina & & sertralina & C1 & $80 \mathrm{cp}(50 \mathrm{mg})$ & $2 \mathrm{cp} / \mathrm{dia}$ & 40 & 60 & -20 \\
\hline Pac2850 & carbamazepina & & carbamazepina & C1 & $120 \mathrm{cp}(200 \mathrm{mg})$ & $3 \mathrm{cp} / \mathrm{dia}$ & 40 & 60 & -20 \\
\hline Pac2850 & sertralina & & sertralina & C1 & $40 \mathrm{cp}$ (50 mg) & $1 \mathrm{cp} / \mathrm{dia}$ & 40 & 60 & -20 \\
\hline Pac1396 & sertratina & & sertralina & C1 & $30 \mathrm{cp}(50 \mathrm{mg})$ & $1 \mathrm{cp} / \mathrm{dia}$ & 30 & 60 & -30 \\
\hline Pac4074 & cartamazepina & & carbamazepina & C1 & $90 \mathrm{cp} \mathrm{(200 \textrm {mg } )}$ & 3 cp/dia & 30 & 60 & -30 \\
\hline Pac4041 & gabapentina & & gabapentina & C1 & $120 \mathrm{cp}(300 \mathrm{mg})$ & $3 \mathrm{cp} / \mathrm{dia}$ & 40 & 60 & -20 \\
\hline Pac4041 & $\begin{array}{l}\text { codeina; } \\
\text { paracetamol }\end{array}$ & & $\begin{array}{l}\text { codeina; } \\
\text { paracetamol }\end{array}$ & $\begin{array}{c}\begin{array}{c}\text { A2 - } \\
\text { adendo }\end{array} \\
\end{array}$ & $160 \mathrm{cp}(30 \mathrm{mg})$ & $4 \mathrm{cp} / \mathrm{dia}$ & 40 & 60 & -20 \\
\hline Pac2333 & DEPAKENE & Abbott & $\begin{array}{l}\text { acido valpröico } \\
\text { (ou derivado) }\end{array}$ & $\mathrm{C} 1$ & $\begin{array}{l}500 \mathrm{ml}(50 \\
\mathrm{mg} / \mathrm{ml})\end{array}$ & $18 \mathrm{~m}$ dia & 28 & 60 & -32 \\
\hline Pac2434 & fenitoina & & \begin{tabular}{|l|l|} 
fenitoina \\
(hidantoina)
\end{tabular} & $\mathrm{Cl}$ & $100 \mathrm{cp}(100 \mathrm{mg})$ & $3 \mathrm{cp} / \mathrm{dia}$ & 33 & 60 & -27 \\
\hline Pac3168 & AMYTRIL & Cristália & amitriptilina & C1 & $30 \mathrm{cp}$ (25 mg) & $1 \mathrm{cp} / \mathrm{dia}$ & 30 & 60 & -30 \\
\hline Pac1741 & DEPAKENE & Abbott & $\begin{array}{l}\text { ácido valpróico } \\
\text { (ou derivado) }\end{array}$ & C1 & $\begin{array}{l}500 \mathrm{ml}(50 \\
\mathrm{mg} / \mathrm{ml})\end{array}$ & $15 \mathrm{mUdia}$ & 33 & 60 & -27 \\
\hline Pac0228 & lenobarbital & & fenobarbital & \begin{tabular}{|c|}
$\begin{array}{c}\mathrm{B} 1- \\
\text { adendo }\end{array}$ \\
\end{tabular} & $60 \mathrm{cp}(100 \mathrm{mg})$ & $2 \mathrm{cp} / \mathrm{dia}$ & 30 & 60 & -30 \\
\hline $\mathrm{Pac0228}$ & lenitoina & & $\begin{array}{l}\text { fenitoina } \\
\text { (hidantoina) }\end{array}$ & C1 & $100 \mathrm{cp}(100 \mathrm{mg})$ & $3 \mathrm{cp} / \mathrm{dia}$ & 33 & 60 & -27 \\
\hline Pac3031 & carbamazepina & & carbamazepine & $\mathrm{C1}$ & $90 \mathrm{cp}(200 \mathrm{mg})$ & $3 \mathrm{cp} / \mathrm{dia}$ & 30 & 60 & -30 \\
\hline Pac1252 & carbamazepina & & carbamazepina & $\mathrm{Cl}$ & $120 \mathrm{cp}(200 \mathrm{mg})$ & $4 \mathrm{cp} / \mathrm{dia}$ & 30 & 60 & -30 \\
\hline Pac1426 & carbamazepina & & cartamazepina & $\mathrm{Cl}$ & $80 \mathrm{cp}(200 \mathrm{mg})$ & $2 \mathrm{cp} / \mathrm{dia}$ & 40 & 60 & -20 \\
\hline Pac2971 & DEPAKENE & Abbott & $\begin{array}{l}\text { acido valpróico } \\
\text { (ou derivado) } \\
\end{array}$ & C1 & $100 \mathrm{cp}(250 \mathrm{mg})$ & $2 \mathrm{cp} / \mathrm{dia}$ & 50 & 60 & -10 \\
\hline Pac0760 & PROGRESSE & Biosintética & gabapentina & Ci & $90 \mathrm{cp}(400 \mathrm{mg})$ & $3 \mathrm{cp} / \mathrm{dia}$ & 30 & 60 & -30 \\
\hline Pac0760 & AMITRRIL & Cristália & amitriptifina & C1 & $100 \mathrm{cp}(25 \mathrm{mg})$ & $3 \mathrm{cp} / \mathrm{dia}$ & 33 & 60 & -27 \\
\hline Pac2988 & cartamazepina & & carbamazepina & C1 & $120 \mathrm{cp}(200 \mathrm{mg})$ & $4 \mathrm{cp} / \mathrm{dia}$ & 30 & 60 & 30 \\
\hline Pac2749 & DEPAKENE & Abbott & $\begin{array}{l}\text { ácido valpróico } \\
\text { (ou derivado) }\end{array}$ & C1 & $250 \mathrm{cp}(500 \mathrm{mg})$ & $6 \mathrm{cp} / \mathrm{dia}$ & 42 & 60 & -18 \\
\hline Pac1414 & AMMTRIL & Cristália & amitriptilina & C1 & $40 \mathrm{cp}(25 \mathrm{mg})$ & 1 cpidia & 40 & 60 & -20 \\
\hline Pac3114 & nuoxetina & & fluoxetina & C1 & $60 \mathrm{cp}(20 \mathrm{mg})$ & $2 \mathrm{cp} / \mathrm{dia}$ & 30 & 60 & 30 \\
\hline Pac3136 & fuoxetina & & fluoxetina & c1 & $60 \mathrm{cp}(20 \mathrm{mg})$ & $2 \mathrm{cp} / \mathrm{dia}$ & 30 & 60 & -30 \\
\hline Pac0561 & ANAFRANIL & Novartis & clomipramina & C1 & $5 \mathrm{cp}(5 \mathrm{mg})$ & $1 \mathrm{cp} / \mathrm{dia}$ & 5 & 60 & -55 \\
\hline Pac0207 & AMVTRR & Cristália & amitriptilina & C1 & $120 \mathrm{cp}(25 \mathrm{mg})$ & $4 \mathrm{cp} / \mathrm{dia}$ & 30 & 60 & 30 \\
\hline Pac0207 & clorpromazina & & clorpromazina & C1 & \begin{tabular}{|l|}
$20 \mathrm{ml}(0,4$ \\
$\mathrm{mg} / \mathrm{mi})$
\end{tabular} & $0,2 \mathrm{ml} / \mathrm{dia}$ & 100 & 60 & 40 \\
\hline Pac4024 & AMYTRIL & Cristalia & amitriptilina & C1 & $40 \mathrm{cp}(25 \mathrm{mg})$ & $1 \mathrm{cp} / \mathrm{dia}$ & 40 & 60 & -20 \\
\hline Pac4024 & TRAMAL & $\begin{array}{l}\text { Pfzer- } \\
\text { Pharmacia }\end{array}$ & tramadol & $\begin{array}{c}\text { A2 - } \\
\text { adendo } \\
\end{array}$ & $60 \mathrm{cp}(50 \mathrm{mg})$ & $4 \mathrm{cp} / \mathrm{dia}$ & 15 & 60 & -45 \\
\hline Pact918 & DEPAKENE & Abbotl & $\begin{array}{l}\text { ácido valproico } \\
\text { (ou derivado) }\end{array}$ & $\mathrm{C1}$ & $\begin{array}{l}500 \mathrm{ml}(50 \\
\mathrm{mg} / \mathrm{ml})\end{array}$ & $14 \mathrm{~m} /$ dia & 36 & 60 & -24 \\
\hline Pac0042 & RIVOTRIL & Roche & clonazepam & B1 & $30 \mathrm{cp}(2 \mathrm{mg})$ & $1 \mathrm{cp} / \mathrm{dia}$ & 30 & 60 & -30 \\
\hline Pac3145 & amitriptinna & & amitriptilina & C1 & $40 \mathrm{cp}$ (25 mg) & $1 \mathrm{cp} / \mathrm{dia}$ & 40 & 60 & -20 \\
\hline Pac3268 & EPILENIL & Biolab-Sanus & \begin{tabular}{|l}
$\begin{array}{l}\text { ácido valpróico } \\
\text { (ou derivado) }\end{array}$ \\
\end{tabular} & C1 & $\begin{array}{l}1200 \mathrm{ml}(50 \\
\mathrm{mg} / \mathrm{ml})\end{array}$ & $30 \mathrm{~m} / \mathrm{dia}$ & 40 & 60 & -20 \\
\hline Pac1082 & fuoxetina & & fluoxetina & C1 & $30 \mathrm{cp}(20 \mathrm{mg})$ & $1 \mathrm{cp} / \mathrm{dia}$ & 30 & 60 & -30 \\
\hline Pac3876 & fluoxetina & & fluoxetina & $\mathrm{Cl}_{1}$ & $30 \mathrm{cp}(20 \mathrm{mg})$ & $1 \mathrm{cp} / \mathrm{dia}$ & 30 & 60 & -30 \\
\hline Pac0044 & TRILEPTAL & Novartis & oxcarbazepina & $\mathrm{Cl}$ & $\begin{array}{l}300 \mathrm{ml}(0,6 \\
\mathrm{mg} / \mathrm{ml})\end{array}$ & 7,5 mUdia & 40 & 60 & -20 \\
\hline Pac2256 & AMYTRIL & Cristália & amitriptilina & $\mathrm{Cl}_{1}$ & $120 \mathrm{cp}(25 \mathrm{mg})$ & $3 \mathrm{cp} / \mathrm{dia}$ & 40 & 60 & -20 \\
\hline Pac2256 & LONGACTL & Cristália & clorpromazina & C1 & $\begin{array}{l}40 \mathrm{ml}(0,4 \\
\mathrm{mg} / \mathrm{ml})\end{array}$ & $2 \mathrm{~m}$ Udia & 20 & 60 & -40 \\
\hline Pac2256 & PROGRESSE & Biosintetica & gabapentina & C1 & $90 \mathrm{cp}$ (300 mg) & $3 \mathrm{cp} / \mathrm{dia}$ & 30 & 60 & -30 \\
\hline Pac3765 & fenobarbital & & fenobarbital & \begin{tabular}{|c|} 
Bi - \\
adendo \\
\end{tabular} & $60 \mathrm{cp}(100 \mathrm{mg})$ & $2 \mathrm{cp} / \mathrm{dia}$ & 30 & 60 & -30 \\
\hline Pac3736 & fenobarbital & & fenobarbital & $\begin{array}{c}\text { B1- } \\
\text { adendo }\end{array}$ & $20 \mathrm{cp}(100 \mathrm{mg})$ & $0,5 \mathrm{cp} / \mathrm{dia}$ & 40 & 60 & -20 \\
\hline
\end{tabular}


DT = Dias de tratamento fornecido $\quad \mathrm{LL}=$ Limite legal

\begin{tabular}{|c|c|c|c|c|c|c|c|c|c|}
\hline \begin{tabular}{|l|} 
código \\
paciente
\end{tabular} & Prescrição & Indústria & Princípio Ativo & Alinea & Fornecimento & Posologia & DT & LL & DT $-L L$ \\
\hline Pac3752 & sertralina & & sertralina & C1 & $60 \mathrm{cp}(50 \mathrm{mg})$ & $2 \mathrm{cp} / \mathrm{dia}$ & 30 & 60 & -30 \\
\hline Pac3218 & sertralina & & sertralina & C1 & $45 \mathrm{cp}(50 \mathrm{mg})$ & $1 \mathrm{cp} / \mathrm{dia}$ & 45 & 60 & -15 \\
\hline Pac3218 & HALDOL & Janssen-Cilag & haloperidol & C1 & $20 \mathrm{cp}(5 \mathrm{mg})$ & $0,5 \mathrm{cp} / \mathrm{dia}$ & 40 & 60 & -20 \\
\hline Pac3185 & haloperidot & & hatoperidol & C1 & $80 \mathrm{cp}(1 \mathrm{mg})$ & $2 \mathrm{cp} / \mathrm{dia}$ & 40 & 60 & -20 \\
\hline Pac1924 & imipramina & & imipramina & C1 & $110 \mathrm{cp}(25 \mathrm{mg})$ & $3 \mathrm{cp} / \mathrm{dia}$ & 37 & 60 & -23 \\
\hline Pac1590 & carbamazepina & & carbamazepina & C1 & $70 \mathrm{cp}(200 \mathrm{mg})$ & $2 \mathrm{cp} / \mathrm{dia}$ & 35 & 60 & -25 \\
\hline Pac2532 & AMYTRIL & Cristália & amitriptiline & C1 & $40 \mathrm{cp}(25 \mathrm{mg})$ & $1 \mathrm{cp} / \mathrm{dia}$ & 40 & 60 & -20 \\
\hline Pac2532 & sertralina & & sertralina & C1 & $45 \mathrm{cp}(50 \mathrm{mg})$ & $1 \mathrm{cp} / \mathrm{dia}$ & 45 & 60 & -15 \\
\hline Pac0878 & cartamazepina & & carbamazepina & C1 & $120 \mathrm{cp}(200 \mathrm{mg})$ & 3 cp/dia & 40 & 60 & -20 \\
\hline Pac1171 & \begin{tabular}{|l} 
codeina; \\
paracetamol
\end{tabular} & & $\begin{array}{l}\text { codeina: } \\
\text { paracetamol }\end{array}$ & $\begin{array}{c}A 2- \\
\text { adendo }\end{array}$ & $40 \mathrm{cp}(30 \mathrm{mg})$ & 4 cpidia & 10 & 60 & -50 \\
\hline$P a c 0260$ & DEPAKENE & Abbott & \begin{tabular}{|l|}
$\begin{array}{l}\text { ácido valpróico } \\
\text { (ou derivado) }\end{array}$ \\
\end{tabular} & C1 & $250 \mathrm{cp}(250 \mathrm{mg})$ & $6 \mathrm{cp} / \mathrm{dia}$ & 42 & 60 & -18 \\
\hline Pac0260 & carbamazepina & & carbamazepina & C1 & $120 \mathrm{cp}(200 \mathrm{mg})$ & $3 \mathrm{cp} / \mathrm{dia}$ & 40 & 60 & -20 \\
\hline Pac0450 & PROLOPA & Roche & $\begin{array}{l}\text { levodopa } \mathrm{e} \\
\text { benserazida }\end{array}$ & C1 & $90 \mathrm{cp}(250 \mathrm{mg})$ & $3 \mathrm{cp} / \mathrm{dia}$ & 30 & 60 & -30 \\
\hline Pac0450 & sologitina & & selegilina & C1 & $40 \mathrm{cp}(5 \mathrm{mg})$ & $1 \mathrm{cp} / \mathrm{dia}$ & 40 & 60 & -20 \\
\hline Pac0276 & fenitoina & & \begin{tabular}{|l|} 
fenitoina \\
(hidantoina)
\end{tabular} & C1 & $60 \mathrm{cp}(100 \mathrm{mg})$ & $2 \mathrm{cp} / \mathrm{dia}$ & 30 & 60 & -30 \\
\hline Pac0276 & DEPAKENE & Abbott & \begin{tabular}{|l}
$\begin{array}{l}\text { acido valpróico } \\
\text { (ou derivado) }\end{array}$ \\
\end{tabular} & C1 & $50 \mathrm{cp}(500 \mathrm{mg})$ & $1 \mathrm{cp} / \mathrm{dia}$ & 50 & 60 & -10 \\
\hline Pac0248 & fenobartital & & fenobarbital & \begin{tabular}{|c|} 
B1 - \\
adendo
\end{tabular} & $120 \mathrm{cp}(100 \mathrm{mg})$ & $2 \mathrm{cp} / \mathrm{dia}$ & 60 & 60 & 0 \\
\hline Pac0248 & fenitoina & & \begin{tabular}{|l} 
fenitoina \\
(hidantoina)
\end{tabular} & C1 & $160 \mathrm{cp}(100 \mathrm{mg})$ & $3 \mathrm{cp} / \mathrm{dia}$ & 53 & 60 & .7 \\
\hline Pac2102 & carbarnazepina & & carbamazepina & C1 & $60 \mathrm{cp}(200 \mathrm{mg})$ & $2 \mathrm{cp} / \mathrm{dia}$ & 30 & 60 & -30 \\
\hline Pac2102 & LONGACTL & Cristália & clorpromazina & c1 & $\begin{array}{l}20 \mathrm{ml}(0,4 \\
\mathrm{mg} / \mathrm{ml})\end{array}$ & $0,5 \mathrm{~m} / \mathrm{dia}$ & 40 & 60 & -20 \\
\hline Pac0709 & TOFRANIL & Novartis & imipramina & C1 & $80 \mathrm{cp}(25 \mathrm{mg})$ & $2 \mathrm{cp} / \mathrm{dia}$ & 40 & 60 & -20 \\
\hline Pac0709 & LONGACTIL & Cristália & clorpromazina & C1 & $\begin{array}{l}40 \mathrm{ml}(0,4 \\
\mathrm{mg} / \mathrm{m})\end{array}$ & $0,8 \mathrm{mV} / \mathrm{dia}$ & 50 & 60 & -10 \\
\hline Pac0919 & AMYTRIL & Cristália & amitriptilina & c1 & $80 \mathrm{cp}$ (25 mg) & $3 \mathrm{cp} / \mathrm{dia}$ & 27 & 60 & .33 \\
\hline Pac2309 & fenobarbital & & fenobarbital & $\begin{array}{c}\text { B1 - } \\
\text { adendo }\end{array}$ & $40 \mathrm{cp}(100 \mathrm{mg})$ & $1 \mathrm{cp} / \mathrm{dia}$ & 40 & 60 & -20 \\
\hline Pac0724 & sertralina & & sertralina & C1 & $45 \mathrm{cp}(50 \mathrm{mg})$ & $1 \mathrm{cp} / \mathrm{dia}$ & 45 & 60 & -15 \\
\hline Pac3168 & ANAFRANIL & Novartis & clomipramina & C1 & $240 \mathrm{cp}(25 \mathrm{mg})$ & $6 \mathrm{cp} / \mathrm{dia}$ & 40 & 60 & -20 \\
\hline Pac0129 & sertralina & & sertralina & C1 & $60 \mathrm{cp}(50 \mathrm{mg})$ & $2 \mathrm{cp} / \mathrm{dia}$ & 30 & 60 & -30 \\
\hline Pac0129 & \begin{tabular}{|l|} 
codeina; \\
paracetamol
\end{tabular} & & \begin{tabular}{|l} 
codeina; \\
paracetamol
\end{tabular} & $\begin{array}{c}\text { A2 - } \\
\text { adendo }\end{array}$ & $120 \mathrm{cp}(30 \mathrm{mg})$ & $4 \mathrm{cp} / \mathrm{dia}$ & 30 & 60 & -30 \\
\hline Pac0129 & PROLOPA HBS & Roche & $\begin{array}{l}\text { levodopa } \theta \\
\text { benserazida }\end{array}$ & C1 & $30 \mathrm{cp}(125 \mathrm{mg})$ & $1 \mathrm{cp} / \mathrm{dia}$ & 30 & 60 & -30 \\
\hline Pac0129 & PROLOPA & Roche & \begin{tabular}{|l|} 
levodopa $\theta$ \\
benserazida
\end{tabular} & C1 & $60 \mathrm{cp}(250 \mathrm{mg})$ & $2 \mathrm{cp} / \mathrm{dia}$ & 30 & 60 & -30 \\
\hline Pac0316 & sertralina & & sertralina & C1 & $60 \mathrm{cp}(50 \mathrm{mg})$ & $2 \mathrm{cp} / \mathrm{dia}$ & 30 & 60 & -30 \\
\hline Pac0332 & fluoxetina & & fluoxetina & C1 & $30 \mathrm{cp}(20 \mathrm{mg})$ & $1 \mathrm{cp} / \mathrm{dia}$ & 30 & 60 & 30 \\
\hline Pac0790 & fluoxetina & & fluoxetina & $C_{1}$ & $60 \mathrm{cp}(20 \mathrm{mg})$ & $2 \mathrm{cp} / \mathrm{dia}$ & 30 & 60 & 30 \\
\hline Pac3809 & sertralina & & sertralina & C1 & $100 \mathrm{cp}(50 \mathrm{mg})$ & $2 \mathrm{cp} / \mathrm{dia}$ & 50 & 60 & -10 \\
\hline Pac1467 & sertralina & & sertralina & C1 & $40 \mathrm{cp}(50 \mathrm{mg})$ & $1 \mathrm{cp} / \mathrm{dia}$ & 40 & 60 & -20 \\
\hline Pac1161 & femproporex & & femproporex & B2 & $60 \mathrm{cp}$ (25 mg) & $2 \mathrm{cp} / \mathrm{dia}$ & 30 & 60 & -30 \\
\hline Pac1161 & fluoxetina & & fluoxetina & C1 & $90 \mathrm{cp}(20 \mathrm{mg})$ & $3 \mathrm{cp} / \mathrm{dia}$ & 30 & 60 & -30 \\
\hline Pac0439 & talidomida & & talidomida & C3 & $30 \mathrm{cp}(100 \mathrm{mg})$ & $1 \mathrm{cp} / \mathrm{dia}$ & 30 & 30 & 0 \\
\hline Pac1622 & amitriptiona & & amitriptilina & C1 & $40 \mathrm{cp}(25 \mathrm{mg})$ & $1 \mathrm{cp} / \mathrm{dia}$ & 40 & 60 & -20 \\
\hline Pac1749 & DUALID S & Asta Módica & \begin{tabular}{|l|} 
anfepramona \\
(dietilpropiona)
\end{tabular} & B2 & $60 \mathrm{cp}$ (75 mg) & $2 \mathrm{cp} / \mathrm{dia}$ & 30 & 60 & .30 \\
\hline Pac0131 & fluoxetina & & fluoxetina & C1 & $10 \mathrm{cp}(20 \mathrm{mg})$ & $2 \mathrm{cp} / \mathrm{dia}$ & 5 & 60 & -55 \\
\hline Pac3836 & fluoxetina & & fluoxetina & c1 & $90 \mathrm{cp}$ (20 mg) & $2 \mathrm{cp} / \mathrm{dia}$ & 45 & 60 & -15 \\
\hline Pac1652 & amitriptilina & & amitriptilina & c1 & $60 \mathrm{cp}$ (25 mg) & $2 \mathrm{cp} / \mathrm{dia}$ & 30 & 60 & -30 \\
\hline Pac2628 & AMYTRIL & Cristália & amitriptilina & C1 & $40 \mathrm{cp}(25 \mathrm{mg})$ & $1 \mathrm{cp} / \mathrm{dia}$ & 40 & 60 & -20 \\
\hline
\end{tabular}


$\mathrm{DT}=$ Dias de tratamento fornecido $\quad \mathrm{LL}=$ Limite legal

\begin{tabular}{|c|c|c|c|c|c|c|c|c|c|}
\hline $\begin{array}{l}\text { código } \\
\text { paciente }\end{array}$ & Prescrição & Indústria & Princíplo Ativo & Alínea & Fornecimento & Posologia & DT & $L L$ & DT. LL \\
\hline Pac2628 & fenitoina & & \begin{tabular}{|l|}
$\begin{array}{l}\text { fenitoina } \\
\text { (hidantoina) }\end{array}$ \\
\end{tabular} & C1 & $20 \mathrm{cp}(100 \mathrm{mg})$ & $1 \mathrm{cp} / \mathrm{dia}$ & 20 & 60 & -40 \\
\hline Pac0021 & carbamazepina & & carbamazepina & $\mathrm{Cl}$ & $120 \mathrm{cp}(200 \mathrm{mg})$ & $4 \mathrm{cp} / \mathrm{dia}$ & 30 & 60 & -30 \\
\hline Pac0021 & TRAMAL & $\begin{array}{l}\text { Pfizer- } \\
\text { Pharmacia }\end{array}$ & tramadol & $\begin{array}{c}\text { A2- } \\
\text { adendo }\end{array}$ & $\begin{array}{l}30 \mathrm{ml}(100 \\
\mathrm{mg} / \mathrm{ml})\end{array}$ & $2 \mathrm{ml} / \mathrm{dia}$ & 15 & 60 & -45 \\
\hline Pac0886 & fluoxetina & & fluoxetina & c1 & $30 \mathrm{cp}(20 \mathrm{mg})$ & $1 \mathrm{cp} / \mathrm{dia}$ & 30 & 60 & -30 \\
\hline Pac3760 & TRYPTANOL & Prodome & amitriptilina & $\mathrm{C1}$ & $40 \mathrm{cp}(25 \mathrm{mg})$ & $1 \mathrm{cp} / \mathrm{dia}$ & 40 & 60 & -20 \\
\hline Pac2500 & fenitoina & & \begin{tabular}{|l|}
$\begin{array}{l}\text { fenitoina } \\
\text { (hidantoina) }\end{array}$ \\
\end{tabular} & c1 & $90 \mathrm{cp}(100 \mathrm{mg})$ & $3 \mathrm{cp} / \mathrm{dia}$ & 30 & 60 & -30 \\
\hline Pac1911 & $\begin{array}{l}\text { DORLESS- } \\
\text { TRAMADOL } \\
\end{array}$ & União Quimica & tramadol & $\begin{array}{c}\text { A2- } \\
\text { adendo }\end{array}$ & $120 \mathrm{cp}(50 \mathrm{mg})$ & $4 \mathrm{cp} / \mathrm{dia}$ & 30 & 60 & -30 \\
\hline Pac3944 & gabapentina & & gabapentina & C1 & $90 \mathrm{cp}(300 \mathrm{mg})$ & $3 \mathrm{cp} / \mathrm{dia}$ & 30 & 60 & -30 \\
\hline Pac1938 & carbamazepina & & carbamazepina & C1 & $90 \mathrm{cp}(200 \mathrm{mg})$ & $3 \mathrm{cp} / \mathrm{dia}$ & 30 & 60 & -30 \\
\hline Pac3168 & \begin{tabular}{|l|} 
codeina; \\
paracetamol
\end{tabular} & & $\begin{array}{l}\text { codeina: } \\
\text { paracetamol }\end{array}$ & $\begin{array}{c}A 2- \\
\text { adendo }\end{array}$ & $40 \mathrm{cp}(30 \mathrm{mg})$ & $4 \mathrm{cp} / \mathrm{dia}$ & 10 & 60 & -50 \\
\hline Pac0208 & $\begin{array}{l}\text { DORLESS- } \\
\text { TRAMADOL }\end{array}$ & Uniāo Quimica & tramadol & $\begin{array}{c}A 2- \\
\text { adendo }\end{array}$ & $60 \mathrm{cp}(50 \mathrm{mg})$ & $4 \mathrm{cp} / \mathrm{dia}$ & 15 & 60 & -45 \\
\hline Pac0208 & emitriptilina & & amitriptiline & C1 & $40 \mathrm{cp}(25 \mathrm{mg})$ & $1 \mathrm{cp} / \mathrm{dia}$ & 40 & 60 & -20 \\
\hline Pac0511 & amitriptilina & & amitriptilina & $c 1$ & $100 \mathrm{cp}(25 \mathrm{mg})$ & $2 \mathrm{cp} / \mathrm{dia}$ & 50 & 60 & -10 \\
\hline Pac1952 & AAYTRIL & Cristália & amitriptilina & C1 & $40 \mathrm{cp}(25 \mathrm{mg})$ & $1 \mathrm{cp} / \mathrm{dia}$ & 40 & 60 & -20 \\
\hline Pac3167 & sertratina & & sertralina & C1 & $60 \mathrm{cp}(50 \mathrm{mg})$ & $2 \mathrm{cp} / \mathrm{dia}$ & 30 & 60 & -30 \\
\hline Pac3178 & $\begin{array}{l}\text { DORLESS- } \\
\text { TRAMADOL } \\
\end{array}$ & Uniāo Quimica & tramadol & $\begin{array}{c}A 2- \\
\text { adendo }\end{array}$ & $60 \mathrm{cp}(50 \mathrm{mg})$ & $2 \mathrm{cp} / \mathrm{dia}$ & 30 & 60 & -30 \\
\hline Pac1288 & TOPAMAX & Janssen-Cilag & topiramato & C1 & $150 \mathrm{cp}(100 \mathrm{mg})$ & $5 \mathrm{cp} / \mathrm{dia}$ & 30 & 60 & -30 \\
\hline Pac0080 & $\begin{array}{l}\text { DORLESS- } \\
\text { TRAMADOL }\end{array}$ & Uniāo Quimica & tramadol & $\begin{array}{c}\text { A2 - } \\
\text { adendo }\end{array}$ & $90 \mathrm{cp}(50 \mathrm{mg})$ & $3 \mathrm{cp} / \mathrm{dia}$ & 30 & 60 & -30 \\
\hline Pac0774 & fenobarbital & & fenobarbital & \begin{tabular}{|c|} 
B1 - \\
adendo
\end{tabular} & $60 \mathrm{cp}(100 \mathrm{mg})$ & $3 \mathrm{cp} / \mathrm{dia}$ & 20 & 60 & -40 \\
\hline Pac0774 & fenitolna & & \begin{tabular}{|l|} 
fenitoina \\
(hidantoina)
\end{tabular} & C1 & $160 \mathrm{cp}(100 \mathrm{mg})$ & $3 \mathrm{cp} / \mathrm{dia}$ & 53 & 60 & -7 \\
\hline Pac2755 & TOPAMAX & Janssen-Cilag & topiramato & C1 & $60 \mathrm{cp}(25 \mathrm{mg})$ & $3 \mathrm{cp} / \mathrm{dia}$ & 20 & 60 & -40 \\
\hline Pac1956 & RIVOTRIL & Roche & clonazepam & 81 & $30 \mathrm{cp}(2 \mathrm{mg})$ & $1 \mathrm{cp} / \mathrm{dia}$ & 30 & 60 & -30 \\
\hline Pac0207 & AMYTRIL & Cristália & amitriptilina & C1 & $120 \mathrm{cp}(25 \mathrm{mg})$ & $4 \mathrm{cp} / \mathrm{dia}$ & 30 & 60 & 30 \\
\hline $\mathrm{Pac0207}$ & LONGACTIL & Cristália & clorpromazina & C1 & $\begin{array}{l}20 \mathrm{ml}(0,4 \\
\mathrm{mg} / \mathrm{ml})\end{array}$ & $0,2 \mathrm{~m} / \mathrm{dia}$ & 100 & 60 & 40 \\
\hline Pac0867 & primidona & & primidona & C1 & $150 \mathrm{cp}(250 \mathrm{mg})$ & $5 \mathrm{cp} / \mathrm{dia}$ & 30 & 60 & -30 \\
\hline Pac0867 & fenobarbital & & fenoberbital & $\begin{array}{c}\text { B1 - } \\
\text { adendo }\end{array}$ & $120 \mathrm{cp}(100 \mathrm{mg})$ & $4 \mathrm{cp} / \mathrm{dia}$ & 30 & 60 & -30 \\
\hline Pac0867 & fenitoina & & \begin{tabular}{|l|} 
fenitoina \\
(hidantoina)
\end{tabular} & C1 & $60 \mathrm{cp}(100 \mathrm{mg})$ & $2 \mathrm{cp} / \mathrm{dia}$ & 30 & 60 & -30 \\
\hline Pac0867 & amitriptilina & & amiltriptilina & C1 & $120 \mathrm{cp}(25 \mathrm{mg})$ & $2 \mathrm{cp} / \mathrm{dia}$ & 60 & 60 & 0 \\
\hline Pac2079 & talidomida & & talidomida & C3 & $90 \mathrm{cp}(100 \mathrm{mg})$ & $3 \mathrm{cp} / \mathrm{dia}$ & 30 & 30 & 0 \\
\hline Pac2079 & cartamazepina & & carbarnazepina & C1 & $60 \mathrm{cp}(200 \mathrm{mg})$ & $2 \mathrm{cp} / \mathrm{dia}$ & 30 & 60 & -30 \\
\hline Pac2079 & AMVTRIL & Cristália & amitriptilina & C1 & $100 \mathrm{cp}(25 \mathrm{mg})$ & $3 \mathrm{cp} / \mathrm{dia}$ & 33 & 60 & -27 \\
\hline Pac2549 & fenitoina & & \begin{tabular}{|l|} 
fenitoina \\
(hidantoina)
\end{tabular} & c1 & $140 \mathrm{cp}(100 \mathrm{mg})$ & $3 \mathrm{cp} / \mathrm{dia}$ & 47 & 60 & -13 \\
\hline Pac0692 & $\begin{array}{l}\text { DORLESS- } \\
\text { TRAMADOL }\end{array}$ & Uniāo Química & tramadol & $\begin{array}{c}\text { A2- } \\
\text { adendo }\end{array}$ & $30 \mathrm{cp}(50 \mathrm{mg})$ & $3 \mathrm{cp} / \mathrm{dia}$ & 10 & 60 & -50 \\
\hline Pac1818 & $\begin{array}{l}\text { Codeina; } \\
\text { paracetamol }\end{array}$ & & \begin{tabular}{|l|} 
codeina; \\
paracetamol
\end{tabular} & $\begin{array}{c}\text { A2- } \\
\text { adendo }\end{array}$ & $60 \mathrm{cp}(30 \mathrm{mg})$ & $4 \mathrm{cp} / \mathrm{dia}$ & 15 & 60 & -45 \\
\hline Pac2076 & imipramina & & imipramina & C1 & $60 \mathrm{cp}(25 \mathrm{mg})$ & $2 \mathrm{cp} / \mathrm{dia}$ & 30 & 60 & -30 \\
\hline Pac3161 & AMYTRIL & Cristália & amitriptilina & C1 & $40 \mathrm{cp}(25 \mathrm{mg})$ & $1 \mathrm{cp} / \mathrm{dia}$ & 40 & 60 & -20 \\
\hline Pac3992 & AMYTRIL & Cristália & amitriptilina & C1 & $40 \mathrm{cp}(25 \mathrm{mg})$ & $1 \mathrm{cp} / \mathrm{dia}$ & 40 & 60 & -20 \\
\hline Pac3992 & fenitoina & & \begin{tabular}{|l|} 
fenitoina \\
(hidantoina)
\end{tabular} & C1 & $100 \mathrm{cp}(100 \mathrm{mg})$ & $3 \mathrm{cp} / \mathrm{dia}$ & 33 & 60 & -27 \\
\hline Pac3120 & LONGACTIL & Cristália & clorpromazina & C1 & $\begin{array}{l}40 \mathrm{ml}(0,4 \\
\mathrm{mg} / \mathrm{ml})\end{array}$ & $0,8 \mathrm{~m} / \mathrm{dia}$ & 50 & 60 & -10 \\
\hline Pac3120 & TRAMAL & \begin{tabular}{|l|} 
Prizer- \\
Pharmacia
\end{tabular} & tramadol & $\begin{array}{c}\text { A2 - } \\
\text { adendo }\end{array}$ & $90 \mathrm{cp}(50 \mathrm{mg})$ & $3 \mathrm{cp} / \mathrm{dia}$ & 30 & 60 & -30 \\
\hline Pac0885 & sertralina & & sertratina & C1 & $30 \mathrm{cp}(50 \mathrm{mg})$ & $1 \mathrm{cp} / \mathrm{dia}$ & 30 & 60 & -30 \\
\hline
\end{tabular}


DT $=$ Dias de tratamento fornecido $\quad L L=$ Limite legal

\begin{tabular}{|c|c|c|c|c|c|c|c|c|c|}
\hline $\begin{array}{l}\text { código } \\
\text { paciente }\end{array}$ & Prescrição & Indústria & Principio Ativo & Alínea & Fornecimento & Posologia & DT & LL & DT - LL \\
\hline Pac0762 & TRAMAL & $\begin{array}{l}\text { Pfizer* } \\
\text { Pharmacia }\end{array}$ & tramadol & \begin{tabular}{|c|}
$\begin{array}{c}\text { A2 - } \\
\text { adendo }\end{array}$ \\
\end{tabular} & $30 \mathrm{cp}$ (50 mg) & $3 \mathrm{cp} / \mathrm{dia}$ & 10 & 60 & -50 \\
\hline Pac4040 & carbamazepina & & carbamazepina & C1 & $210 \mathrm{cp}(200 \mathrm{mg})$ & $7 \mathrm{cp} / \mathrm{dia}$ & 30 & 60 & -30 \\
\hline Pac4040 & clobazam & & clobazam & B1 & $60 \mathrm{cp}(10 \mathrm{mg})$ & $2 \mathrm{cp} / \mathrm{dia}$ & 30 & 60 & -30 \\
\hline Pac2941 & carbamazepina & & carbamazepina & C1 & $60 \mathrm{cp}(200 \mathrm{mg})$ & $2 \mathrm{cp} / \mathrm{dia}$ & 30 & 60 & -30 \\
\hline Pac2941 & AMYTRIL & Cristália & amitriptilina & C1 & $120 \mathrm{cp}(25 \mathrm{mg})$ & $3 \mathrm{cp} / \mathrm{dia}$ & 40 & 60 & -20 \\
\hline Pac2941 & LONGACTIL & Cristália & clorpromazina & C1 & $\begin{array}{l}40 \mathrm{ml}(0,4 \\
\mathrm{mg} / \mathrm{ml})\end{array}$ & $0,5 \mathrm{ml} / \mathrm{dia}$ & 80 & 60 & 20 \\
\hline Pac1671 & LONGACTIL & Cristalla & clorpromazina & C1 & \begin{tabular}{|l|}
$20 \mathrm{ml}(0,4$ \\
$\mathrm{mg} / \mathrm{ml})$
\end{tabular} & $0,5 \mathrm{ml} / \mathrm{dia}$ & 40 & 60 & -20 \\
\hline Pac0272 & carbamazepina & & carbamazepina & C1 & $90 \mathrm{cp}(200 \mathrm{mg})$ & $3 \mathrm{cp} / \mathrm{dia}$ & 30 & 60 & -30 \\
\hline Pac0272 & AMVTRIL & Cristália & amitriptilina & C1 & $40 \mathrm{cp}(25 \mathrm{mg})$ & $1 \mathrm{cp} / \mathrm{dia}$ & 40 & 60 & -20 \\
\hline Pac0665 & carbamazepina & & carbamazepina & C1 & $28 \mathrm{cp} \mathrm{(200} \mathrm{mg)}$ & $0,5 \mathrm{cp} / \mathrm{dia}$ & 56 & 60 & -4 \\
\hline Pac2395 & AMVTRIL & Cristallia & amitriptilina & C1 & $40 \mathrm{cp}(25 \mathrm{mg})$ & $1 \mathrm{cp} / \mathrm{dia}$ & 40 & 60 & -20 \\
\hline Pac2759 & fluoxetina & & fluoxetina & C1 & $30 \mathrm{cp}(20 \mathrm{mg})$ & $1 \mathrm{cp} / \mathrm{dia}$ & 30 & 60 & -30 \\
\hline Pac2702 & amitriptilina & & amitriptilina & C1 & $20 \mathrm{cp}(25 \mathrm{mg})$ & $0,5 \mathrm{cp} / \mathrm{dia}$ & 40 & 60 & -20 \\
\hline Pac2447 & sertralina & & sertralina & C1 & $90 \mathrm{cp}(50 \mathrm{mg})$ & $3 \mathrm{cp} / \mathrm{dia}$ & 30 & 60 & -30 \\
\hline Pac2276 & amitriptilina & & amitriptilina & C1 & $40 \mathrm{cp}(25 \mathrm{mg})$ & $1 \mathrm{cp} / \mathrm{dia}$ & 40 & 60 & -20 \\
\hline Pac2872 & $\begin{array}{l}\text { DORLESS- } \\
\text { TRAMADOL } \\
\end{array}$ & Uniāo Quimica & tramadol & \begin{tabular}{|c|} 
A2 - \\
adendo
\end{tabular} & $90 \mathrm{cp}(50 \mathrm{mg})$ & $3 \mathrm{cp} / \mathrm{dia}$ & 30 & 60 & -30 \\
\hline Pac1397 & amitriptilina & & amitriptitina & $c_{1}$ & $60 \mathrm{cp}(25 \mathrm{mg})$ & $2 \mathrm{cp} / \mathrm{dia}$ & 30 & 60 & -30 \\
\hline Pac0546 & imipramina & & imipramina & C1 & $240 \mathrm{cp}(25 \mathrm{mg})$ & $8 \mathrm{cp} / \mathrm{dia}$ & 30 & 60 & -30 \\
\hline Pac3979 & \begin{tabular}{|l|} 
codeina: \\
paracetamol
\end{tabular} & & $\begin{array}{l}\text { codeina; } \\
\text { paracetamol }\end{array}$ & \begin{tabular}{|c|}
$\begin{array}{c}\mathrm{A} \text { - } \\
\text { adendo }\end{array}$ \\
\end{tabular} & $10 \mathrm{cp}(30 \mathrm{mg})$ & $3 \mathrm{cp} / \mathrm{dia}$ & 3 & 60 & -57 \\
\hline Pac2271 & RISPERDAL & Janssen-Cilag & risperidona & C1 & $30 \mathrm{ml}(1 \mathrm{mg})$ & $2 \mathrm{~m}$ /dia & 15 & 60 & -45 \\
\hline Pac2271 & NEULEPTIL & Aventis & periciazina & c1 & $\begin{array}{l}20 \mathrm{ml}(0,4 \\
\mathrm{mg} / \mathrm{ml})\end{array}$ & $0,15 \mathrm{~m} / \mathrm{dia}$ & 133 & 60 & 73 \\
\hline Pac3673 & AMYTRIL & Cristália & amitriptilina & C1 & $60 \mathrm{cp}(25 \mathrm{mg})$ & $1 \mathrm{cp} / \mathrm{dia}$ & 60 & 60 & 0 \\
\hline Pac0195 & TEGRETOL & Novartis & carbamazepina & C1 & $200 \mathrm{cp}(200 \mathrm{mg})$ & $4 \mathrm{cp} / \mathrm{dia}$ & 50 & 60 & -10 \\
\hline Pac1796 & imipramina & & imipramina & C1 & $90 \mathrm{cp}(25 \mathrm{mg})$ & $3 \mathrm{cp} / \mathrm{dia}$ & 30 & 60 & .30 \\
\hline Pac2233 & PROLOPA HBS & Roche & $\begin{array}{l}\text { levodopa e } \\
\text { benserazida }\end{array}$ & C1 & $120 \mathrm{cp}(120 \mathrm{mg})$ & $4 \mathrm{cp} / \mathrm{dia}$ & 30 & 60 & -30 \\
\hline Pac2233 & $\begin{array}{l}\text { lovodopa } \theta \\
\text { benserazida }\end{array}$ & & $\begin{array}{l}\text { levodopa o } \\
\text { benserazida }\end{array}$ & C1 & $\begin{array}{l}10 \mathrm{cp}(200 / 50 \\
\mathrm{mg})\end{array}$ & $0,25 \mathrm{cp} / \mathrm{dia}$ & 40 & 60 & -20 \\
\hline Pac1806 & $\begin{array}{l}\text { DORLESS- } \\
\text { TRAMADOL } \\
\end{array}$ & Uniăo Química & tramadol & $\begin{array}{c}\text { A2 - } \\
\text { adendo }\end{array}$ & $30 \mathrm{cp}(50 \mathrm{mg})$ & $3 \mathrm{cp} / \mathrm{dia}$ & 10 & 60 & -50 \\
\hline Pac1478 & $\begin{array}{l}\text { codeina: } \\
\text { paracetamol }\end{array}$ & & $\begin{array}{l}\text { codeina: } \\
\text { paracetamol }\end{array}$ & $\begin{array}{c}A 2- \\
\text { adendo }\end{array}$ & $30 \mathrm{cp}(30 \mathrm{mg})$ & $3 \mathrm{cp} / \mathrm{dia}$ & 10 & 60 & -50 \\
\hline Pac2782 & sertralina & & sertralina & c1 & $30 \mathrm{cp}(50 \mathrm{mg})$ & $1 \mathrm{cp} / \mathrm{dia}$ & 30 & 60 & .30 \\
\hline Pac2635 & TRAMAL & $\begin{array}{l}\text { Pfizer- } \\
\text { Pharmacia }\end{array}$ & tramadol & \begin{tabular}{|c|}
$\begin{array}{c}A 2- \\
\text { adendo }\end{array}$ \\
\end{tabular} & $30 \mathrm{cp}(50 \mathrm{mg})$ & $3 \mathrm{cp} / \mathrm{dia}$ & 10 & 60 & -50 \\
\hline Pac2635 & AMYTRIL & Cristália & amitriptilina & C1 & $20 \mathrm{cp}(25 \mathrm{mg})$ & $3 \mathrm{cp} / \mathrm{dia}$ & 7 & 60 & -53 \\
\hline Pac3175 & TRAMAL & $\begin{array}{l}\text { Prizer- } \\
\text { Pharmacia }\end{array}$ & tramadol & $\begin{array}{c}\text { A2 - } \\
\text { adendo }\end{array}$ & $120 \mathrm{cp}(50 \mathrm{mg})$ & $4 \mathrm{cp} / \mathrm{dia}$ & 30 & 60 & -30 \\
\hline Pac1589 & AMYTRIL & Cristália & amitriptilina & $\mathrm{C1}$ & $60 \mathrm{cp}(25 \mathrm{mg})$ & $1 \mathrm{cp} / \mathrm{dia}$ & 60 & 60 & 0 \\
\hline Pac2112 & carbamazepina & & carbamazepina & $C_{1}$ & $90 \mathrm{cp}(200 \mathrm{mg})$ & $1 \mathrm{cp} / \mathrm{dia}$ & 90 & 60 & 30 \\
\hline Pac2112 & DEPAKENE & Abbott & $\begin{array}{l}\text { ácido valpróico } \\
\text { (ou derivado) }\end{array}$ & c1 & $100 \mathrm{cp}(500 \mathrm{mg})$ & $2 \mathrm{cp} / \mathrm{dia}$ & 50 & 60 & -10 \\
\hline Pac1346 & imipramina & & imipramina & $c_{1}$ & $60 \mathrm{cp}(25 \mathrm{mg})$ & $2 \mathrm{cp} / \mathrm{dia}$ & 30 & 60 & 30 \\
\hline Pac3257 & \begin{tabular}{|l} 
codeina; \\
paracetarnol
\end{tabular} & & $\begin{array}{l}\text { codeina; } \\
\text { paracetamol }\end{array}$ & $\begin{array}{c}\text { A2 - } \\
\text { adendo }\end{array}$ & $120 \mathrm{cp}(30 \mathrm{mg})$ & $4 \mathrm{cp} / \mathrm{dia}$ & 30 & 60 & -30 \\
\hline Pac3314 & PROLOPA & Roche & $\begin{array}{l}\text { levodopa e } \\
\text { benserazida }\end{array}$ & C1 & $150 \mathrm{cp}(250 \mathrm{mg})$ & $5 \mathrm{cp} / \mathrm{dia}$ & 30 & 60 & -30 \\
\hline Pac3314 & imipramina & & imipramina & c1 & $60 \mathrm{cp}(25 \mathrm{mg})$ & $2 \mathrm{cp} / \mathrm{dia}$ & 30 & 60 & -30 \\
\hline Pac2521 & \begin{tabular}{|l} 
codeina; \\
paracetamol
\end{tabular} & & $\begin{array}{l}\text { codeina: } \\
\text { paracotamol }\end{array}$ & \begin{tabular}{|c|}
$\begin{array}{c}\text { A2 - } \\
\text { adendo }\end{array}$ \\
\end{tabular} & $30 \mathrm{cp}(30 \mathrm{mg})$ & $3 \mathrm{cp} / \mathrm{dia}$ & 10 & 60 & -50 \\
\hline Pac1222 & AMVTRIL & Cristália & amitriptilina & C1 & $60 \mathrm{cp}(25 \mathrm{mg})$ & $2 \mathrm{cp} / \mathrm{dia}$ & 30 & 60 & -30 \\
\hline Pac0828 & $\begin{array}{l}\text { DORLESS- } \\
\text { TRAMADOL }\end{array}$ & Uniảo Quimica & tramadol & \begin{tabular}{|c|} 
A2 - \\
adendo
\end{tabular} & $30 \mathrm{cp}(50 \mathrm{mg})$ & $4 \mathrm{cp} / \mathrm{dia}$ & 8 & 60 & -53 \\
\hline
\end{tabular}


DT = Dias de tratamento fornecido $\quad L L=$ Limite legal

\begin{tabular}{|c|c|c|c|c|c|c|c|c|c|}
\hline $\begin{array}{l}\text { código } \\
\text { paciente }\end{array}$ & Prescrição & Indústria & Principio Ativo & Alinea & Fornecimento & Posologia & DT & LL & DT - LL \\
\hline Pac1938 & $\begin{array}{l}\text { DORLESS- } \\
\text { TRAMADOL }\end{array}$ & Uniåo Química & tramadol & $\begin{array}{c}A 2- \\
\text { adendo }\end{array}$ & $60 \mathrm{cp}(50 \mathrm{mg})$ & $4 \mathrm{cp} / \mathrm{dia}$ & 15 & 60 & -45 \\
\hline Pac1938 & AMYTRIL & Cristália & amitriptilina & C1 & $40 \mathrm{cp}(25 \mathrm{mg})$ & $1 \mathrm{cp} / \mathrm{dia}$ & 40 & 60 & -20 \\
\hline Pac2943 & $\begin{array}{l}\text { codeina: } \\
\text { paracetamol }\end{array}$ & & \begin{tabular}{|l|} 
codeina; \\
paracetamol
\end{tabular} & $\begin{array}{c}\text { A2 - } \\
\text { adendo }\end{array}$ & $30 \mathrm{cp}(30 \mathrm{mg})$ & $3 \mathrm{cp} / \mathrm{dia}$ & 10 & 60 & -50 \\
\hline Pac2157 & $\begin{array}{l}\text { DORLESS- } \\
\text { TRAMADOL }\end{array}$ & União Quimica & tramadol & $\begin{array}{c}\text { A2 - } \\
\text { adendo }\end{array}$ & $30 \mathrm{cp}(50 \mathrm{mg})$ & $3 \mathrm{cp} / \mathrm{dia}$ & 10 & 60 & -50 \\
\hline Pac2505 & AMYTRIL & Cristália & amitriptilina & C1 & $40 \mathrm{cp}(25 \mathrm{mg})$ & $1 \mathrm{cp} / \mathrm{dia}$ & 40 & 60 & -20 \\
\hline Pac2855 & AMYTRIL & Cristália & amitriptilina & C1 & $40 \mathrm{cp}(25 \mathrm{mg})$ & $1 \mathrm{cp} / \mathrm{dia}$ & 40 & 60 & -20 \\
\hline Pac1142 & AMYTRIL & Cristália & amitriptilina & $\mathrm{C1}$ & $120 \mathrm{cp}(25 \mathrm{mg})$ & $4 \mathrm{cp} / \mathrm{dia}$ & 30 & 60 & -30 \\
\hline Pac1083 & \begin{tabular}{|l|} 
codeina: \\
paracetamol
\end{tabular} & & $\begin{array}{l}\begin{array}{l}\text { codeina; } \\
\text { paracetamol }\end{array} \\
\end{array}$ & \begin{tabular}{|c|}
$\begin{array}{c}\text { A2 - } \\
\text { adendo }\end{array}$ \\
\end{tabular} & $40 \mathrm{cp}(30 \mathrm{mg})$ & $1 \mathrm{cp} / \mathrm{dia}$ & 40 & 60 & -20 \\
\hline Pac2169 & PROGRESSE & Biosintética & gabapentina & C1 & $30 \mathrm{cp}(300 \mathrm{mg})$ & $3 \mathrm{cp} / \mathrm{dia}$ & 10 & 60 & -50 \\
\hline Pac0408 & PROZAC & Eli Lilly & fluoxetina & C1 & $30 \mathrm{cp}(20 \mathrm{mg})$ & $1 \mathrm{cp} / \mathrm{dia}$ & 30 & 60 & -30 \\
\hline Pac2233 & selegilina & & selegilina & C1 & $40 \mathrm{cp}(5 \mathrm{mg})$ & $1 \mathrm{cp} / \mathrm{dia}$ & 40 & 60 & -20 \\
\hline Pac2233 & CINETOL & Cristália & biperideno & C1 & $30 \mathrm{cp}(2 \mathrm{mg})$ & $1 \mathrm{cp} / \mathrm{dia}$ & 30 & 60 & -30 \\
\hline Pac3627 & imipramina & & imipramina & C1 & $50 \mathrm{cp}(25 \mathrm{mg})$ & $1 \mathrm{cp} / \mathrm{dja}$ & 50 & 60 & -10 \\
\hline Pac3627 & PROGRESSE & Biosintética & gabapentina & C1 & $240 \mathrm{cp}(300 \mathrm{mg})$ & $6 \mathrm{cp} / \mathrm{dia}$ & 40 & 60 & -20 \\
\hline Pac0365 & imipramina & & imipramina & C1 & $140 \mathrm{cp}(25 \mathrm{mg})$ & $2 \mathrm{cp} / \mathrm{dia}$ & 70 & 60 & 10 \\
\hline Pac0365 & carbamazepina & & carbamazepina & c1 & $460 \mathrm{cp}(200 \mathrm{mg})$ & $6 \mathrm{cp} / \mathrm{dia}$ & 77 & 60 & 17 \\
\hline $\operatorname{Pac} 2602$ & AMYTRIL & Cristália & amitriptilina & C1 & $100 \mathrm{cp}(25 \mathrm{mg})$ & $3 \mathrm{cp} / \mathrm{dia}$ & 33 & 60 & -27 \\
\hline Pac2602 & LONGACTIL & Cristália & clorpromazina & C1 & $\begin{array}{l}20 \mathrm{ml}(0,4 \\
\mathrm{mg} / \mathrm{ml})\end{array}$ & $0,4 \mathrm{~m} / \mathrm{dia}$ & 50 & 60 & -10 \\
\hline Pac0038 & AMYTRIL & Cristália & amitriptilina & C1 & $20 \mathrm{cp}(25 \mathrm{mg})$ & $1 \mathrm{cp} / \mathrm{dia}$ & 20 & 60 & -40 \\
\hline Pac1015 & gabapentina & & gabapentina & C1 & $90 \mathrm{cp}(400 \mathrm{mg})$ & $3 \mathrm{cp} / \mathrm{dia}$ & 30 & 60 & -30 \\
\hline Pac1015 & AMYTRIL & Cristália & amitriptilina & $c_{1}$ & $180 \mathrm{cp}(25 \mathrm{mg})$ & $6 \mathrm{cp} / \mathrm{dia}$ & 30 & 60 & -30 \\
\hline Pac1015 & AMPLICTIL & Aventis & clorpromazina & C1 & $120 \mathrm{cp}(25 \mathrm{mg})$ & $4 \mathrm{cp} / \mathrm{dia}$ & 30 & 60 & -30 \\
\hline Pac1767 & AMYTRIL & Cristália & amitriptilina & C1 & $40 \mathrm{cp}(25 \mathrm{mg})$ & $1 \mathrm{cp} / \mathrm{dia}$ & 40 & 60 & -20 \\
\hline Pac2084 & tramadol & & tramadol & $\begin{array}{c}\mathrm{A2} \text { - } \\
\text { adendo }\end{array}$ & $60 \mathrm{cp}(50 \mathrm{mg})$ & $2 \mathrm{cp} / \mathrm{dia}$ & 30 & 60 & -30 \\
\hline Pac2178 & fenitoina & & $\begin{array}{l}\begin{array}{l}\text { fenitoina } \\
\text { (hidantoina) }\end{array} \\
\end{array}$ & C1 & $90 \mathrm{cp}(100 \mathrm{mg})$ & $3 \mathrm{cp} / \mathrm{dia}$ & 30 & 60 & 30 \\
\hline Pac2178 & fenobarbital & & fenobarbital & $\begin{array}{c}\mathrm{Bi}- \\
\text { adendo }\end{array}$ & $40 \mathrm{cp}(100 \mathrm{mg})$ & $1 \mathrm{cp} / \mathrm{dia}$ & 40 & 60 & -20 \\
\hline Pac0830 & \begin{tabular}{|l} 
codeina; \\
paracetamol
\end{tabular} & & $\begin{array}{l}\text { codeina; } \\
\text { paracetamol }\end{array}$ & $\begin{array}{c}\text { A2 - } \\
\text { adendo }\end{array}$ & $120 \mathrm{cp}(30 \mathrm{mg})$ & $4 \mathrm{cp} / \mathrm{dia}$ & 30 & 60 & -30 \\
\hline Pac3297 & amitriptilina & & amitriptilina & C1 & $40 \mathrm{cp}(25 \mathrm{mg})$ & $1 \mathrm{cp} / \mathrm{dia}$ & 40 & 60 & -20 \\
\hline Pac0874 & fenitoina & & \begin{tabular}{|l}
$\begin{array}{l}\text { fenitoina } \\
\text { (hidantoina) }\end{array}$ \\
\end{tabular} & C1 & $100 \mathrm{cp}(100 \mathrm{mg})$ & $3 \mathrm{cp} / \mathrm{dia}$ & 33 & 60 & .27 \\
\hline Pac1700 & DEPAKENE & Abbott & \begin{tabular}{|l|}
$\begin{array}{l}\text { ácido valpróico } \\
\text { (ou derivado) }\end{array}$ \\
\end{tabular} & c1 & $200 \mathrm{cp}(250 \mathrm{mg})$ & $6 \mathrm{cp} / \mathrm{dia}$ & 33 & 60 & -27 \\
\hline Pac1700 & fenitoina & & \begin{tabular}{|l|} 
fenitoina \\
(hidantoina)
\end{tabular} & C1 & $60 \mathrm{cp}(100 \mathrm{mg})$ & $2 \mathrm{cp} / \mathrm{dia}$ & 30 & 60 & -30 \\
\hline Pac2953 & fenitoina & & \begin{tabular}{|l|}
$\begin{array}{l}\text { fenitoina } \\
\text { (hidantoina) }\end{array}$ \\
\end{tabular} & C1 & $90 \mathrm{cp}(100 \mathrm{mg})$ & $3 \mathrm{cp} / \mathrm{dia}$ & 30 & 60 & -30 \\
\hline Pac2953 & AMYTRIL & Cristália & amitriptilina & C1 & $60 \mathrm{cp}(25 \mathrm{mg})$ & $2 \mathrm{cp} / \mathrm{dia}$ & 30 & 60 & -30 \\
\hline Pac2953 & carbamazepina & & carbamazepina & c1 & $90 \mathrm{cp}$ (200 mg) & $3 \mathrm{cp} / \mathrm{dia}$ & 30 & 60 & -30 \\
\hline Pac0834 & AMYTRIL & Cristalia & amitriptilina & C1 & $40 \mathrm{cp}(25 \mathrm{mg})$ & $1 \mathrm{cp} / \mathrm{dia}$ & 40 & 60 & -20 \\
\hline Pac3168 & tramadol & & tramadol & $\begin{array}{c}\text { A2 - } \\
\text { adendo }\end{array}$ & $160 \mathrm{cp}(50 \mathrm{mg})$ & $4 \mathrm{cp} / \mathrm{dia}$ & 40 & 60 & -20 \\
\hline Pac3168 & LONGACTIL & Cristália & clorpromazina & C1 & $\begin{array}{l}40 \mathrm{ml}(0,4 \\
\mathrm{mg} / \mathrm{ml})\end{array}$ & 1,2 mudia & 33 & 60 & -27 \\
\hline Pac3168 & imipramina & & imipramina & C1 & $50 \mathrm{cp}(25 \mathrm{mg})$ & $1 \mathrm{cp} / \mathrm{dia}$ & 50 & 60 & -10 \\
\hline Pac2110 & sertralina & & sertralina & C1 & $30 \mathrm{cp}(50 \mathrm{mg})$ & $1 \mathrm{cp} / \mathrm{dia}$ & 30 & 60 & -30 \\
\hline Pac2110 & PROLOPA & Roche & $\begin{array}{l}\text { levodopa e } \\
\text { benserazida }\end{array}$ & c1 & $60 \mathrm{cp}(250 \mathrm{mg})$ & $3 \mathrm{cp} / \mathrm{dia}$ & 20 & 60 & -40 \\
\hline Pac0955 & \begin{tabular}{|l|} 
codeina; \\
paracotamol
\end{tabular} & & \begin{tabular}{|l} 
Godeina; \\
paracetamol
\end{tabular} & $\begin{array}{c}\text { A2:- } \\
\text { adendo }\end{array}$ & $90 \mathrm{cp}(30 \mathrm{mg})$ & $3 \mathrm{cp} / \mathrm{dia}$ & 30 & 60 & -30 \\
\hline Pac0955 & AMYTRIL & Cristália & amitriptilina & C1 & $100 \mathrm{cp}(25 \mathrm{mg})$ & $3 \mathrm{cp} / \mathrm{dia}$ & 33 & 60 & -27 \\
\hline
\end{tabular}


$D T=$ Dias de tratamento fornecido $\quad L L=$ Limite legal

\begin{tabular}{|c|c|c|c|c|c|c|c|c|c|}
\hline $\begin{array}{l}\text { código } \\
\text { paciente }\end{array}$ & Prescrição & Indústria & Principio Ativo & Alínea & Fornecimento & Posologia & DT & LL. & DT - LL \\
\hline Pac1642 & fenobarbital & & fenobarbital & \begin{tabular}{|c|}
$\mathrm{B1}-$ \\
adendo
\end{tabular} & $60 \mathrm{cp}$ (100 mg) & 1,5 cp/dia & 40 & 60 & -20 \\
\hline Pac3563 & TRAMAL & $\begin{array}{l}\text { Pfizer- } \\
\text { Pharmacia }\end{array}$ & tramadol & \begin{tabular}{|c|}
$\mathrm{A} 2-$ \\
adendo
\end{tabular} & $120 \mathrm{cp}(50 \mathrm{mg})$ & $4 \mathrm{cp} / \mathrm{dia}$ & 30 & 60 & -30 \\
\hline Pac0827 & $\begin{array}{l}\text { codeina; } \\
\text { paracetamol }\end{array}$ & & $\begin{array}{l}\text { codeina; } \\
\text { paracetamol }\end{array}$ & $\begin{array}{c}\text { A2 - } \\
\text { adendo }\end{array}$ & $120 \mathrm{cp}(30 \mathrm{mg})$ & $4 \mathrm{cp} / \mathrm{dia}$ & 30 & 60 & -30 \\
\hline Pac0245 & PROLOPA & Roche & \begin{tabular}{|l|} 
levodopa $\mathbf{e}$ \\
benserazida
\end{tabular} & c1 & $60 \mathrm{cp} \mathrm{(125} \mathrm{mg)}$ & $1 \mathrm{cp} / \mathrm{dia}$ & 60 & 60 & 0 \\
\hline Pac0245 & RIVOTRIL & Roche & clonazepam & 81 & $90 \mathrm{cp}(2 \mathrm{mg})$ & $3 \mathrm{cp} / \mathrm{dia}$ & 30 & 60 & -30 \\
\hline Pac3608 & DEPAKENE & Abbott & \begin{tabular}{|l|}
$\begin{array}{l}\text { acido valpróico } \\
\text { (ou derivado) }\end{array}$ \\
\end{tabular} & $\mathrm{Cl}$ & $100 \mathrm{cp}(250 \mathrm{mg})$ & $3 \mathrm{cp} / \mathrm{dia}$ & 33 & 60 & -27 \\
\hline Pac3853 & carbamazepina & & carbamazepina & c1 & $120 \mathrm{cp}(200 \mathrm{mg})$ & $4 \mathrm{cp} / \mathrm{dia}$ & 30 & 60 & -30 \\
\hline Pac3674 & sertralina & & sertralina & C1 & $30 \mathrm{cp}(20 \mathrm{mg})$ & 1 cpidia & 30 & 60 & -30 \\
\hline Pac0194 & fluoxetina & & fluoxetina & C1 & $40 \mathrm{cp}(20 \mathrm{mg})$ & $1 \mathrm{cp} / \mathrm{dia}$ & 40 & 60 & -20 \\
\hline Pac0763 & $\begin{array}{l}\text { codeina; } \\
\text { paracetamol }\end{array}$ & & \begin{tabular}{|l} 
codeina; \\
paracetamol
\end{tabular} & \begin{tabular}{|c|}
$\begin{array}{c}A 2- \\
\text { adendo }\end{array}$ \\
\end{tabular} & $90 \mathrm{cp}(30 \mathrm{mg})$ & $3 \mathrm{cp} / \mathrm{dia}$ & 30 & 60 & -30 \\
\hline Pac1238 & \begin{tabular}{|l|} 
codeina; \\
paracetamol
\end{tabular} & & $\begin{array}{l}\text { codeína; } \\
\text { paracetamol }\end{array}$ & \begin{tabular}{|c|}
$\begin{array}{c}A 2- \\
\text { adendo }\end{array}$ \\
\end{tabular} & $120 \mathrm{cp}$ (30 mg) & $4 \mathrm{cp} / \mathrm{dia}$ & 30 & 60 & -30 \\
\hline Pac0894 & carbamazepina & & carbamazepina & C1 & $150 \mathrm{cp}(200 \mathrm{mg})$ & $5 \mathrm{cp} / \mathrm{dia}$ & 30 & 60 & -30 \\
\hline Pac1064 & carbamazepina & & carbamazepina & c1 & $150 \mathrm{cp}(200 \mathrm{mg})$ & $5 \mathrm{cp} / \mathrm{dia}$ & 30 & 60 & -30 \\
\hline Pac2199 & carbamazepina & & carbamazepina & C1 & $60 \mathrm{cp}(200 \mathrm{mg})$ & $2 \mathrm{cp} / \mathrm{dia}$ & 30 & 60 & -30 \\
\hline Pac3529 & $\begin{array}{l}\text { codeina; } \\
\text { paracetamol }\end{array}$ & & \begin{tabular}{|l} 
codeina; \\
paracetamol
\end{tabular} & \begin{tabular}{|c|} 
A2 - \\
adendo
\end{tabular} & $120 \mathrm{cp}(30 \mathrm{mg})$ & $4 \mathrm{cp} / \mathrm{dia}$ & 30 & 60 & -30 \\
\hline Pac2758 & amitriptilina & & amitriptilina & C1 & $40 \mathrm{cp}(25 \mathrm{mg})$ & $1 \mathrm{cp} / \mathrm{dia}$ & 40 & 60 & -20 \\
\hline Pac00007 & amitriptilina & & amitriptilina & C1 & $60 \mathrm{cp}(25 \mathrm{mg})$ & $2 \mathrm{cp} / \mathrm{dia}$ & 30 & 60 & -30 \\
\hline Pac1944 & amitriptilina & & amitriptilina & C1 & $40 \mathrm{cp}(25 \mathrm{mg})$ & $1 \mathrm{cp} / \mathrm{dia}$ & 40 & 60 & -20 \\
\hline Pac1328 & fenitoina & & $\begin{array}{l}\text { fenitoina } \\
\text { (hidantoina) }\end{array}$ & C1 & $160 \mathrm{cp}(100 \mathrm{mg})$ & $3 \mathrm{cp} / \mathrm{dia}$ & 53 & 60 & -7 \\
\hline Pac4015 & amitriptilina & & amitriptilina & C1 & $120 \mathrm{cp}(25 \mathrm{mg})$ & $4 \mathrm{cp} / \mathrm{dia}$ & 30 & 60 & -30 \\
\hline Pac4015 & clorpromazina & & clorpromazina & C1 & $\begin{array}{l}40 \mathrm{ml}(0,4 \\
\mathrm{mg} / \mathrm{ml})\end{array}$ & $0,8 \mathrm{mi} / \mathrm{dia}$ & 50 & 60 & -10 \\
\hline Pac3092 & fluoxetina & & fluoxetina & C1 & $60 \mathrm{cp}(20 \mathrm{mg})$ & $2 \mathrm{cp} / \mathrm{dia}$ & 30 & 60 & -30 \\
\hline Pac0662 & PONDERA & Eurofarma & paroxetina & C1 & $60 \mathrm{cp}(20 \mathrm{mg})$ & $2 \mathrm{cp} / \mathrm{dia}$ & 30 & 60 & -30 \\
\hline Pac3576 & bromazepam & & bromazepam & B1 & $30 \mathrm{cp}(3 \mathrm{mg})$ & $1 \mathrm{cp} / \mathrm{dia}$ & 30 & 60 & -30 \\
\hline Pac2404 & AMYTRIL & Cristália & amitriptilina & C1 & $60 \mathrm{cp}(25 \mathrm{mg})$ & $2 \mathrm{cp} / \mathrm{dia}$ & 30 & 60 & -30 \\
\hline Pac1691 & AMYTRIL & Cristália & amitriptilina & C1 & $100 \mathrm{cp}(25 \mathrm{mg})$ & $3 \mathrm{cp} / \mathrm{dia}$ & 33 & 60 & -27 \\
\hline Pac1691 & LONGACTIL & Cristalia & clorpromazina & C1 & \begin{tabular}{|l|}
$40 \mathrm{ml}(0,4$ \\
$\mathrm{mg} / \mathrm{ml})$
\end{tabular} & $1 \mathrm{~m} / \mathrm{dia}$ & 40 & 60 & -20 \\
\hline Pac1289 & fenitoina & & \begin{tabular}{|l|}
$\begin{array}{l}\text { fenitoina } \\
\text { (hidantoina) }\end{array}$ \\
\end{tabular} & C1 & $100 \mathrm{cp}(100 \mathrm{mg})$ & $3 \mathrm{cp} / \mathrm{dia}$ & 33 & 60 & -27 \\
\hline Pac0781 & fenitoina & & \begin{tabular}{|l|}
$\begin{array}{l}\text { fenitoina } \\
\text { (hidantoina) }\end{array}$ \\
\end{tabular} & C1 & $90 \mathrm{cp}(100 \mathrm{mg})$ & 3 cp/dia & 30 & 60 & -30 \\
\hline Pac0781 & fenobarbital & & fenobarbital & $\begin{array}{c}\text { B1 - } \\
\text { adendo }\end{array}$ & $40 \mathrm{cp}(100 \mathrm{mg})$ & $1 \mathrm{cp} / \mathrm{dia}$ & 40 & 60 & -20 \\
\hline Pac3017 & imipramina & & imipramina & C1 & $80 \mathrm{cp}(25 \mathrm{mg})$ & $3 \mathrm{cp} / \mathrm{dia}$ & 27 & 60 & 33 \\
\hline Pac3168 & AMYTRIL & Cristália & amitriptilina & C1 & $40 \mathrm{cp}(25 \mathrm{mg})$ & $1 \mathrm{cp} / \mathrm{dia}$ & 40 & 60 & -20 \\
\hline Pac3168 & LONGACTIL & Cristália & clorpromazina & C1 & $\begin{array}{l}20 \mathrm{ml}(0,4 \\
\mathrm{mg} / \mathrm{ml})\end{array}$ & $0,45 \mathrm{~m} / \mathrm{dia}$ & 44 & 60 & -16 \\
\hline Pac0088 & $\begin{array}{l}\text { codeina; } \\
\text { paracetamol }\end{array}$ & & $\begin{array}{l}\text { codeina; } \\
\text { paracetamol }\end{array}$ & $\begin{array}{c}\text { A2 - } \\
\text { adendo }\end{array}$ & $90 \mathrm{cp}(30 \mathrm{mg})$ & $4 \mathrm{cp} / \mathrm{dia}$ & 23 & 60 & -38 \\
\hline Pac1653 & sertralina & & sertralina & C1 & $120 \mathrm{cp}(50 \mathrm{mg})$ & $4 \mathrm{cp} / \mathrm{dia}$ & 30 & 60 & -30 \\
\hline Pac3170 & fluoxetina & & fluoxetina & C1 & $40 \mathrm{cp}(20 \mathrm{mg})$ & $1 \mathrm{cp} / \mathrm{dia}$ & 40 & 60 & -20 \\
\hline Pac2269 & fenitoina & & $\begin{array}{l}\begin{array}{l}\text { fenitoina } \\
\text { (hidantoina) }\end{array} \\
\end{array}$ & c1 & $90 \mathrm{cp}(100 \mathrm{mg})$ & $3 \mathrm{cp} / \mathrm{dia}$ & 30 & 60 & -30 \\
\hline Pac2776 & fluoxetina & & fluoxetina & $c_{1}$ & $60 \mathrm{cp}(20 \mathrm{mg})$ & $2 \mathrm{cp} / \mathrm{dia}$ & 30 & 60 & -30 \\
\hline Pac 3093 & carbamazepina & & carbamazepina & C1 & $240 \mathrm{cp}(200 \mathrm{mg})$ & $8 \mathrm{cp} / \mathrm{dia}$ & 30 & 60 & -30 \\
\hline Рac3093 & fenobarbital & & fenobarbital & \begin{tabular}{|c|} 
B1- \\
adendo
\end{tabular} & $40 \mathrm{cp}$ (100 mg) & $1 \mathrm{cp} / \mathrm{dia}$ & 40 & 60 & -20 \\
\hline Pac3093 & sertralina & & sertralina & $\mathrm{Cl}$ & $30 \mathrm{cp}(50 \mathrm{mg})$ & $1 \mathrm{cp} / \mathrm{dia}$ & 30 & 60 & -30 \\
\hline Pac3168 & carbamazepina & & carbamazepina & $\mathrm{Cl}$ & $180 \mathrm{cp}(200 \mathrm{mg})$ & $6 \mathrm{cp} / \mathrm{dia}$ & 30 & 60 & 30 \\
\hline
\end{tabular}


$D T=$ Dias de tratamento fornecido $\quad L L=$ Limite legal

\begin{tabular}{|c|c|c|c|c|c|c|c|c|c|}
\hline $\begin{array}{l}\text { código } \\
\text { paciente }\end{array}$ & Prescrição & Indústria & Princípio Ativo & Alínea & Fornecimento & Posologia & DT & $\mathbf{L L}$ & DT - LL \\
\hline Pac3168 & AMPLICTIL & Aventis & clorpromazina & C1 & $20 \mathrm{cp}(25 \mathrm{mg})$ & $2 \mathrm{cp} / \mathrm{dia}$ & 10 & 60 & .50 \\
\hline Pac3168 & AMVTRIL & Cristália & amitriptilina & C1 & $60 \mathrm{cp}(25 \mathrm{mg})$ & $2 \mathrm{cp} / \mathrm{dia}$ & 30 & 60 & -30 \\
\hline Pac2411 & sertralina & & sertralina & C1 & $30 \mathrm{cp}(50 \mathrm{mg})$ & $1 \mathrm{cp} / \mathrm{dia}$ & 30 & 60 & -30 \\
\hline Pac1424 & carbamazepina & & carbamazepina & c1 & $90 \mathrm{cp}(200 \mathrm{mg})$ & $3 \mathrm{cp} / \mathrm{dia}$ & 30 & 60 & -30 \\
\hline Pac1424 & AMYTRIL & Cristália & amitriptilina & C1 & $40 \mathrm{cp}(25 \mathrm{mg})$ & $1 \mathrm{cp} / \mathrm{dla}$ & 40 & 60 & -20 \\
\hline Pac2576 & fenobarbital & & fenobarbital & \begin{tabular}{|c|}
$\begin{array}{c}\mathrm{B1}- \\
\text { adendo }\end{array}$ \\
\end{tabular} & $100 \mathrm{cp}(100 \mathrm{mg})$ & $3 \mathrm{cp} / \mathrm{dia}$ & 33 & 60 & -27 \\
\hline Pac2576 & DEPAKENE & Abbott & $\begin{array}{l}\text { ácido valproico } \\
\text { (ou derivado) }\end{array}$ & C1 & $100 \mathrm{cp}(250 \mathrm{mg})$ & $3 \mathrm{cp} / \mathrm{dia}$ & 33 & 60 & -27 \\
\hline Pac3756 & amitriptilina & & amitriptilina & C1 & $60 \mathrm{cp}(25 \mathrm{mg})$ & $2 \mathrm{cp} / \mathrm{dia}$ & 30 & 60 & -30 \\
\hline Pac1511 & carbamazepina & & cartamazepina & $\mathrm{Ct}$ & $180 \mathrm{cp}(200 \mathrm{mg})$ & $6 \mathrm{cp} / \mathrm{dia}$ & 30 & 60 & -30 \\
\hline Pac1511 & DEPAKENE & Abbott & $\begin{array}{l}\text { ácido valpróico } \\
\text { (ou derivado) }\end{array}$ & C1 & $125 \mathrm{cp}(250 \mathrm{mg})$ & $4 \mathrm{cp} / \mathrm{dia}$ & 31 & 60 & -29 \\
\hline Pac3168 & TRAMAL. & $\begin{array}{l}\text { Pfizer- } \\
\text { Pharmacia }\end{array}$ & tramadol & $\begin{array}{c}\text { A2 - } \\
\text { adendo }\end{array}$ & $30 \mathrm{cp}(50 \mathrm{mg})$ & $3 \mathrm{cp} / \mathrm{dia}$ & 10 & 60 & -50 \\
\hline Pac2543 & fluoxetina & & fluoxetina & C1 & $40 \mathrm{cp}(20 \mathrm{mg})$ & $1 \mathrm{cp} / \mathrm{dia}$ & 40 & 60 & -20 \\
\hline Pac0471 & fluoxetina & & fluoxetina & C1 & $40 \mathrm{cp}(20 \mathrm{mg})$ & $1 \mathrm{cp} / \mathrm{dia}$ & 40 & 60 & -20 \\
\hline Pac3976 & amantadina & & amantadina & C1 & $60 \mathrm{cp}(100 \mathrm{mg})$ & $2 \mathrm{cp} / \mathrm{dia}$ & 30 & 60 & 30 \\
\hline Pac2382 & carbamazepina & & carbamazepina & C1 & $180 \mathrm{cp}(200 \mathrm{mg})$ & $6 \mathrm{cp} / \mathrm{dia}$ & 30 & 60 & 30 \\
\hline Pac2382 & clobazam & & clobazam & B1 & $30 \mathrm{cp}(10 \mathrm{mg})$ & $1 \mathrm{cp} / \mathrm{dia}$ & 30 & 60 & -30 \\
\hline Pac0888 & carbamazepina & & carbamazepina & C1 & $90 \mathrm{cp}(200 \mathrm{mg})$ & $3 \mathrm{cp} / \mathrm{dia}$ & 30 & 60 & -30 \\
\hline Pac0888 & AMYTRIL & Cristália & amitriptilina & C1 & $40 \mathrm{cp}(25 \mathrm{mg})$ & $1 \mathrm{cp} / \mathrm{dia}$ & 40 & 60 & -20 \\
\hline Pac3550 & DEPAKENE & Abbott & \begin{tabular}{|l|}
$\begin{array}{l}\text { ácido valpróico } \\
\text { (ou derivado) }\end{array}$ \\
\end{tabular} & C1 & $100 \mathrm{cp}(500 \mathrm{mg})$ & $2 \mathrm{cp} / \mathrm{dia}$ & 50 & 60 & -10 \\
\hline Pac3550 & carbamazepina & & carbamazepina & C1 & $60 \mathrm{cp}(200 \mathrm{mg})$ & $2 \mathrm{cp} / \mathrm{dia}$ & 30 & 60 & -30 \\
\hline Pac2328 & AMTTRIL & Cristália & amitriptilina & $\mathrm{C1}$ & $60 \mathrm{cp}(25 \mathrm{mg})$ & $2 \mathrm{cp} / \mathrm{dia}$ & 30 & 60 & -30 \\
\hline Pac2431 & sertralina & & sertralina & C1 & $30 \mathrm{cp}(50 \mathrm{mg})$ & $1 \mathrm{cp} / \mathrm{dia}$ & 30 & 60 & -30 \\
\hline Pac1056 & fenobarbital & & fenobarbital & \begin{tabular}{|c|}
$\begin{array}{c}\text { B1 - } \\
\text { adendo }\end{array}$ \\
\end{tabular} & $40 \mathrm{cp}(100 \mathrm{mg})$ & $1 \mathrm{cp} / \mathrm{dia}$ & 40 & 60 & -20 \\
\hline Pac1056 & carbamazepina & & carbamazepina & C1 & $60 \mathrm{cp}(200 \mathrm{mg})$ & $2 \mathrm{cp} / \mathrm{dia}$ & 30 & 60 & -30 \\
\hline Pac0424 & ANAFRANIL & Novartis & clomipramina & $\mathrm{Ct}$ & $60 \mathrm{cp}(25 \mathrm{mg})$ & $2 \mathrm{cp} / \mathrm{dia}$ & 30 & 60 & -30 \\
\hline Pac2891 & DEPAKENE & Abbolt & $\begin{array}{l}\text { ácido valpróico } \\
\text { (ou derivado) } \\
\end{array}$ & c1 & $100 \mathrm{cp}(500 \mathrm{mg})$ & $2 \mathrm{cp} / \mathrm{dia}$ & 50 & 60 & -10 \\
\hline Pac1562 & AMMTRIL & Cristália & amitriptilina & C1 & $60 \mathrm{cp}(25 \mathrm{mg})$ & $2 \mathrm{cp} / \mathrm{dia}$ & 30 & 60 & -30 \\
\hline Pac1562 & LONGACTIL & Cristália & clorpromazina & C1 & $\begin{array}{l}40 \mathrm{ml}(0,4 \\
\mathrm{mg} / \mathrm{ml})\end{array}$ & $2,25 \mathrm{~m} / \mathrm{dia}$ & 18 & 60 & -42 \\
\hline Pac1645 & AMYTRIL & Cristália & amitriptilina & $\mathrm{Cl}$ & $60 \mathrm{cp}(25 \mathrm{mg})$ & $2 \mathrm{cp} / \mathrm{dia}$ & 30 & 60 & -30 \\
\hline Pac1645 & LONGACTIL & Cristália & clorpromazina & C1 & $\begin{array}{l}40 \mathrm{ml}(0,4 \\
\mathrm{mg} / \mathrm{ml})\end{array}$ & $1 \mathrm{~mL} / \mathrm{dia}$ & 40 & 60 & -20 \\
\hline Pac3962 & $\begin{array}{l}\text { codoina; } \\
\text { paracetamol } \\
\end{array}$ & & $\begin{array}{l}\text { codeina; } \\
\text { paracetamol }\end{array}$ & \begin{tabular}{|c|}
$\begin{array}{c}\text { A2 - } \\
\text { adendo }\end{array}$ \\
\end{tabular} & $20 \mathrm{cp}(30 \mathrm{mg})$ & $2 \mathrm{cp} / \mathrm{dia}$ & 10 & 60 & -50 \\
\hline Pac1093 & AMYTRIL & Cristália & amitriptitina & C1 & $40 \mathrm{cp}$ (25 mg) & $1 \mathrm{cp} / \mathrm{dia}$ & 40 & 60 & -20 \\
\hline Pac0s03 & leflunomida & & leflunomida & C1 & $3 \mathrm{cp}(100 \mathrm{mg})$ & $1 \mathrm{cp} / \mathrm{dia}$ & 3 & 60 & -57 \\
\hline Pac0903 & leflunomida & & leflunomida & $\mathrm{Cl}_{1}$ & $30 \mathrm{cp}(20 \mathrm{mg})$ & $1 \mathrm{cp} / \mathrm{dia}$ & 30 & 60 & -30 \\
\hline Pac1565 & AMYTRL & Cristália & amitriptilina & C1 & $40 \mathrm{cp}(25 \mathrm{mg})$ & $1 \mathrm{cp} / \mathrm{dia}$ & 40 & 60 & -20 \\
\hline Pac0349 & AMVTRIL & Cristália & amitriptilina & C1 & $40 \mathrm{cp}$ (25 mg) & 1 cp/dia & 40 & 60 & -20 \\
\hline Pac23338 & imipramina & & imipramina & C1 & $60 \mathrm{cp}(25 \mathrm{mg})$ & $2 \mathrm{cp} / \mathrm{dia}$ & 30 & 60 & -30 \\
\hline Pac2338 & LONGACTIL & Cristália & clorpromazina & C1 & $\begin{array}{l}80 \mathrm{ml}(0,4 \\
\mathrm{mg} / \mathrm{ml})\end{array}$ & $1,2 \mathrm{~mL} / \mathrm{dia}$ & 67 & 60 & 7 \\
\hline Pac0570 & imipramina & & imipramina & C1 & $120 \mathrm{cp}(25 \mathrm{mg})$ & $4 \mathrm{cp} / \mathrm{dia}$ & 30 & 60 & -30 \\
\hline Pac0504 & TRAMAL & \begin{tabular}{|l} 
Pfizer- \\
Pharmacia \\
\end{tabular} & tramadol & \begin{tabular}{|c|}
$\begin{array}{c}\text { A2 - } \\
\text { adendo }\end{array}$ \\
\end{tabular} & $120 \mathrm{cp}(50 \mathrm{mg})$ & $4 \mathrm{cp} / \mathrm{dia}$ & 30 & 60 & -30 \\
\hline Pac0504 & LONGACTIL & Cristália & clorpromazina & C1 & $\begin{array}{l}40 \mathrm{ml}(0,4 \\
\mathrm{mg} / \mathrm{ml})\end{array}$ & 1 muldia & 40 & 60 & -20 \\
\hline Pac0504 & imipramina & & imipramina & C1 & $30 \mathrm{cp}(25 \mathrm{mg})$ & $1 \mathrm{cp} / \mathrm{dia}$ & 30 & 60 & -30 \\
\hline Pac0971 & DEPAKENE & Abbott & $\begin{array}{l}\text { ácido valpróico } \\
\text { (ou derivado) }\end{array}$ & C1 & $100 \mathrm{cp}(250 \mathrm{mg})$ & $3 \mathrm{cp} / \mathrm{dia}$ & 33 & 60 & -27 \\
\hline Pac0971 & fenitoina & & \begin{tabular}{|l|}
$\begin{array}{l}\text { fenitoina } \\
\text { (hidantoina) }\end{array}$ \\
\end{tabular} & C1 & $90 \mathrm{cp}(100 \mathrm{mg})$ & 3 cp/dia & 30 & 60 & 30 \\
\hline
\end{tabular}


$D T=$ Dias de tratamento fornecido $\quad L L=$ Limite legal

\begin{tabular}{|c|c|c|c|c|c|c|c|c|c|}
\hline $\begin{array}{l}\text { código } \\
\text { paciente }\end{array}$ & Prescriçāo & Indústria & Princípio Ativo & Alinea & Fornecimento & Posologia & DT & $\mathbf{L L}$ & DT $-L L$ \\
\hline Pac3601 & AMYTRIL & Cristália & amitriptilina & $\mathrm{C} 1$ & $100 \mathrm{cp}(25 \mathrm{mg})$ & $3 \mathrm{cp} / \mathrm{dia}$ & 33 & 60 & -27 \\
\hline Pac3601 & LONGACTIL & Cristália & clorpromazina & $\mathrm{ct}$ & $\begin{array}{l}80 \mathrm{ml}(0,4 \\
\mathrm{mg} / \mathrm{ml})\end{array}$ & $2 \mathrm{mV} / \mathrm{dia}$ & 40 & 60 & -20 \\
\hline Pac1431 & DEPAKENE & Abbott & $\begin{array}{l}\text { ácido valpróico } \\
\text { (ou derivado) }\end{array}$ & $\mathrm{C1}$ & $\begin{array}{l}300 \mathrm{ml}(50 \\
\mathrm{mg} / \mathrm{ml})\end{array}$ & $5 \mathrm{~m} / \mathrm{dia}$ & 60 & 60 & 0 \\
\hline Pac1218 & AMYTRIL & Cristália & amitriptilina & $\mathrm{C1}$ & $40 \mathrm{cp}(25 \mathrm{mg})$ & $1 \mathrm{cp} / \mathrm{dia}$ & 40 & 60 & -20 \\
\hline Pac1525 & fluoxetina & & fluoxetina & C1 & $40 \mathrm{cp}(20 \mathrm{mg})$ & $1 \mathrm{cp} / \mathrm{dia}$ & 40 & 60 & -20 \\
\hline Pac2205 & DEPAKENE & Abbott & $\begin{array}{l}\text { ácido valpróico } \\
\text { (ou derivado) }\end{array}$ & c1 & $\begin{array}{l}100 \mathrm{ml}(50 \\
\mathrm{mg} / \mathrm{ml})\end{array}$ & $12 \mathrm{ml} / \mathrm{dia}$ & 8 & 60 & -52 \\
\hline Pac3522 & DEPAKENE & Abbott & $\begin{array}{l}\text { ácido valpróico } \\
\text { (ou derivado) }\end{array}$ & C1 & $\begin{array}{l}500 \mathrm{ml}(50 \\
\mathrm{mg} / \mathrm{ml})\end{array}$ & $15 \mathrm{mi} / \mathrm{dia}$ & 33 & 60 & -27 \\
\hline Pac3009 & carbamazepina & & carbamazepina & C1 & $60 \mathrm{cp}(200 \mathrm{mg})$ & $2 \mathrm{cp} / \mathrm{dia}$ & 30 & 60 & -30 \\
\hline Pac3306 & $\begin{array}{l}\text { DORLESS- } \\
\text { TRAMADOL }\end{array}$ & Uniāo Quimica & tramadol & \begin{tabular}{|c|} 
A2 - \\
adendo
\end{tabular} & $90 \mathrm{cp}(50 \mathrm{mg})$ & $3 \mathrm{cp} / \mathrm{dia}$ & 30 & 60 & -30 \\
\hline Pac3306 & amitriptilina & & amitriptilina & C1 & $40 \mathrm{cp}(25 \mathrm{mg})$ & $1 \mathrm{cp} / \mathrm{dia}$ & 40 & 60 & -20 \\
\hline Pac3306 & fenobarbital & & fenobarbital & \begin{tabular}{|c|}
$\begin{array}{c}\text { B1- - } \\
\text { adendo }\end{array}$ \\
\end{tabular} & $40 \mathrm{cp}(100 \mathrm{mg})$ & $1 \mathrm{cp} / \mathrm{dia}$ & 40 & 60 & -20 \\
\hline Pac3930 & $\begin{array}{l}\text { DORLESS: } \\
\text { TRAMADOL }\end{array}$ & Uniǎo Quimica & tramadol & $\begin{array}{c}\text { A2 - } \\
\text { adendo } \\
\end{array}$ & $120 \mathrm{cp}(50 \mathrm{mg})$ & $4 \mathrm{cp} / \mathrm{dia}$ & 30 & 60 & -30 \\
\hline Pac3930 & imipramina & & imipramina & C1 & $30 \mathrm{cp}$ (25 mg) & $1 \mathrm{cp} / \mathrm{dia}$ & 30 & 60 & -30 \\
\hline Pac0628 & carbamazepina & & carbamazepina & C1 & $60 \mathrm{cp}(200 \mathrm{mg})$ & $2 \mathrm{cp} / \mathrm{dia}$ & 30 & 60 & -30 \\
\hline Pac3814 & PROLOPA & Roche & \begin{tabular}{|l|} 
levodopa $\theta$ \\
benserazida
\end{tabular} & C1 & $30 \mathrm{cp}(250 \mathrm{mg})$ & $0,5 \mathrm{cp} / \mathrm{dia}$ & 60 & 60 & 0 \\
\hline Pac2002 & amitriptilina & & amitriptilina & C1 & $15 \mathrm{cp}$ (25 mg) & $0,5 \mathrm{cp} / \mathrm{dia}$ & 30 & 60 & -30 \\
\hline Pac3168 & $\begin{array}{l}\text { codeina; } \\
\text { paracetamol }\end{array}$ & & $\begin{array}{l}\text { codeina; } \\
\text { paracetamol }\end{array}$ & \begin{tabular}{|c|} 
A2 - \\
adendo \\
\end{tabular} & $30 \mathrm{cp}(30 \mathrm{mg})$ & $3 \mathrm{cp} / \mathrm{dia}$ & 10 & 60 & -50 \\
\hline Pac3201 & DAFORIN & Sigma Pharma & fluoxetina & C1 & $40 \mathrm{cp}(20 \mathrm{mg})$ & $1 \mathrm{cp} / \mathrm{dia}$ & 40 & 60 & -20 \\
\hline Pac3079 & $\begin{array}{l}\text { codeina; } \\
\text { paracetamol }\end{array}$ & & $\begin{array}{l}\text { codeina; } \\
\text { paracetamol }\end{array}$ & \begin{tabular}{|c|}
$\begin{array}{c}A 2- \\
\text { adendo }\end{array}$ \\
\end{tabular} & $120 \mathrm{cp}(30 \mathrm{mg})$ & $4 \mathrm{cp} / \mathrm{dia}$ & 30 & 60 & -30 \\
\hline Pac3079 & clomipramina & & clomipramina & $\mathrm{Cl}$ & $360 \mathrm{cp}$ (25 mg) & $12 \mathrm{cp} / \mathrm{dia}$ & 30 & 60 & -30 \\
\hline Pac3079 & LONGACTIL & Cristália & clorpromazina & $c 1$ & $\begin{array}{l}60 \mathrm{ml}(0,4 \\
\mathrm{mg} / \mathrm{ml}) \\
\end{array}$ & $3,5 \mathrm{ml} / \mathrm{dia}$ & 17 & 60 & -43 \\
\hline Pac3079 & gabapentina & & gabapentina & C1 & $60 \mathrm{cp}(300 \mathrm{mg})$ & $2 \mathrm{cp} / \mathrm{dia}$ & 30 & 60 & -30 \\
\hline Pac4009 & amitriptilina & & amitriptilina & C1 & $100 \mathrm{cp}(25 \mathrm{mg})$ & $3 \mathrm{cp} / \mathrm{dia}$ & 33 & 60 & -27 \\
\hline Pac0879 & DEPAKENE & Abbott & \begin{tabular}{|l|} 
ácido valpróico \\
(ou derivado)
\end{tabular} & c1 & $100 \mathrm{cp}(500 \mathrm{mg})$ & $3 \mathrm{cp} / \mathrm{dia}$ & 33 & 60 & -27 \\
\hline Pac2830 & TRYPTANOL & Prodome & amitriptilina & $\mathrm{C1}$ & $20 \mathrm{cp}(25 \mathrm{mg})$ & 1 cp/dia & 20 & 60 & -40 \\
\hline Pac2156 & TRAMAL & $\begin{array}{l}\text { Pfizer- } \\
\text { Pharmacia }\end{array}$ & tramadol & \begin{tabular}{|c|} 
A2 - \\
adendo
\end{tabular} & $90 \mathrm{cp}(100 \mathrm{mg})$ & $3 \mathrm{cp} / \mathrm{dia}$ & 30 & 60 & -30 \\
\hline Pac2156 & LONGACTL & Cristália & clorpromazina & c1 & $\begin{array}{l}20 \mathrm{ml}(0,4 \\
\mathrm{mg} / \mathrm{ml})\end{array}$ & $0,3 \mathrm{~m} /$ dia & 67 & 60 & 7 \\
\hline Pac2156 & amitriptilina & & amitriptilina & $\mathrm{Cl}_{1}$ & $20 \mathrm{cp}(25 \mathrm{mg})$ & $1 \mathrm{cp} / \mathrm{dia}$ & 20 & 60 & -40 \\
\hline Pac3575 & \begin{tabular}{|l} 
codeína; \\
paracetamol
\end{tabular} & & $\begin{array}{l}\text { codeina; } \\
\text { paracetamol }\end{array}$ & $\begin{array}{r}\text { A2- } \\
\text { adendo } \\
\end{array}$ & $90 \mathrm{cp}(30 \mathrm{mg})$ & $3 \mathrm{cp} / \mathrm{dia}$ & 30 & 60 & -30 \\
\hline Pac3500 & OXYCONTIN & Zodiac & oxicodona & A1 & $100 \mathrm{cp}(10 \mathrm{mg})$ & 2 cpidia & 50 & 30 & 20 \\
\hline Pac3500 & amitriptilina & & amitriptilina & C1 & $150 \mathrm{cp}(25 \mathrm{mg})$ & $3 \mathrm{cp} / \mathrm{dia}$ & 50 & 60 & -10 \\
\hline Pac3500 & carbarnazepina & & carbamazepina & C1 & $150 \mathrm{cp}(200 \mathrm{mg})$ & $3 \mathrm{cp} / \mathrm{dia}$ & 50 & 60 & -10 \\
\hline Pac1238 & PROLOPA & Roche & $\begin{array}{l}\text { levodopa e } \\
\text { benserazida }\end{array}$ & C1 & $60 \mathrm{cp}(250 \mathrm{mg})$ & $2 \mathrm{cp} / \mathrm{dia}$ & 30 & 60 & 30 \\
\hline Pac1238 & AMPLICTIL & Aventis & clorpromazina & C1 & $\begin{array}{l}40 \mathrm{ml}(0,4 \\
\mathrm{mg} / \mathrm{m})\end{array}$ & $1,2 \mathrm{~m} / \mathrm{dia}$ & 33 & 60 & -27 \\
\hline Pac1112 & $\begin{array}{l}\text { codeina; } \\
\text { paracetamol }\end{array}$ & & $\begin{array}{l}\text { Codeina; } \\
\text { paracetamol }\end{array}$ & \begin{tabular}{|c|}
$\begin{array}{c}\text { A2 - } \\
\text { adendo }\end{array}$ \\
\end{tabular} & $120 \mathrm{cp}(30 \mathrm{mg})$ & $4 \mathrm{cp} / \mathrm{dia}$ & 30 & 60 & -30 \\
\hline Pac2278 & \begin{tabular}{|l} 
codeina; \\
paracetamol
\end{tabular} & & $\begin{array}{l}\text { codeina; } \\
\text { paracetamol }\end{array}$ & \begin{tabular}{|c|}
$\begin{array}{c}\text { A2 - } \\
\text { adendo }\end{array}$ \\
\end{tabular} & $30 \mathrm{cp}(30 \mathrm{mg})$ & $3 \mathrm{cp} / \mathrm{dia}$ & 10 & 60 & -50 \\
\hline $\mathrm{Pac0243}$ & DEPAKENE & Abbott & \begin{tabular}{|l} 
acido valpróico \\
(ou derviado) \\
\end{tabular} & C1 & $25 \mathrm{cp}(250 \mathrm{mg})$ & $7 \mathrm{cp} / \mathrm{dia}$ & 4 & 60 & -56 \\
\hline Pac2393 & ANAFRANIL & Novartis & clomipramina & C1 & $120 \mathrm{cp}(25 \mathrm{mg})$ & $4 \mathrm{cp} / \mathrm{dia}$ & 30 & 60 & -30 \\
\hline Pac0566 & AMYTRIL & Cristália & amitriptilina & C1 & $100 \mathrm{cp}(25 \mathrm{mg})$ & $3 \mathrm{cp} / \mathrm{dia}$ & 33 & 60 & -27 \\
\hline Pac1023 & DEPAKENE & Abbott & $\begin{array}{l}\text { ácido valpróico } \\
\text { (ou derivado) }\end{array}$ & C1 & $\begin{array}{l}500 \mathrm{ml}(50 \\
\mathrm{mg} / \mathrm{ml})\end{array}$ & $15 \mathrm{ml} / \mathrm{dia}$ & 33 & 60 & -27 \\
\hline Pac0236 & amitriptilina & & amitriptilina & C1 & $60 \mathrm{cp}(5 \mathrm{mg})$ & $1 \mathrm{cp} / \mathrm{dia}$ & 60 & 60 & 0 \\
\hline
\end{tabular}


$\mathrm{DT}=$ Dias de tratamento fornecido $\quad \mathrm{LL}=$ Limite legal

\begin{tabular}{|c|c|c|c|c|c|c|c|c|c|}
\hline $\begin{array}{l}\text { código } \\
\text { paciente }\end{array}$ & Prescrição & Indústria & Princípio Ativo & Alínea & Fornecimento & Posologia & DT & LL. & DT - U \\
\hline Pac1411 & GARDENAL & Aventis & fenobarbital & \begin{tabular}{c|}
$\mathrm{Bt}-$ \\
adendo
\end{tabular} & $40 \mathrm{cp}(100 \mathrm{mg})$ & $1 \mathrm{cp} / \mathrm{dia}$ & 40 & 60 & -20 \\
\hline Pac1411 & HIDANTAL & Aventis & $\begin{array}{l}\text { fenitoina } \\
\text { (hidantoina) }\end{array}$ & $\mathrm{C1}$ & $60 \mathrm{cp}(100 \mathrm{mg})$ & $2 \mathrm{cp} / \mathrm{dia}$ & 30 & 60 & -30 \\
\hline Pac1791 & fenitoina & & $\begin{array}{l}\text { fenitoina } \\
\text { (hidantoina) }\end{array}$ & $\mathrm{Cl}$ & $90 \mathrm{cp}(100 \mathrm{mg})$ & $2 \mathrm{cp} / \mathrm{dia}$ & 45 & 60 & -15 \\
\hline Pac3423 & DEPAKENE & Abbott & $\begin{array}{l}\text { ácido valpróico } \\
\text { (ou derivado) }\end{array}$ & C1 & $200 \mathrm{cp}(500 \mathrm{mg})$ & $6 \mathrm{cp} / \mathrm{dia}$ & 33 & 60 & -27 \\
\hline Pac3423 & GARDENAL & Aventis & fenobarbital & \begin{tabular}{c|}
$\mathrm{B1}-$ \\
adendo
\end{tabular} & $60 \mathrm{cp}(100 \mathrm{mg})$ & 2 cp/dia & 30 & 60 & -30 \\
\hline Pac1656 & amitriptilina & & amitriptilina & $\overline{C t}$ & $60 \mathrm{cp}(25 \mathrm{mg})$ & $3 \mathrm{cp} / \mathrm{dia}$ & 20 & 60 & -40 \\
\hline Pac3973 & TRAMAL & $\begin{array}{l}\text { Pfizer- } \\
\text { Pharmacia }\end{array}$ & tramadol & $\begin{array}{c}\text { A2 - } \\
\text { adendo }\end{array}$ & $40 \mathrm{cp}(50 \mathrm{mg})$ & $4 \mathrm{cp} / \mathrm{dia}$ & 10 & 60 & -50 \\
\hline Pac2189 & $\begin{array}{l}\text { codeína; } \\
\text { paracetamol }\end{array}$ & & $\begin{array}{l}\text { codeina; } \\
\text { paracetamol }\end{array}$ & \begin{tabular}{c|}
$\begin{array}{c}A 2- \\
\text { adendo }\end{array}$ \\
\end{tabular} & $30 \mathrm{cp}(30 \mathrm{mg})$ & $3 \mathrm{cp} / \mathrm{dia}$ & 10 & 60 & -50 \\
\hline Pac3870 & clorpromazina & & clorpromazina & C1 & $\begin{array}{l}40 \mathrm{ml}(0,4 \\
\mathrm{mg} / \mathrm{ml})\end{array}$ & $601 \mathrm{~m} / \mathrm{dia}$ & 0 & 60 & -60 \\
\hline Pac3870 & fluoxetina & & fluoxetina & $\mathrm{c1}$ & $60 \mathrm{cp}(20 \mathrm{mg})$ & $3 \mathrm{cp} / \mathrm{dia}$ & 20 & 60 & -40 \\
\hline Pac1316 & fluoxetina & & fluoxetina & $\mathrm{C1}$ & $60 \mathrm{cp}(20 \mathrm{mg})$ & $1 \mathrm{cp} / \mathrm{dia}$ & 60 & 60 & 0 \\
\hline Pac2465 & amitriptilina & & amitriptilina & C1 & $60 \mathrm{cp}(25 \mathrm{mg})$ & $2 \mathrm{cp} / \mathrm{dia}$ & 30 & 60 & -30 \\
\hline Pac2705 & DEPAKENE & Abbott & $\begin{array}{l}\text { ácido valpróico } \\
\text { (ou derivado) }\end{array}$ & C1 & $\begin{array}{l}900 \mathrm{ml}(50 \\
\mathrm{mg} / \mathrm{ml})\end{array}$ & $28,5 \mathrm{~m} / \mathrm{dia}$ & 32 & 60 & -28 \\
\hline Pac0385 & TRAMAL & $\begin{array}{l}\text { Pfizer- } \\
\text { Pharmacia }\end{array}$ & tramadol & \begin{tabular}{|c|} 
A2 - \\
adendo
\end{tabular} & $30 \mathrm{cp}(50 \mathrm{mg})$ & $3 \mathrm{cp} / \mathrm{dia}$ & 10 & 60 & .50 \\
\hline Pac1684 & amitriptilina & & amitriptilina & C1 & $60 \mathrm{cp}(25 \mathrm{mg})$ & $1 \mathrm{cp} / \mathrm{dia}$ & 60 & 60 & 0 \\
\hline Pac0088 & \begin{tabular}{|l} 
codeina; \\
paracelamol
\end{tabular} & & $\begin{array}{l}\text { codeina: } \\
\text { paracetamol }\end{array}$ & \begin{tabular}{|c|} 
A2 - \\
adendo
\end{tabular} & $90 \mathrm{cp}(30 \mathrm{mg})$ & $4 \mathrm{cp} / \mathrm{dia}$ & 23 & 60 & -38 \\
\hline Pac0323 & amitriptilina & & amitriptilina & C1 & $240 \mathrm{cp} \mathrm{(25} \mathrm{mg)}$ & $4 \mathrm{cp} / \mathrm{dia}$ & 60 & 60 & 0 \\
\hline Pac0323 & NEOZINE & Aventis & $\begin{array}{l}\text { levomepromazina } \\
\text { (metotrimeprazina) }\end{array}$ & C1 & $60 \mathrm{cp}(25 \mathrm{mg})$ & $2 \mathrm{cp} / \mathrm{dia}$ & 30 & 60 & -30 \\
\hline Pac0323 & sertralina & & sertralina & $\mathrm{Cl}$ & $30 \mathrm{cp}(50 \mathrm{mg})$ & $1 \mathrm{cp} / \mathrm{dia}$ & 30 & 60 & -30 \\
\hline Pac0323 & TRAMAL & $\begin{array}{l}\text { Pfizer- } \\
\text { Pharmacia }\end{array}$ & tramadol & $\begin{array}{c}\text { A2 - } \\
\text { adendo }\end{array}$ & $120 \mathrm{cp}(50 \mathrm{mg})$ & $4 \mathrm{cp} / \mathrm{dia}$ & 30 & 60 & -30 \\
\hline Pac0696 & fluoxetina & & fluoxetina & C1 & $60 \mathrm{cp}(20 \mathrm{mg})$ & $2 \mathrm{cp} / \mathrm{dia}$ & 30 & 60 & -30 \\
\hline Pac0659 & $\begin{array}{l}\text { codeina; } \\
\text { paracetamol }\end{array}$ & & \begin{tabular}{|l|} 
codeína; \\
paracetamol
\end{tabular} & \begin{tabular}{|c|}
$\begin{array}{c}\text { A2 - } \\
\text { adendo }\end{array}$ \\
\end{tabular} & $40 \mathrm{cp}(30 \mathrm{mg})$ & $4 \mathrm{cp} / \mathrm{dia}$ & 10 & 60 & -50 \\
\hline Pact712 & PROGRESSE & Biosintética & gabapentina & C1 & $60 \mathrm{cp}(400 \mathrm{mg})$ & $3 \mathrm{cp} / \mathrm{dia}$ & 20 & 60 & -40 \\
\hline Pac1296 & amitriptilina & & amitriptilina & c1 & $60 \mathrm{cp}(25 \mathrm{mg})$ & $1 \mathrm{cp} / \mathrm{dia}$ & 60 & 60 & 0 \\
\hline Pac1299 & fluoxetina & & nuoxetina & $\mathrm{C1}$ & $40 \mathrm{cp}(20 \mathrm{mg})$ & $1 \mathrm{cp} / \mathrm{dia}$ & 40 & 60 & -20 \\
\hline Pac1746 & $\begin{array}{l}\text { codeina; } \\
\text { paracetamol }\end{array}$ & & $\begin{array}{l}\text { codeina; } \\
\text { paracetamol }\end{array}$ & \begin{tabular}{c|} 
A2 - \\
adendo
\end{tabular} & $120 \mathrm{cp}(30 \mathrm{mg})$ & $4 \mathrm{cp} / \mathrm{dia}$ & 30 & 60 & -30 \\
\hline Pac2150 & sertralina & & sertralina & $\mathrm{Cl}$ & $30 \mathrm{cp}(50 \mathrm{mg})$ & $1 \mathrm{cp} / \mathrm{dia}$ & 30 & 60 & -30 \\
\hline Pac0179 & amitriptilina & & amitriptilina & C1 & $40 \mathrm{cp}(25 \mathrm{mg})$ & $1 \mathrm{cp} / \mathrm{dia}$ & 40 & 60 & -20 \\
\hline Pac0179 & $\begin{array}{l}\text { DORLESS- } \\
\text { TRAMADOL } \\
\end{array}$ & Uniåo Quimica & tramadol & \begin{tabular}{|c|}
$\begin{array}{c}\text { A2 - } \\
\text { adendo }\end{array}$ \\
\end{tabular} & $40 \mathrm{cp}(50 \mathrm{mg})$ & $2 \mathrm{cp} / \mathrm{dia}$ & 20 & 60 & -40 \\
\hline Pac2226 & amitriptilina & & amitriptilina & $\mathrm{Cl}$ & $60 \mathrm{cp}(25 \mathrm{mg})$ & $2 \mathrm{cp} / \mathrm{dia}$ & 30 & 60 & -30 \\
\hline Pac2130 & AMVTRIL & Cristália & amitriptilina & C1 & $40 \mathrm{cp}(25 \mathrm{mg})$ & $1 \mathrm{cp} / \mathrm{dia}$ & 40 & 60 & .20 \\
\hline Pac0297 & AMYTRIL & Cristália & amitriptilina & C1 & $20 \mathrm{cp}(25 \mathrm{mg})$ & $1 \mathrm{cp} / \mathrm{dia}$ & 20 & 60 & -40 \\
\hline Pac1764 & AMYTRIL & Cristália & amitriptilina & $\mathrm{ct}$ & $40 \mathrm{cp}$ (25 mg) & $4 \mathrm{cp} / \mathrm{dia}$ & 10 & 60 & -50 \\
\hline Pac2478 & DAFORIN & Sigma Pharma & fluoxelina & C1 & $60 \mathrm{cp}(20 \mathrm{mg})$ & $2 \mathrm{cp} / \mathrm{dia}$ & 30 & 60 & -30 \\
\hline Pac0646 & NOTUSS & Aché & $\begin{array}{l}\text { difenidramina; } \\
\text { pseudoefedrina; } \\
\text { dropropizina; } \\
\text { paracetamol }\end{array}$ & D1 & $\begin{array}{l}120 \mathrm{ml}(8,3 \\
\mathrm{mg} / \mathrm{ml})\end{array}$ & $10 \mathrm{~m} / \mathrm{dia}$ & 12 & & \\
\hline Pac2155 & amitriptilina & & amitriptilina & C1 & $40 \mathrm{cp}(25 \mathrm{mg})$ & $1 \mathrm{cp} / \mathrm{dia}$ & 40 & 60 & -20 \\
\hline Pac2155 & \begin{tabular}{|l} 
codeina; \\
paracetarnol
\end{tabular} & & $\begin{array}{l}\text { codeina; } \\
\text { paracetamol }\end{array}$ & $\begin{array}{c}\begin{array}{c}\text { A2 - } \\
\text { adendo }\end{array} \\
\end{array}$ & $30 \mathrm{cp}(30 \mathrm{mg})$ & $1 \mathrm{cp} / \mathrm{dia}$ & 30 & 60 & -30 \\
\hline Pac1357 & TRAMAL & $\begin{array}{l}\text { Pfizer- } \\
\text { Pharmacia }\end{array}$ & tramadol & $\begin{array}{c}\text { A2 - } \\
\text { adendo }\end{array}$ & $60 \mathrm{cp}(50 \mathrm{mg})$ & $4 \mathrm{cp} / \mathrm{dia}$ & 15 & 60 & -45 \\
\hline
\end{tabular}


$\mathrm{DT}=$ Dias de tratamento fornecido $\quad \mathrm{LL}=$ Limite legal

\begin{tabular}{|c|c|c|c|c|c|c|c|c|c|}
\hline $\begin{array}{l}\text { código } \\
\text { paciente }\end{array}$ & Prescrição & Indústria & Princípio Ativo & Alinea & Fornecimento & Posologia & DT & 나. & DT - LL \\
\hline Pac2124 & nitrazepam & & nitrazepam & B1 & $60 \mathrm{cp}(5 \mathrm{mg})$ & $2 \mathrm{cp} / \mathrm{dia}$ & 30 & 60 & 30 \\
\hline Pac2705 & nitrazepam & & nitrazepam & B1 & $150 \mathrm{cp}(5 \mathrm{mg})$ & $5 \mathrm{cp} / \mathrm{dia}$ & 30 & 60 & -30 \\
\hline Pac3827 & nitrazepam & & nitrazepam & B1 & $90 \mathrm{cp}(5 \mathrm{mg})$ & $3 \mathrm{cp} / \mathrm{dia}$ & 30 & 60 & .30 \\
\hline Pac0894 & nitrazepam & & nitrazepam & B1 & $60 \mathrm{cp}(5 \mathrm{mg})$ & $2 \mathrm{cp} / \mathrm{dia}$ & 30 & 60 & -30 \\
\hline Pac0491 & ROHYPNOL & Roche & flunitrazepam & B1 & $60 \mathrm{cp}(1 \mathrm{mg})$ & $2 \mathrm{cp} / \mathrm{dia}$ & 30 & 60 & 30 \\
\hline Pac1773 & RIVOTRIL & Roche & clonazepam & B1 & $40 \mathrm{cp}(2 \mathrm{mg})$ & $1 \mathrm{cp} / \mathrm{dia}$ & 40 & 60 & -20 \\
\hline Pac0656 & RIVOTRIL & Roche & clonazepam & B1 & $160 \mathrm{cp}$ (2 mg) & $5 \mathrm{cp} / \mathrm{dia}$ & 32 & 60 & -28 \\
\hline Pac3522 & RIVOTRIL & Roche & clonazepam & B1 & $60 \mathrm{cp}(2 \mathrm{mg})$ & $2 \mathrm{cp} / \mathrm{dia}$ & 30 & 60 & -30 \\
\hline Pac3251 & RIVOTRIL & Roche & clonazepam & B1 & $60 \mathrm{cp}(2 \mathrm{mg})$ & $2 \mathrm{cp} / \mathrm{dia}$ & 30 & 60 & -30 \\
\hline Pac4088 & RIVOTRIL & Roche & clonazepam & B1 & $50 \mathrm{cp}(2 \mathrm{mg})$ & 4 cp/dia & 13 & 60 & -48 \\
\hline Pac1717 & RIVOTRIL & Roche & clonazepam & B1 & $40 \mathrm{cp}(2 \mathrm{mg})$ & $1 \mathrm{cp} / \mathrm{dia}$ & 40 & 60 & -20 \\
\hline Pac0669 & RIVOTRIL & Roche & clonazepam & B1 & $40 \mathrm{cp}(2 \mathrm{mg})$ & $1 \mathrm{cp} / \mathrm{dia}$ & 40 & 60 & -20 \\
\hline Pac3853 & diazepam & & diazepam & B1 & $120 \mathrm{cp}(10 \mathrm{mg})$ & $4 \mathrm{cp} / \mathrm{dia}$ & 30 & 60 & 30 \\
\hline Pac1642 & diazepam & & diazepam & B1 & $30 \mathrm{cp}(10 \mathrm{mg})$ & $1 \mathrm{cp} / \mathrm{dia}$ & 30 & 60 & -30 \\
\hline Pac3267 & diazepam & & diazepam & B1 & $30 \mathrm{cp}(10 \mathrm{mg})$ & $1 \mathrm{cp} / \mathrm{dia}$ & 30 & 60 & .30 \\
\hline Pac00323 & diazepam & & diazepam & B1 & $30 \mathrm{cp}(10 \mathrm{mg})$ & $1 \mathrm{cp} / \mathrm{dia}$ & 30 & 60 & 30 \\
\hline Pac0736 & diazepam & & diazepam & 81 & $30 \mathrm{cp}(10 \mathrm{mg})$ & $2 \mathrm{cp} / \mathrm{dia}$ & 15 & 60 & -45 \\
\hline Pac0873 & diazepam & & diazepam & B1 & $120 \mathrm{cp}(10 \mathrm{mg})$ & $4 \mathrm{cp} / \mathrm{dia}$ & 30 & 60 & -30 \\
\hline Pac0277 & diazepam & & diazepam & B1 & $30 \mathrm{cp}(10 \mathrm{mg})$ & $1 \mathrm{cp} / \mathrm{dia}$ & 30 & 60 & -30 \\
\hline Pac2381 & FRISIUM & Aventis & clobazam & B1 & $40 \mathrm{cp}(10 \mathrm{mg})$ & $1 \mathrm{cp} / \mathrm{dia}$ & 40 & 60 & -20 \\
\hline Pac3889 & clobazam & & clobazam & 81 & $60 \mathrm{cp}(10 \mathrm{mg})$ & $2 \mathrm{cp} / \mathrm{dia}$ & 30 & 60 & 30 \\
\hline Pac3638 & FRISIUM & Aventis & clobazam & B1 & $180 \mathrm{cp}(10 \mathrm{mg})$ & $6 \mathrm{cp} / \mathrm{dia}$ & 30 & 60 & -30 \\
\hline Pac3526 & FRISIUM & Aventis & clobazam & B1 & $40 \mathrm{cp}(10 \mathrm{mg})$ & $1 \mathrm{cp} / \mathrm{dia}$ & 40 & 60 & -20 \\
\hline Pac3728 & FRISIUM & Aventis & clobazam & B1 & $40 \mathrm{cp}(10 \mathrm{mg})$ & $1 \mathrm{cp} / \mathrm{dia}$ & 40 & 60 & -20 \\
\hline Pac1023 & FRISIUM & Aventis & clobazam & B1 & $40 \mathrm{cp}(10 \mathrm{mg})$ & $1 \mathrm{cp} / \mathrm{dia}$ & 40 & 60 & -20 \\
\hline Pac3093 & FRISIUM & Aventis & clobazam & 81 & $100 \mathrm{cp}(10 \mathrm{mg})$ & $3 \mathrm{cp} / \mathrm{dia}$ & 33 & 60 & -27 \\
\hline Pac1703 & FRISIUM & Aventis & clobazam & B1 & $60 \mathrm{cp}(10 \mathrm{mg})$ & $2 \mathrm{cp} / \mathrm{dia}$ & 30 & 60 & -30 \\
\hline Pac0879 & FRISIUM & Aventis & clobazam & B1 & $60 \mathrm{cp}(10 \mathrm{mg})$ & $1,5 \mathrm{cp} / \mathrm{dia}$ & 40 & 60 & -20 \\
\hline Pac0611 & FRISIUM & Aventis & clobazam & B1 & $60 \mathrm{cp}(10 \mathrm{mg})$ & $1,5 \mathrm{cp} / \mathrm{dia}$ & 40 & 60 & -20 \\
\hline Pac3608 & FRISIUM & Aventis & clobazam & 81 & $60 \mathrm{cp}(10 \mathrm{mg})$ & $1.5 \mathrm{cp} / \mathrm{dia}$ & 40 & 60 & -20 \\
\hline Pac1889 & FRISIUM & Aventis & clobazam & B1 & $180 \mathrm{cp}(10 \mathrm{mg})$ & $6 \mathrm{cp} / \mathrm{dia}$ & 30 & 60 & -30 \\
\hline Pac1288 & FRISIUM & Aventis & clobazam & B1 & $160 \mathrm{cp}(10 \mathrm{mg})$ & $5 \mathrm{cp} / \mathrm{dia}$ & 32 & 60 & -28 \\
\hline Pac0243 & URBANIL & Aventis & clobazam & B1 & $60 \mathrm{cp}(10 \mathrm{mg})$ & $1,5 \mathrm{cp} / \mathrm{dia}$ & 40 & 60 & -20 \\
\hline Pac2205 & FRISIUM & Aventis & clobazam & B1 & $100 \mathrm{cp}(10 \mathrm{mg})$ & $3 \mathrm{cp} / \mathrm{dia}$ & 33 & 60 & -27 \\
\hline Pac2807 & FRISIUM & Aventis & clobezam & B1 & $120 \mathrm{cp}(10 \mathrm{mg})$ & $4 \mathrm{cp} / \mathrm{dia}$ & 30 & 60 & -30 \\
\hline Pac0165 & morfina & & morrina & At & $120 \mathrm{cp}(30 \mathrm{mg})$ & $4 \mathrm{cp} / \mathrm{dia}$ & 30 & 30 & 0 \\
\hline Pac2073 & morfina & & morfina & A1 & $180 \mathrm{cp}(10 \mathrm{mg})$ & $6 \mathrm{cp} / \mathrm{dia}$ & 30 & 30 & 0 \\
\hline Pac1015 & morfina & & morfina & A1 & $120 \mathrm{cp}(30 \mathrm{mg})$ & $4 \mathrm{cp} / \mathrm{dia}$ & 30 & 30 & 0 \\
\hline Pac1490 & morfina & & morfina & A1 & $240 \mathrm{cp}(10 \mathrm{mg})$ & $6 \mathrm{cp} / \mathrm{dia}$ & 40 & 30 & 10 \\
\hline Pac1255 & morfina & & morrina & A1 & $360 \mathrm{cp}(30 \mathrm{mg})$ & $16 \mathrm{cp} / \mathrm{dia}$ & 23 & 30 & -8 \\
\hline Pac0020 & amitriptibna & & amitriptilina & C1 & $100 \mathrm{cp}(25 \mathrm{mg})$ & $3 \mathrm{cp} / \mathrm{dia}$ & 33 & 60 & -27 \\
\hline Pac0020 & levomepromazina & & $\begin{array}{l}\text { levomepromazina } \\
\text { (mototrimeprazina) }\end{array}$ & C1 & $60 \mathrm{cp}$ (25 mg) & $2 \mathrm{cp} / \mathrm{dia}$ & 30 & 60 & 30 \\
\hline Pac0611 & fenitoina & & $\begin{array}{l}\text { Ienitoina } \\
\text { (hidantoina) }\end{array}$ & c1 & $60 \mathrm{cp}(100 \mathrm{mg})$ & $2 \mathrm{cp} / \mathrm{dia}$ & 30 & 60 & -30 \\
\hline Pac0611 & carbamazepina & & carbamazepina & C1 & $90 \mathrm{cp}(200 \mathrm{mg})$ & $3 \mathrm{cp} / \mathrm{dia}$ & 30 & 60 & -30 \\
\hline Pac1822 & AMYTRIL & Cristália & amitriptilina & $\mathrm{Ct}_{1}$ & $100 \mathrm{cp}(25 \mathrm{mg})$ & $3 \mathrm{cp} / \mathrm{dia}$ & 33 & 60 & -27 \\
\hline Pac3955 & DAFORIN & Sigma Pharma & fluoxetina & C1 & $120 \mathrm{cp}(10 \mathrm{mg})$ & $4 \mathrm{cp} / \mathrm{dia}$ & 30 & 60 & 30 \\
\hline Pac2580 & carbamazepina & & carbamazepina & C1 & $270 \mathrm{cp}(200 \mathrm{mg})$ & $9 \mathrm{cp} / \mathrm{dia}$ & 30 & 60 & -30 \\
\hline Pac2580 & topiramato & & topiramato & C1 & $120 \mathrm{cp}$ (25 mg) & $4 \mathrm{cp} / \mathrm{dia}$ & 30 & 60 & -30 \\
\hline
\end{tabular}


DT = Dias de tratamento fornecido $\quad L L=$ Limite legal

\begin{tabular}{|c|c|c|c|c|c|c|c|c|c|}
\hline \begin{tabular}{|l|}
$\begin{array}{l}\text { código } \\
\text { paciente }\end{array}$ \\
\end{tabular} & Prescrição & Indústria & Princípio Ativo & Alínea & Fornecimento & Posologia & DT & LL. & DT - LL \\
\hline Pac2580 & fenobarbital & & fenobarbital & $\begin{array}{c}\text { B1 - } \\
\text { adendo }\end{array}$ & $60 \mathrm{cp}$ (100 mg) & $2 \mathrm{cp} / \mathrm{dia}$ & 30 & 60 & -30 \\
\hline Pac0568 & gabapentina & & gabapentina & C1 & $60 \mathrm{cp}(300 \mathrm{mg})$ & $2 \mathrm{cp} / \mathrm{dia}$ & 30 & 60 & -30 \\
\hline Pac0668 & DAFORIN & Sigma Pharma & fluoxetina & C1 & $40 \mathrm{cp}(20 \mathrm{mg})$ & $1 \mathrm{cp} / \mathrm{dia}$ & 40 & 60 & -20 \\
\hline Pac1214 & imipramina & & imipramina & $\mathrm{Cl}$ & $60 \mathrm{cp}(25 \mathrm{mg})$ & $2 \mathrm{cp} / \mathrm{dia}$ & 30 & 60 & -30 \\
\hline Pac3894 & $\begin{array}{l}\text { CINETIC- } \\
\text { CISAPRIDA }\end{array}$ & Biolab-Sanus & cisaprida & $\mathrm{Cl}$ & $60 \mathrm{cp}(0,5 \mathrm{mg})$ & $2 \mathrm{cp} / \mathrm{dia}$ & 30 & 60 & -30 \\
\hline Pac1569 & amitriptilina & & amitriptilina & C1 & $40 \mathrm{cp}(25 \mathrm{mg})$ & $1 \mathrm{cp} / \mathrm{dia}$ & 40 & 60 & -20 \\
\hline Pac1372 & AMYTRIL & Cristália & amitriptilina & C1 & $540 \mathrm{cp}(25 \mathrm{mg})$ & $6 \mathrm{cp} / \mathrm{dia}$ & 90 & 60 & 30 \\
\hline Pac1372 & LONGACTIL & Cristália & clorpromazina & C1 & $\begin{array}{l}120 \mathrm{ml}(0,4 \\
\mathrm{mg} / \mathrm{ml})\end{array}$ & $4 \mathrm{ml} / \mathrm{dia}$ & 30 & 60 & -30 \\
\hline Pac1372 & carbamazepina & & carbamazepina & C1 & $90 \mathrm{cp}(200 \mathrm{mg})$ & $3 \mathrm{cp} / \mathrm{dia}$ & 30 & 60 & -30 \\
\hline Pac1372 & \begin{tabular}{|l|} 
codeina; \\
paracetamol
\end{tabular} & & \begin{tabular}{|l|} 
codeina; \\
paracetamol
\end{tabular} & $\begin{array}{c}\text { A2- } \\
\text { adendo }\end{array}$ & $120 \mathrm{cp}(30 \mathrm{mg})$ & $4 \mathrm{cp} / \mathrm{dia}$ & 30 & 60 & -30 \\
\hline Pac3441 & fenitoina & & \begin{tabular}{|l|}
$\begin{array}{l}\text { fenitoina } \\
\text { (hidantoina) }\end{array}$ \\
\end{tabular} & C1 & $90 \mathrm{cp}(100 \mathrm{mg})$ & $2 \mathrm{cp} / \mathrm{dia}$ & 45 & 60 & -15 \\
\hline Pac3441 & DEPAKENE & Abbott & \begin{tabular}{|l}
$\begin{array}{l}\text { ácido valpróico } \\
\text { (ou derivado) }\end{array}$ \\
\end{tabular} & c1 & $50 \mathrm{cp}(250 \mathrm{mg})$ & $1 \mathrm{cp} / \mathrm{dia}$ & 50 & 60 & -10 \\
\hline Pac3347 & TOPAMAX & Janssen-Cilag & topiramato & C1 & $60 \mathrm{cp}(25 \mathrm{mg})$ & $1 \mathrm{cp} / \mathrm{dia}$ & 60 & 60 & 0 \\
\hline Pac1687 & \begin{tabular}{|l} 
codeina; \\
paracetamol
\end{tabular} & & \begin{tabular}{|l} 
codeina; \\
paracetamol
\end{tabular} & $\begin{array}{c}\text { A2- } \\
\text { adendo }\end{array}$ & $30 \mathrm{cp}(30 \mathrm{mg})$ & $4 \mathrm{cp} / \mathrm{dia}$ & 8 & 60 & -53 \\
\hline Pac3381 & haloperidol & & haloperidol & C1 & $60 \mathrm{cp}(1 \mathrm{mg})$ & $2 \mathrm{cp} / \mathrm{dia}$ & 30 & 60 & -30 \\
\hline Pac3022 & carbamazepina & & carbamazepina & c1 & $150 \mathrm{cp}$ (200 mg) & $5 \mathrm{cp} / \mathrm{dia}$ & 30 & 60 & -30 \\
\hline Pac3022 & fluoxetina & & fluoxetina & C1 & $100 \mathrm{cp}(20 \mathrm{mg})$ & $3 \mathrm{cp} / \mathrm{dia}$ & 33 & 60 & -27 \\
\hline Pac3926 & sertralina & & sertralina & C1 & $120 \mathrm{cp}(50 \mathrm{mg})$ & $4 \mathrm{cp} / \mathrm{dia}$ & 30 & 60 & -30 \\
\hline Pac3844 & LONGACTIL & Cristália & clorpromazina & C1 & $\begin{array}{l}20 \mathrm{ml}(0,4 \\
\mathrm{mg} / \mathrm{ml})\end{array}$ & $0,2 \mathrm{~m} / / \mathrm{dia}$ & 100 & 60 & 40 \\
\hline Pac3329 & fluoxetina & & fluoxetina & C1 & $40 \mathrm{cp}(20 \mathrm{mg})$ & $1 \mathrm{cp} / \mathrm{dia}$ & 40 & 60 & -20 \\
\hline Pac3168 & \begin{tabular}{|l} 
codeina: \\
paracetamol
\end{tabular} & & \begin{tabular}{|l|} 
codeina; \\
paracetamol
\end{tabular} & $\begin{array}{c}\text { A2 - } \\
\text { adendo }\end{array}$ & $30 \mathrm{cp}(30 \mathrm{mg})$ & $3 \mathrm{cp} / \mathrm{dia}$ & 10 & 60 & -50 \\
\hline Pac3873 & \begin{tabular}{|l} 
codeina: \\
paracetamol
\end{tabular} & & \begin{tabular}{|l|} 
codeina; \\
paracetamol
\end{tabular} & $\begin{array}{c}\text { A2- } \\
\text { adendo }\end{array}$ & $60 \mathrm{cp}(30 \mathrm{mg})$ & $2 \mathrm{cp} / \mathrm{dia}$ & 30 & 60 & -30 \\
\hline Pac3873 & carbamazepina & & carbamazepina & C1 & $30 \mathrm{cp}(200 \mathrm{mg})$ & $1 \mathrm{cp} / \mathrm{dia}$ & 30 & 60 & -30 \\
\hline Pac3873 & amitriptilina & & amitriptilina & C1 & $40 \mathrm{cp}(25 \mathrm{mg})$ & $1 \mathrm{cp} / \mathrm{dia}$ & 40 & 60 & -20 \\
\hline Pac1073 & sertralina & & sertralina & C1 & $60 \mathrm{cp}(50 \mathrm{mg})$ & $2 \mathrm{cp} / \mathrm{dia}$ & 30 & 60 & -30 \\
\hline Pac2153 & DAFORIN & Sigma Pharma & fluoxetina & $\mathrm{C}_{1}$ & $40 \mathrm{cp}(20 \mathrm{mg})$ & $1 \mathrm{cp} / \mathrm{dia}$ & 40 & 60 & -20 \\
\hline Pac3728 & fenobarbital & & fenobarbital & $\begin{array}{c}\text { B1- } \\
\text { adendo }\end{array}$ & $40 \mathrm{cp}(100 \mathrm{mg})$ & $1 \mathrm{cp} / \mathrm{dia}$ & 40 & 60 & -20 \\
\hline Pac3728 & carbarnazepina & & carbamazepina & C1 & $180 \mathrm{cp}(200 \mathrm{mg})$ & $6 \mathrm{cp} / \mathrm{dia}$ & 30 & 60 & -30 \\
\hline Pac1322 & AMYTRIL & Cristália & amitriptilina & C1 & $40 \mathrm{cp}(25 \mathrm{mg})$ & $1 \mathrm{cp} / \mathrm{dia}$ & 40 & 60 & .20 \\
\hline Pac3827 & carbamazepina & & carbamazepina & $\mathrm{C1}$ & $90 \mathrm{cp}(200 \mathrm{mg})$ & $3 \mathrm{cp} / \mathrm{dia}$ & 30 & 60 & -30 \\
\hline Pac3827 & fenobarbital & & fenobarbital & $\begin{array}{c}\text { B1- } \\
\text { adendo }\end{array}$ & $60 \mathrm{cp}$ (100 mg) & $2 \mathrm{cp} / \mathrm{dia}$ & 30 & 60 & -30 \\
\hline Pac3827 & nitrazepam & & nitrazepam & B1 & $90 \mathrm{cp}(5 \mathrm{mg})$ & $3 \mathrm{cp} / \mathrm{dia}$ & 30 & 60 & -30 \\
\hline Pac2298 & fluoxetina & & fluoxetina & C1 & $60 \mathrm{cp}(20 \mathrm{mg})$ & $2 \mathrm{cp} / \mathrm{dia}$ & 30 & 60 & -30 \\
\hline Pac1787 & AMYTRIL & Cristália & amitriptilina & $\mathrm{C1}_{1}$ & $120 \mathrm{cp}(25 \mathrm{mg})$ & $4 \mathrm{cp} / \mathrm{dia}$ & 30 & 60 & -30 \\
\hline Pac1635 & fluoxetina & & fluoxetina & C1 & $100 \mathrm{cp}(20 \mathrm{mg})$ & $2 \mathrm{cp} / \mathrm{dia}$ & 50 & 60 & -10 \\
\hline Pac2577 & AMYTRIL & Cristália & amitriptikina & $\mathrm{Cl}$ & $180 \mathrm{cp}$ (25 mg) & $6 \mathrm{cp} / \mathrm{dia}$ & 30 & 60 & -30 \\
\hline Pac0410 & AMVTRIL & Cristália & amitriptilina & $\mathrm{Cl}$ & $40 \mathrm{cp}(25 \mathrm{mg})$ & $1 \mathrm{cp} / \mathrm{dia}$ & 40 & 60 & -20 \\
\hline Pac0113 & carbamazepina & & carbamazepina & C1 & $110 \mathrm{cp}(200 \mathrm{mg})$ & $3,5 \mathrm{cp} / \mathrm{dla}$ & 31 & 60 & -29 \\
\hline Pac1890 & carbamazepina & & carbamazepina & $\mathrm{C1}$ & $180 \mathrm{cp}(200 \mathrm{mg})$ & $6 \mathrm{cp} / \mathrm{dia}$ & 30 & 60 & -30 \\
\hline Pac1890 & fenitoina & & \begin{tabular}{|l} 
fenitoina \\
(hidantoina)
\end{tabular} & $\mathrm{C1}_{1}$ & $60 \mathrm{cp}(100 \mathrm{mg})$ & $2 \mathrm{cp} / \mathrm{dia}$ & 30 & 60 & -30 \\
\hline Pac1226 & sertralina & & sertralina & C1 & $30 \mathrm{cp}(50 \mathrm{mg})$ & $1 \mathrm{cp} / \mathrm{dia}$ & 30 & 60 & -30 \\
\hline Pac2698 & DAFORIN & Sigma Pharma & fluoxetina & $\mathrm{Cl}$ & $60 \mathrm{cp}(20 \mathrm{mg})$ & $2 \mathrm{cp} / \mathrm{dia}$ & 30 & 60 & -30 \\
\hline
\end{tabular}


$\mathrm{DT}=$ Dias de tratamento fornecido $\quad \mathrm{LL}=$ Limite legal

\begin{tabular}{|c|c|c|c|c|c|c|c|c|c|}
\hline $\begin{array}{l}\text { código } \\
\text { paciente }\end{array}$ & Prescriçāo & Indústria & Principio Ativo & Alinea & Fornecimento & Posologia & DT & LL & OT $=L L$ \\
\hline Pac0656 & HALDOL & Janssen-Cilag & haloperidol & ci & $120 \mathrm{cp}(1 \mathrm{mg})$ & $4 \mathrm{cp} / \mathrm{dia}$ & 30 & 60 & -30 \\
\hline Pac0656 & amitriptilina & & amitriptilina & C1 & $40 \mathrm{cp}(25 \mathrm{mg})$ & $1 \mathrm{cp} / \mathrm{dia}$ & 40 & 60 & -20 \\
\hline Pac0656 & NEOZINE & Aventis & $\begin{array}{l}\text { levomepromazina } \\
\text { (metotrimeprazina) }\end{array}$ & c1 & $60 \mathrm{cp}(25 \mathrm{mg})$ & $2 \mathrm{cp} / \mathrm{dia}$ & 30 & 60 & -30 \\
\hline Pac1488 & gabapentina & & gabapentina & C1 & $30 \mathrm{cp}(200 \mathrm{mg})$ & $1 \mathrm{cp} / \mathrm{dia}$ & 30 & 60 & -30 \\
\hline Pac1441 & carbamazepina & & carbamazepina & C1 & $90 \mathrm{cp}(200 \mathrm{mg})$ & $3 \mathrm{cp} / \mathrm{dia}$ & 30 & 60 & -30 \\
\hline Pac144t & fenobarbital & & fenobarbital & $\begin{array}{l}\mathrm{B1} \text { - } \\
\text { adendo }\end{array}$ & $60 \mathrm{cp}(100 \mathrm{mg})$ & $2 \mathrm{cp} / \mathrm{dia}$ & 30 & 60 & -30 \\
\hline Pac1441 & fenitoina & & $\begin{array}{l}\text { fenitoina } \\
\text { (hidantoina) }\end{array}$ & C1 & $90 \mathrm{cp}(90 \mathrm{mg})$ & $3 \mathrm{cp} / \mathrm{dia}$ & 30 & 60 & -30 \\
\hline Pac3056 & fenobarbital & & fenobarbital & $\begin{array}{c}\text { B1- } \\
\text { adendo }\end{array}$ & $60 \mathrm{cp} \mathrm{(100} \mathrm{mg)}$ & $2 \mathrm{cp} / \mathrm{dia}$ & 30 & 60 & -30 \\
\hline Pac3056 & renitoina & & $\begin{array}{l}\text { fenitoina } \\
\text { (hidantoina) }\end{array}$ & C1 & $60 \mathrm{cp}(100 \mathrm{mg})$ & $2 \mathrm{cp} / \mathrm{dja}$ & 30 & 60 & -30 \\
\hline Pac3417 & carbamazepina & & carbamazepina & C1 & $30 \mathrm{cp}(200 \mathrm{mg})$ & $1 \mathrm{cp} / \mathrm{dia}$ & 30 & 60 & -30 \\
\hline Pac3417 & fenobarbital & & fenobarbital & $\begin{array}{l}\text { B1- } \\
\text { adendo }\end{array}$ & $60 \mathrm{cp}(100 \mathrm{mg})$ & $2 \mathrm{cp} / \mathrm{dla}$ & 30 & 60 & -30 \\
\hline Pac1677 & $\begin{array}{l}\text { codeina; } \\
\text { paracotamol }\end{array}$ & & $\begin{array}{l}\text { codeina; } \\
\text { paracetamol }\end{array}$ & $\begin{array}{c}\text { A2 - } \\
\text { adendo }\end{array}$ & $30 \mathrm{cp}$ (30 mg) & $3 \mathrm{cp} / \mathrm{dia}$ & 10 & 60 & .50 \\
\hline Pac1677 & fluoxetina & & fluoxetina & C1 & $60 \mathrm{cp}(20 \mathrm{mg})$ & $2 \mathrm{cp} / \mathrm{dia}$ & 30 & 60 & -30 \\
\hline Pac1079 & amitriptilina & & amitriptilina & C1 & $60 \mathrm{cp}(25 \mathrm{mg})$ & $2 \mathrm{cp} / \mathrm{dia}$ & 30 & 60 & -30 \\
\hline Pac1801 & cartamazepina & & carbamazepina & C1 & $180 \mathrm{cp}(200 \mathrm{mg})$ & $6 \mathrm{cp} / \mathrm{dia}$ & 30 & 60 & -30 \\
\hline Pac1801 & AMYTRIL & Cristália & amitriptilina & C1 & $40 \mathrm{cp}$ (25 mg) & $1 \mathrm{cp} / \mathrm{dia}$ & 40 & 60 & -20 \\
\hline Pac0265 & fenobarbital & & fenobarbital & $\begin{array}{c}\text { B1- } \\
\text { adendo }\end{array}$ & $60 \mathrm{cp}(100 \mathrm{mg})$ & $2 \mathrm{cp} / \mathrm{dia}$ & 30 & 60 & 30 \\
\hline Pac0265 & fenitoina & & $\begin{array}{l}\text { fenitoina } \\
\text { (hidantoina) }\end{array}$ & C1 & $120 \mathrm{cp}(100 \mathrm{mg})$ & $4 \mathrm{cp} / \mathrm{dia}$ & 30 & 60 & -30 \\
\hline Pac3208 & carbamazepina & & carbamazepina & $\mathrm{Cl}$ & $120 \mathrm{cp}(200 \mathrm{mg})$ & $4 \mathrm{cp} / \mathrm{dia}$ & 30 & 60 & 30 \\
\hline Pac4049 & fenitoina & & $\begin{array}{l}\text { fenitoína } \\
\text { (hidantoina) }\end{array}$ & C1 & $100 \mathrm{cp}(100 \mathrm{mg})$ & $3,5 \mathrm{cp} / \mathrm{dia}$ & 29 & 60 & -31 \\
\hline Pac4049 & fenobarbital & & fenobarbital & $\begin{array}{c}\text { B1 - } \\
\text { adendo }\end{array}$ & $40 \mathrm{cp}(100 \mathrm{mg})$ & $1 \mathrm{cp} / \mathrm{dia}$ & 40 & 60 & -20 \\
\hline Pac2314 & fenobarbital & & fenobarbital & $\begin{array}{c}B 1- \\
\text { adendo }\end{array}$ & $60 \mathrm{cp} \mathrm{(100} \mathrm{mg)}$ & $2 \mathrm{cp} / \mathrm{dia}$ & 30 & 60 & -30 \\
\hline Pac2314 & fenitoina & & $\begin{array}{l}\text { fenitoina } \\
\text { (hidantoina) }\end{array}$ & C1 & $60 \mathrm{cp}(100 \mathrm{mg})$ & $2 \mathrm{cp} / \mathrm{dia}$ & 30 & 60 & -30 \\
\hline Pac3440 & carbamazepina & & carbamazepina & C1 & $120 \mathrm{cp}(200 \mathrm{mg})$ & $4 \mathrm{cp} / \mathrm{dia}$ & 30 & 60 & .30 \\
\hline Pac3596 & carbamazepina & & carbamazepina & $\mathrm{C1}$ & $210 \mathrm{cp}(200 \mathrm{mg})$ & $7 \mathrm{cp} / \mathrm{dia}$ & 30 & 60 & -30 \\
\hline Pac3596 & fenobarbital & & fenobarbital & $\begin{array}{c}\text { B1- } \\
\text { adendo }\end{array}$ & $60 \mathrm{cp}(100 \mathrm{mg})$ & $2 \mathrm{cp} / \mathrm{dia}$ & 30 & 60 & -30 \\
\hline Pac3186 & DAFORIN & Sigma Pharma & fluoxetina & C1 & $40 \mathrm{cp}(20 \mathrm{mg})$ & $1 \mathrm{cp} / \mathrm{dia}$ & 40 & 60 & .20 \\
\hline Pac1412 & DAFORIN & Sigma Pharma & fluoxetina & C1 & $60 \mathrm{cp}(20 \mathrm{mg})$ & $2 \mathrm{cp} / \mathrm{dla}$ & 30 & 60 & -30 \\
\hline Pac1052 & DAFORIN & Sigma Pharma & fluoxetina & C1 & $60 \mathrm{cp}(20 \mathrm{mg})$ & $2 \mathrm{cp} / \mathrm{dia}$ & 30 & 60 & 30 \\
\hline
\end{tabular}




\section{ANEXO 3 - Listas de substâncias controladas internacionalmente}

\section{ESTUPEFACIENTES SUJETOS A FISCALIZACIÓN INTERNACIONAL}

\section{Sección 1}

Estupefacientes incluidos en la Lista I de la Convención de 1961

Estupefaciente Descripción/Denominación química

Acetil-alfa-metilfentanil N-[1-(alfa-metilfenetil)-4-piperidil]acetanilida

Acetilmetadol 3-acetoxi-6-dimetilamino-4,4-difenilheptano

Acetorfina 3-0-acetiltetrahidro-7alfa-(1-hidroxi-1-metilbutil)-6, 14-endoeteno-

oripavina

Alfacetilmetadol alfa-3-acetoxi-6-dimetilamino-4,4-difenilheptano

Alfameprodina alfa-3-etil-1-metil-4-fenil-4-propionoxipiperidina

Alfametadol alfa-6-dimetilamino-4,4-difenil-3-heptanol

Alfa-metilfentanil $\mathrm{N}$-[1-(alfa-metilfenetil)-4-piperidil]propionanilida

Alfa-metiltiofentanil $\mathrm{N}$-[1-[1-metil-2-(2-€tienil)etil]-4-piperidil]propionanilida

Alfaprodina alfa-1,3-dimetil-4-fenil-4-propionoxipiperidina

Alfentanil N-[1-[2-(4-etil-4,5-dihidro-5-oxo-1H-tetrazol-1-il)etil]-4-(metoximetil)-4piperidinill- $N$-fenilpropanamida

Alilprodina 3-alil-1-metil-4-fenil-4-propionoxipiperidina

Anileridina éster etílico del ácido 1-para-aminofenetil-4-fenilpiperidín-4-

carboxílico

Becitramida 1-(3-ciano-3,3-difenilpropil)-4-(2-oxo-3-propionil-1-bencimidazolinil)piperidina

Bencetidina éster etílico del ácido 1-(2-benciloxietil)-4-fenilpiperidín-4-carboxílico Bencilmorfina 3-O-bencilmorfina

Betacetilmetadol beta-3-acetoxi-6-dimetilamino-4,4-difenilheptano

Beta-hidroxifentanil N-[1-(beta-hidroxifenetil)-4-piperidil]propionanilida

Beta-hidroxi-3-metilfentanil N-[1-(beta-hidroxifenetil)-3-metil-4-

piperidil]propionanilida

Betameprodina beta-3-etil-1-metil-4-fenil-4-propionoxipiperidina

Betametadol beta-6-dimetilamino-4,4-difenil-3-heptanol

Betaprodina beta-1,3-dimetil-4-fenil-4-propionoxipiperidina

Butirato de dioxafetilo etil-4-morfolín-2,2-difenilbutirato

Cannabis y resina de cannabis y

extractos y tinturas de cannabis

cáñamo índico y resina de cáñamo índico

Cetobemidona 4-meta-hidroxifenil-1-metil-4-propionilpiperidina

Clonitaceno 2-para-clorobencil-1-dietilaminoetil-5-nitrobencimidazol

Coca (hoja de)*

Cocaína éster metílico de la benzoilecgonina*

Codoxima dihidrocodeinona-6-carboximetiloxima

Concentrado de paja de adormidera el material que se obtiene cuando la paja de adormidera ha entrado en un proceso de concentración

de sus alcaloides, en el momento en que pasa al comercio

Desomorfina dihidrodeoximorfina

Dextromoramida (+)-4-[2-metil-4-oxo-3,3-difenil-4-(1-pirrolidinil)butil]-morfolina

Diampromida $\mathrm{N}$-[2-(metilfenetilamino)-propil]propionanilida

Dietiltiambuteno 3-dietilamino-1,1-di-(2'-tienil)-1-buteno 
Difenoxilato éster etílico del ácido 1-(3-ciano-3,3-difenilpropil)-4-fenilpiperidín-4carboxílico

Difenoxina ácido 1-(3-ciano-3,3-difenilpropil)-4-fenilisonipecótico

Dihidroetorfina 7,8-dihidro-7-alfa-[1-(R)-hidroxi-1-metilbutil]-6,14-endo-

etanotetrahidrooripavina

\begin{abstract}
* De conformidad con lo dispuesto en la Convención de 1961, al elaborar las previsiones y las estadísticas, los preparados con un contenido de cocaina superior al $0,1 \%$ y hechos directamente de hoja de coca deberán considerarse hoja de coca (preparados).
\end{abstract}

Estupefaciente Descripción/Denominación química

Dihidromorfina

Dimefeptanol 6-dimetilamino-4,4-difenil-3-heptanol

Dimenoxadol 2-dimetilaminoetil-1-etoxi-1,1-difenilacetato

Dimetiltiambuteno 3-dimetilamino-1,1-di-(2'-tienil)-1-buteno

Dioxafetil (butirato de) etil-4-morfolino-2,2-difenilbutirato

Dipipanona 4,4-difenil-6-piperidín-3-heptanona

Drotebanol 3, 4-dimetoxi-17-metilmorfinán-6-beta, 14-diol

Ecgonina sus ésteres y derivados que sean convertibles en ecgonina y cocaína

Etilmetiltiambuteno 3-etilmetilamino-1,1-di-(2'-tienil)-1-buteno

Etonitaceno 1-dietilaminoetil-2-para-etoxibencil-5-nitrobencimidazol

Etorfina tetrahidro-7-alfa-(1-hidroxi-1-metilbutil)-6, 14-endoeteno-oripavina)

Etoxeridina éster etilico del ácido 1-[2-(2-hidroxietoxi)-etil]-4-fenilpiperidín-4carboxílico

Fenadoxona 6-morfolín-4,4-difenil-3-heptanona

Fenampromida N-(1-metil-2-piperidinoetil)-propionanilida

Fenazocina 2'-hidroxi-5,9-dimetil-2-fenetil-6,7-benzomorfán

Fenomorfán 3-hidroxi-N-fenetilmorfinán

Fenoperidina éster etílico del ácido 1-(3-hidroxi-3-fenilpropil)-4-fenilpiperidin-4carboxilico

Fentanil 1-fenetil-4-N-propionilanilinopiperidina

Furetidina éster etílico del ácido 1-(2-tetrahidrofurfuriloxietil)-4-fenilpiperidín-4carboxilico

Heroina diacetilmorfina

Hidrocodona dihidrocodeinona

Hidromorfinol 14-hidroxidihidromorfina

Hidromorfona dihidromorfinona

Hidroxipetidina éster etillico del ácido 4-meta-hidroxifenil-1-metilpiperidín-4carboxilico

Isometadona 6-dimetilamino-5-metil-4,4-difenil-3-hexanona

Levofenacilmorfán (-)-3-hidroxi-N-fenacilmorfinán

Levometorfán $\square(-)$-3-metoxi-N-metilmorfinán

Levomoramida (-)-4-[2-metil-4-oxo-3,3-difenil-4-(1-pirrolidinil)-butil]morfolina

Levorfano/* (-)-3-hidroxi-N-metilmorfinán

Metadona 6-dimetilamino-4,4-difenil-3-heptanona

Metadona, intermediario de la 4-ciano-2-dimetilamino-4,4-difenilbutano

Metazocina 2'-hidroxi-2,5,9-trimetil-6,7-benzomorfán

Metildesorfina 6-metil-delta-6-deoximorfina

Metildihidromorfina 6-metildihidromorfina 
3-metilfentanil N-(3-metil-1-(fenetil-4-piperidil)propionanilida

3-metiltiofentanil N-[3-metil-1-[2-(2-tienil)etil]-4-piperidil]propionanilida

Metopón 5-metildihidromorfinona

Mirofina miristilbencilmorfina

Moramida, intermediario de la ácido 2-metil-3-morfolín-1,1-difenilpropano

carboxilico

Morferidina éster etilico del ácido 1-(2-morfolinoetil)-4-fenilpiperidín-4-carboxilico Morfina

Morfina, bromometilato de y otros derivados de la morfina con nitrógeno

pentavalente, incluidos en particular los derivados de

$\mathrm{N}$-oximorfina, uno de los cuales es la $\mathrm{N}$-oxicodeína

MPPP propionato de 1-metil-4-fenil-4-piperinidol (éster)

GEl dextrometorfán ((+)-3-hidroxi-N-metilmorfinán) y el dextrorfán ((+)-3-hidroxi-Nmetilmorfinán) son isómeros que están

expresamente excluidos de esta Lista.

Estupefaciente Descripción/Denominación química

Nicomorfina 3,6-dinicotinilmorfina

Noracimetadol ( \pm )-alfa-3-acetoxi-6-metilamino-4,4-difenilheptano

Norlevorfanol (-)-3-hidroximorfinán

Normetadona 6-dimetilamino-4,4-difenil-3-hexanona

Normorfina demetilmorfina o morfina $\mathrm{N}$-demetilada

Norpipanona 4,4-difenil-6-piperidín-3-hexanona

N-oximorfina

Opio*

Oxicodona 14-hidroxidihidrocodeinona

Oximorfona 14-hidroxidihidromorfinona

Para-fluorofentanil 4'-fluoro-N-(1-fenetil-4-piperidil])propionanilida

PEPAP acetato de 1-fenetil-4-fenil-4-piperidinol (éster)

Petidina éster etílico del ácido 1-metil-4-fenilpiperidín-4-carboxilico

Petidina, intermediario A de la 4-ciano-1-metil-4-fenilpiperidina

Petidina, intermediario $B$ de la éster etílico del ácido 4-fenilpiperidín-4-carboxílico

Petidina, intermediario $\mathrm{C}$ de la ácido 1-metil-4-fenilpiperidín-4-carboxilico

Piminodina éster etílico del ácido 4-fenil-1-(3-fenilaminopropil)-piperidín-4carboxilico

Piritramida amida del ácido 1-(3-ciano-3,3-difenilpropil)-4-(1-piperidín)-piperidín4-carboxílico

Proheptacina 1,3-dimetil-4-fenil-4-propionoxiazacicloheptano

Properidina éster isopropilico del ácido 1-metil-4-fenilpiperidín-4-carboxílico

Racemetorfán ( \pm )-3-metoxi-N-metilmorfinán

Racemoramida (士)-4-[2-metil-4-oxo-3,3-difenil-4-(1-pirrolidinil)-butil]-morfolina

Racemorfán ( \pm )-3-hidroxi-N-metilmorfinán

Remifentanil éster metílico del ácido 1-(2-metoxicarboniletil)-4-

(fenilpropionilamino)-piperidín-4-carboxilico

Sufentanil N-[4-(metoximetil)-1-[2-(2-tienil)-etil]-4-piperidil]propionanilida

Tebacón acetildihidrocodeinona

Tebaina

Tilidina ( \pm )-etil-trans-2-(dimetilamino)-1-fenil-3-ciclohexeno-1-carboxilato

Tiofentanil N-[1-[2-(2-tienil)etil]-4-piperidil]propionanilida 
Trimeperidina 1,2,5-trimetil-4-fenil-4-propionoxipiperidina

Y los isómeros de los estupefacientes de esta Lista, a menos que estén

expresamente exceptuados y siempre que la existencia de dichos

isómeros sea posible dentro de la nomenclatura química específica;

los ésteres y éteres de los estupefacientes de esta Lista, siempre y cuando no

figuren en otra Lista y la existencia de dichos ésteres o

éteres sea posible;

las sales de los estupefacientes de esta Lista, incluidas las sales de ésteres,

éteres e isómeros, según la descripción prevista y siempre

que la existencia de dichas sales sea posible.

\begin{abstract}
*De conformidad con lo dispuesto en la Convención de 1961, para el cálculo de las previsiones y las estadísticas, todos los

preparados hechos directamente de opio deberán considerarse opio (preparados).

Cuando los preparados no estén hechos

directamente de opio propiamente tal sino que se obtengan mediante una mezcla

de alcaloides de opio (como ocurre, por

ejemplo, con el pantopón, el omnopón y el papaveretum) deberán considerarse morfina (preparados).
\end{abstract}

\title{
Sección 2
}

Estupefacientes incluidos en la Lista II de la Convención de 1961

Estupefaciente Descripción/Denominación química

Acetildihidrocodeina

Codeina 3-0-metilmorfina

Dextropropoxifeno propionato de alfa-(+)-4-dimetilamino-1,2-difenil-3-metil-2-

butanol

\section{Dihidrocodeína}

Etilmorfina 3-O-etilmorfina

Folcodina morfoliniletilmorfina

Nicocodina 6-nicotinilcodeína

Nicodicodina 6-nicotinildihidrocodeína

Norcodeina $N$-demetilcodeina

Propiramo N-(1-metil-2-piperidin-etil)-N-2-piridilpropionamida

$Y$ los isómeros de los estupefacientes de esta Lista, a menos que estén

expresamente exceptuados y siempre que la existencia de dichos

isómeros sea posible dentro de la nomenclatura química específica;

las sales de los estupefacientes de esta Lista, incluidas las sales de los isómeros según la descripción prevista y siempre que la existencia

de dichas sales sea posible.

\section{Sección 3}

Estupefacientes incluidos en la Lista IV de la Convención de 1961

Estupefaciente Descripción/Denominación química

Acetil-alfa-metilfentanil N-[1-(alfa-metilfenetil)-4-piperidil]acetanilida

Acetorfina 3-0-acetiltetrahidro-7-alfa-(1-hidroxi-1-metilbutil)-6,14-endoeteno-

oripavina

Alfa-metilfentanil $N$-[1-(alfa-metilfenetil)-4-piperidil]propionanilida

Alfa-metiltiofentanil N-[1-[1-metil-2-(2-tienil)etil]-4-piperidil]propionanilida

Beta-hidroxifentanil N-[1-(beta-hidroxifenetil)-4-piperidil]propionanilida 
Beta-hidroxi-3-metilfentanil N-[1-(beta-hidroxifenetil)-3-metil-4piperidil]propionanilida

Cannabis (cáñamo índico) y su resina

Cetobemidona 4-meta-hidroxifenil-1-metil-4-propionilpiperidina

Desomorfina dihidrodeoximorfina

Etorfina tetrahidro-7-alfa-(1-hidroxi-1-metilbutil)-6, 14-endoeteno-oripavina

Heroina diacetilmorfina

3-metilfentanil $\mathrm{N}$-(3-metil-1-fenetil-4-piperidil)propionanilida

3-metiltiofentanil N-[3-metil-1-[2-(2-tienil)etil]-4-piperidil]propionanilida

MPPP propionato de 1-metil-4-fenil-4-piperidinol (éster)

Para-fluorofentanil 4'-fluoro-N-(1-fenetil-4-piperidil])propionanilida

PEPAP acetato de 1-fenetil-4-fenil-4-piperidinol (éster)

Tiofentanil N-[1-[2-(2-tienil)etil]-4-piperidil]propionanilida

Y las sales de los estupefacientes de esta Lista, siempre que sea posible formar dichas sales.

\section{PREPARADOS DE ESTUPEFACIENTES EXENTOS DE ALGUNAS DISPOSICIONES E INCLUIDOS EN LA LISTA III DE LA CONVENCIÓN DE 1961}

1. Preparados de: Acetildihidrocodeina,

Codeina,

Dihidrocodeina,

Etilmorfina,

Folcodina,

Nicocodina,

Nicodicodina, $y$

Norcodeina

cuando estén mezclados con uno o varios ingredientes más y no contengan más de 100 miligramos del estupefaciente por unidad de dosificación y la concentración no exceda de $2,5 \%$ en los preparados no divididos.

2. Preparados de: Propiram que contengan una cantidad no superior a 100 miligramos de

propiramo por unidad de dosificación y estén mezclados con por lo menos la misma cantidad de metilcelulosa.

3. Preparados de: Dextropropoxifeno para uso oral que contengan una cantidad no

superior a 135 miligramos de dextropropoxifeno como base por unidad de dosificación o con una concentración no superior al 2,5\% en preparados no divididos, siempre que tales preparados no contengan ninguna sustancia sujeta a fiscalización con arreglo al Convenio sobre Sustancias Sicotrópicas de 1971.

4. Preparados de: Cocaína que contengan una cantidad no superior al $0,1 \%$ de cocaína calculado en cocaina base; y

Preparados de: Opio o morfina que contengan una cantidad no superior al $0,2 \%$ de

morfina calculado en morfina base anhidra y estén mezclados con uno o varios ingredientes más, de tal manera que el estupefaciente no pueda 
separarse por medios sencillos o en cantidades que constituyan un peligro para la salud pública.

5. Preparados de: Difenoxina que contengan, por unidad de dosificación, una cantidad no

superior a 0,5 miligramos de difenoxina y una cantidad de sulfato de atropina equivalente, como mínimo, a un $5 \%$ de la dosis de difenoxina.

6. Preparados de: Difenoxilato que contengan, por unidad de dosificación, una cantidad

no superior a un 2,5 miligramos de difenoxilato calculado como base, $y$ una cantidad de sulfato de atropina equivalente, como mínimo, al $1 \%$ de la dosis de difenoxilato.

7. Preparados de: Pulvis ipecacuanhae et opii compositus $10 \%$ de opio en polvo

$10 \%$ de raiz de ipecacuana, en polvo y bien mezclado con $80 \%$ de cualquier otro ingrediente en polvo que no contenga estupefaciente alguno.

8. Los preparados que respondan a cualesquiera de las fórmulas incluidas en la presente Lista $y$ las mezclas de dichos preparados con cualquier ingrediente que no contenga estupefaciente

alguno. 
Lista verde - Substancias Psicotrópicas

Denominaciones Comunes Internacionales (DCI)

BROLANFETAMINA

CATINONA

ETICICLIDINA

ETRIPTAMINA

(+)-LISÉRGIDA

PSILOCIBINA

ROLICICLIDINA

TENANFETAMINA

TENOCICLIDINA

Denominaciones Comunes

Internacionales (DCl)

ANFETAMINA

DEXANFETAMINA

DRONABINOL*

FENCICLIDINA

FENETILINA

FENMETRACINA

LEVANFETAMINA

MECLOCUALONA

METACUALONA

METANFETAMINA

METILFENIDATO

SECOBARBITAL

ZIPEPROL

Denominaciones Comunes

Internacionales (DCI)

AMOBARBITAL

BUPRENORFINA

BUTALBITAL

CATINA

CICLOBARBITAL

FLUNITRAZEPAM

GLUTETIMIDA

PENTAZOCINA

PENTOBARBITAL

Denominaciones Comunes

Internacionales (DCI)

ALOBARBITAL

ALPRAZOLAM

AMINOREX

ANFEPRAMONA

BARBITAL

BENZFETAMINA

BROMAZEPAM

BROTIZOLAM

CAMAZEPAM

CLOBAZAM

CLONAZEPAM
CLORAZEPATO

CLORDIAZEPÓXIDO

CLOTIAZEPAM

CLOXAZOLAM

DELORAZEPAM

DIAZEPAM

ESTAZOLAM

ETCLORVINOL

ETINAMATO

ETILANFETAMINA

FENCAMFAMINA

FENDIMETRACINA

FENOBARBITAL

FENPROPOREX

FENTERMINA

FLUDIAZEPAM

FLURAZEPAM

HALAZEPAM

HALOXAZOLAM

KETAZOLAM

LEFETAMINA

LOFLAZEPATO

DE ETILO

LOPRAZOLAM

LORAZEPAM

MAZINDOL

MEDAZEPAM

MEFENOREX

MEPROBAMATO

MESOCARBO

METILFENOBARBITAL

METIPRILÓN

MIDAZOLAM

NIMETAZEPAM

NITRAZEPAM

NORDAZEPAM

OXAZEPAM

OXAZOLAM

PEMOLINA

PINAZEPAM

PIPRADROL

PIROVALERONA

PRAZEPAM

SECBUTABARBITAL

TEMAZEPAM

TETRAZEPAM

TRIAZOLAM

VINILBITAL

ZOLPIDEM 